\title{
Um sistema de autorização baseado em uma infra-estrutura de gerenciamento de privilégios
}

\author{
Fábio Correa Xavier
}

Dissertação apresentada

ao

Instituto de Matemática e Estatística

da

Universidade de São Paulo

para

obtenção do grau

de

Mestre em Ciência da Computação

Área de Concentração: Segurança da Informação

Orientador: Prof. Dr. Routo Terada 


\section{Um sistema de autorização baseado em uma infra-estrutura de gerenciamento de privilégios}

\section{Este exemplar corresponde à redação final da dissertação de Mestrado devidamente corrigida e defendida por Fábio Correa Xavier}

e aprovada pela comissão julgadora.

São Paulo, Julho de 2004.

Banca examinadora:

- Prof. Dr. Routo Terada (Orientador) - IME-USP

- Prof. Dr. Nicolau Reinhard - FEA-USP

- Prof. Dr. Marcos Dimas Gubitoso - IME-USP 
Para meu filho Gabriel e minha esposa Heliane, por me darem a estrutura familiar necessária para a realização deste trabalho e principalmente por (quase sempre) compreenderem a minha ausência em casa. 


\section{AGRADECIMENTOS}

Agradeço inicialmente a Deus, que me permite viver com muita saúde e disposição para vencer todos os desafios.

A minha esposa Heliane, por estar sempre ao meu lado, dando o suporte necessário para que esse trabalho se realizasse.

Ao meu filho Gabriel, o Bi, por cada sorriso, cada abraço, e cada brincadeira que sempre me revigoram para todo e qualquer novo desafio. Desculpe o papai, por eu não compartilhar mais tempo com você...

Ao senhor Raimundo Correa Xavier e à senhora Ana Maria da Aparecida Xavier, meus amados pais, que não mediram esforços para criarem com todo o carinho e dedicação quatro filhos. Obrigado por me mostrarem o valor da educação para a formação completa de um homem. Espero ter a mesma sabedoria para criar da melhor maneira possível o pequeno Gabriel.

Ao meu orientador, professor Routo Terada, pelo apoio e orientação imprescindíveis para o sucesso deste trabalho.

A professora Cristiane, pela grande ajuda na revisão gramatical deste texto.

Finalmente, ao meu pequeno filho Gabriel, por cada brincadeira, por cada palavra e por cada sorriso que me revigoravam e me inspiravam a sempre buscar o melhor de mim em todas as minhas atitudes. 


\section{RESUMO}

XAVIER, F. C. Um sistema de autorização baseado em uma infra-estrutura de gerenciamento de privilégios. 2004. 149f. Dissertação (Mestrado em Ciência da Computação) - Instituto de Matemática e Estatística, Universidade de São Paulo, São Paulo, 2004.

A quarta edição da recomendação X.509 da ITU-T definiu a base sobre a qual pode-se construir uma infra-estrutura de gerenciamento de privilégios, com a utilização de certificados de atributos. Certificados de atributos podem ser utilizados em uma ampla variedade de cenários e ambientes, com grande interoperabilidade, fornecendo serviços de autorização por meio da atribuição de privilégios. Para tal, faz-se necessária a construção de uma infra-estrutura capaz de criar, gerenciar e distribuir os certificados de atributos. Nesse contexto, aparece a infra-estrutura de gerenciamento de privilégios (PMI - Privilege Management Infrastructure), uma estrutura similar à infra-estrutura de chaves públicas (PKI - Public-Key Infrastrucure), porém voltada a prestar serviços de autorização. Este trabalho apresenta a infra-estrutura de gerenciamento de privilégios padronizada pela RFC 3281, mostrando suas características principais, servindo como referência em língua portuguesa sobre o assunto. Além disso, apresentamos também uma proposta de implementação dessa infra-estrutura que torna o certificado de atributos dinâmico, otimizando o processo de revogação ou alteração de privilégios. Finalmente, foi construído um protótipo do modelo proposto, concretizando sua viabilidade.

Palavras-chave: PMI, autorização, segurança, certificado de atributos, atributos, privilégios. 


\section{ABSTRACT}

XAVIER, F. C. A system of authorization based on a privilege management infrastructure. 2004. 149f. Dissertation (Master on Computer Science) - Math and Statistics Institute, Universidade de São Paulo, São Paulo, 2004.

The fourth edition of the ITU-T, X 509 recommendation defined the basis on which a privilege management infrastructure can be built, with the usage of the attribute certificates. Attribute certificates can be used in a wide variety of scenarios and environments, with great inter-operating capacity, providing authorization services by means of the attribution of privileges. In order to achieve it there is the need to build an infrastructure capable of creating, managing and distributing the attribute certificates. In this context the privilege management infrastructure (PMI) appears, which is similar to the public key infrastructure (PKI), however, aiming at providing authorization services. This research presents the privilege management infrastructure patterned by RFC 3281, with its main characteristics, and can work as a reference about the subject in the Portuguese language. Furthermore, a proposal for the implementation of this infrastructure is presented here, which makes the attribute certificate dynamic, optimizing the process of removing or modifying the privileges. Finally, a prototype of the suggested model was built, making its viability concrete.

Key words: PMI, authorization, security, attribute certificate, attributes, privileges. 


\section{LISTA DE FIGURAS}

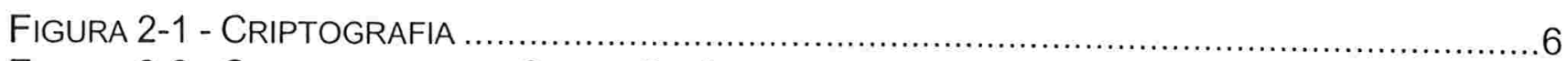

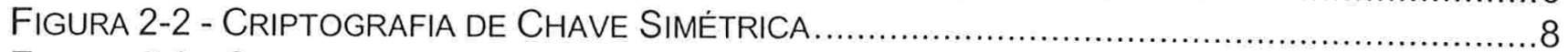

FIGURA 2-3 - GERENCIAMENTO DE CHAVES SIMÉTRICAS - UM DESAFIO ................................

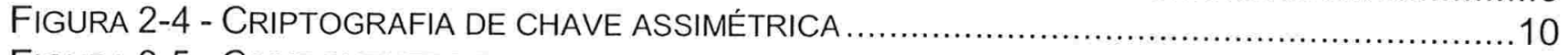

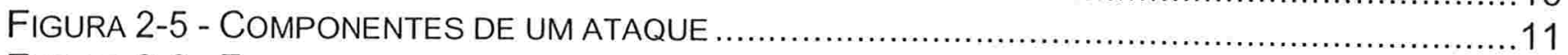

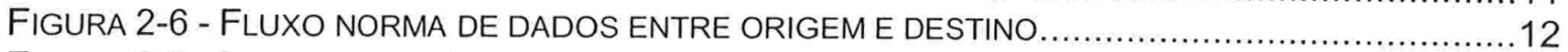

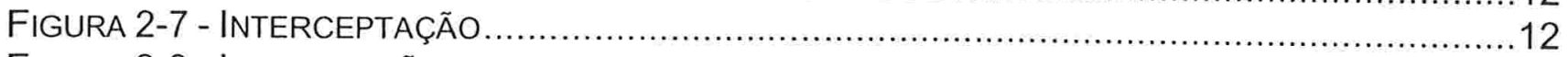

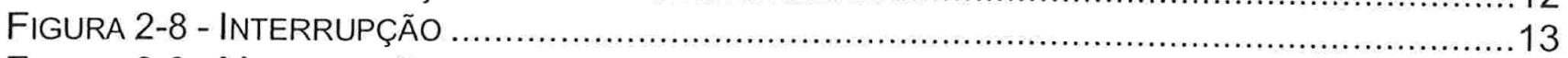

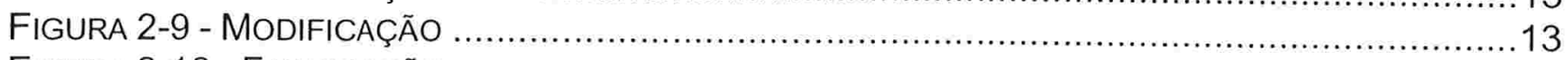

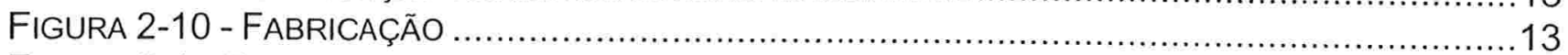

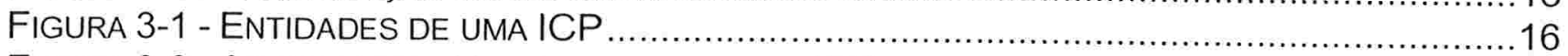

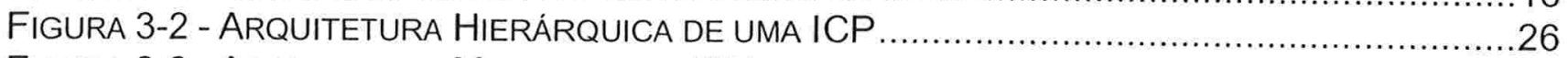

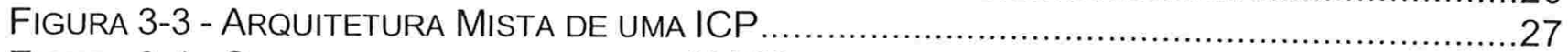

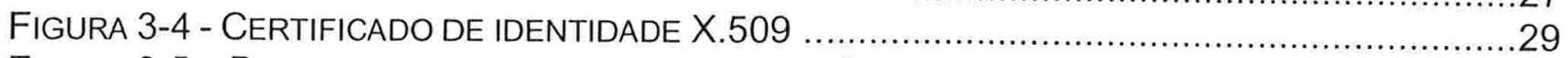

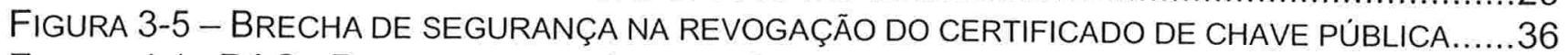

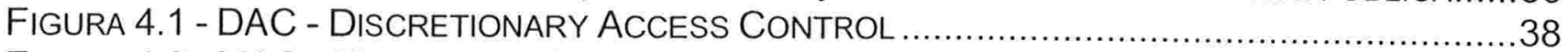

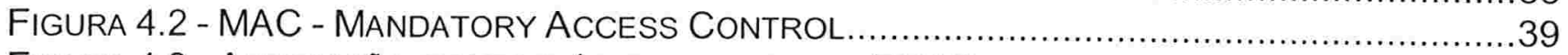

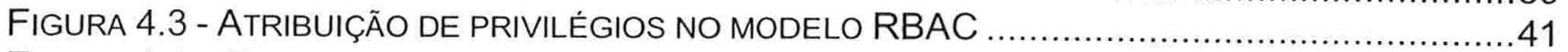

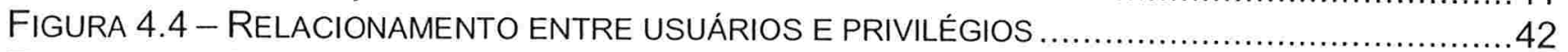

FIGURA 5-1 - ORGANOGRAMA DA EMPRESA FICTICIA FHG CONSULTORIA ...............................44

FIGURA 5-2 - FORMAS DE DISTRIBUIÇÃO DE CERTIFICADOS DE ATRIBUTOS..............................45

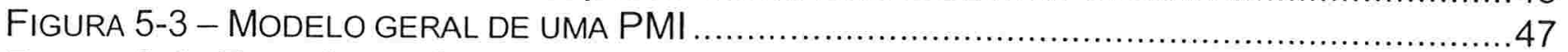

FIGURA 5-4 - EMISSÃO DE CERTIFICADOS DE ATRIBUTO NO MODELO GERAL ...............................4 48

FIGURA 5-5 - MODELO GERAL - CONCEDENDO ACESSO A UM OBJETO PROTEGIDO ..........................49

FIGURA 5-6 - MODELO GERAL - NEGANDO ACESSO A UM OBJETO PROTEGIDO ................................49

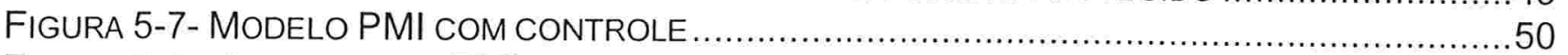

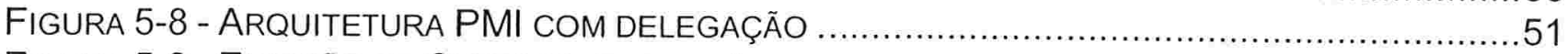

FIGURA 5-9 - EMISSÃO DE CERTIFICADOS DE ATRIBUTO NO MODELO COM DELEGAÇÃO …...............53

FIGURA 5-10 - MODELO COM DELEGAÇÃO - CONCEDENDO ACESSO A UM OBJETO PROTEGIDO ...54

FIGURA 5-11 - MODELO COM DELEGAÇÃO - NEGANDO ACESSO A UM OBJETO PROTEGIDO .........55

FIGURA 5-12 - MODELO PMI COM SUPORTE A PAPÉIS ................................................5

FIGURA 5 - 13 - EMISSÃO DE CERTIFICADO DE ESPECIFICAÇÃO DE PAPEL NO MODELO COM SUPORTE A PAPÉIS .

FIgURA 5 - 14 - EMISSÃO dE CERTIFICADOS dE ATRIBUIÇÃO DE PAPEL NO MODELO COM SUPORTE

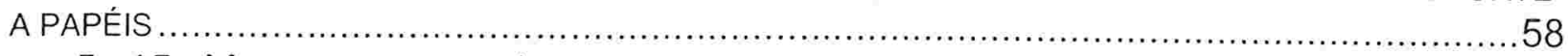

FIGURA 5 - 15 - MODELO COM PAPÉIS - CONCEDENDO ACESSO A UM OBJETO PROTEGIDO ..............59

FIGURA 5 - 16 - MODELO COM PAPÉIS - NEGANDO ACESSO A UM OBJETO PROTEGIDO ...................60

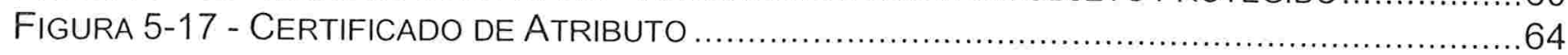

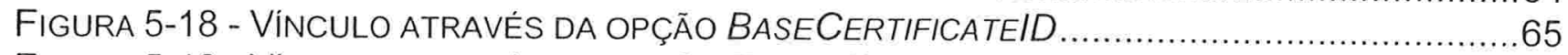

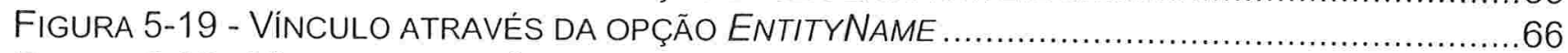

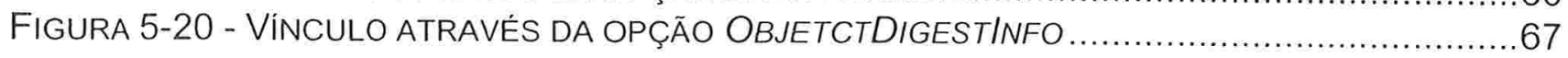


FIGURA 6-1 - VALIDAÇÃO DO CERTIFICADO DE ATRIBUTOS ............................................ 74

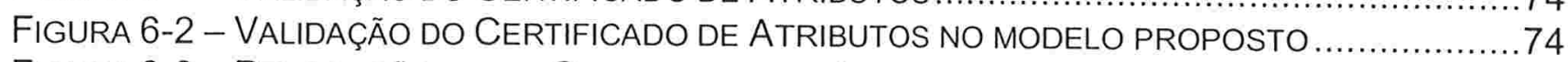

FIGURA 6-3 - REVOGAÇÃO DE UM CERTIFICADO DE ATRIBUTO NO MODELO TRADICIONAL ...............76

FIGURA 6-4 - REVOGAÇÃO DE UM CERTIFICADO DE ATRIBUTO NO MODELO PROPOSTO ..................76

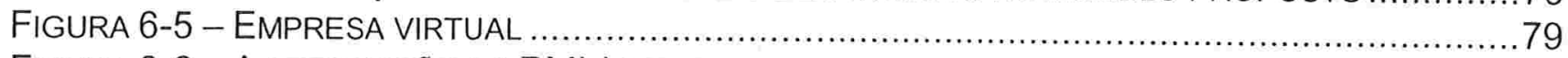

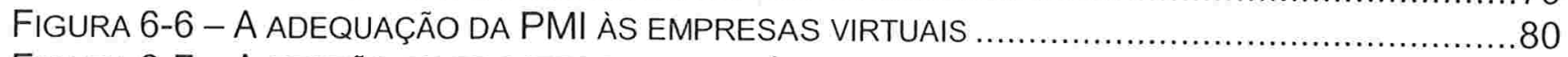

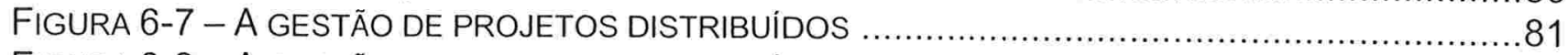

FIGURA 6-8 - A GESTÃO DE PROJETOS DISTRIBUIDOS E A INFRA-ESTRUTURA DE GERENCIAMENTO

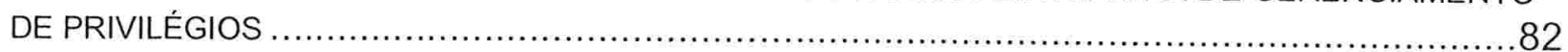

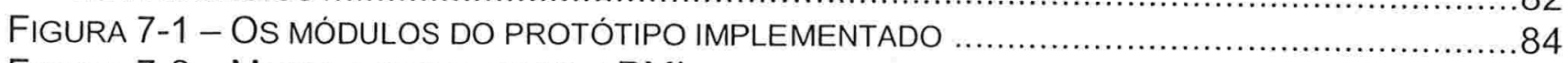

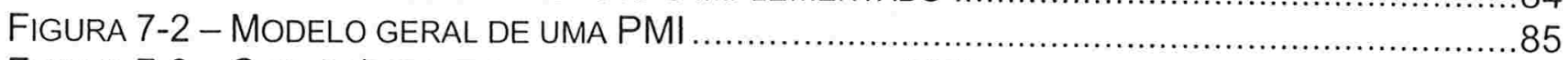

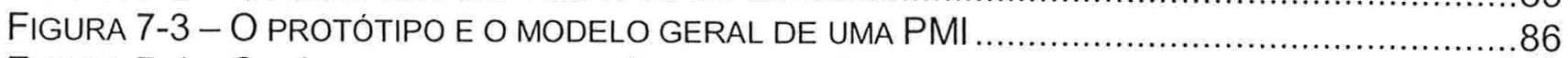

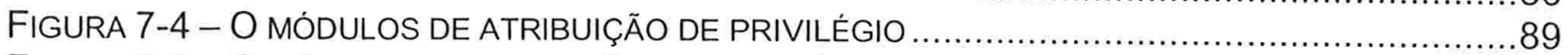

FIGURA 7-5 - O MÓDULO DE ATRIBUIÇÃO DE PRIVILÉGIO INTERAGINDO COM KEYTOOL ...................90

FIGURA 7-6 - SELECIONANDO UM CERTIFICADO DE CHAVE PÚBLICA NO MÓDULO DE ATRIBUIÇÃO DE

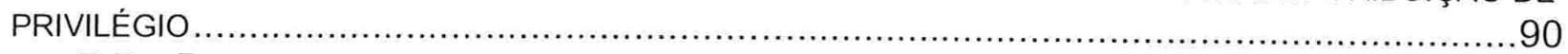

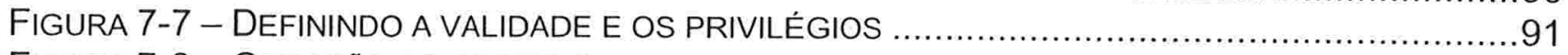

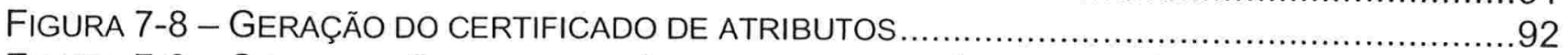

FIGURA 7-9 - COMPARAÇÃO ENTRE O MÓDULO DE ATRIBUIÇÃO DE PRIVILÉGIOS E O CERTIFICADO

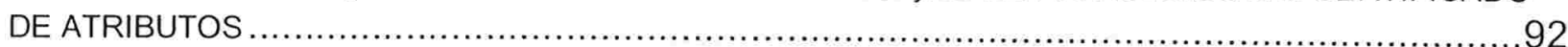

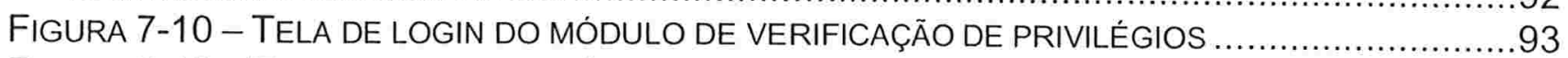

FIGURA 7-10 - TELA DE LOGIN DO MÓDULO DE VERIFICAÇÃO DE PRIVILÉGIOS ............................94 


\section{LISTA DE TABELAS}

TABELA 2-1 - PROTOCOLO DE CRIPTOGRAFIA POR SUBSTITUIÇÃO - CIFRA DE CÉSAR.................7

TABELA 3-1 - COMPONENTES DE UM ICP

TABELA 5 - 3 - COMPONENTES DE UMA PMI

TABELA 7-2 - TESTES dE VALIDAÇÃO DO MÓDULO DE ATRIBUIÇÃO DE PRIVILÉGIOS 96

TABELA 7-2 - TESTES dE VALIDAÇÃO DO MÓdULO DE VERIFICAÇÃo dE PRIVILÉGIOS 97 


\section{LISTA DE ABREVIAÇÕES}

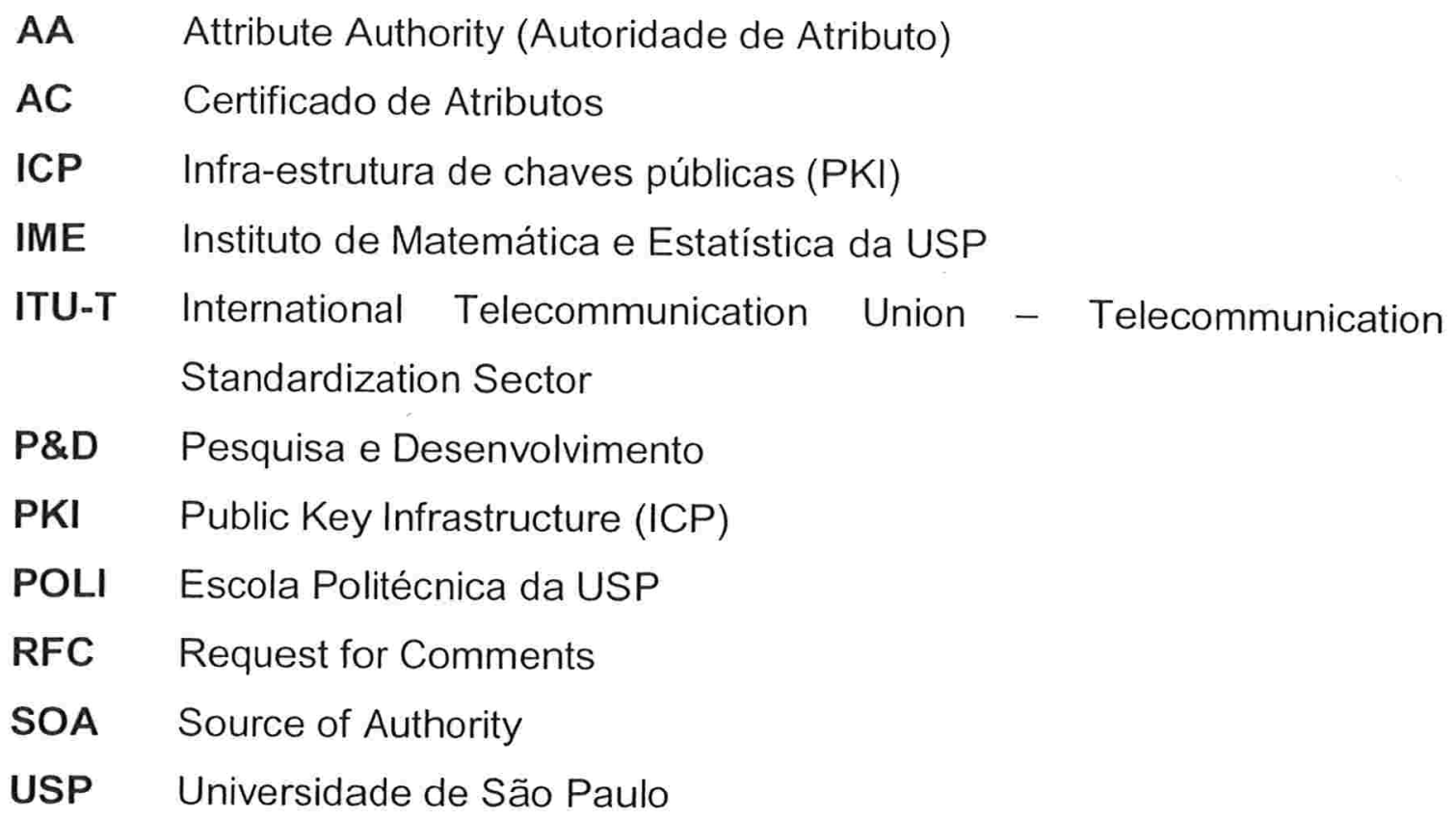




\section{SUMÁRIO}

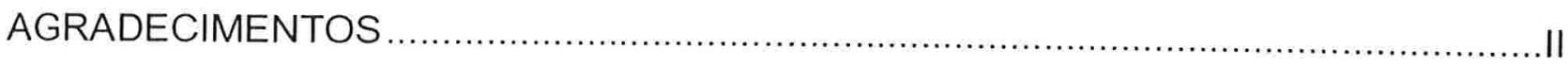

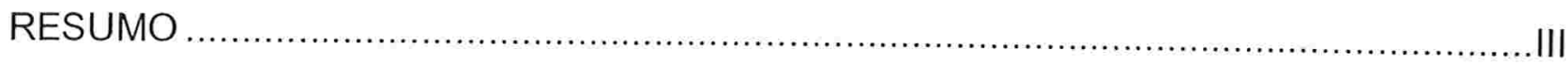

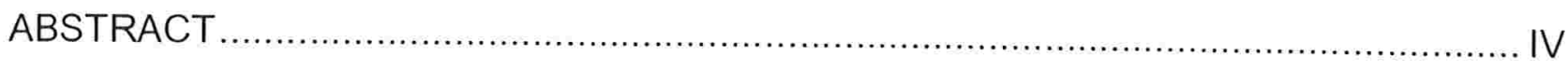

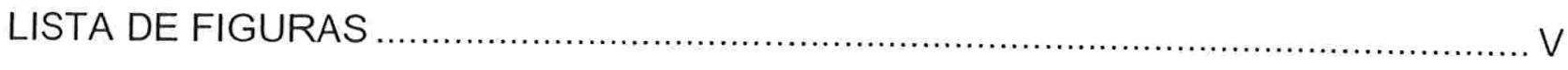

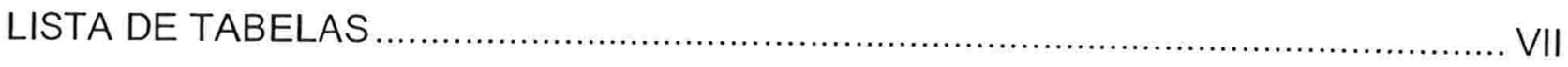

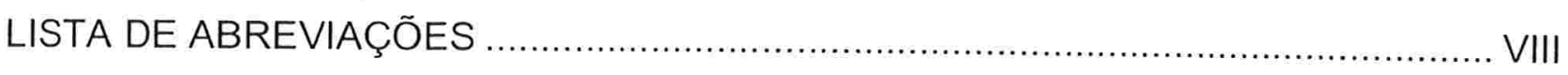

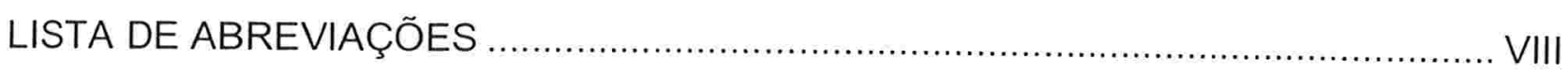

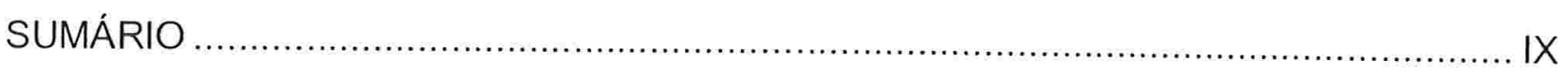

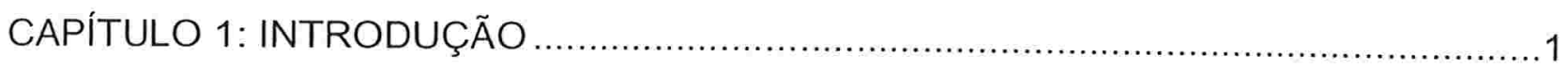

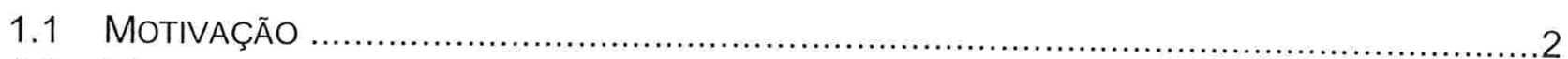

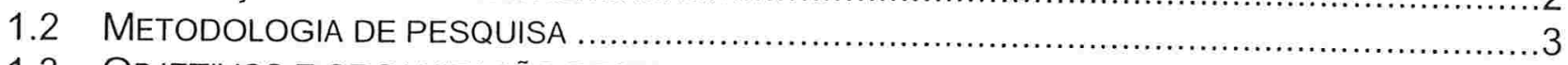

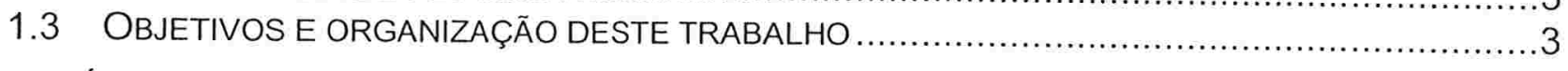

CAPÍTULO 2: FUNDAMENTOS DE CRIPTOGRAFIA ...........................................

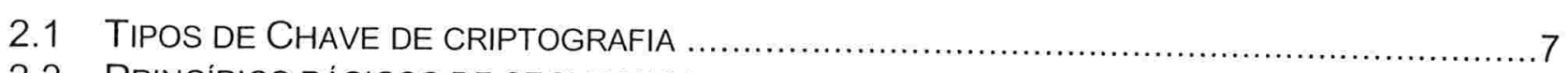

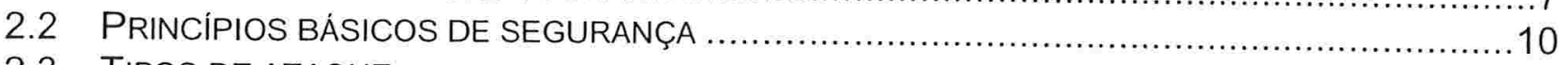

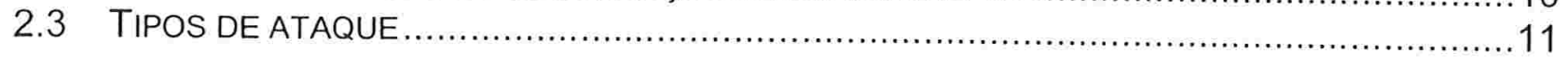

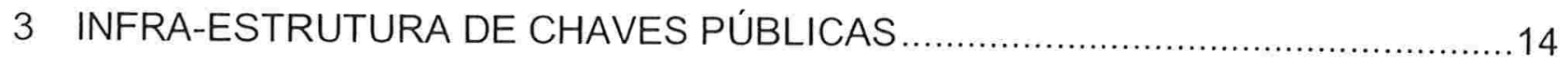

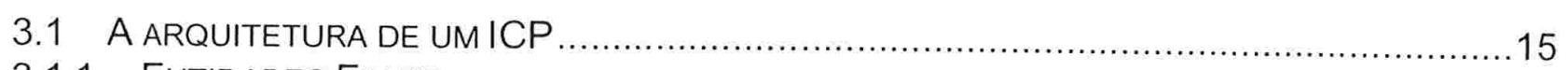

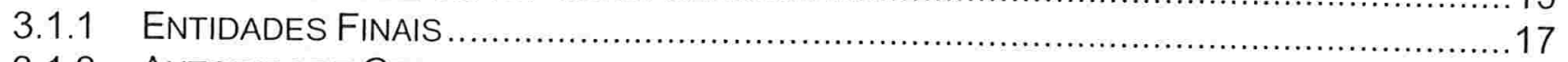

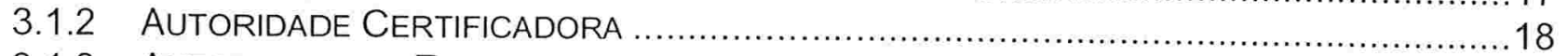

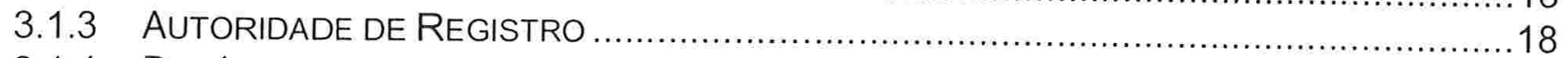

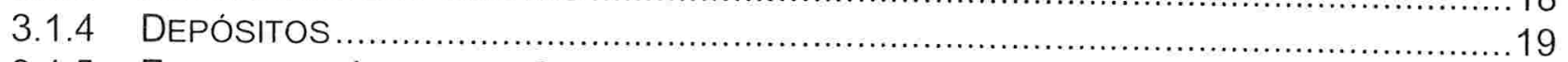

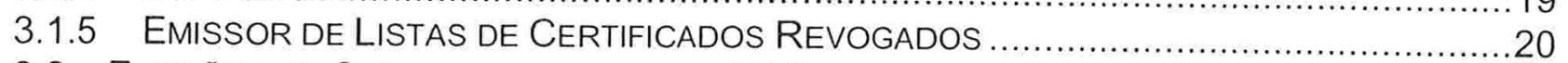

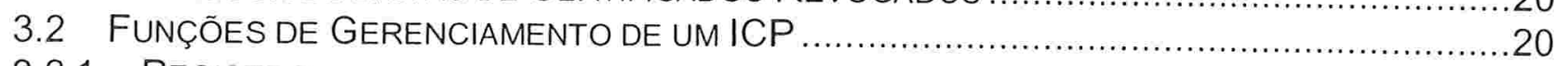

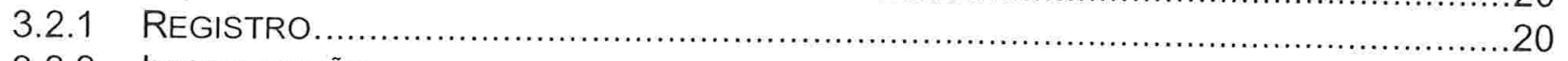

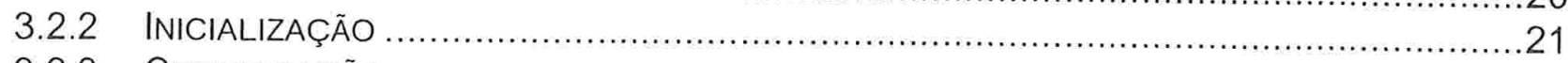

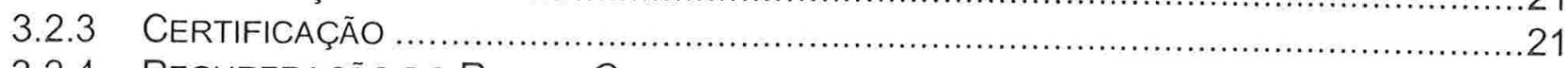

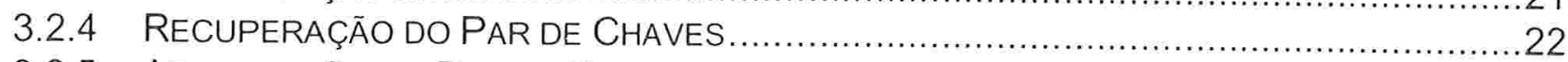

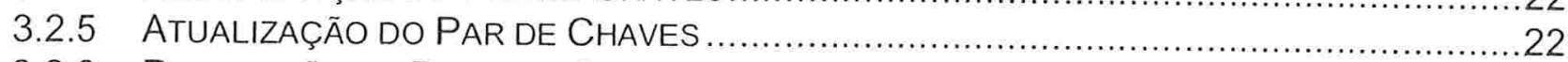

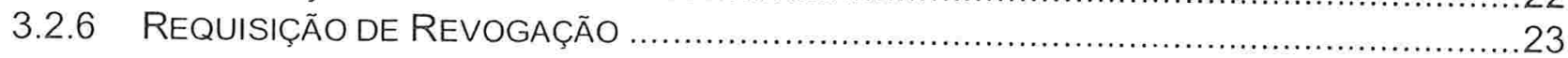




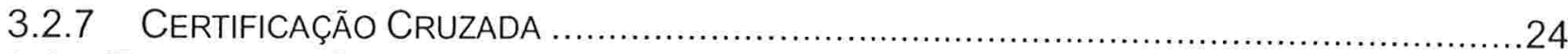

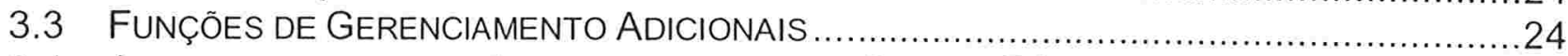

3.4 ARQUITETURAS DE UMA INFRA-ESTRUTURA DE CHAVES PÚBLICAS ...........................2.25

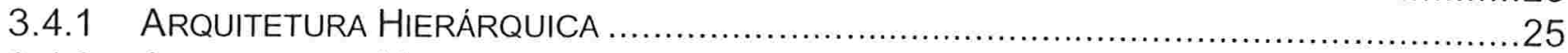

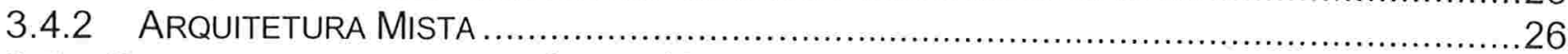

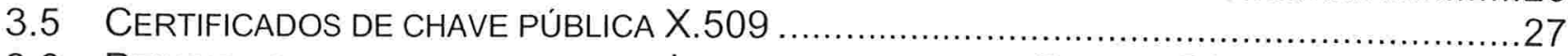

3.6 PRINCIPAIS VULNERABILIDADES DA INFRA-ESTRUTURA DE CHAVES PÚBLICAS ...................31

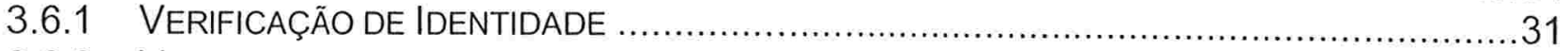

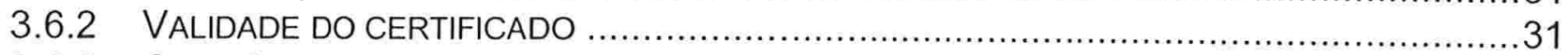

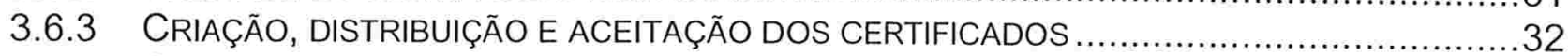

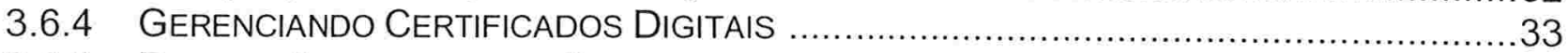

3.6.5 REVELAÇÃO DE INFORMAÇÕES SIGILOSAS SOBRE O CLIENTE _.................................33

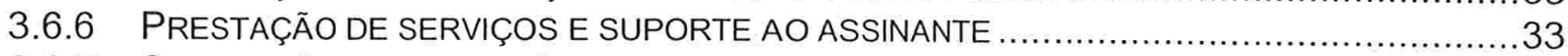

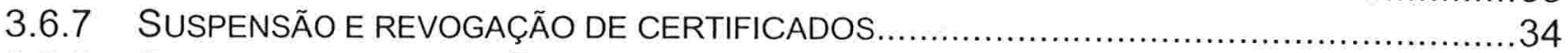

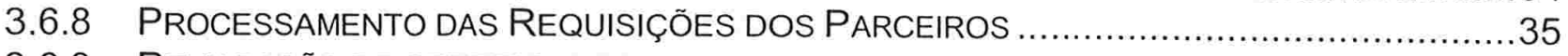

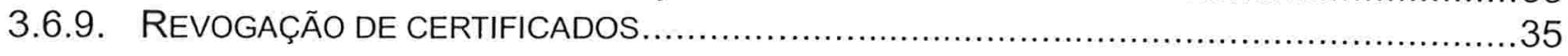

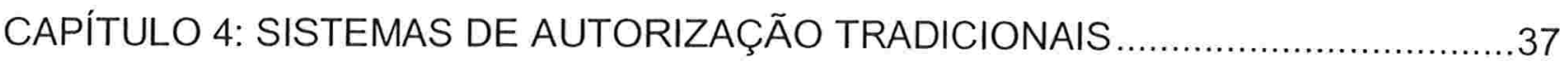

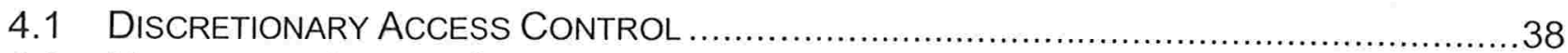

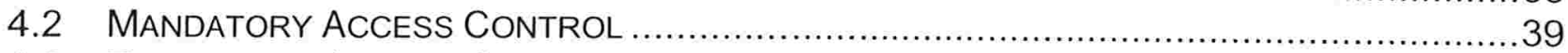

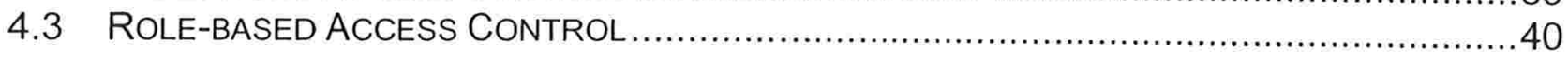

CAPÍTULO 5: AUTORIZAÇÃO COM CERTIFICADOS DE ATRIBUTOS .......................44

5.1 FORMAS DE DISTRIBUIÇÃO DE CERTIFICADOS DE ATRIBUTOS ….................................4.4

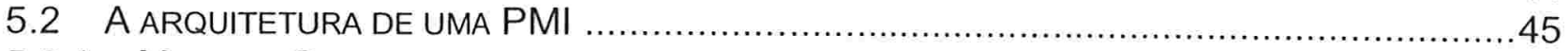

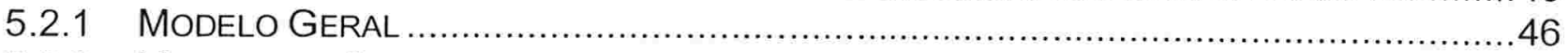

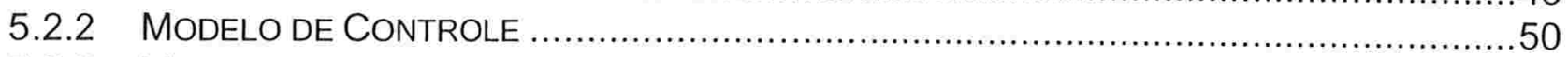

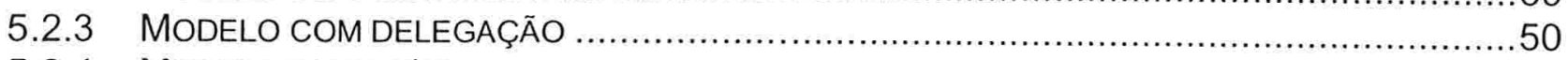

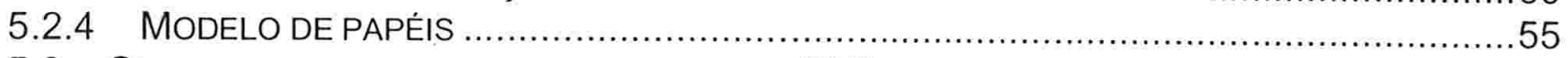

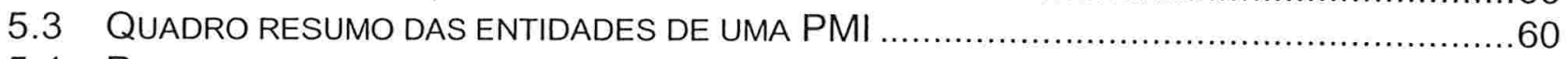

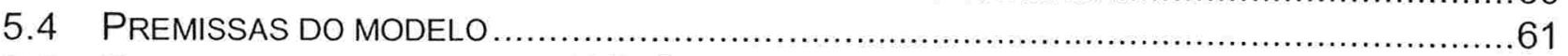

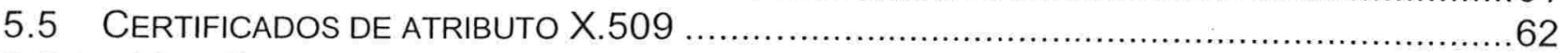

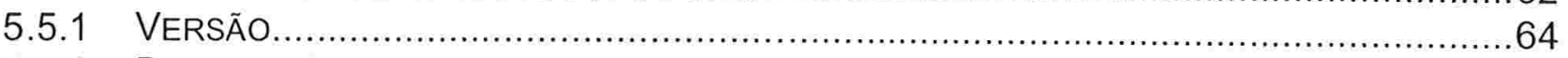

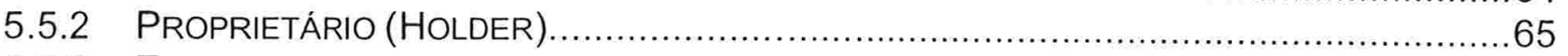

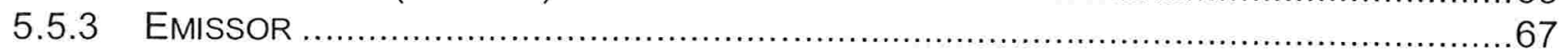

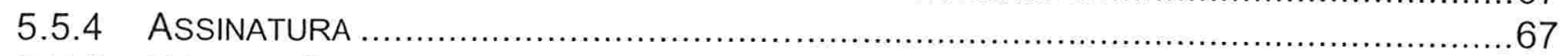

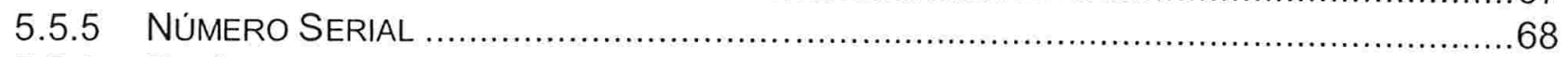

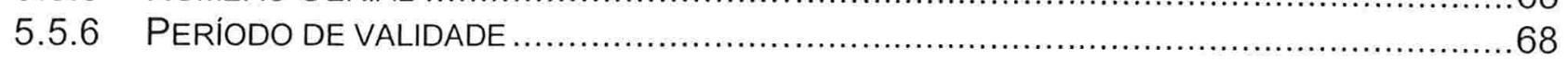

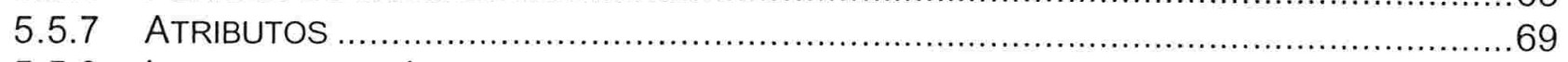

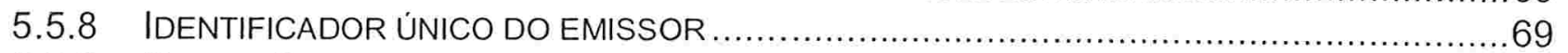

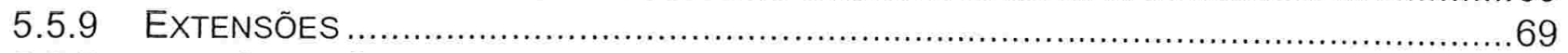

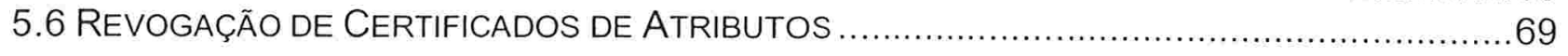

CAPITULO 6: UM CERTIFICADO DE ATRIBUTOS DINÂMICO ..................................... 71

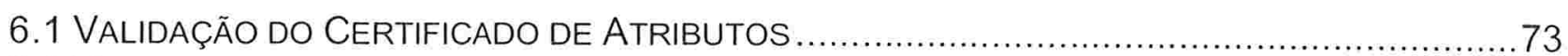

6.2 VANTAGENS E DESVANTAGENS DO MODELO PROPOSTO …............................................. 75

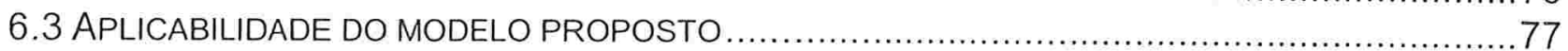

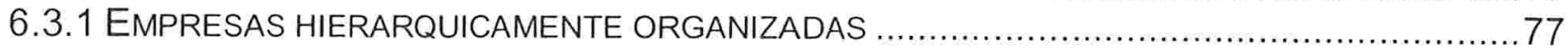

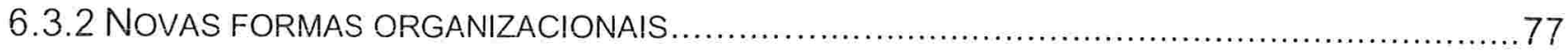




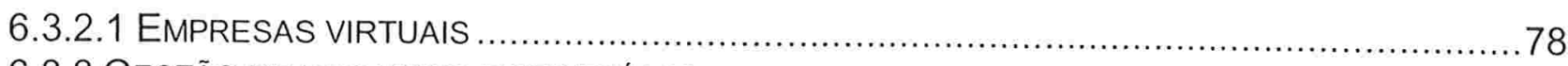

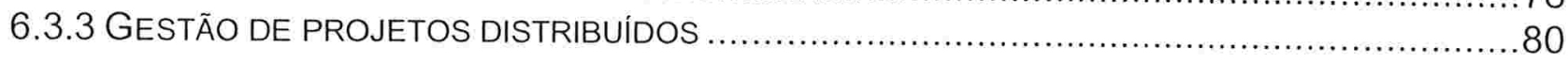

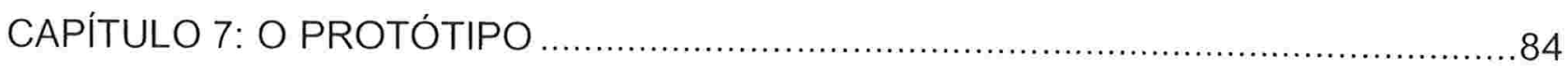

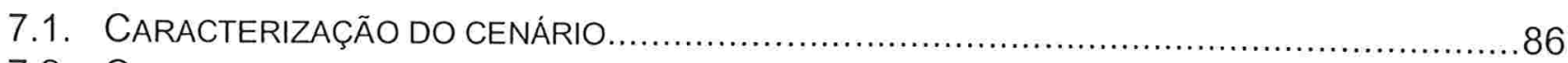

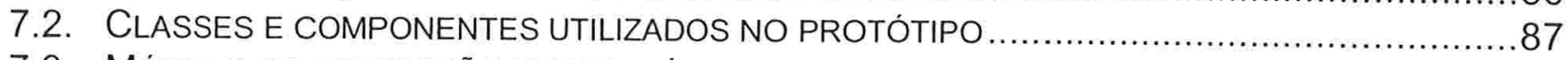

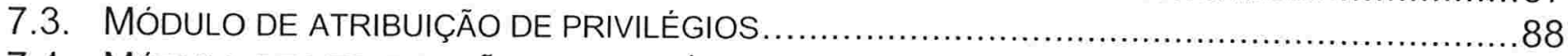

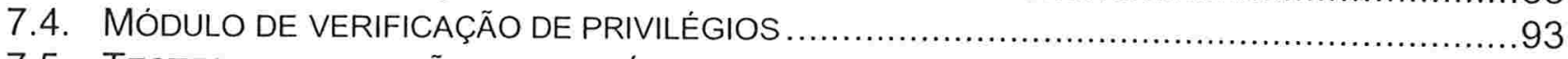

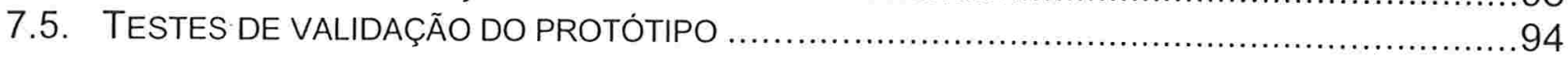

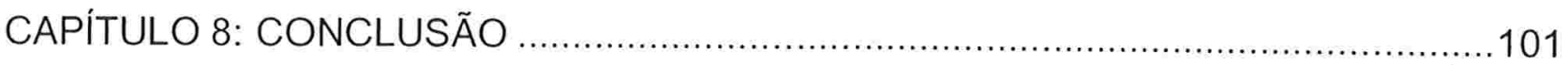

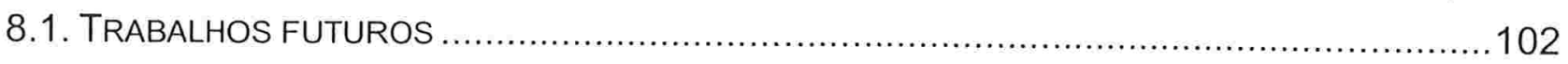

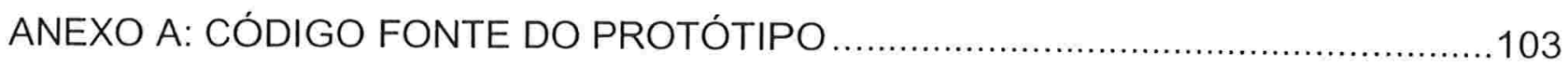

A.1 - MÓDULO DE ATRIBUIÇÃO DE PRIVILÉGIOS ............................................103

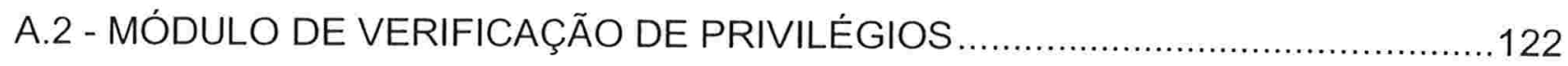

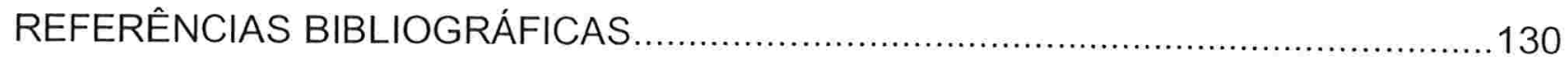

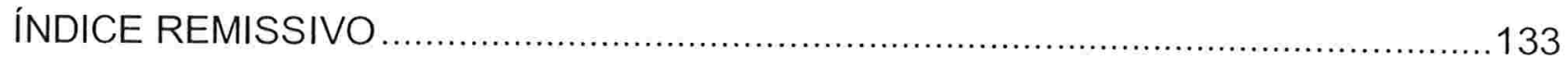




\section{CAPÍTULO 1: INTRODUÇÃO}

É de conhecimento geral que pelo uso de um serviço de autenticação é possível provar quem realmente você é. Certificados de identidade ou certificados de chave pública fornecem a melhor solução para integrar esse serviço de autenticação básico à maioria das aplicações desenvolvidas para a Internet que requeiram o uso de assinaturas digitais.

No entanto, novas aplicações, particularmente na área de comércio eletrônico, necessitam de um serviço de autorização para determinar quais são as permissões ou qual é o papel (role) de um usuário, ou seja, quais são as ações que um certo usuário pode fazer. Nesse caso, privilégios para executar tarefas devem ser considerados.

Um exemplo é a necessidade de definição por parte de uma empresa de quais serão os privilégios de seus funcionários sobre os recursos disponibilizados por ela, como uma pasta ou documentos de acesso restrito. Nesse caso, o serviço de autorização tornase importante, pois diferentes conjuntos de privilégios sobre recursos serão atribuídos a diferentes categorias de funcionários. No caso de aplicações distribuídas em que recursos da empresa são compartilhados com empresas parceiras, fornecedores ou clientes, o serviço de autorização torna-se essencial.

A autorização não é um problema recente e diversas soluções foram tentadas no passado. No entanto, as soluções tradicionais não atendem de maneira adequada a diversas aplicações para a Internet, pois não têm uma fácil implementação em ambientes em que a utilização de certificados de identidade são necessárias. Nesses casos, o uso de objetos de dados independentes que contenham os privilégios do usuário é mais indicado. O certificado de atributo, proposto pela recomendação X.509 da ITU-T (International Telecommunications Union) [ITU 00], forneceu uma solução apropriada, que pode ser utilizada em conjunto com certificados de identidade.

Embora o uso de certificados de identidade seja uma boa solução, o seu uso em um serviço de autenticação de grande abrangência só é viável com a implementação de uma estrutura eficiente para gerenciar e distribuir todos os certificados no sistema. 
Atualmente isso é feito por uma entidade conhecida como Infra-estrutura de Chaves Públicas (ICP), que, ao mesmo tempo, suporta criptografia, integridade e não-repudiação. Sem o seu uso, é praticamente inviável o uso de aplicações com assinatura digital em larga escala[NAS 01][ADA 99a].

De modo análogo, os certificados de atributos sugeridos pela ITU-T são a base para a construção das Infra-estruturas de Gerenciamento de Privilégios (PMI - Privilege Management Infrastructure).

Ambas as infra-estruturas aqui tratadas são independentes, porém, devem ser interconectadas por meio de algum campo comum nos certificados gerados. Esse interrelacionamento é necessário, uma vez que, para se conceder autorização, é necessário que o evento de autenticação já tenha ocorrido.

Embora interconectadas, ambas as estruturas são autônomas e podem ser gerenciadas independentemente. As tarefas de criação e manutenção de identidades podem ser separadas das tarefas de concessão de autorização. Na verdade, toda a infraestrutura de autenticação deve estar funcionando antes da implantação de uma estrutura de autorização.

Em ambientes empresariais, essa independência das infra-estruturas é um fator positivo. A razão para isso é que a identidade tem um significado global, cujo certificado pode ser emitido por uma Autoridade Certificadora externa à empresa. Por outro lado, um atributo tende a ter um significado local. Assim, a concessão de privilégios depende muitas vezes de conhecimento de fatos ou informações confidenciais. Nesses casos, é razoável pensar que a própria empresa, dona das informações, deverá emitir os certificados de atributos necessários.

\subsection{Motivação}

Diversas motivações para a construção de um modelo de serviço de autorização serão abordadas a seguir. O serviço de autorização concede privilégios a um usuário, ou, em outras palavras, define o papel (role) daquele usuário naquele momento. O serviço de autorização deve ser dinâmico e acomodar as mudanças de papéis, muitas vezes associados à função do funcionário na empresa.

Um papel pode representar a competência para fazer tarefas específicas, como as de um físico ou farmacêutico. Também pode incorporar autoridade e responsabilidade, 
como no caso de um gerente de projeto. Autoridade e responsabilidade são diferentes de competência. Papéis representam a designação de trabalhos específicos que podem ser revezados entre muitos usuários, serviços de autorização e suas implementações devem ter a habilidade de tratar todas as nuances do conceito de papel.

Um estudo no NIST [FER 93] demonstrou que o controle de acesso baseado em papéis é uma necessidade de vários setores comerciais e governamentais. Nesse estudo, as premissas para a definição dos papéis foram baseadas em diversas funções dentro e fora da empresa, como a função de cliente, funcionário ou acionista. Além disso, fatos como o nível de sigilo da informação, o uso não autorizado de telefonia de longa distância e a aderência a perfis profissionais também foram considerados. O estudo concluiu que muitas empresas baseiam sua decisão de controle de acesso no papel (role) que o indivíduo tem na organização, ou seja, seu cargo ou função na empresa.

O principal objetivo de um serviço de autorização é facilitar a administração e a revisão da segurança [SAN 96]. Com esse intuito, muitos sistemas de controle de acesso bem-sucedidos voltados para computadores de grande porte implementavam papéis para a administração da segurança.

Diante do exposto, a definição de um modelo de serviço de autorização que atenda às expectativas e particularidades das empresas torna-se uma necessidade. Mais que isso: o serviço de autorização aqui estudado deve estar integrado a um serviço de autenticação confiável e terceirizado, fornecido por infra-estruturas de chaves públicas.

\subsection{Metodologia de pesquisa}

Para este trabalho foi adotada a metodologia de pesquisa descritiva bibliográfica, que se constitui em leituras de livros, publicações periódicas, artigos isolados, dissertações de mestrado, consultas aos principais sítios da Internet e estudos de caso. Além disso, valer-se-á dos conhecimentos adquiridos para a construção de um protótipo do modelo estudado.

\subsection{Objetivos e organização deste trabalho}

Este trabalho dedica-se a estudar, propor e implementar um protótipo para empresas que optaram por terceirizar os serviços de autenticação, por meio do uso de infra-estruturas de chaves públicas confiáveis, mas decidiram também manter os serviços 
de autorização internos à empresa. Além disso, este trabalho também poderá servir como referência em português sobre o assunto Privilege Management Infrastructure (PMI) ou Infra-estrutura de Gerenciamento de Privilégios, ainda novo no meio científico e sem nenhuma referência em língua portuguesa.

A estrutura do texto é a seguinte: o capítulo 1 apresenta uma breve introdução ao assunto. O capítulo 2 traz uma revisão sucinta dos conceitos básicos de criptografia, em que são definidos os requisitos de segurança e os dois tipos de criptografia mais comuns - simétrica e assimétrica -, apresentando suas mais relevantes características, vantagens e desvantagens, bem como os principais problemas a serem gerenciados. (Esses conceitos são necessários para um melhor entendimento do restante do trabalho e também para familiarizar o leitor que não conhece criptografia aos jargões utilizados no universo criptográfico.) O capítulo 3 resume os principais conceitos da Infra-estrutura de Chaves Públicas (ICP) padrão, definindo Autoridade Certificadora e Autoridade de Registro, apresentando os modelos, políticas e caminhos de certificação, explicando como é feita a solicitação, verificação e revogação de certificados digitais e, finalmente, apontando as principais vulnerabilidades dessa infra-estrutura. No capítulo 4 apresentamse os modelos tradicionais de gerenciamento e concessão de autorização, assim como suas principais características. No capítulo seguinte trata-se do modelo de autorização com uso de certificados de atributos, focando o discurso na recomendação X.509 da ITUT. O capítulo 6 apresenta o modelo de gerenciamento proposto, com uma pequena modificação no certificado de atributos de modo a torná-lo dinâmico. O capítulo 7 apresenta o protótipo implementado definindo os casos em que esse protótipo se aplica e, por fim, o capítulo 8 conclui o trabalho. 


\section{CAPÍTULO 2: FUNDAMENTOS DE CRIPTOGRAFIA}

Segundo o dicionário Novo Aurélio - Dicionário da Língua Portuguesa - século XXI [FER 99], criptografia é "1. A arte de escrever em cifra ou em código. 2. Conjunto de técnicas que permitem criptografar informações (como mensagens escritas, dados armazenados ou transmitidos por computador, etc.)". A radical cripto tem sua origem na palavra grega Kryptós, que significa escondido. Assim, o objetivo da criptografia é esconder informações de modo que somente o destinatário desejado possa desvendá-las. Esse processo de ocultar é chamado de criptografia, e ao processo de revelar, dá-se o nome de decriptografia. Uma cifra é uma técnica utilizada para realizar a criptografia e a decriptografia. Por convenção, adota-se o nome texto claro para o texto que se deseja ocultar e texto cifrado para esse mesmo texto após a criptografia.

A arte de escrever em código surgiu da necessidade de manter a privacidade de informações sigilosas. Na Antigüidade, utilizavam-se técnicas simples de criptografia, como a substituição ou a troca de símbolos, com o objetivo de confundir pessoas não autorizadas que se apoderassem das mensagens. O princípio da substituição e troca de simbolos continua valendo para a computação, porém os simbolos agora são digitais e as técnicas empregadas nessa substituição são muitas vezes mais complexas.

A complexidade das técnicas empregadas vem ao encontro do fato de que a segurança dos dados criptografados é inversamente proporcional à facilidade de quebra do código cifrado, geralmente fundamentado na utilização de chaves de codificação e que são, em alguma instância, de conhecimento do emissor e do receptor dos dados. Assim, durante os anos, pesquisadores tentaram desenvolver técnicas que produzissem uma criptografia forte, dificultando a ação de pessoas mal-intencionadas.

Assim sendo, quando afirmamos que uma técnica criptográfica é segura, na verdade estamos afirmando que o esforço necessário para a quebra do código cifrado gerado e obtenção da mensagem original é muito grande se considerados os recursos, conhecimentos e tecnologias atuais, tornando a quebra inviável. Isso é o que chamamos de computacionalmente impossivel [TER 00]. 
Nos últimos vinte anos, um paradigma foi quebrado: pensava-se que o fato de se ocultar o algoritmo de criptografia ou a técnica utilizada para se criptografar, como exibido na letra "A") da Figura 2-1, era um ponto crucial para manter a segurança. Tal prática caiu em desuso, e, hoje em dia, quando um novo algoritmo é "inventado", ele é colocado à prova em eventos, em que vários pesquisadores tentam quebrá-lo. A segurança de um algoritmo criptográfico é baseada não no algoritmo em si, mas nas chaves criptográficas utilizadas.
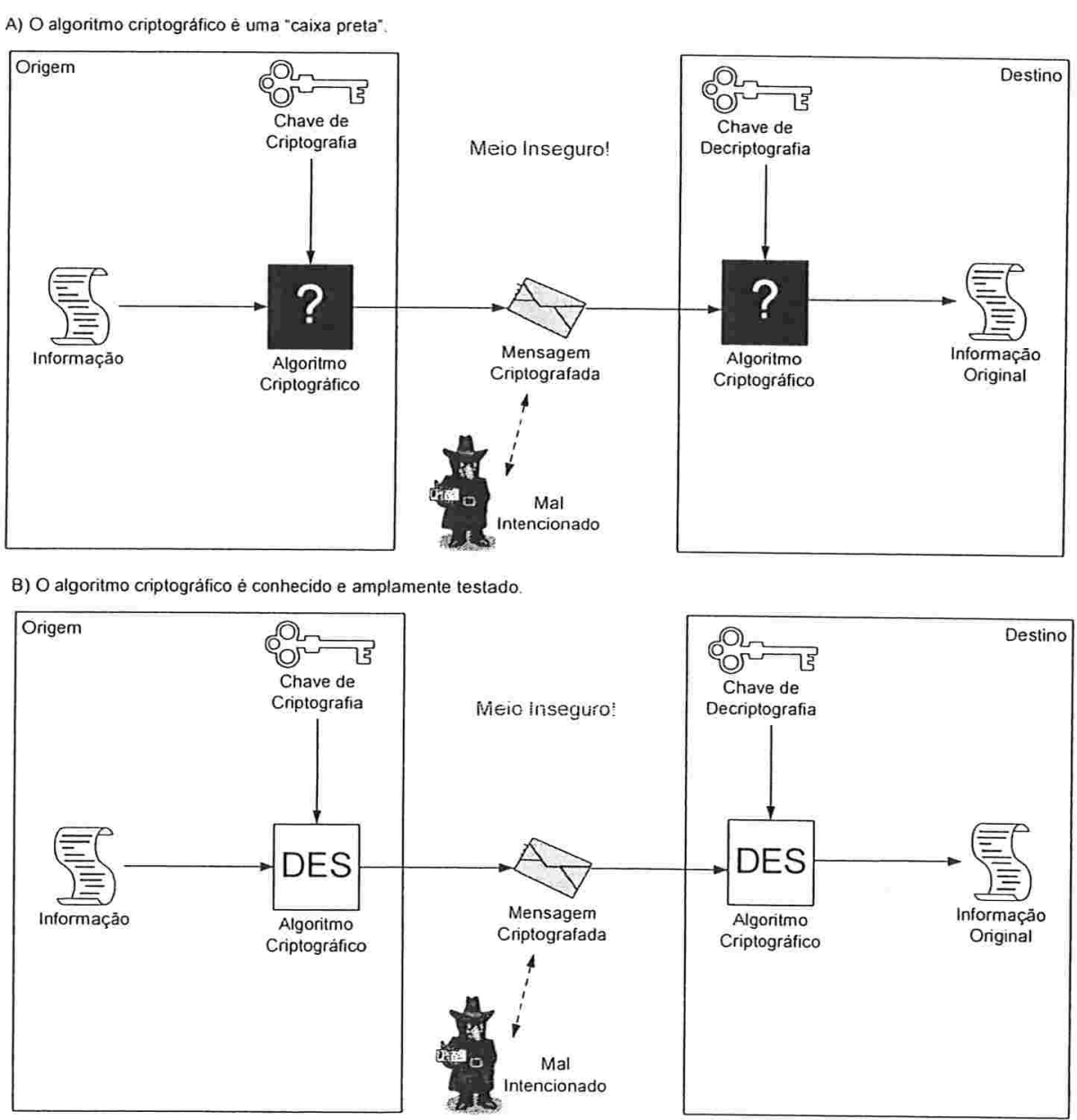

Figura 2-1 - Criptografia

A história da criptografia tem sido documentada há mais de 4000 anos, sendo encontrados indícios do seu uso no Egito antigo. No início, a criptografia limitava-se a técnicas de permutação e substituição, e as partes envolvidas na troca de mensagens combinavam os parâmetros necessários para tornar a mensagem ininteligivel para os demais. Assim, após a combinação inicial, a mensagem poderia ser trocada em um meio inseguro, sujeita à interceptação, com algum nível de segurança. Júlio César usou sua 
própria criptografia, conhecida como Cifra de César. Basicamente, a Cifra de César realizava um giro das letras do alfabeto para a direita, por três letras. Como um exemplo de uma criptografia utilizando a Cifra de César, vamos supor que Alice queira enviar uma mensagem para Beto. Assim, antes da troca de informações, Alice combina com Beto que a regra de codificação de texto utilizada na comunicação será a substituição da letra original pela $3^{\mathrm{a}}$ (terceira) letra subseqüente do alfabeto português. A Tabela 2-1 a seguir mostra esse código - a Cifra de César:

Tabela 2-1 - Protocolo de criptografia por substituição - Cifra de César

\section{Letra Original}

\begin{tabular}{l|l|l|l|l|l|l|l|l|l|l|l|l|l|l|l|l|l|l|l|l|l|l}
\hline A & B & C & D & E & F & G & H & I & J & L & M & N & O & P & Q & R & S & T & U & V & X & Z \\
\hline D & E & F & G & H & I & J & L & M & N & O & P & Q & R & S & T & U & V & X & Z & A & B & C \\
\hline
\end{tabular}

Codificação Cifrada

Supondo ainda que a mensagem a ser enviada de Alice para Beto sejam as palavras "BELO HORIZONTE", e aplicando o protocolo acordado entre as partes, a mensagem enviada seria "EHOR LRUMCRQXH", que, se capturada pelo malintencionado Carlos, não faria nenhum sentido, pois o intruso desconhece o protocolo utilizado.

\subsection{Tipos de Chave de criptografia}

A criptografia usa dois tipos de chaves: simétrica e assimétrica.

As chaves simétricas são mais antigas e utilizam uma única chave para a criptografia e para a decriptografia. Esse tipo de chave chama-se chave secreta ou particular, pois você deve mantê-la em segredo. Caso contrário, qualquer pessoa de posse da chave poderá decriptografar as mensagens que foram criptografadas com ela.

No exemplo anterior, Alice e Beto definiram a regra de codificação a ser utilizada, a Cifra de César, antes do envio da mensagem. Nessa fase, as mensagens para a definição das regras trafegarão por um meio inseguro e sem qualquer codificação, de modo que, se Carlos capturar essas informações, ele também ficará apto a decriptar toda e qualquer informação criptografada que passar na linha. Nesse contexto, podemos classificar a forma de codificação exibida na Tabela 2-1 como a chave criptográfica, e essa técnica de criptografia como criptografia de chave simétrica. 


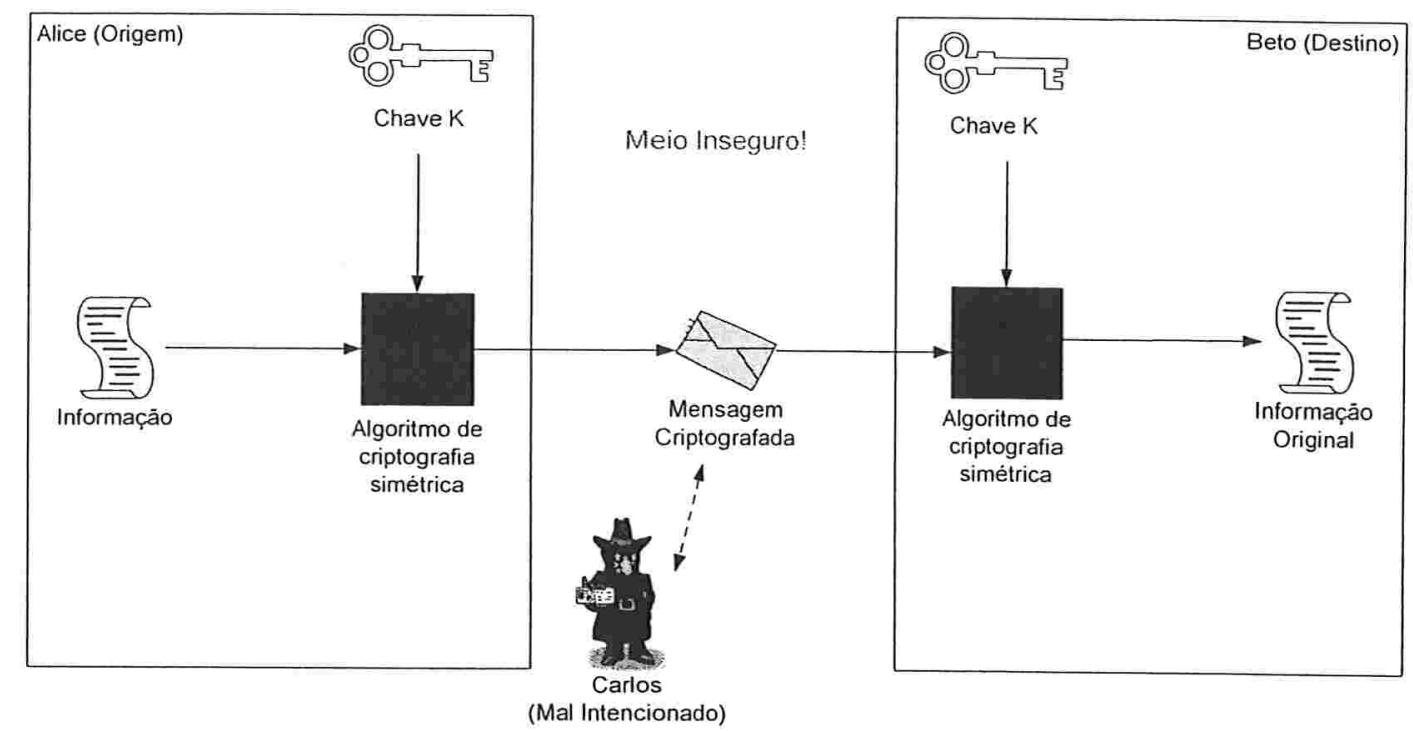

Figura 2-2 - Criptografia de Chave Simétrica

A criptografia de chave simétrica tem três problemas principais: a troca da chave, a autenticidade de mensagens e a necessidade de uma chave para cada canal seguro. O problema da troca da chave já foi abordado anteriormente. Como só existe uma chave para criptografar e decriptografar, essa chave deve ser "trocada" entre as partes envolvidas na comunicação, sendo essa uma fase de forte vulnerabilidade.

O segundo problema origina-se no fato de a chave ser única e conhecida por ambas as partes de uma comunicação segura. Para garantir a autenticidade de uma mensagem, é necessário gerar alguma informação adicional de modo que se possa provar que somente uma pessoa poderia ter "assinado" determinada mensagem. Para formar a informação adicional, é utilizada a chave de criptografia. Na técnica de criptografia simétrica, a chave de criptografia não pode ser utilizada, pois essa é conhecida e compartilhada por mais de uma pessoa. Um exemplo: suponhamos que Alice queira mandar uma mensagem assinada para uma amiga, Clara. Ela então utilizaria a chave $M$, que também é conhecida por Beto. Como Clara teria certeza de que a mensagem recebida e assinada foi realmente enviada por Alice, já que Beto também conhece a chave criptográfica? Além disso, mesmo que essa verificação fosse possivel, teríamos que compartilhar a chave $\mathrm{M}$ com Clara para que ela pudesse validar a assinatura.

E o terceiro problema reside no fato de que cada par origem/destino necessita de uma chave para se comunicar de forma segura. Matematicamente, para uma rede de $\mathrm{n}$ 
usuários seriam necessárias $(2 n-1)$ chaves, quantidade que dificulta o gerenciamento das chaves. A Figura 2-3 ilustra essa situação.

Dificuldade de Gerenciamento de chaves

7 hosts $\rightarrow 6$ chaves ( $k 0$ a k5)

1000 hosts $\rightarrow 999$ chaves

1000000 hosts $\rightarrow 999999$ chaves!

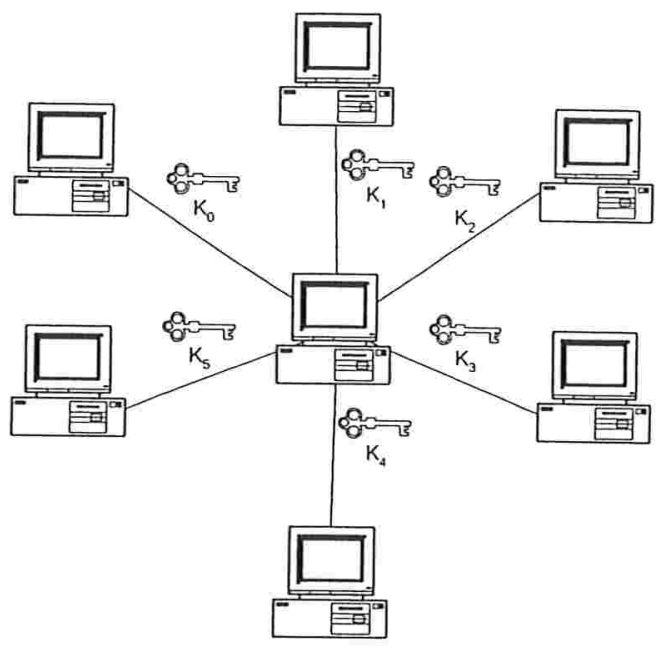

Figura 2-3 - Gerenciamento de chaves simétricas - um desafio

Os algoritmos usados na criptografia por chave simétrica, em sua maioria, já existem há muito tempo e são bastante conhecidos, de modo que é secreta apenas a chave de criptografia. Alguns dos algoritmos criptográficos de chave simétrica mais conhecidos são o DES - Data Encryption Standard -, seu sucessor, o AES - Advanced Encryption Standard - e o padrão europeu IDEA - International Data Encryption Algorithm. Mais informações sobre o funcionamento desses algoritmos podem ser encontradas na referência [TER 00].

Em 1976, Whitfield Diffie e Martin Hellman, da Universidade de Stanford Estados Unidos, introduziram publicamente o conceito de criptografia de chave pública ou assimétrica implementando uma técnica que visava a atacar diretamente os três pontos falhos da criptografia por chave simétrica: o compartilhamento e o gerenciamento das chaves, assim como a autenticação. Essa técnica utiliza a filosofia de chaves complementares em que uma delas é utilizada para codificar os dados e outra é utilizada para decodificar. A operação executada com a utilização de uma chave só pode ser revertida com a utilização da sua respectiva chave complementar.

Com isso, podemos implementar uma política em que uma das chaves é de conhecimento de todos (chave pública) e a outra é reservada e de conhecimento restrito 
(chave privada). A estratégia permite que possamos trocar informações utilizando a combinação de chaves públicas e privadas dos dois indivíduos envolvidos no processo e resolver os três problemas da chave simétrica.

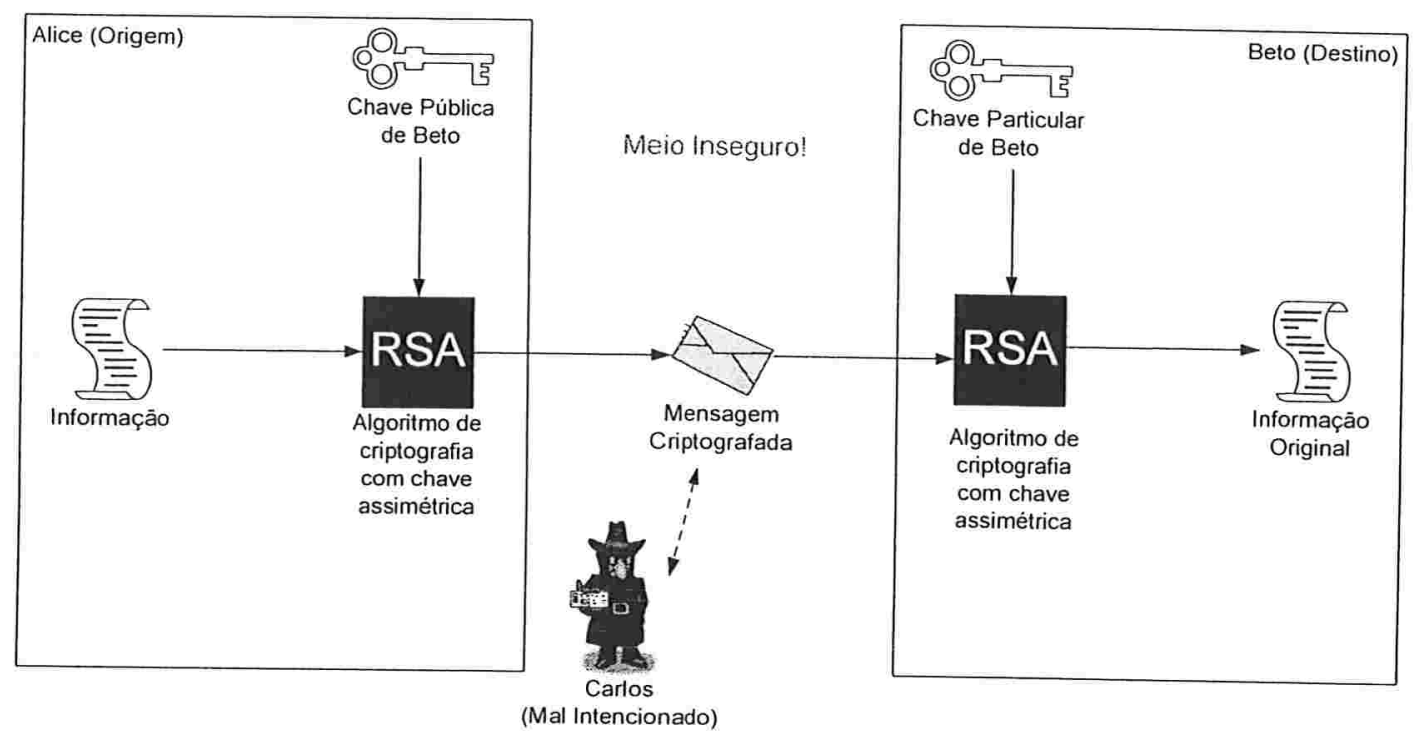

Figura 2-4 - Criptografia de chave assimétrica

A criptografia assimétrica é relativamente nova na história da criptografia. algoritmo Diffie-Hellman permitiu que a chave secreta dos algoritmos de chave simétrica pudesse ser trocada de forma segura.

Os algoritmos de chave assimétrica mais conhecidos são o Diffie-Hellman e o RSA - Rivest, Shamir e Adleman. Mais informações acerca do funcionamento desses algoritmos podem ser obtidas na referência [TER 00].

\subsection{Princípios básicos de segurança}

Segundo a norma NBR ISO/EIC 17799, a segurança da informação deve proteger a informação de diversos tipos de ameaças para garantir a continuidade dos negócios, minimizando os danos e maximizando o retorno dos investimentos [ABN 01]. Ainda segundo essa norma, a informação é um ativo que, como qualquer outro ativo importante para os negócios, tem um valor para a organização e conseqüentemente necessita ser adequadamente protegido [ABN 01]. Para tal, deve-se buscar a confidencialidade, a integridade e a disponibilidade da informação. Por confidencialidade entende-se a garantia de que o acesso à informação seja obtido somente por pessoas autorizadas. A integridade busca a salvaguarda da exatidão e completeza da informação e dos métodos de processamento. A disponibilidade busca garantir que os usuários 
autorizados obtenham acesso à informação e aos ativos correspondentes sempre que necessário [ABN 01].

Alguns outros principios que devem ser observados são a autenticidade e a nãorepudiação. Segundo William Stallings [STA 02], autenticidade é a garantia de que os participantes de uma comunicação sejam corretamente identificados, tendo-se certeza absoluta das identidades, e não repudiação é a garantia que nem a origem nem o destino das informações possam negar posteriormente sua transmissão, recepção ou posse.

\subsection{Tipos de ataque}

Ataque pode ser definido como uma técnica específica para se aproveitar de uma vulnerabilidade, ou seja, é uma fraqueza inerente de um elemento de um sistema, podendo ser uma brecha, ponto fraco ou falha que podem ser explorados. Segundo a RFC2828 [STA 02], ataque é uma agressão sobre um sistema de segurança que deriva de uma ameaça, isto é, um ato inteligente que é deliberadamente tentado para esquivarse de serviços de segurança e violar as políticas de segurança de um sistema. Ainda segundo a RFC2828 [STA 02], o ataque pode ser ativo, quando tenta modificar recursos do sistema ou afetar sua operação, ou passivo, quando tenta aprender ou fazer uso de informações do sistema, mas não afeta seus recursos. O ataque também pode ser interno, quando é iniciado de dentro do perímetro de segurança, isto é, quando uma entidade que tem acesso aos recursos do sistema utiliza esse acesso de modo não autorizado, ou externo, quando é iniciado de fora do perímetro de segurança, da Internet, por exemplo. A Figura 2-5 mostra os componentes de um ataque.

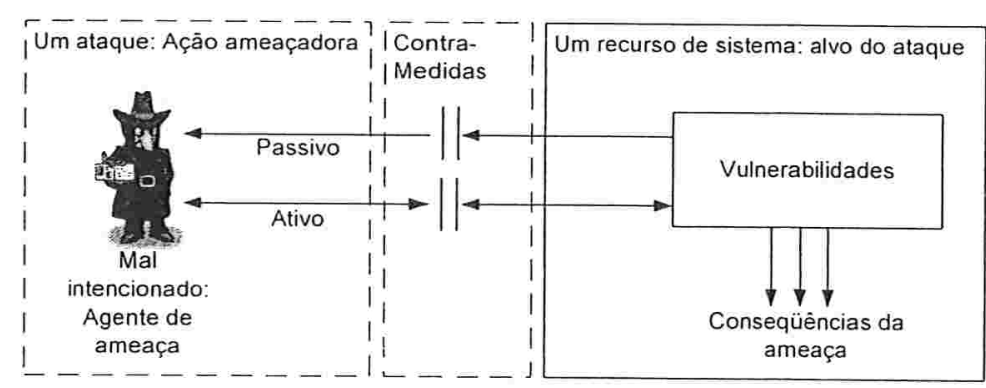

Figura 2-5 - Componentes de um ataque

Em um ambiente computacional, as informações fluem entre os diversos equipamentos de rede de uma origem A para destino B, conforme a Figura 2-6 a seguir. Analisando esta figura, as informações são encapsuladas na origem $A$, fluem pela rede $e$ chegam ao destino B, onde são desencapsuladas. 


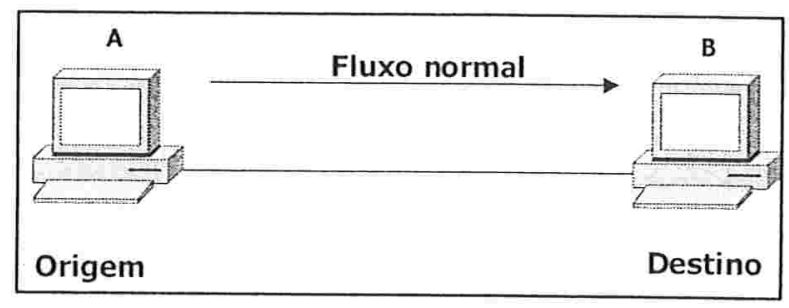

Figura 2-6 - Fluxo norma de dados entre origem e destino

Muitos dos ataques são baseados justamente nesse princípio, atuando no ponto mais vulnerável, quando o dado está trafegando da origem para o destino. Os ataques, de uma maneira geral, podem ser classificados em interceptação, interrupção, modificação e fabricação de informações.

O objetivo da interceptação é capturar o que está sendo transmitido sem que o sistema perceba, ou seja, ataca-se a confidencialidade das informações.

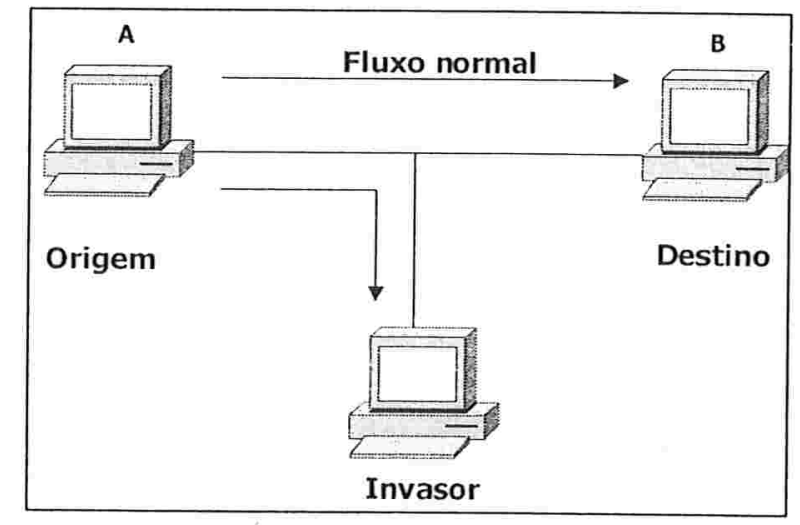

Figura 2-7 - Interceptação

Um dos principais tipos de ataque dessa classificação é o man-in-the-middle, no qual o invasor simula ser o parceiro de ambas as partes envolvidas na conexão, assumindo a identidade de um usuário válido.

$\mathrm{Na}$ interrupção o objetivo é interromper o serviço oferecido, ou seja, ataca-se a disponibilidade das informações.

O principal tipo de ataque classificado como interrupção é o Denial of Service (DoS), que é o envio de requisições em massa para um determinado computador, de modo que o mesmo não consiga responder a todas elas, ficando sobrecarregado e levando o serviço a parar de funcionar. 


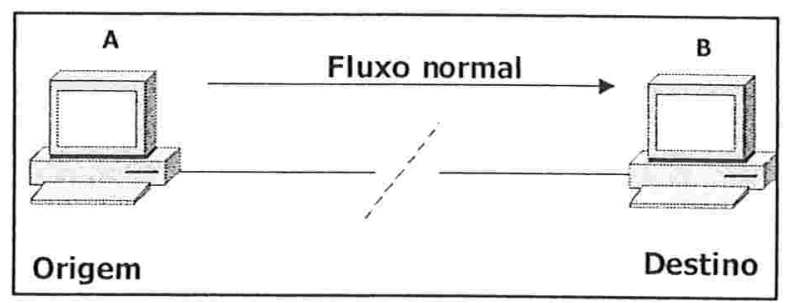

Figura 2-8 - Interrupção

A modificação visa à alteração da informação que está sendo transmitida, ou seja, ataca-se a integridade da mesma. Um exemplo de ataque dessa classificação é o Replay, em que parte de uma transmissão da rede é copiada e reproduzida posteriormente, simulando um usuário autorizado.

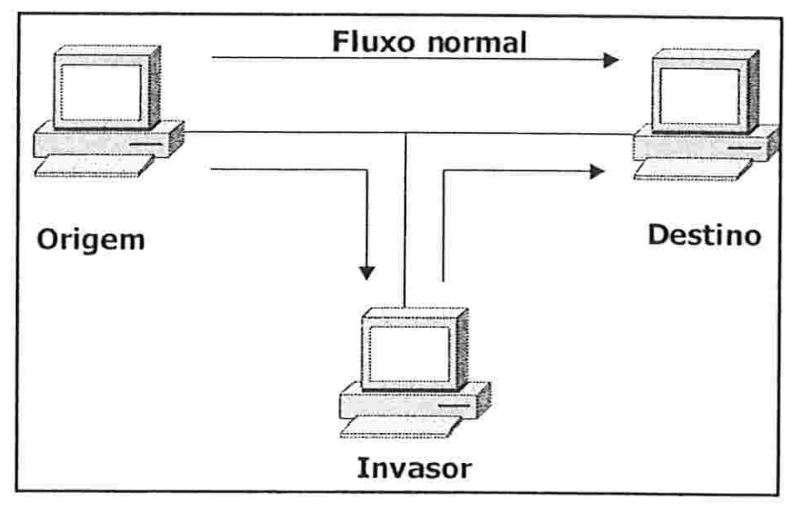

Figura 2-9 - Modificação

O objetivo da fabricação é se passar por um usuário do sistema, a fim de obter informações para transmitir dados na rede, ou seja, ataca-se a autenticidade das informações.

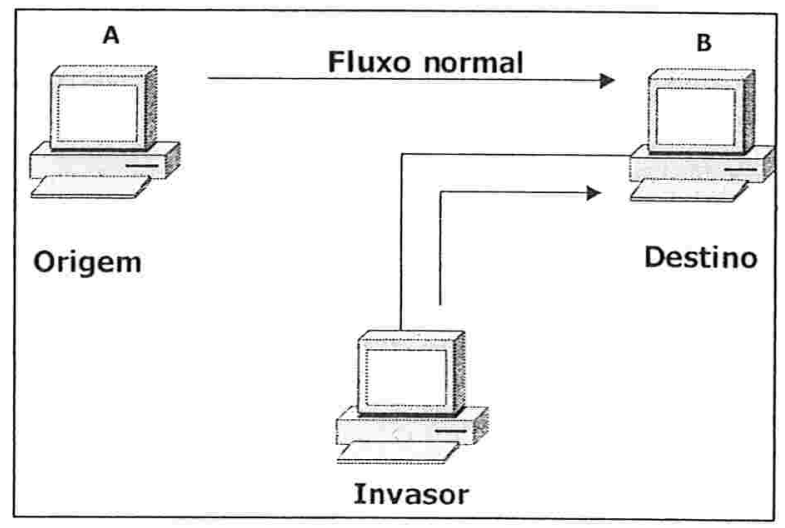

Figura 2-10 - Fabricação

O tipo de ataque de fabricação mais comum é o IP Spoofing, que consiste na substituição do endereço IP do computador do invasor, fazendo com que ele se passe por um computador confiável da rede, podendo, assim, obter privilégios na comunicação. 


\section{INFRA-ESTRUTURA DE CHAVES PÚBLICAS}

Os sistemas eletrônicos de informação atuais são tão complexos quanto as relações de negócios que eles servem. A expressão "Segurança da Informação" é comum e conhecida em todos os níveis hierárquicos de uma empresa. Quando vista de uma perspectiva corporativa, a segurança da informação é um facilitador dos objetivos de negócios tradicionais no ambiente eletrônico. O aumento do faturamento por meio do acesso a novos mercados, a redução dos custos com o uso eficiente de estruturas de extranet e internet para a distribuição de informações e a diminuição do risco de endividamento, tudo de forma compatível com as leis do governo e da indústria, representam apenas alguns exemplos da importância da política de segurança em uma infra-estrutura de rede. A questão fundamental hoje não é mais se a empresa deve ter uma infra-estrutura de segurança, mas qual infra-estrutura deve adotar.

Um dos pontos mais cruciais em qualquer transação é a identidade da entidade com a qual a transação está sendo feita. Em uma transação tradicional são utilizados métodos como assinatura de contratos, documentos registrados em cartório ou advogados para ajudar a estabelecer confiança entre as partes em uma relação de negócios. Assim como há vários métodos que garantem a autenticidade das partes em uma transação tradicional, deve haver, em uma transação eletrônica, um método que garanta a confiabilidade e a autenticidade das partes. De modo similar, a necessidade de confidencialidade na integridade da informação trocada é crítica. Podemos ainda aumentar a lista de serviços de segurança: há a necessidade de estabelecer acordos de não-repudiação e, digitalmente, aprovar e, seguramente, datar uma transação.

Como o mundo do comércio está se tornando altamente dependente do armazenamento eletrônico, a acessibilidade a esses dados e a entrega de informação valiosa à manutenção de um bom nível de confiança em todo o processo tornam-se críticas. Todos os serviços de segurança mencionados anteriormente devem ser utilizados para maximizar as vantagens do comércio eletrônico. A infra-estrutura de 
chaves públicas (ICP) foi concebida para fornecer uma solução eficiente para a disponibilização dos serviços de segurança, especialmente a autenticação.

Conforme abordado no capítulo anterior, a criptografia assimétrica é baseada em um par de chaves. Quando utilizamos um par de chaves, somente uma das chaves, aquela conhecida com chave particular, deve ser mantida em segredo e, geralmente, sob o controle de seu proprietário. A outra chave, conhecida como chave pública, pode ser disseminada livremente para uso por outra pessoa que deseje participar de serviços seguros com a pessoa que possui a chave particular correspondente. Isso é possivel porque as chaves são matematicamente relacionadas, mas é computacionalmente difícil gerar a chave particular a partir da chave pública. Em teoria, qualquer indivíduo pode enviar para o proprietário de uma chave particular uma mensagem criptografada com sua chave pública e somente o proprietário poderá ler a mensagem segura, ou seja, decriptografá-la. De modo análogo, o proprietário de uma chave particular pode estabelecer a integridade e a origem de uma informação enviada para a outra parte se ele assinar digitalmente a informação usando sua chave particular. Qualquer pessoa que receba a informação pode usar a chave pública associada para validá-la, garantindo que a informação veio do proprietário da chave particular, além de se certificar de que a integridade do dado foi mantida.

\subsection{A arquitetura de um ICP}

Uma Infra-estrutura de Chaves Públicas (ICP) pode ser definida com um conjunto de hardware, software, pessoas, políticas e procedimentos necessários para criar, gerenciar, armazenar, distribuir e revogar certificados de chave pública.

A arquitetura de uma ICP tem se mantido basicamente a mesma desde sua primeira publicação no original Internet Certificate and Certificate Revocation List (CRL) Profile [HOU 99]. O último modelo foi publicado na mais recente versão do Internet and CRL Profiile [HOU 02]. A figura 3-1 a seguir ilustra a arquitetura tradicional de uma Infraestrutura de Chaves Públicas. 


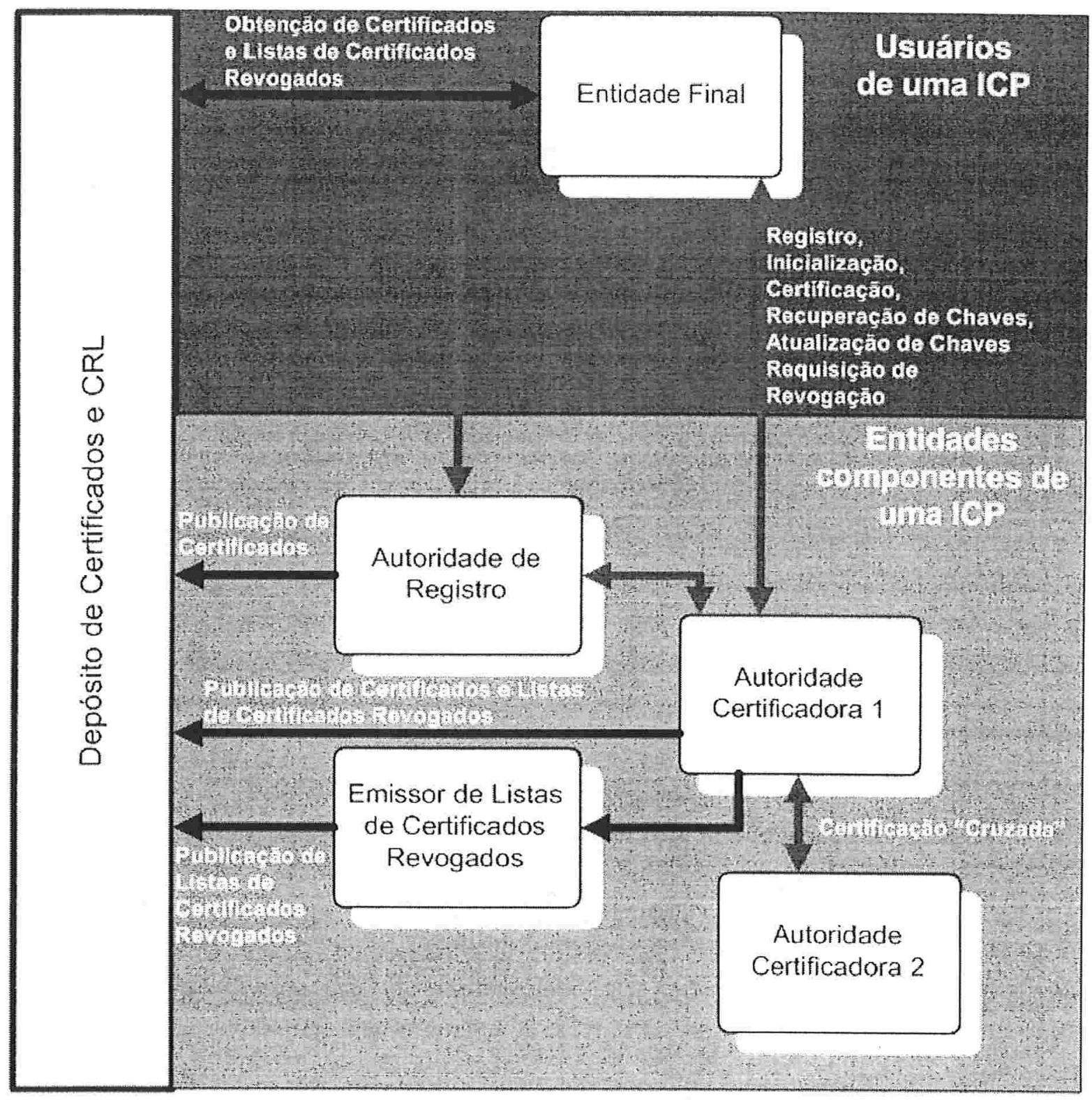

Figura 3-1 - Entidades de uma ICP

Para melhor entendimento da figura 3-1 anterior, a Tabela 3-1 a seguir resume as principais funções das entidades existentes na arquitetura de uma ICP. Tais entidades serão alvo de detalhamento neste capítulo.

Tabela 3-1 - Componentes de um ICP 


\begin{tabular}{|c|c|}
\hline Entidade & Função \\
\hline Entidade Final & $\begin{array}{l}\text { Entidade Final é um termo genérico utilizado para designar usuários } \\
\text { finais, dispositivos como servidores e roteadores, ou qualquer outra } \\
\text { entidade que pode ser identificada no campo sujeito (subject) de um } \\
\text { certificado de chave pública. Entidades finais fazem uso de serviços } \\
\text { relacionados a uma ICP ou dão suporte a eles. }\end{array}$ \\
\hline $\begin{array}{l}\text { Autoridade } \\
\text { Certificadora } \\
\text { (AC) }\end{array}$ & $\begin{array}{l}\text { A Autoridade Certificadora (AC) é o emissor de certificados e Listas de } \\
\text { Certificados Revogados (LCR). Ela também pode dar suporte a várias } \\
\text { tarefas administrativas, embora tais tarefas sejam geralmente } \\
\text { delegadas para uma ou mais Autoridades de Registro. }\end{array}$ \\
\hline $\begin{array}{l}\text { Autoridade de } \\
\text { Registro (AR) }\end{array}$ & $\begin{array}{l}\text { A Autoridade de Registro (AR) é um componente opcional na } \\
\text { arquitetura de uma ICP que pode assumir algumas funções } \\
\text { administrativas da AC. A AR é freqüentemente associada com o } \\
\text { processo de registro da Entidade Final, mas pode também ser útil em } \\
\text { várias outras áreas. }\end{array}$ \\
\hline Depósito & $\begin{array}{l}\text { Um depósito é um termo genérico usado para denotar qualquer método } \\
\text { de armazenamento de certificados e Listas de Certificados Revogados } \\
\text { de modo que eles possam ser obtidos pelas Entidades Finais. }\end{array}$ \\
\hline $\begin{array}{ll}\text { Emissor de } \\
\text { Listas de } \\
\text { Certificados }\end{array}$ & $\begin{array}{l}\text { O Emissor de Listas de Certificados Revogados também é um } \\
\text { componente opcional para o qual uma Autoridade Certificadora pode } \\
\text { delegar a função de publicação de Certificados. }\end{array}$ \\
\hline
\end{tabular}

\subsubsection{Entidades Finais}

Entidades Finais são algumas vezes associadas a usuários finais. Apesar de esse ser freqüentemente o caso, o termo Entidade Final é mais abrangente. Uma Entidade Final pode ser um usuário final como também um roteador, um servidor, um processo ou qualquer objeto que possa ser identificada no campo sujeito ("subject") de um certificado de chave pública. Outra forma de conceituar o termo Entidade Final é como sendo um cliente de serviços fornecidos por uma Infra-estrutura de Chaves Públicas. Há casos em que um fornecedor de serviços de ICP pode ser considerado uma Entidade Final. Essa situação existe no relacionamento entre uma Autoridade de Registro e uma 
Autoridade Certificadora, pois, nesse caso, a Autoridade de Registro está fazendo uso de serviços fornecidos pela Autoridade Certificadora.

\subsubsection{Autoridade Certificadora}

Chaves públicas são distribuídas na forma de certificados de chave pública. A Autoridade Certificadora (AC) é a principal fundação de uma Infra-estrutura de Chaves Públicas (ICP), uma vez que é o único componente a emitir os certificados de chave pública, que, por sua vez, são assinados pela Autoridade Certificadora emissora e amarra o nome do sujeito à chave pública. Além disso, as Autoridades Certificadoras são responsáveis também pela emissão de Listas de Certificados Revogados (LCR). Esta última função pode ser delegada a uma outra entidade, conhecida como Emissor de Listas de Certificados Revogados.

Autoridades Certificadoras podem igualmente realizar algumas tarefas administrativas, como registro de usuários finais, ou servir como facilitador de recuperação e cópia de segurança de chaves. Porém, nas implementações mais comuns, essas tarefas são delegadas a componentes separados.

\subsubsection{Autoridade de Registro}

Uma Autoridade de Registro é um componente opcional na arquitetura de uma Infra-Estrutura de Chaves Públicas. Porém, o seu uso pode retirar muitas das tarefas administrativas que uma Autoridade Certificadora assumiria no caso da ausência da Autoridade de Registro. Dentre as atividades executadas por uma Autoridade de Registro temos:

- Verificação de identidade da entidade final que solicita o registro em uma ICP;

- Validação dos atributos do sujeito solicitante;

- Verificação de posse real da chave particular, tarefa conhecida como "prova de possessão";

- Geração de segredos compartilhados para dar suporte aos processos de certificação e inicialização;

- Geração do par de chaves pública e particular;

- Validação de parâmetros de chaves públicas apresentadas para registro. 
É importante ressaltar que, embora a Autoridade de Registro execute muitas funções, ela nunca poderá emitir um certificado de chave pública. Essa tarefa é feita exclusivamente pela Autoridade Certificadora.

O uso inteligente de Autoridades de Registro oferece duas vantagens principais. A primeira é que esse componente ajuda a reduzir os custos envolvidos na criação e manutenção de uma Infra-estrutura de Chaves públicas. Isso é especialmente verdade em empresas grandes e geograficamente dispersas, que exigem que seus usuários estejam fisicamente presentes antes que certas atividades relacionadas com uma ICP sejam permitidas. Um exemplo típico è o registro do usuário final, mas outras atividades administrativas de uma ICP, como revogação de certificados ou recuperação de chaves, também poderiam se adaptar a essa política. Uma outra situação ocorre quando a empresa decide terceirizar os serviços de uma Autoridade Certificadora, mas deseja ainda manter o controle sobre o processo de registro.

A segunda grande vantagem é que, aliviando a carga de tarefas administrativas das Autoridades Certificadoras, a empresa pode operar sua AC em modo off-line. Assim, as janelas de oportunidade para ataques remotos são minimizadas.

\subsubsection{Depósitos}

O termo depósito é freqüentemente associado a um diretório; todavia, esse não é necessariamente o caso. Em uma arquitetura de um ICP, um depósito é um termo genérico usado para denotar qualquer método para armazenamento e recuperação de informações associadas a uma Infra-estrutura de Chaves Públicas, como certificados de chave pública e Listas de Certificados Revogados. Um depósito pode ser implementado como um diretório baseado no padrão $\times .500$ com o acesso do cliente por meio de Ligthweight Directory Access Protocolo (LDAP). O depósito pode ser implementado também de um modo mais simples como, por exemplo, pelo armazenamento das informações em arquivos-texio em um servidor remoto cujo acesso pelo cliente pode ser via File Transfer Protocolo (FTP) ou Hyper Text Transfer Protocol (http). Ou seja, o conceito é amplo, bem como as implementações possiveis. O grupo de trabalho do Internet Engineering Task Force Public Key Infrastructure (IETF PK!), responsável pela padronizaçäo dessa estrutura, definiu diversos protocolos operacionais para facilitar a 
distribuição de certificados de chaves públicas e Listas de Certificados Revogados, incluindo LDAP, HTTP e FTP.

Também é possivel retirar a carga de certas funções dos sistemas clientes para uma entidade confiável. Por exemplo, o Online Certificate Status Protocol [MYE 99] pode ser usado para perguntar a uma entidade confiável sobre a situação de um ou mais certificados, ou seja, saber se um determinado certificado foi revogado.

O ponto-chave aqui é que a entidade final tenha algum mecanismo para consultar os certificados e as listas de certificados revogados. Os depósitos fornecem esse mecanismo para as entidades finais.

\subsubsection{Emissor de Listas de Certificados Revogados}

A responsabilidade pela emissão de certificados e também pela emissão de Listas de Certificados Revogados é tipicamente de uma Autoridade Certificadora. Entretanto, é possível que a Autoridade Certificadora delegue esta última função para outra entidade. Listas de Certificados Revogados emitidos por outra entidade são chamadas de Listas Indiretas de Certificados Revogados.

\subsection{Funções de Gerenciamento de um ICP}

Uma Infra-estrutura de Chaves Públicas necessita de algumas funções que "potencialmente precisam ser suportadas por protocolos de gerenciamento" [HOU 02]. A figura 3-2 apresenta a interação entre os vários componentes de uma ICP, além de apresentar resumidamente as relações que devem ocorrer entre esses componentes. É importante notar que algumas das funções administrativas podem ser feitas de modo offline. As seções seguintes abordarão detalhadamente cada uma das funções administrativas referenciadas na tabela 3.1. Além dessas funções, existem outras opcionais, que serão abordadas mais adiante no capitulo, bem como os protocolos de gerenciamento que devem ser usados para sua realização.

\subsubsection{Registro}

Entidades Finais devem se matricular em uma Infra-estrutura de Chaves Públicas antes que elas possam utilizar os serviços disponibilizados por uma ICP. O Registro é o primeiro passo no processo de matrícula, que é caracterizado pelo fato de a Entidade Final se apresentar, tornar-se conhecida para uma Autoridade Certificadora 
[HOU 02]. O Registro é usualmente associado com o processo de verificação da identidade de uma Entidade Final, que terá um rigor maior ou menor de acordo com a finalidade do uso do certificado, com políticas associadas ao ICP ou empresa contratante, e com o ambiente envolvido. O Registro poderia ser feito diretamente em uma Autoridade Certificadora ou, conforme visto anteriormente, por meio de uma Autoridade de Registro, num processo totalmente on-line, totalmente off-line ou um misto dos dois anteriores, dependendo das políticas adotadas.

Uma vez que a identidade da Entidade Final é verificada e está de acordo com as políticas adotadas, o componente que está acompanhando o processo de matrícula emite um ou mais segredos compartilhados, além de uma informação de identificação que será utilizada para autenticação quando o processo de matrícula continuar. A distribuição dos segredos compartilhados, por razões de segurança, é feita out-of-band e poderia utilizar segredos compartilhados pré-existentes.

\subsubsection{Inicialização}

O próximo passo no processo de matrícula é a Inicialização, uma etapa que envolve definir o componente de confiança que atenderá à Entidade Final solicitante. Informações adicionais como aquelas necessárias para atender às politicas para emissão de certificados também devem ser fornecidas pela Entidade Final nessa fase.

A fase de Inicialização é geralmente a criação do par de chaves associado à Entidade Final, isto é, a criação das chaves pública e particular que garantirão a identidade da Entidade Final.

O par de chaves pode ser gerado em vários lugares: a geração pode ser feita por um sistema da Entidade Final, pela Autoridade de Registro, pela Autoridade Certificadora ou um outro componente, como um módulo de segurança em hardware. As políticas adotadas pela Infra-estrutura de Chaves Públicas serão as responsáveis por definir onde e por quem o par de chaves poderá ser gerado. Geralmente a limitação se dá pelo ambiente no qual as chaves serão utilizadas.

\subsubsection{Certificação}

A Certificação é a conclusão do processo de matrícula de uma Entidade Final. É nessa fase que será emitido o Certificado de Chave Pública para a Entidade Final. 
Conforme mencionado anteriormente, a emissão do Certificado de Chave Pública é feita somente pela Autoridade Certificadora. Se o par de chaves foi gerado fora da Autoridade Certificadora, a chave pública que fará parte do Certificado deverá ser passada à AC de uma maneira segura.

Após a emissão, o Certificado de Chave Pública é enviado à Entidade Final e pode ser publicado no Depósito, possibilitando consultas.

Embora as fases de registro, inicialização e certificação sejam independentes, elas podem ser agrupadas em um único protocolo de operação [HOU 02].

\subsubsection{Recuperação do Par de Chaves}

O par de chaves pública e particular é usado para a criação e verificação de assinaturas digitais, criptografia e decriptografia de mensagens ou ambas as situações. Quando uma chave pública é utilizada para criptografar uma mensagem, em alguns casos é importante termos um mecanismo de recuperação da chave particular quando o acesso a ela não for mais possivel, por alguma razão válida. Caso a recuperação da chave não seja possivel, a recuperação da mensagem original também não será. A chave particular pode se tornar indisponivel por inúmeras razões, como esquecimento de senhas, discos rígidos danificados, estrago ou perda de token, dentre outros. A função administrativa de recuperação de par de chaves permite que uma entidade final obtenha novamente seu par de chaves de uma entidade autorizada, tipicamente uma Autoridade Certificadora.

Existem outras situações nas quais a recuperação de chaves é válida, como aquelas em que a relação da Entidade Final com sua Empresa muda, no caso de uma demissão, por exemplo, e a empresa necessita recuperar informações que foram criptografadas com o par de chaves daquela Entidade Final. Há ainda a possibilidade de que a informação criptografada seja requerida por alguma medida judicial, independentemente da vontade da Entidade Final. Para esses casos, a recuperação de chaves torna-se uma função vital, embora a maioria das políticas de segurança proíba tal atitude.

\subsubsection{Atualização do Par de Chaves}

Os certificados são emitidos com uma validade definida. Embora em alguns casos a validade seja bem generosa, em algum momento o certificado expirará. A 
atualização do par de chaves pode também ser solicitada quando da revogação de um determinado certificado, função a ser discutida na próxima seção.

A atualização do par de chaves envolve a geração de um novo par de chaves e a conseqüente emissão de um novo certificado de chave pública para a Entidade Final. Essa função é distinta da função de emissão de novo certificado, na qual não há a geração de um novo par de chaves, mas apenas a emissão de um novo certificado de chave pública.

O processo de atualização do par de chaves pode ser feito em seguida a uma expiração de certificado, mantendo a Entidade Final sempre de posse de um certificado válido. Esse procedimento não é recomendado pelo PKIX Working Group para uso na Internet [HOU 02], embora seja possível estabelecer períodos de validade diferentes para as chaves particulares e públicas, usadas, respectivamente, para assinar e verificar uma assinatura. Essa situação cria uma janela, na qual uma informação assinada com uma chave particular expirada possa ser validada e verificada por uma chave pública ainda válida, até que o processo de atualização do par de chaves esteja finalizado.

\subsubsection{Requisição de Revogação}

Como mencionado anteriormente, os Certificados de Chave Pública são geralmente emitidos com um prazo de validade muito grande. Tal situação pode gerar um problema: o Certificado pode não ser mais válido antes que seu prazo de validade expire. Essa situação pode ocorrer quando há o comprometimento da chave particular, quando há uma mudança na relação da Entidade Final com a empresa, quando há mudança de nome, dentre outras.

Para esses casos, existe a possibilidade de se revogar o Certificado emitido antes da expiração do prazo de validade. A Requisição de Revogação permite a uma Entidade Final ou a uma Autoridade de Registro revogar um dado Certificado de Chave Pública. Para essa função, podem ser utilizados mecanismos out-of-band, e, em alguns casos, a Entidade Final nem precisa, ou nem deve, ser envolvida no processo.

A informação de que houve um determinado Certificado revogado deve ser publicada e se tornar disponível para os usuários. Essa função é responsabilidade da Autoridade Certificadora que emitiu o Certificado ou pode ser delegada para um Emissor de Listas de Certificados Revogados. A freqüência de publicação é altamente dependente 
das políticas e do ambiente para o qual o Certificado foi emitido. Esse processo é exibido na figura 3-1 anterior.

É importante ressaltar que as Entidades Finais, ou terceiros operando com essas, devem verificar se os Certificados envolvidos nas transações ainda são válidos. Para isso, não basta verificar a data de validade; é necessário também consultar a lista de certificados revogados.

\subsubsection{Certificação Cruzada}

O processo de certificação cruzada ocorre entre Autoridades Certificadoras distintas, ou seja, um certificado cruzado é um certificado de chave pública que é emitido por uma Autoridade Certificadora para outra Autoridade Certificadora. Em outras palavras, um certificado cruzado é um certificado de chave pública que contém a chave pública de uma Autoridade Certificadora e é assinado por outra Autoridade Certificadora.

A certificação cruzada pode ser uni ou bidirecional. A certificação unidirecional ocorre tipicamente em um modelo de confiança hierárquico, no qual Autoridades Certificadoras superiores emitem certificados cruzados para Autoridades Certificadoras subordinadas. Nesse modelo, uma Autoridade Certificadora subordinada nunca emite um certificado cruzado para uma Auțridade Certificadora superior. A certificação cruzada bidirecional ocorre entre Autoridades Certificadoras, podendo uma Autoridade emitir um certificado para a outra e vice-versa.

\subsection{Funções de Gerenciamento Adicionais}

Nas seções anteriores, foram abordadas as funções típicas de uma Infraestrutura de Chaves Públicas [HOU 02]. Entretanto, existem algumas funções adicionais que podem ser úteis e necessárias em alguns cenários, e o PKIX working group reconhece essas funções e os protocolos definidos para dar suporte a elas. Algumas dessas funções adicionais incluem [ADA 99b]:

- Divulgação de atualização de chave da Autoridade Certificadora - fornece um mecanismo para que uma Autoridade Certificadora divulgue que seu par de chaves foi trocado. 
- Divulgação de Certificado - apresenta um método para divulgação de um certificado quando os métodos tradicionais, como o depósito, não estão disponíveis.

- Divulgação de Revogação - define um método para informar à Entidade Final que seu Certificado de Chave Pública foi ou será revogado.

- Divulgação de Listas de Certificados Revogados - implementa um método para a Autoridade Certificadora divulgar que uma nova Lista de Certificados Revogados foi emitida.

- Confirmação do Certificado - permite à Entidade Final explicitamente aceitar ou rejeitar o Certificado de Chave Pública que foi emitido para ela.

- Arquivo de Chaves - usado para explicitamente requisitar a recuperação da chave particular, usada na decriptografia de informações criptografadas, descrita na seção 0 - 3.2.4 Recuperação do Par de Chaves.

O Arquivo de Chaves, além de ser utilizado para dar suporte à operação de Recuperação do Par de Chaves, pode também ser utilizado para armazenamento de chaves particulares por um longo período, bem como para armazenamento de certificados de chave públicas usadas para verificação de assinaturas. Essa situação é desejável em diversos cenários, pois permite que Entidades Finais recuperem as chaves utilizadas durante um período longo, possibilitando a criação de um histórico de chaves. O histórico, por sua vez, permite que seja possivel a verificação de assinaturas que foram feitas há muito tempo, mesmo com a utilização de chaves que já expiraram. Isso pode ser útil na validação ou revalidação de documentos antigos, assinados com chaves antigas.

\subsection{Arquiteturas de uma Infra-estrutura de Chaves Públicas}

As Autoridades Certificadoras podem ser interligadas de várias formas. Para atender às necessidades da empresa ou órgão que fará uso de uma ICP, uma arquitetura para implementação da solução deverá ser adotada. Existem duas arquiteturas tradicionais da ICP disponiveis: a arquitetura hierárquica ou a arquitetura mista.

\subsubsection{Arquitetura Hierárquica}

$\mathrm{Na}$ arquitetura hierárquica, as autoridades são dispostas hierarquicamente abaixo da AC raiz. Nesse modelo, ocorre apenas a certificação cruzada unidirecional, ou 
seja, apenas as Autoridades Certificadoras superiores emitem certificados para as Autoridades subordinadas.

Numa ICP hierárquica, todas as partes confiáveis conhecem a chave pública da $A C$ raiz. Qualquer certificado pode ser validado pela verificação do caminho de validação dos certificados da AC raiz. Como exemplo, vamos observar a figura 3-2 a seguir. Se a Entidade Final 1 deseja manter uma comunicação confiável com a Entidade Final 2, o certificado de chave pública desta precisa ser validado. Após essa validação, a Entidade Final 1 tem que validar o certificado da entidade que emitiu o certificado da Entidade Final 2, neste caso, a Autoridade Certificadora 4. Após essa validação, o processo deve continuar até que seja atingida a Autoridade Certificadora Raiz, cuja chave pública é conhecida de todos, inclusive da Entidade Final 1, que iniciou esse processo, conhecido como caminho de certificação.

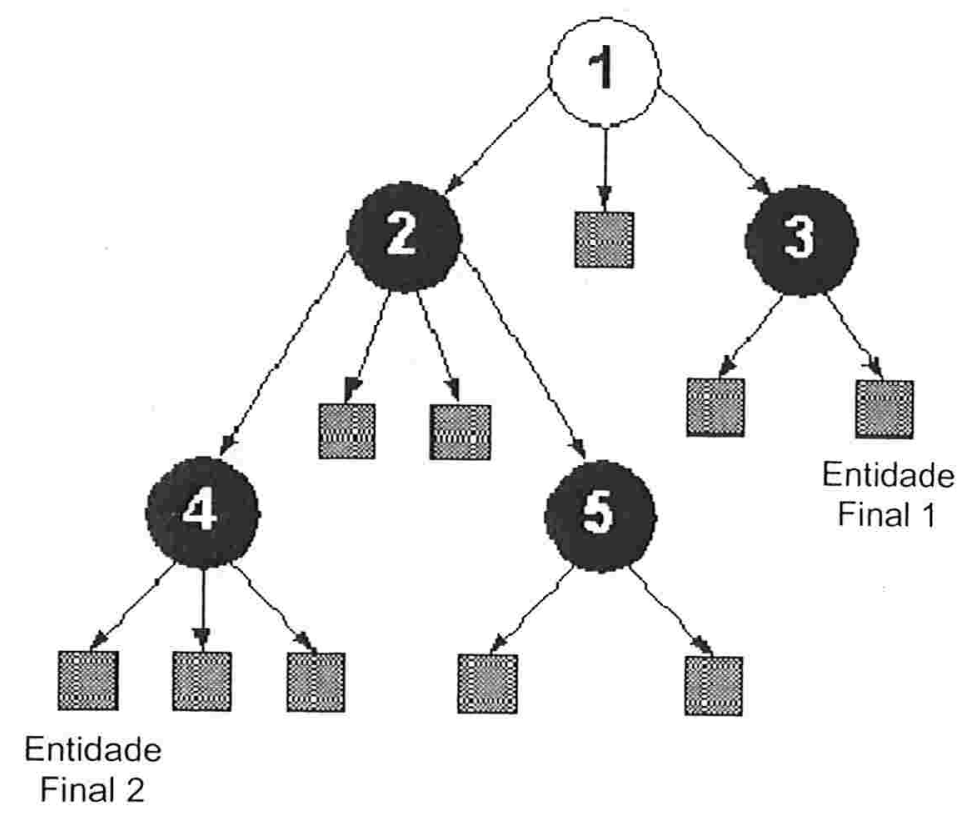

Figura 3-2 - Arquitetura Hierárquica de uma ICP

\subsubsection{Arquitetura Mista}

$\mathrm{Na}$ arquitetura mista, existem várias Autoridades Certificadoras independentes que se autenticam mutuamente, ou seja, nesse caso há a autenticação cruzada bidirecional. O resultado dessas autenticações cruzadas é a criação de inúmeras relações de confiança entre as ACs parceiras. Uma parte confiável conhece a chave pública de uma $A C$ próxima a ela mesma, geralmente aquela que emitiu seu certificado. A parte 
confiável valida o certificado pela verificação do caminho de validação dos certificados que derivam daquela $\mathrm{AC}$ parceira. Como exemplo, vamos observar a figura 3-3 a seguir. A Entidade Final 1 conhece a chave pública da AC 3, e a Entidade Final 2, por sua vez, conhece a chave pública da AC 4. Existem vários caminhos de certificação que conduzem a Entidade Final 2 até a Entidade Final 1. O mais curto requer que a Entidade Final 1 valide o certificado da Entidade Final 2, emitido pela $A C$ 4, ai o certificado da $A C 4$ emitido pela AC 5 e, finalmente, o certificado da AC 5 emitido pela AC 3. A AC 3 é a AC da Entidade Final 1, que confia nela e conhece sua chave pública.

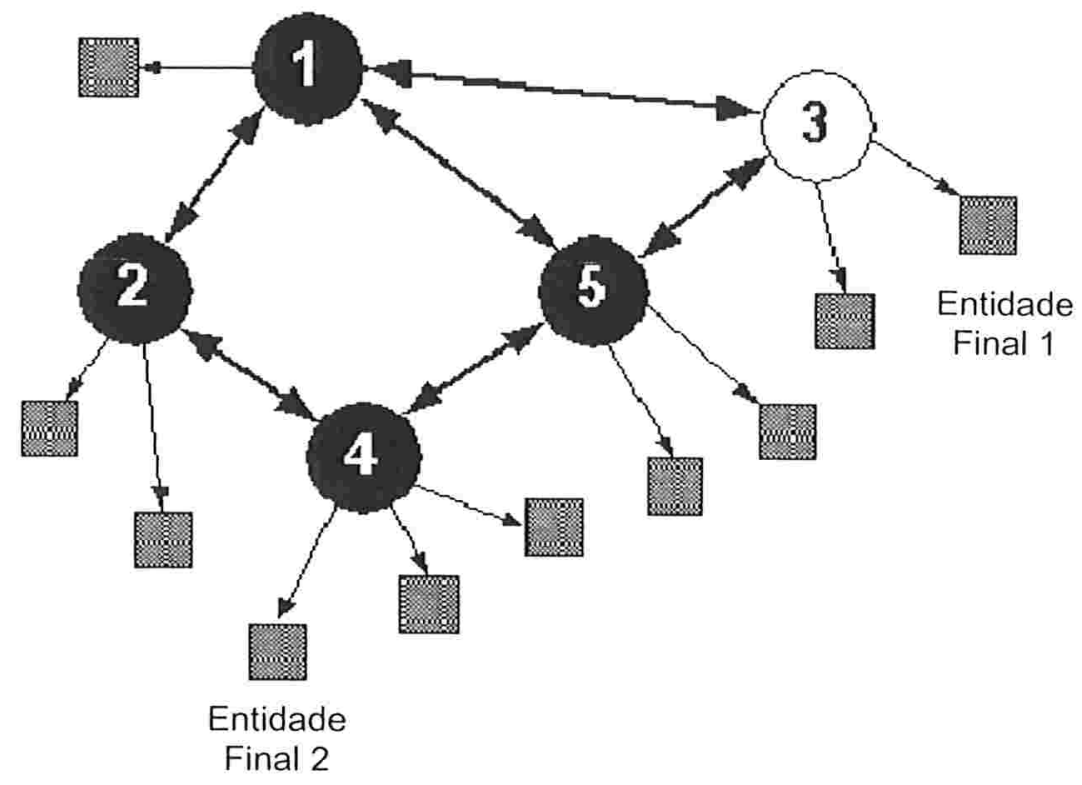

Figura 3-3 - Arquitetura Mista de uma ICP

\subsection{Certificados de chave pública X.509}

Desde a sua primeira versão, os certificados de chave pública X.509 criados pela IETF evoluíram muito em busca de uma maior flexibilidade, estando atualmente em sua terceira versão. O certificado de chave pública X.509 pode ser utilizado para transportar vários tipos de informações, que são colocadas em dois tipos de campos prédefinidos: os obrigatórios e os opcionais.

Para permitir que o certificado seja válido, ele é assinado digitalmente pelo seu emissor. Assim, os usuários dos certificados têm apenas que verificar a assinatura do emissor para validarem o certificado. Uma vez validado, as informações de um certificado de chave pública X.509 são confiáveis. 
Os certificados possuem um conjunto padrão de campos e podem incluir um número opcional de extensões. Existem dez campos-padrão, seis obrigatórios e quatro opcionais. A figura 3.4 a seguir exibe estes campos.

Os campos obrigatórios são:

1. número de série;

2. algoritmo identificador da assinatura do certificado;

3. nome do emissor do certificado;

4. período de validade do certificado;

5. chave pública; $e$

6. nome do sujeito.

O sujeito é a Entidade Final que detém o controle da chave particular correspondente à chave pública do Certificado. Os quatro campos opcionais são:

1. número da versão;

2. dois identificadores únicos, sendo um do Emissor e o outro do Sujeito; e

3. extensões. 


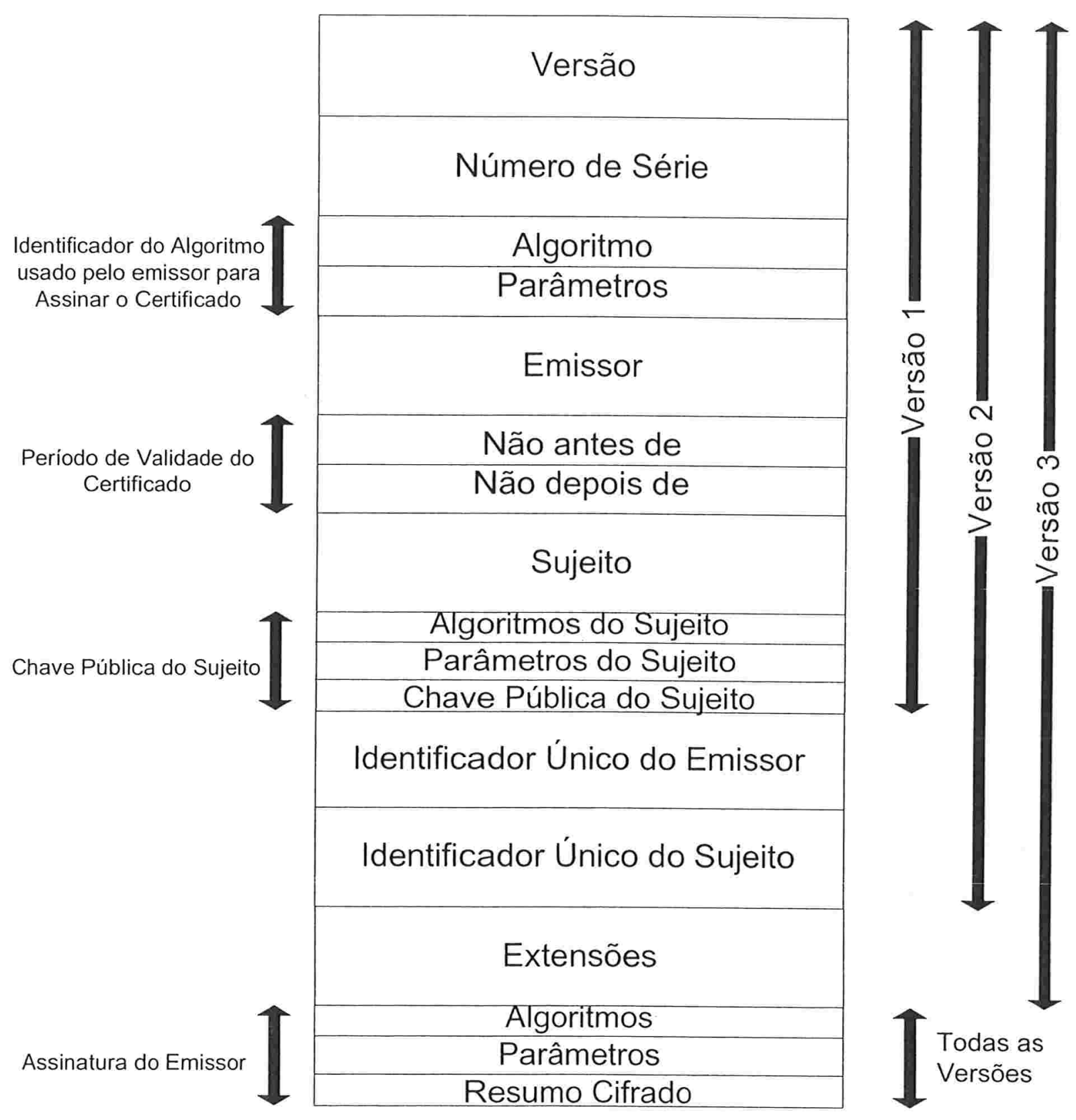

Figura 3-4 - Certificado de identidade X.509

Os campos opcionais aparecem somente nos certificados das versões 2 e 3 . 0 campo versão descreve justamente que versão do certificado está sendo utilizada. Como esse campo é opcional, quando ele não existir, o certificado será tratado como na sintaxe da versão original, ou seja, da versão 1.

As diferenças fundamentais entre as versões dos certificados estão na quantidade de campos tratados. Os certificados da versão 1 não possuem identificadores únicos para o emissor e o sujeito, nem extensões. Os certificados da versão 2 já incluem 
identificadores únicos, mas sem extensões. Quando o certificado inclui extensões, como acontece com a maioria deles atualmente, o campo versão indica versão 3.

O número serial é um número inteiro atribuído pelo emissor para o certificado e deve ser único para cada certificado gerado pelo emissor, o que torna possível a identificação unívoca de qualquer certificado, pela combinação do nome do emissor e do número serial.

O campo assinatura indica o algoritmo utilizado pelo emissor para assinar o certificado emitido.

O campo emissor contém o nome único padrão X.500 da autoridade confiável que emitiu o certificado.

O campo validade indica o período de validade do certificado, descrevendo a data inicial e final desse período.

O campo sujeito contém o nome único da Entidade Final que detém a chave particular correspondente à chave pública contida no certificado.

O campo Chave Pública do Sujeito contém informações sobre a chave pública do sujeito: além da própria chave pública, esse campo contém o nome do algoritmo usado para gerar as chaves e alguns parâmetros adicionais que foram utilizados na geração do par de chaves.

Os campos de identificadores únicos para o emissor e para o sujeito contêm os números de identificação dessas entidades e só aparecem nos certificados da versão 2 ou 3. Os identificadores únicos do sujeito e do emissor são utilizados para permitir a reutilização dos nomes do sujeito ou do emissor. Entretanto, essa reutilização não é recomendada quando se exige um alto grau de segurança. Portanto, a utilização desses campos também não é recomendada nesses casos.

O campo Extensões, que só existe nos certificados da versão 3, podem ser utilizados para acrescentar mais informações ao certificado. As extensões mais comuns de certificados foram definidas pelo ISO para a ANSI, para resolver questões que não podiam ser resolvidas pelos campos originais.

Essas extensões possibilitam que uma Autoridade Certificadora inclua informações que normalmente não seriam fornecidas pelos campos originais de um certificado. Qualquer empresa pode definir suas extensões próprias, de acordo com suas necessidades. 
As extensões possuem três componentes: identificador, um sinalizador de criticidade e um valor. O identificador mostra o formato e a semântica do campo valor. O sinalizador de criticidade indica a importância da extensão e, quando estiver ligado, indica que a informação é essencial para o uso do certificado. Portanto, se um sinalizador de criticidade desconhecido for encontrado, o certificado poderá não ser aceito ou, no melhor caso, ignorado.

\subsection{Principais vulnerabilidades da Infra-estrutura de Chaves Públicas}

O processo de emissão de certificados de chaves públicas envolve, além da emissão propriamente dita, algumas tarefas criticas que implicam algum risco no processo. Tarefas como garantir a identidade dos assinantes, determinar o conteúdo apropriado para o certificado digital, criar, distribuir, garantir a aceitação do Certificado, além de promover a segurança interna, devem ser tratadas com o máximo de cuidado pela Autoridade Certificadora. As seções seguintes abrangem algumas tarefas que expõem a Autoridade Certificadora a riscos de segurança e integridade.

\subsubsection{Verificação de Identidade}

O primeiro passo para o registro de uma Entidade Final é a verificação da identidade dessa Entidade. Para confirmar a identidade de uma Entidade Final, a Autoridade Certificadora verifica as credenciais fornecidas pela Entidade. Essa função também pode estar delegada para uma Autoridade de Registro, que deverá verificar a identidade da Entidade Final.

O risco no processo de verificação de Identidade está no fato de haver uma falsa confirmação de identidade, ou seja, a AC ou a AR validam a identidade de uma Entidade Final falsa. A conseqüência seria a perda de confiança na estrutura que foi criada para ser uma entidade de confiança. Além disso, a AC estará sujeita a sanções judiciais cabíveis.

$O$ cuidado com a identidade não se restringe ao processo de verificação. Pode ser que a identidade anteriormente verificada sofra alguma mudança de situação e, de acordo com as políticas adotadas, a partir dessa mudança, ela não atenda mais aos requisitos. Assim, faz-se necessária uma auditoria constante nas identidades das Entidades finais para as quais foram emitidos Certificados de Chave Pública.

\subsubsection{Validade do certificado}


Os campos que compõem o certificado variam de versão para versão. O campo mais importante de um certificado, especialmente quanto à segurança, é o campo de validade. Quanto mais distante for a data de expiração de um certificado, maior será o risco assumido pela Autoridade Certificadora que o emitiu. A segurança de um certificado passa por vulnerabilidades físicas e lógicas que extrapolam o software utilizado para gerar a assinatura digital. Quanto mais tempo esse software estiver em uso, maiores são as chances de ser corrompido ou de que alguém consiga um acesso não autorizado.

\subsubsection{Criação, distribuição e aceitação dos certificados}

O processo de criação, distribuição e documentação do histórico de aceitação do certificado de um determinado assinante expõe a $A C$ aos riscos relacionados à transação, à estratégia e à reputação. Na criação do certificado, os riscos de transação e de reputação aparecem a partir de possíveis erros nos sistemas que atribuem as limitações apropriadas para cada certificado dependendo das características únicas de cada assinante. A exposição a esses riscos está associada às políticas e procedimentos que regem esse processo. A distribuição e aceitação dos certificados, muitas vezes não é uma tarefa exclusiva das ACs. O cliente terá que obter recursos tecnológicos para criar assinaturas digitais a partir de um fornecedor de software ou outra empresa de tecnologia.

Entretanto, o certificado não estará completo enquanto a $\mathrm{AC}$ não atestar a capacidade de assinatura do cliente com a sua própria assinatura digital antes de gerar o certificado. Em um sistema de AC fechada, o risco pode ser limitado pelo contrato que estabelecerá claramente as tarefas e responsabilidades das partes envolvidas. O risco envolvido em uma transação pode ser creditado a uma organização, ao cliente individual ou a uma outra entidade que tenha a guarda do banco de dados de certificados. Todavia, a $A C$ terá um risco na sua reputação se algum problema com a tecnologia for a ela atribuído. Geralmente, um certificado digital não poderá ser usado até que o assinante aceite o certificado assinado. A aceitação implica que o cliente concorda com os termos e condições estabelecidos pela AC para o sistema como um todo, assim como qualquer outra condição específica que seja aplicada ao assinante. Erros que forem gerados durante o processo de comunicação relativos à aceitação, seja por dificuldades técnicas seja por políticas e procedimentos inadequados, expõem a AC a riscos na sua reputação e transação. 


\subsubsection{Gerenciando Certificados Digitais}

Quando a AC emite um certificado para suportar a assinatura digital de um cliente, normalmente irá interagir somente com o cliente, seu representante, ou um agente atuando em nome dele. Todavia, se a AC optar por também gerenciar certificados de terceiros, por exemplo agindo como um repositório, a AC irá transacionar com as entidades que recebem as mensagens. A discussão a seguir descreve os riscos que irão surgir quando lidamos com o serviço de repositório para o assinante e parceiros e está organizada de forma a abordar os quatro aspectos do gerenciamento de chaves digitais:

- Revelação de informações sigilosas sobre o cliente;

- Prestação de serviços e suporte ao assinante;

- Suspensão e revogação de certificados; e

- Processamento de pedidos dos parceiros.

\subsubsection{Revelação de informações sigilosas sobre o cliente}

Apesar de não haver até o momento uma legislação específica acerca de revelação de informação, a AC terá que fornecer alguma informação abrangendo os serviços básicos ofertados e os direitos e responsabilidades dos assinantes e de seus parceiros. A natureza da quebra do sigilo terá impactos na reputação e na transação da AC. Por exemplo, se forem divulgados claramente a política de privacidade e os procedimentos para resolução de erros de uma $A C$, pode haver menos confusão por parte dos usuários. Além disso, se a AC fornecer documentação técnica sobre o uso do software que for associado aos certificados, os assinantes terão melhores condições para distinguir problemas causados pelo software ao invés de culpá-la, evitando, dessa forma, riscos à reputação da $A C$.

\subsubsection{Prestação de serviços e suporte ao assinante}

Como muitos dos novos produtos e serviços da tecnologia de informação, a AC precisa fornecer suporte aos seus clientes, o que é uma fonte para o risco à reputação. $A$ AC deverá possuir um sistema de suporte via telefone ou alguma outra forma de interação direta com os assinantes e seus parceiros. As políticas, procedimentos e operações do atendimento telefônico são uma fonte em potencial de riscos para a reputação e transação. Resolver os problemas ou erros que os assinantes e seus parceiros irão 
encontrar devido à falta de familiaridade com o uso da tecnologia envolvida irá requerer recursos substanciais por parte da AC ou de uma empresa de serviços contratada. Apesar de a AC normalmente não fornecer software para a criação de assinaturas digitais, podem ocorrer situações em que o assinante atribua a AC toda a sua dificuldade em usar a tecnologia.

Os assinantes podem ter problemas técnicos devido à configuração dos softwares em seus computadores pessoais, que podem estar encobertos antes de eles tentarem assinar uma mensagem ou uma transação. Se uma organização que fornece serviços de AC desejar manter um bom relacionamento com seus clientes, a decisão mais prática pode ser o fornecimento do serviço com recursos próprios ou por meio da contratação de uma empresa com experiência no ramo. Algumas empresas de tecnologia fornecem um cartão inteligente (smart card) para armazenar o certificado do assinante. Ao invés de copiar o software para o disco rígido do seu computador pessoal, o assinante manteria um leitor de cartão inteligente conectado ao seu PC. O cartão inteligente e o leitor seriam programados previamente para carregar a informação do certificado do assinante apropriadamente. Podemos reduzir os riscos de reputação e de transação pela simplicidade no uso do hardware mencionado, ao invés de requerer do usuário a utilização de software de fontes externas.

\subsubsection{Suspensão e revogação de certificados}

Existe a possibilidade de o sistema ser comprometido e ficar disponivel para uso não autorizado devido à responsabilidade do assinante na guarda da assinatura. Portanto, a AC pode ser acionada para suspender ou revogar um certificado. Se a AC (ou outra entidade responsável dentro do sistema) não monitorar e tomar as medidas necessárias dentro do tempo necessário, ela pode autenticar mensagens ou transações que carreguem uma assinatura digital expirada. Assim, uma AC que não cancelar rapidamente um certificado inválido, estará potencialmente exposta a riscos em sua reputação, estratégia e transação. As políticas e os procedimentos inadequados são uma fonte para o risco estratégico, quando implementadas, expõem a $A C$ aos riscos de reputação e transação. O intervalo de tempo das atualizações necessárias no repositório pode variar de acordo com o tipo de certificado envolvido; um atraso na suspensão de um certificado usado em transações ou mensagens importantes significa um risco alto. 
Um certificado digital pode ficar inválido de duas formas. A AC pode cancelar o certificado se ela tiver certeza de que o assinante tenha tido a sua capacidade de assinar comprometida. O caso mais comum seria a perda da chave privada por parte do usuário. Se a chave privada do usuário tornar-se conhecida, pessoas não autorizadas poderiam assinar mensagens e transações. Se houver qualquer dúvida sobre o status de um certificado, ele deve ser suspenso até que sua situação possa ser determinada. Os riscos de reputação e de transação podem ser resultados de erros no processamento, na suspensão ou do cancelamento de certificados. Por exemplo, o usuário cujo certificado foi equivocadamente suspenso e está impossibilitado de assinar mensagens, poderá sofrer perdas e pode demandar medidas legais, denegrindo a reputação da $A C$ no processo. Por outro lado, uma AC também pode ficar exposta se um parceiro aceitar uma mensagem ou transação que foi assinada por um usuário cujo certificado deveria ter sido revogado ou suspenso.

\subsubsection{Processamento das Requisições dos Parceiros}

O processamento das requisições dos parceiros relativas ao status de certificados individuais pode expor uma $A C$ aos riscos de reputação, estratégia e transação. Apesar de a relação contratual entra a $A C$ e o usuário definir algumas obrigações aos assinantes e terceiros, essa proteção contratual pode não existir nas transações com os parceiros, principalmente em sistemas abertos. Por exemplo, se a AC apresenta um certificado revogado como operacional para um parceiro, a AC estará exposta à perda de reputação ou ao recebimento de demandas judiciais. Existe um risco adicional em sistemas abertos se as circunstâncias de um usuário ou grupo de usuários mudarem durante o período de validade de um certificado que está circulando. Qualquer atraso no processamento das requisições de cancelamento de certificados que for causado por falhas de políticas e procedimentos ou falhas operacionais pode resultar nesse tipo de erro. A exposição ao risco é maior ainda se o repositório processar as requisições no modo "batch" ao invés de "tempo real". Conforme aumenta o volume de transações processadas pelo repositório, e mais certificados são colocados em circulação, carregando limitações variadas e datas de expiração, a exposição ao risco também aumenta.

\subsubsection{Revogação de certificados}


Quando há um comprometimento da chave particular de um AC ou de uma entidade final, um certificado pode ser revogado. Além dessa situação crítica, quando há a necessidade de alteração de qualquer informação contida no certificado de chave pública, devemos revogar o antigo e emitir um novo com as alterações desejadas. A revogação de certificados tem geralmente as seguintes fases:

- ocorrência de algum evento que comprometa a chave particular, chamado de fato gerador da revogação;

- solicitação da revogação, que deve ser feita pela entidade final à $A C$;

- revogação do certificado, feita pela AC que o emitiu;

- publicação de uma nova lista de certificados revogados (LCR).

O processo acima descrito pode muitas vezes demandar um tempo grande. Além disso, muitas vezes, quando a entidade final descobre que sua chave particular está comprometida, já se passou algum tempo. Assim, temos um sério problema de segurança, no intervalo de tempo compreendido entre o comprometimento da chave particular e a efetiva publicação da nova LCR, como podemos ver na figura a seguir:

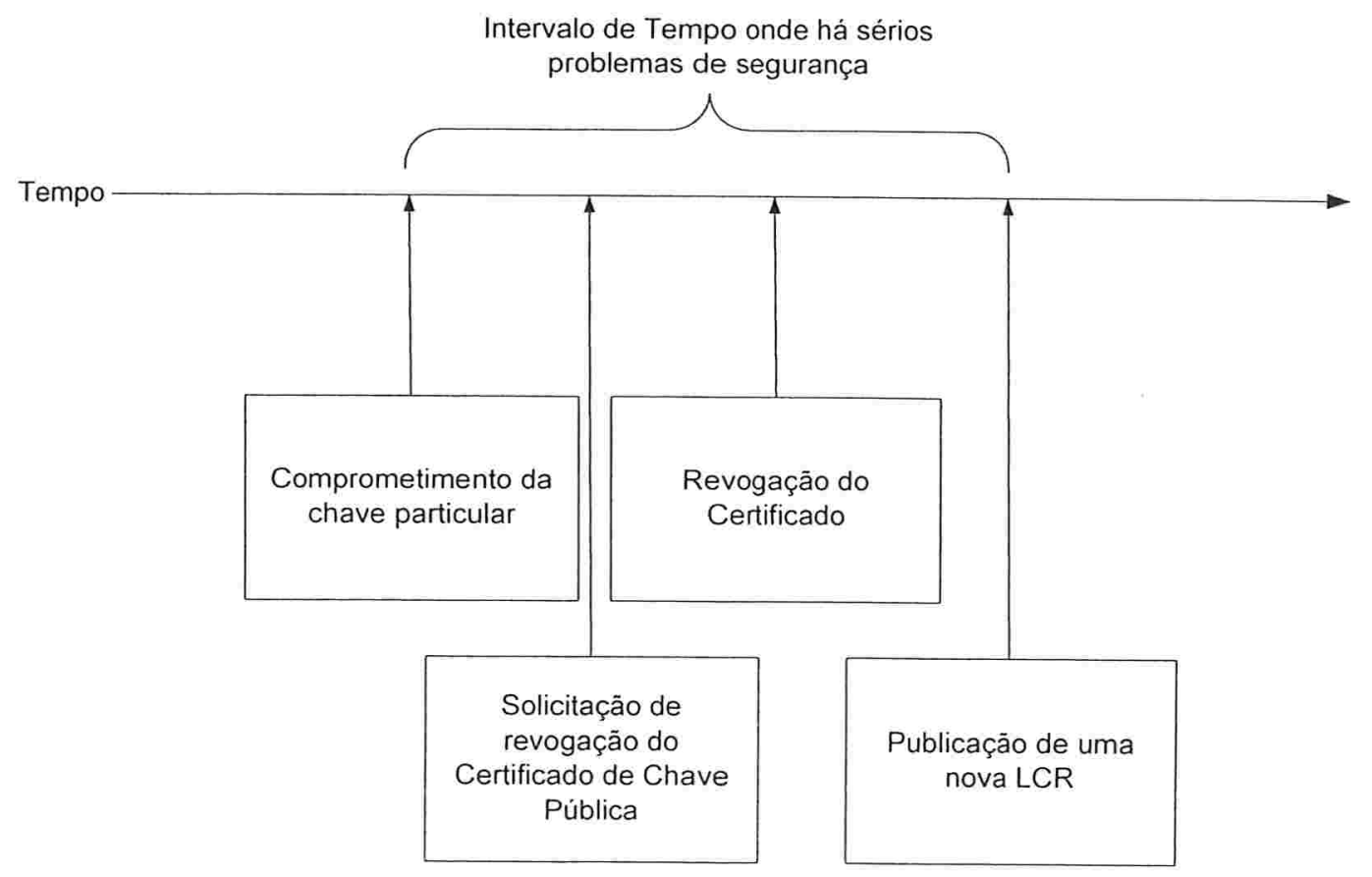

Figura 3-5 - Brecha de segurança na revogação do certificado de chave pública

Nesse intervalo de tempo, a chave particular pode ser indevidamente utilizada por pessoas mal-intencionadas, gerando problemas sérios de segurança. Esse é um dos grandes problemas das Infra-estruturas de chaves públicas atuais. 


\section{CAPÍTULO 4: SISTEMAS DE AUTORIZAÇÃO TRADICIONAIS}

Sistemas de controle de autorização são fundamentais para a segurança de qualquer aplicação. Como já abordado anteriormente, autorização e controle de acesso são termos freqüentemente confundidos. Autorização é o ato de verificar se um usuário tem a permissão necessária para executar uma determinada ação, assumindo que o usuário já foi autenticado com sucesso. Autorização é muito mais focado em credenciais e dependente de regras mais específicas que o controle de acesso. Um processo de verificação de autorização envolve muitas vezes verificar se o usuário pertence a um determinado grupo, identificar a posse de um particular nível de classificação ou procurar aquele usuário em uma lista de controle de acesso aprovada pelo recurso. Qualquer mecanismo de controle de autorização é altamente dependente de um processo de autenticação anterior.

Uma grande diversidade de políticas de segurança e necessidades existe em organizações governamentais e privadas. Cada organização tem requisitos de segurança únicos, que atendem somente a ela, o que acaba restringindo as tecnologias que podem ser utilizadas. Além disso, a tecnologia de segurança deve garantir a política organizacional, como manter e forçar os preceitos éticos associados às diversas funções dentro da empresa.

Antes de escolher qualquer método de autorização, vários passos preliminares ajudam a determinar que método melhor atende às expectativas da empresa. Alguns desses passos são os seguintes:

- Analisar o valor relativo da informação a ser protegida quanto à confidencialidade, sensibilidade, classificação, privacidade e integridade relacionadas à empresa, bem como aos usuários. Para isso, deve-se considerar a perda financeira causada por um acesso não autorizado, modificação de informação ou negação de serviço.

- Especificar o processo de concessão ou revogação de direitos de acesso, explicitando se ele será um processo manual, automático após a criação da conta ou dependente de uma ferramenta administrativa; 
- Alinhar os mecanismos de autorização à política de segurança da empresa.

As seções seguintes abordam as principais técnicas para concessão de autorização em ambientes computacionais.

\subsection{Discretionary Access Control}

Discretionary Access Control (DAC) baseia-se em restringir o acesso a uma determinada informação de acordo com a identidade dos usuários e/ou grupos dos quais esse usuário é membro. As decisões são tipicamente baseadas nas autorizações garantidas pelo usuário de acordo com as credenciais apresentadas por ele no momento da autenticação no sistema. Em um sistema DAC típico, é possível mudar as informações de autorização de maneira discreta, sem a anuência do usuário. A figura a seguir exemplifica o DAC.

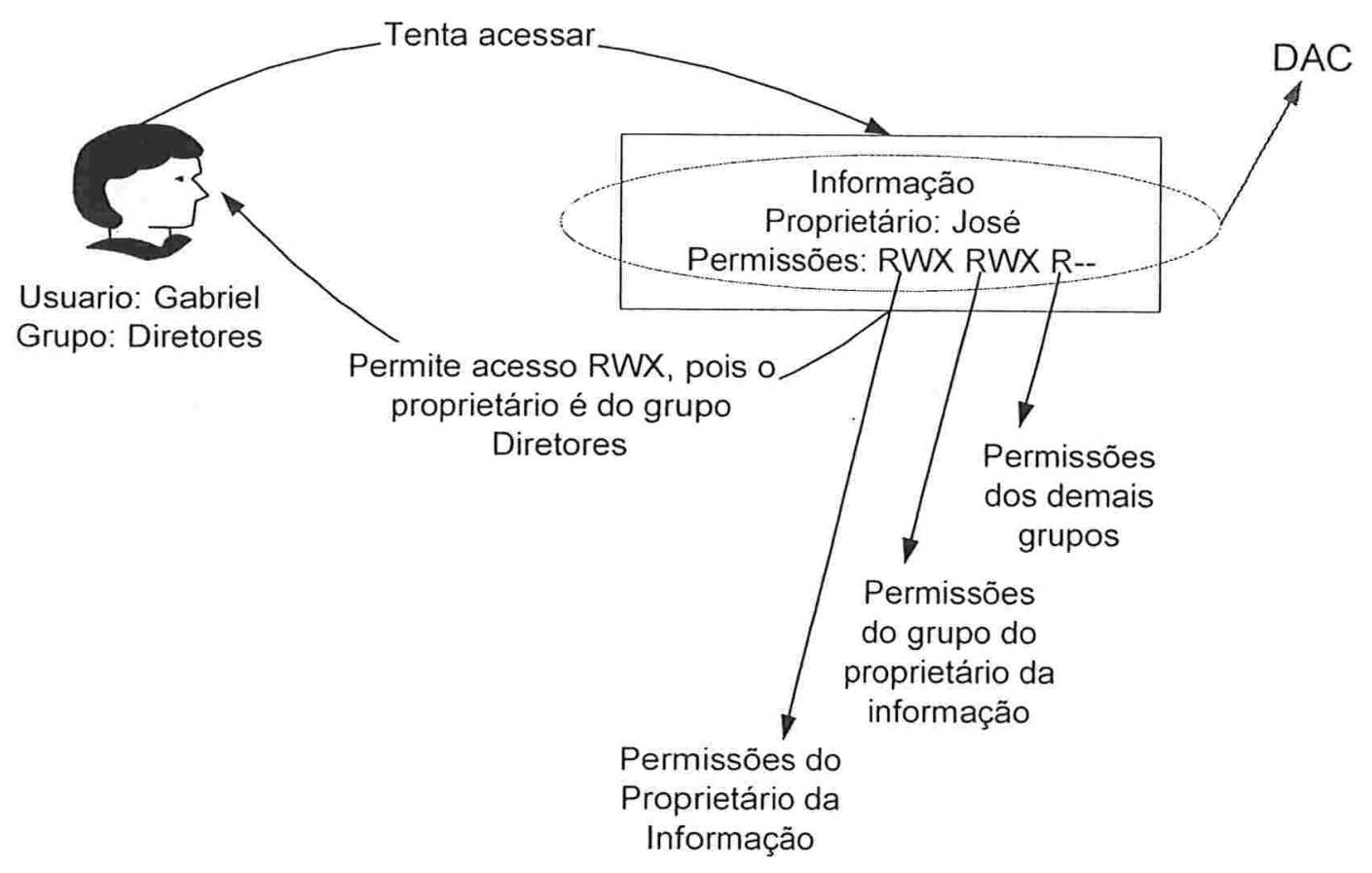

Figura 4.1 - DAC - Discretionary Access Control

Um controle de acesso baseado em DAC geralmente tem uma ou mais das seguintes características:

- Proprietários da informação podem transferir essa propriedade para outros usuários;

- Proprietários da informação podem determinar o tipo de acesso que deve ser dado a outros usuários; 
- Falhas repetitivas de acesso ao mesmo objeto geram alarmes ou restringem o acesso do usuário;

- Usuários que não têm acesso à informação não deveriam ter como obter características dessa informação, como tamanho, nome, diretório;

- O acesso à informação é determinado em listas de controle de acesso baseados na identificação do usuário ou em grupos de que ele é membro.

\subsection{Mandatory Access Control}

Mandatory Access Control (MAC) protege a informação atribuindo etiquetas de sensibilidade (label) sobre a informação e a compara ao nivel de autorização do usuário, ou seja, que nível de sensibilidade o usuário está autorizado a acessar. Em geral, o MAC é mais seguro que o DAC, embora tenha um desempenho pior. Mecanismos MAC atribuem um nivel de segurança a todas as informações, por meio das etiquetas de sensibilidade, e atribuem um nível de privilégio aos usuários e garantem que somente os usuários que têm o nível privilégio necessário terão acesso às informações etiquetadas. MAC é tipicamente apropriado para sistemas que exijam um alto grau de segurança, como aplicações militares ou aplicações críticas. Nesse ambiente, podemos, por exemplo, classificar as informações em três níveis: pública, confidencial e secreta. Após classificar as informações, devemos definir para que nível cada usuário estará autorizado a acessar. A figura a seguir ilustra o MAC.

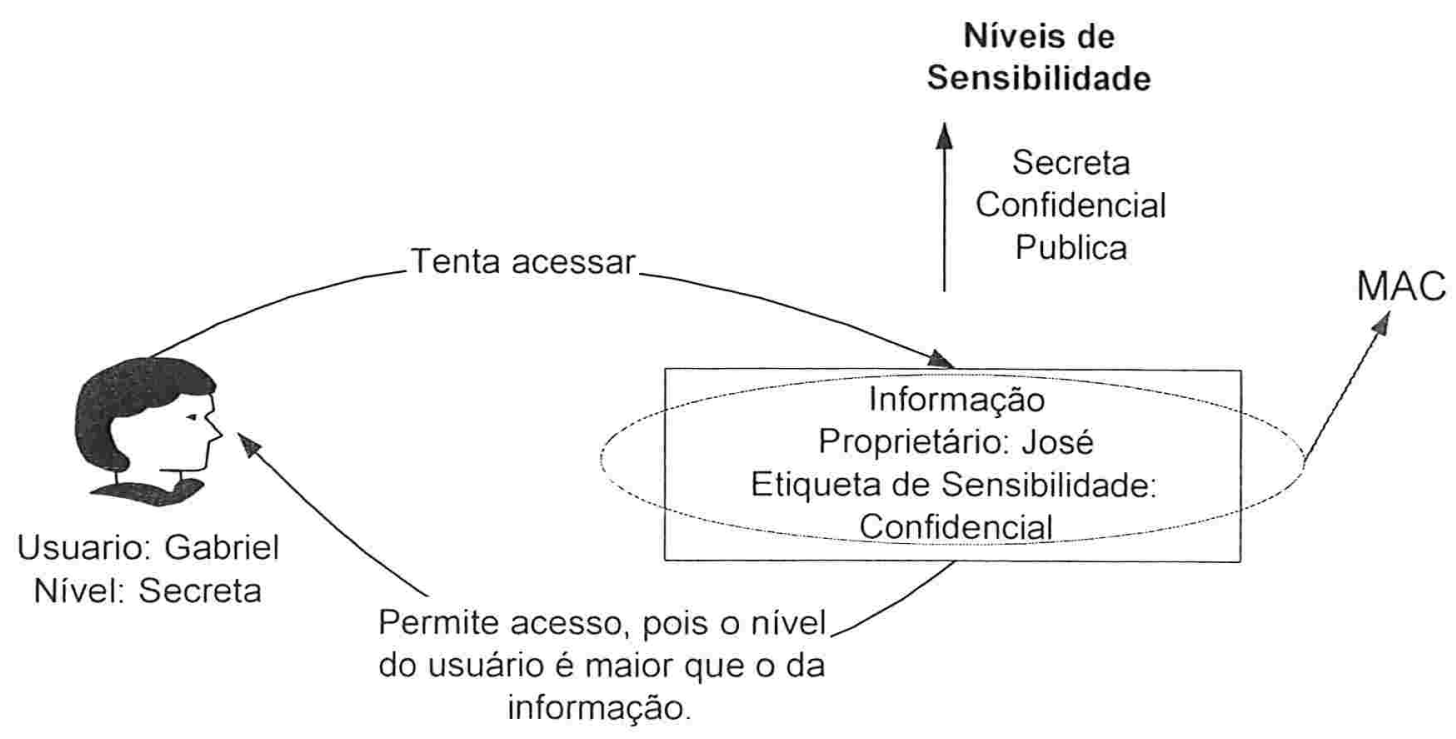

Figura 4.2 - MAC - Mandatory Access Control 
A idéia por trás do MAC é atribuir um nível de segurança às informações, por meio das etiquetas, e um nível de confiança aos usuários, ou seja, definir que nível de informação esse usuário pode ter acesso.

Um modelo de controle de acesso MAC tem uma ou mais das seguintes características:

- Só administradores, e não os proprietários dos dados, podem mudar uma etiqueta de nível de segurança;

- Para todo dado é atribuido um nível de segurança que reflete sua sensibilidade relativa, confidencialidade e valor;

- Todos os usuários podem ler uma informação com um nível de classificação menor do que aquele a que tem direito;

- Para todos os usuários são dados os direitos de leitura e gravação para objetos da mesma classificação que a sua.

\subsection{Role-based Access Control}

Embora as soluções anteriormente apresentadas sejam mais comuns, nem sempre são as que atendem aos requisitos de segurança das organizações.

No modelo Role-Based Access Control (RBAC), as decisões de acesso são baseadas nos papéis (roles) e responsabilidades do indivíduo dentro da empresa ou organização. O processo de definição de papéis é geralmente baseado na análise dos objetivos e estrutura desses papéis na organização, mantendo a aderência à política de segurança da empresa. Por exemplo, em uma organização médica os papéis poderiam ser de médicos, enfermeiros, atendentes, pacientes, etc. Obviamente, cada um desses papéis tem diferentes níveis de acesso com o objetivo de executar suas funções. A figura a seguir exibe essa atribuição indireta de privilégios: 


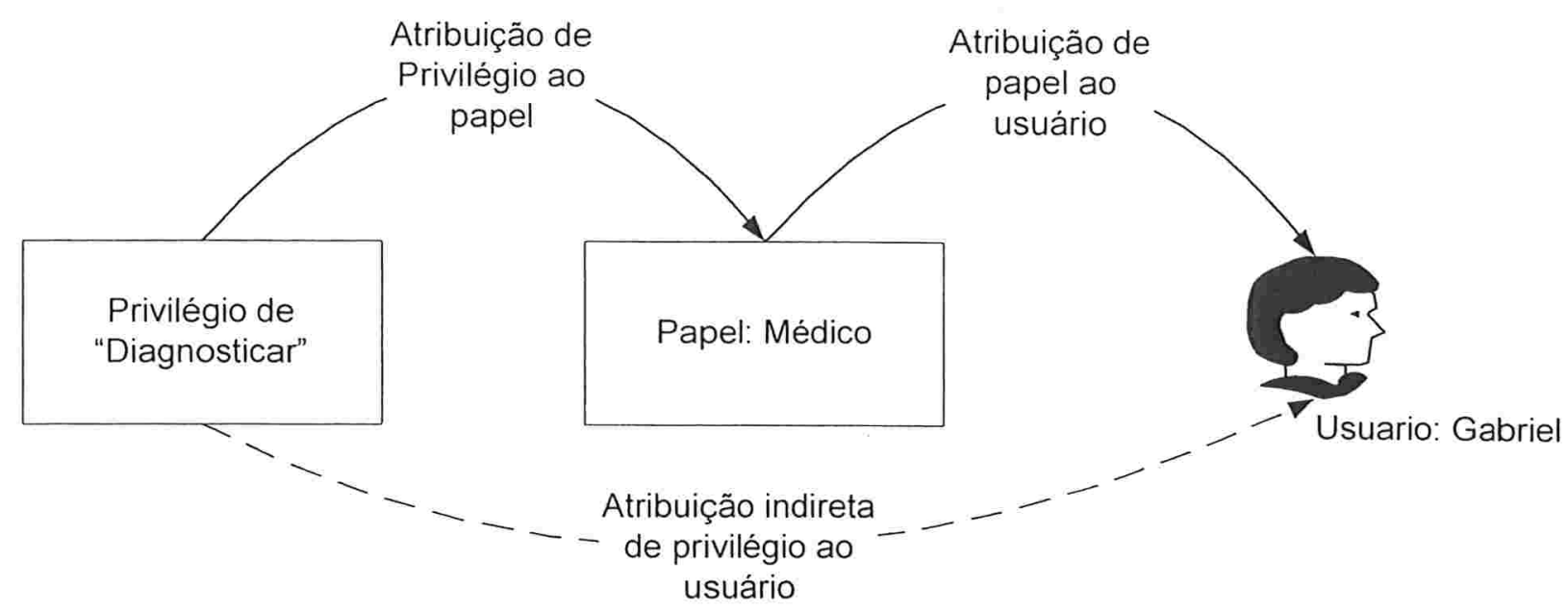

Figura 4.3 - Atribuição de privilégios no modelo RBAC

De fato, o modelo RBAC pode ser considerado uma forma de MAC, mas não é baseado em requisitos de segurança multi-nível. Como visto na seção anterior, MAC é um método de autorização baseado na sensibilidade da informação, representada por uma etiqueta de segurança (label) atribuída, e uma autorização formal para que usuários possam acessar os diversos níveis de segurança.

Já o modelo RBAC preocupa-se mais com a autorização para exercer funções e acessar informações estritamente necessárias para que cada usuário possa desempenhar seu papel na empresa.

Papéis são orientados por grupo. Para cada papel, atribuímos alguns privilégios. Para cada papel atribuímos alguns usuários. Isso gera um relacionamento muitos para muitos entre os usuários e os privilégios, que é mostrado na figura 4.4 a seguir: 


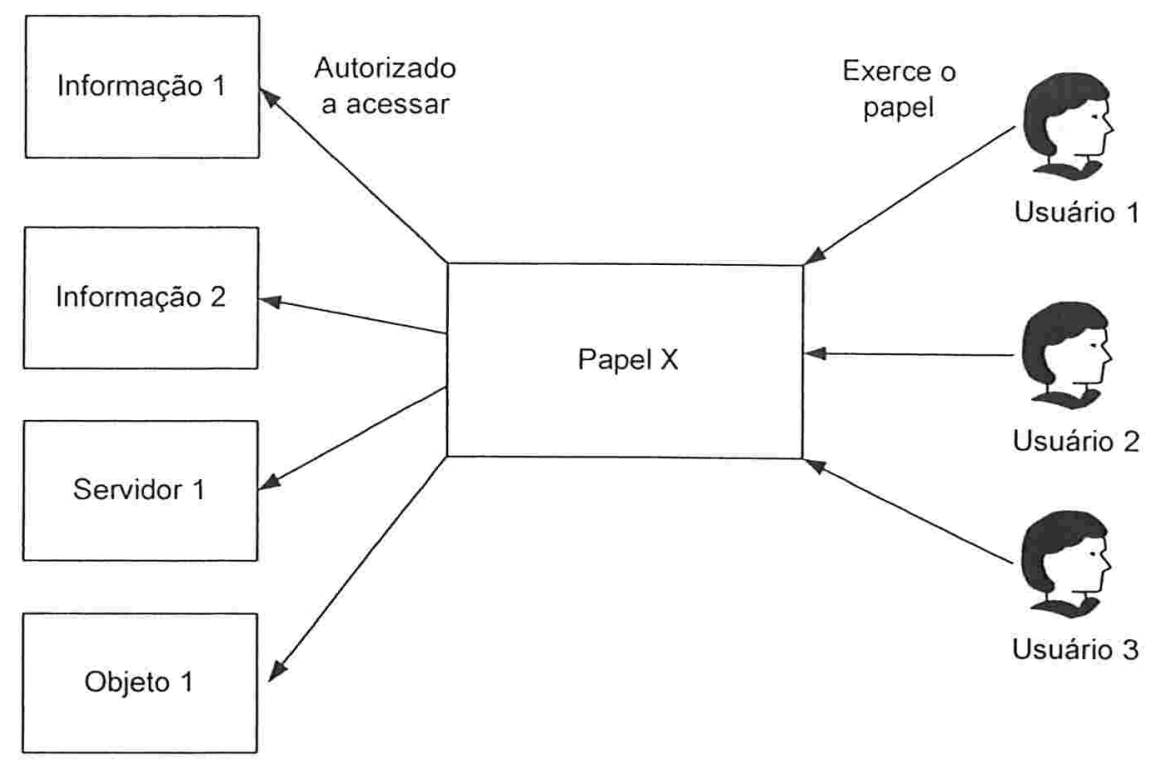

Figura 4.4 - Relacionamento entre usuários e privilégios

Um sistema de autorização baseado em RBAC tem uma ou várias das seguintes características:

- Papéis são atribuídos baseados na estrutura organizacional com ênfase na política de segurança;

- Papéis geralmente são atribuídos pelo administrador baseado nos relacionamentos dentro da organização;

- Para cada papel é atribuído um perfil que inclui todos os comandos autorizados, transações e acesso às informações autorizadas;

- Papéis são determinados com uma separação de tarefas como objetivo;

- Papéis podem ser ativados estática ou dinamicamente;

- Papéis podem ser transferidos ou delegados;

- Papéis são gerenciados de maneira centralizada. 


\section{CAPÍTULO 5: AUTORIZAÇÃO COM CERTIFICADOS DE ATRIBUTOS}

Os certificados de chave pública X.509 vinculam uma identidade a uma chave pública. Um certificado de atributo (AC) não contém chave pública. Um certificado de atributo contém atributos que especificam privilégios de um grupo, usuário, papel (role) ou outra informação de autorização associada com o proprietário do AC. A sintaxe para o certificado de atributo também é definida na Recomendação X.509 da ITU-T, tornando o termo "certificado X.509" ambíguo [ITU 00].

Há uma confusão comum no mercado acerca dos certificados de chave pública e do certificado de atributos. Como analogia, um certificado de chave pública pode ser considerado como um passaporte: ele identifica o proprietário, tende a ter uma validade longa, e o processo de obtenção não é dos mais triviais. Um certificado de atributos, por sua vez, pode ser comparado a um visto de entrada: ele é geralmente emitido por uma autoridade diferente e seu prazo de validade é curto. Além do mais, para requerer um visto de entrada é necessário apresentar o passaporte e o seu processo de obtenção é, na maioria das vezes, mais simples [ADA 99a].

Para fornecer informações de autorização com certificados X.509, podem-se utilizar dois métodos: colocar essa informação em uma extensão do certificado de chave pública ou utilizar um certificado de atributos. A primeira opção é geralmente indesejada por duas razões principais. A primeira é que o tempo de vida da autorização é geralmente menor que o tempo de vida da identidade e da chave pública. Quando essas informações estão em um mesmo certificado, o que ocorre é que o tempo de vida do certificado de chave pública é reduzido para se adequar às exigências da informação de autorização. $O$ segundo motivo é que o emissor do certificado de chave pública não é usualmente o mais indicado para conceder autorização. Essa situação geraria passos adicionais para obter as informações de autorização no processo de emissão do certificado de chave pública.

Por essas razões, a melhor opção geralmente é utilizar um certificado de atributos para separar as informações de autorização do certificado de chave pública. Ao adotar essa solução, deve haver um meio de se vincular uma identidade, atestada pelo 
certificado de chave pública, aos seus privilégios. O certificado de atributos fornece uma solução para essa situação.

Um certificado de atributos pode ser utilizado também para fornecer serviços de não-repudiação. Nesse contexto, os atributos contidos no certificado fornecem informação adicional sobre a entidade que emitiu o certificado, garantindo sua originalidade.

O uso de certificados de atributos permite a delegação de privilégios. O padrão X.509 [ITU 00] define autorização como sendo "transporte de privilégios de uma entidade que possui algum privilégio para outra entidade" [ADA 99a]. Os certificados de atributos, que são um método de autorização, são muito eficientes para delegar privilégios de uma entidade para outra, permitindo até mesmo a substituição.

Para tornar nossa explanação mais inteligivel, utilizaremos uma empresa fictícia chamada FHG Consultoria, que deseja implementar uma infra-estrutura de autorização. O organograma dessa empresa é apresentado na figura a seguir.

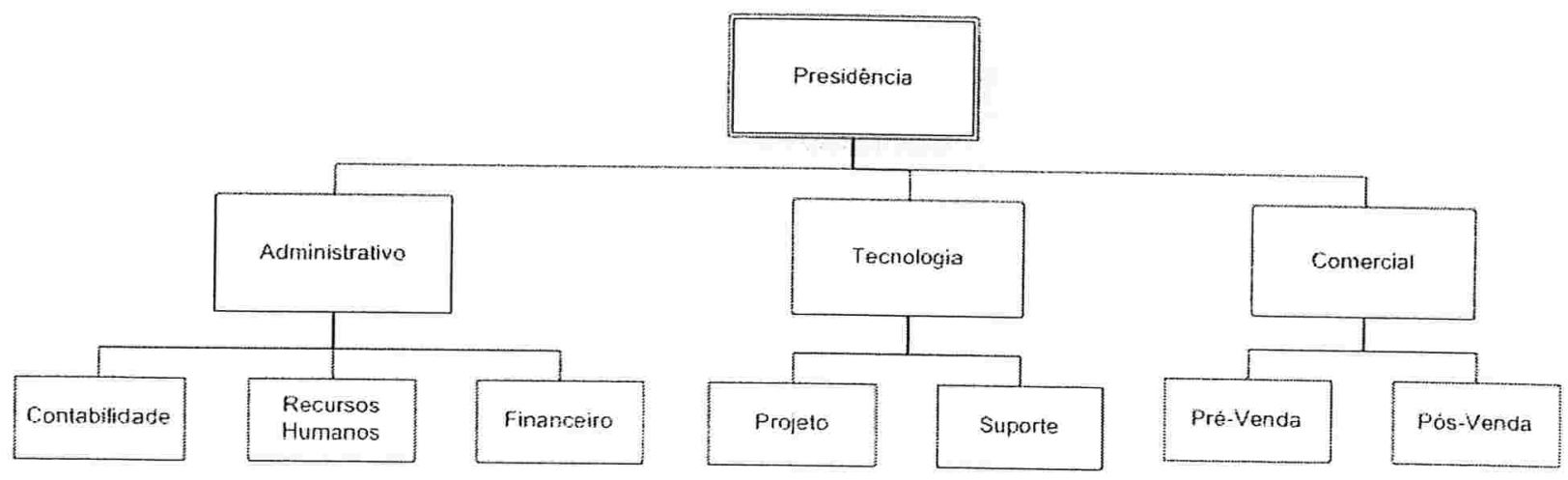

Figura 5-1 - Organograma da empresa fictícia FHG Consultoria

O organograma acima é apenas ilustrativo e não tem a intenção de descrever ou comportar todas as áreas de uma empresa real. O objetivo aqui é apenas didático, de forma que a empresa FHG Consultoria torne-se objeto de estudo para a aplicação dos conceitos que serão discutidos no capítulo.

\subsection{Formas de distribuição de certificados de atributos}

Os certificados de atributos fornecem informações de autorização para diversos ambientes, incluindo aplicações, acessos físicos, acessos lógicos, dentre outros. Para que o certificado seja utilizado, ele deve ser apresentado ao objeto que fará uso dessas informações de autorização. Para isso, existem dois métodos principais: push e pull. 
Em alguns ambientes, é desejável que o usuário apresente seu certificado de atributos para um servidor. Esse é o método push, que isenta o servidor de solicitar ou procurar o certificado de atributos em uma terceira entidade, melhorando o desempenho do sistema como um todo. Além disso, o cliente apresenta ao servidor somente os atributos que o servidor precisa saber. Esse modelo é especialmente útil em arquiteturas intra-domínios, na qual os privilégios de um usuário devem ser atribuídos dentro do domínio do original do usuário.

Em outros casos, é interessante que o usuário somente se autentique no servidor, que deverá solicitar (método pull) ao emissor ou a um repositório o certificado de atributos desse usuário. A principal vantagem do modelo pull é que não é necessária nenhuma modificação no lado do cliente. Ou seja, a forma de comunicação clienteservidor permanece inalterada. Entretanto, uma carga de trabalho extra é passada para o servidor, a que é atribuída a tarefa de solicitar e verificar o certificado de atributo do usuário. Esse modelo é especialmente útil em arquiteturas inter-domínios, na qual os privilégios de um usuário devem ser atribuídos dentro do domínio do servidor ao invés de no domínio original do usuário.

A figura a seguir exibe o método push na letra A) e o método pull na letra B).
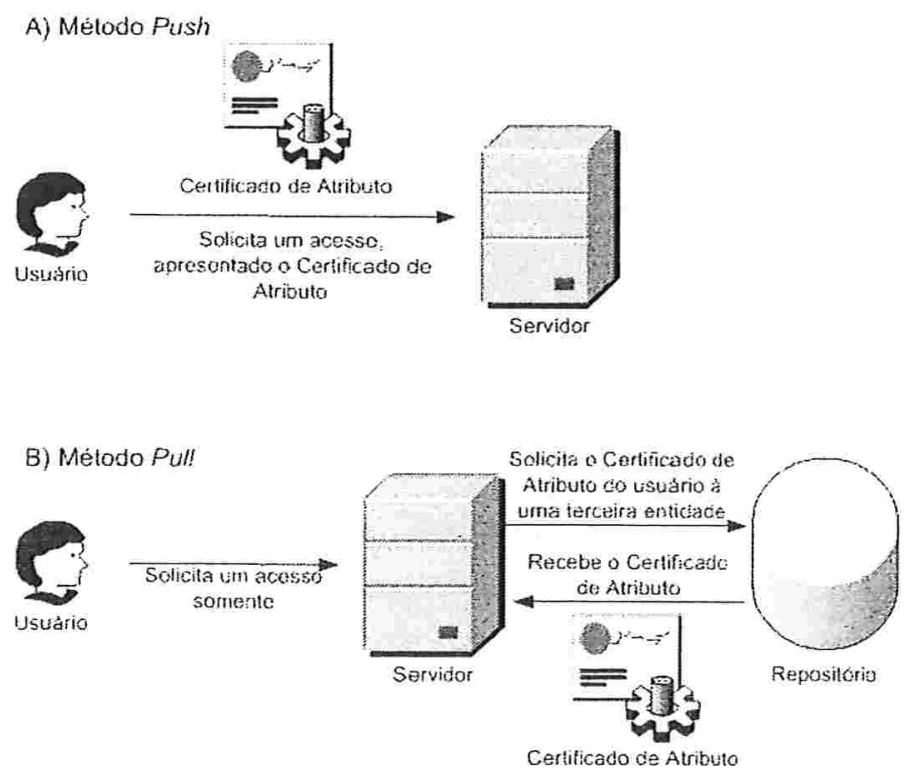

Figura 5-2 - Formas de distribuição de certificados de atributos.

\subsection{A arquitetura de uma PMI}


A quarta edição da recomendação ITU-T X.509 de 2000 apresenta quatro modelos de uma Privilege Management Infrastructure - PMI: modelo geral, modelo de controle, modelo com delegação e modelo com papéis.

As seções seguintes abordam cada um desses modelos.

\subsubsection{Modelo Geral}

O modelo de gerenciamento de privilégio geral é composto por três entidades: o objeto, o declarador de privilégio e o verificador de privilégio.

O objeto pode ser um recurso a ser protegido, que possui métodos que podem ser solicitados pelo declarador de privilégio. Por exemplo, se considerarmos que o objeto é um diretório em um servidor, os métodos de leitura ou gravação podem ser solicitados.

O declarador de privilégio, por sua vez, é a entidade que detém privilégios que são declarados quando necessário.

O verificador de privilégio é a entidade que determina se os privilégios declarados são suficientes ou não para um dado contexto.

A decisão de autorizar ou não o acesso depende basicamente de quatro aspectos:

- Privilégios apresentados pelo declarador de privilégio;

- Política de privilégios adotada, ou seja, que privilégios são necessários para obter o acesso a um determinado método do objeto;

- Variáveis de ambiente atuais, se for o caso;

- Sensibilidade do método do objeto, se relevante.

A Figura 5-3 abaixo exibe o modelo geral de uma PMI. 


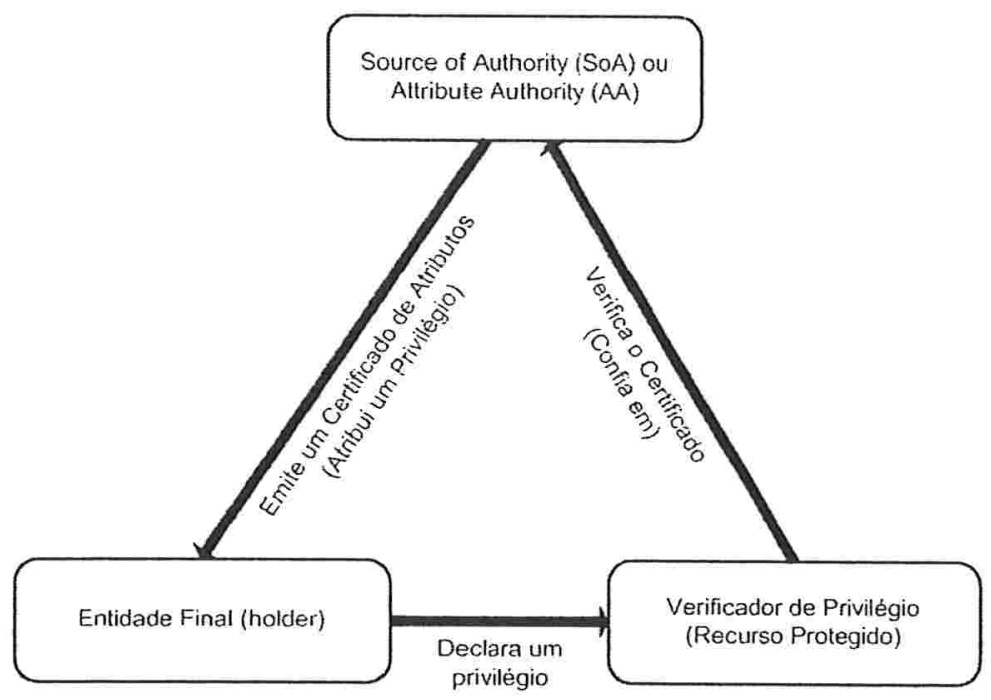

Figura 5-3 - Modelo geral de uma PMI

O privilégio que uma entidade possui reflete o grau de confiança que o emissor do certificado tem nessa entidade, além de manter a aderência às políticas de autorização adotadas.

As políticas de privilégio especificam o grau de privilégio que é suficiente para uma dada sensibilidade do método do objeto ou um dado contexto de uso. As políticas podem ser das mais variadas possiveis, de políticas locais a políticas universais, de acordo com a estratégia da empresa. Em outras palavras, a política de privilégio define um limite mínimo aceitável de um dado conjunto de privilégios [ITU 00] que garantirão o acesso ao método desejado. Dessa forma, o verificador de privilégios tem como decidir de maneira precisa quando um declarador de privilégio terá ou não o acesso requisitado.

A sensibilidade do método do objeto pode refletir atributos do documento ou requisição, como saldo de uma conta para autorização de transferência ou saldo da cota de impressão de um usuário, ou também o grau de confidencialidade do conteúdo de um documento.

Vamos aplicar esse modelo na nossa empresa FHG Consultoria. Quem deveria ser a SOA? A SOA é uma entidade que sabe que privilégios podem ser atribuídos aos usuários. Em grande parte dos casos, o diretor de tecnologia seria indicado para ser a SOA. Porém, algumas vezes o diretor ou sua equipe necessitarão de apoio de outras áreas para que o modelo de autorização não apresente falhas. Para contextualizar melhor, os recursos a serem protegidos são os servidores. Cada departamento da empresa tem seu próprio servidor. A política de segurança da empresa diz que somente 
os funcionários do departamento têm acesso ao seu servidor local. Além disso, os diretores têm acesso a todos os servidores de sua diretoria e o presidente tem acesso a todos os servidores da empresa.

Nesse contexto, segundo o modelo geral, teríamos:

- Os objetos protegidos seriam os servidores da empresa;

- A SOA seria o diretor de tecnologia, assessorado por sua equipe e por outros departamentos da empresa, quando necessário;

- O declarador de privilégio seria qualquer usuário que solicitasse um acesso a qualquer servidor da empresa;

- O verificador de privilégio seria qualquer servidor que estivesse tendo uma solicitação de acesso.

A primeira fase seria a emissão do certificado de atributos. No modelo geral, a SOA emite todos os certificados de atributos necessários. A figura a seguir ilustra essa fase.

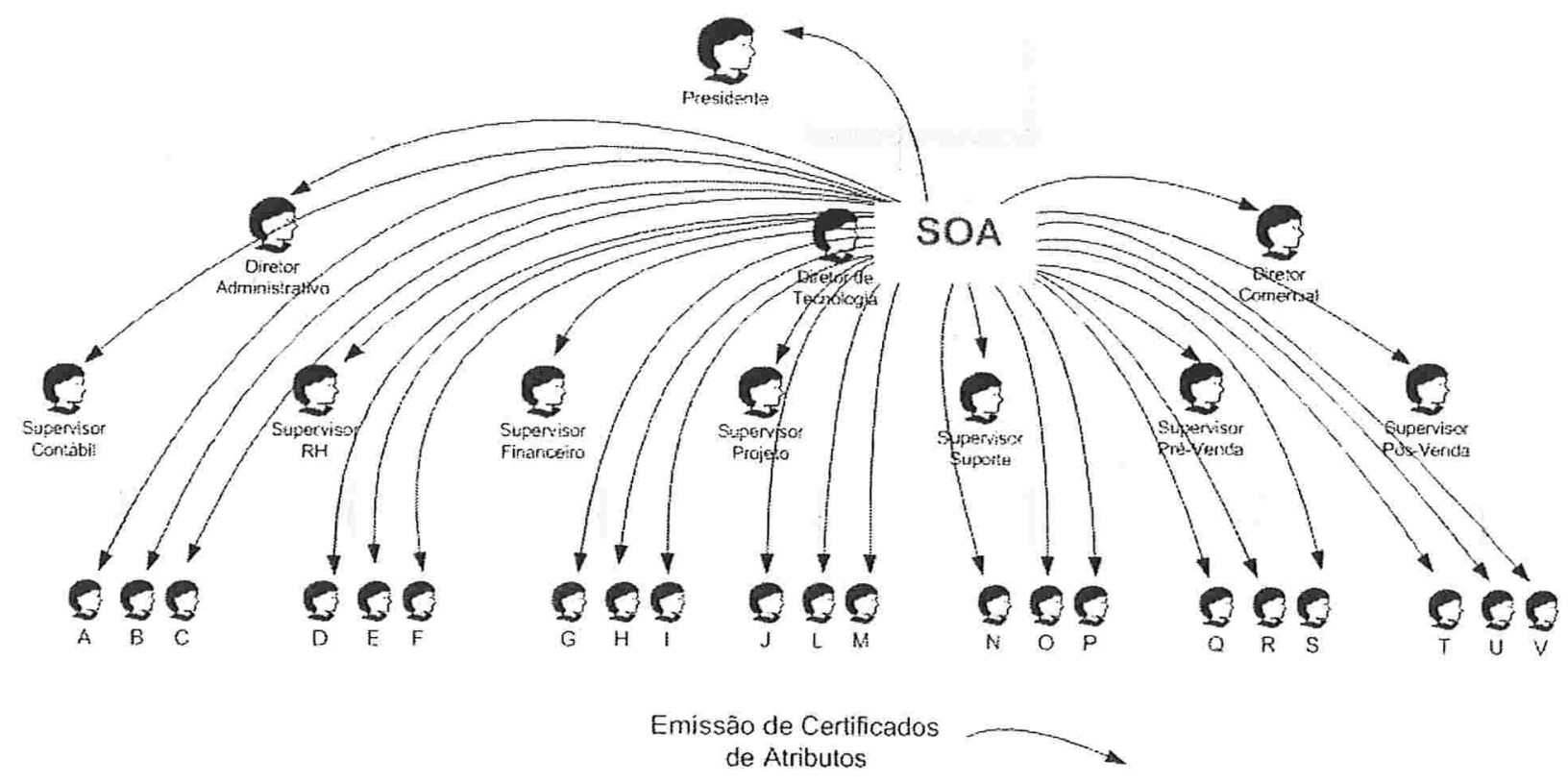

Figura 5-4 - Emissão de Certificados de Atributo no modelo Geral

Assim, se o usuário D do departamento de recursos humanos tentasse acessar o servidor de seu departamento, ele apresentaria seu certificado de atributos (método push) e o Servidor de RH faria a verificação se o certificado de atributos apresentado é válido e se os atributos constantes do certificado são suficientes para o acesso desejado. A figura a seguir ilustra essa situação. 
1. Apresenta um

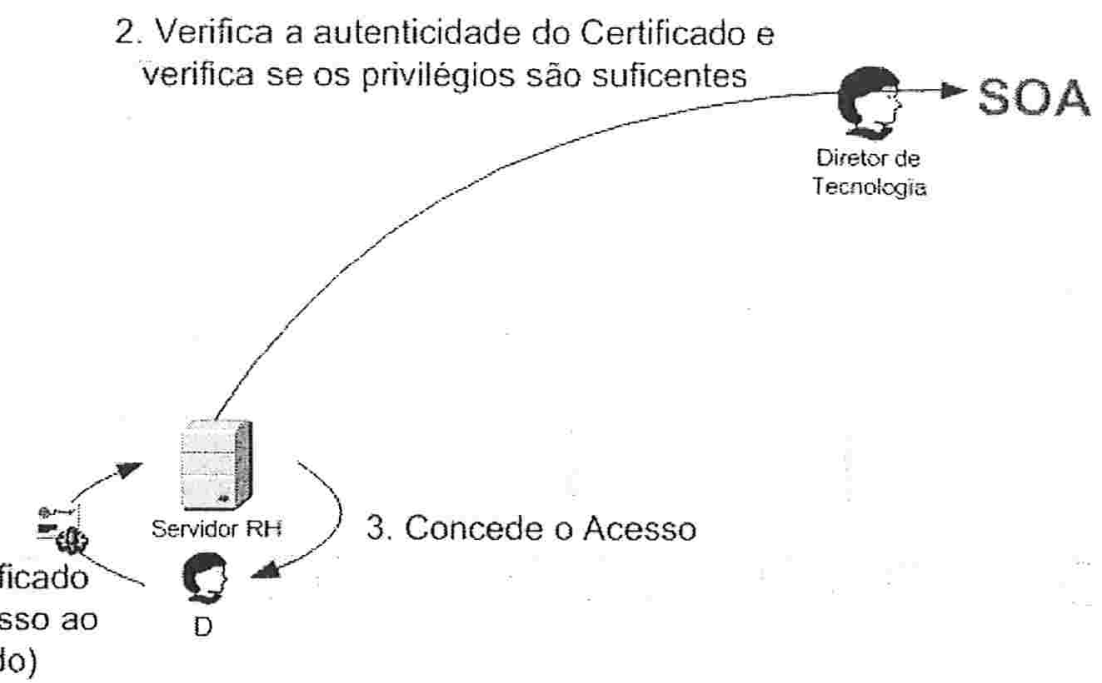
privilégio, por meio do certificado
de atributos, para obter acesso ao servidor (objeto protegido)

Figura 5-5 - Modelo Geral - concedendo acesso a um objeto protegido

Se esse mesmo usuário $D$ do departamento de recursos humanos tentasse acessar o servidor financeiro, esse servidor, trabalhando como verificador de privilégios, não concederia o acesso, pois embora o certificado seja válido, os privilégios apresentados não são suficientes para o acesso desejado. A Figura 5-6 a seguir mostra justamente essa situação de negação de acesso.

1. Apresenta um privilégio, por meio do certificado de atributos, para obter acesso ao servidor (objeto protegido)

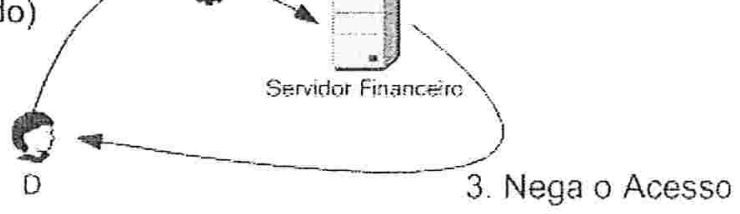

Figura 5-6 - Modelo Geral - Negando acesso a um objeto protegido 


\subsubsection{Modelo de Controle}

O modelo de controle não é um modelo de arquitetura propriamente dito, mas é um modelo conceitual que ilustra como o certificado de atributo pode ser utilizado para controlar o acesso a um determinado método do objeto. Esse modelo consiste de cinco componentes, a saber:

- Declarador de privilégio, que tem o privilégio e o apresenta ao verificador de privilégio;

- O verificador de privilégio, que decide se os privilégios apresentados são suficientes para garantir o acesso ao método desejado;

- O método do objeto a ser requisitado, que pode ter uma sensibilidade;

- A política de privilégio adotada na empresa ou instituição;

- As variáveis de ambiente que influirão na decisão a ser tomada pelo verificador de privilégio.

A Figura 5-7 exibe o modelo aqui apresentado.

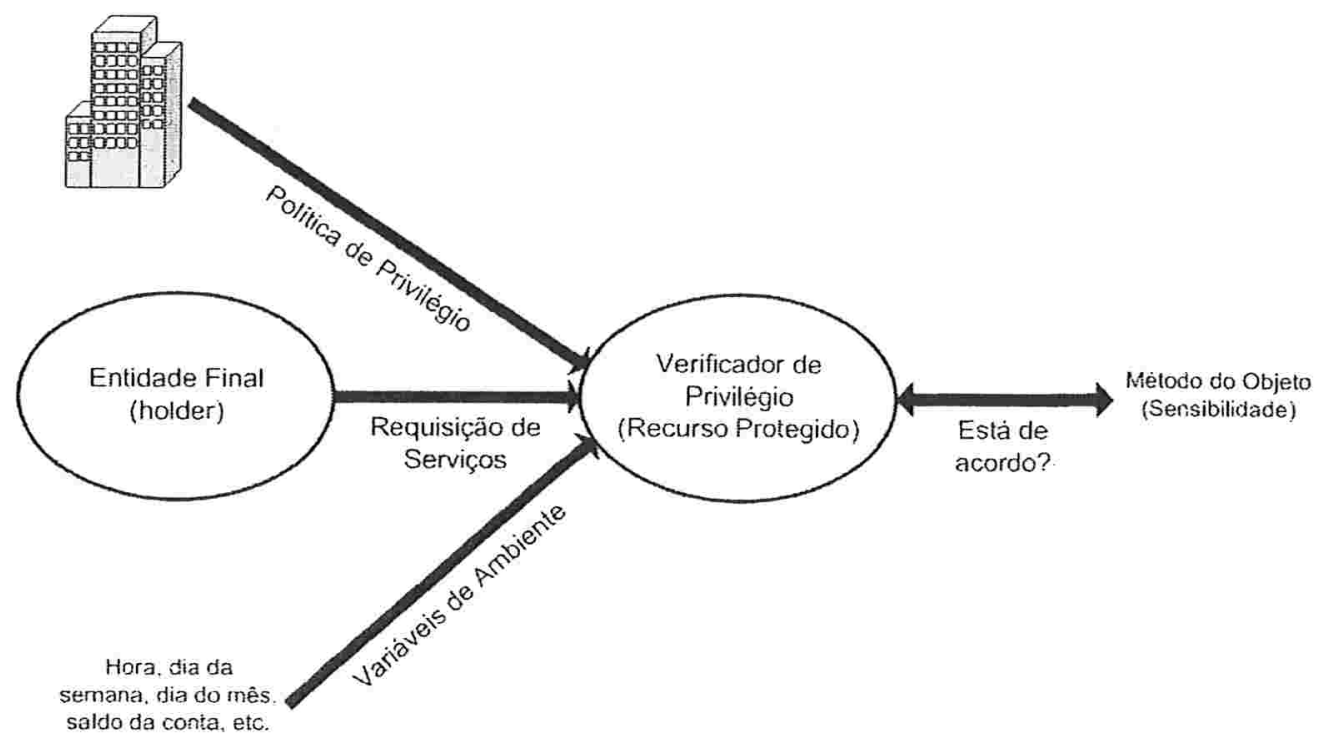

Figura 5-7- Modelo PMI com controle

\subsubsection{Modelo com delegação}

Em muitos ambientes, existe a necessidade de se delegar alguns privilégios a outras entidades. Pensando nisso, a quarta edição da recomendação X.509 da ITU-T definiu um modelo que possibilita essa delegação. O modelo com delegação é composto 
basicamente de quatro elementos: o verificador de privilégios, a SOA, outras autoridades de atributo e o declarador de privilégio.

A SOA é o emissor inicial de certificados que atribuem privilégios a entidades. No modelo geral visto anteriormente, só existe a SOA, que é uma autoridade de atributos que emite os certificados de atributos. No modelo com delegação, a SOA, além de atribuir privilégios, também autoriza que a entidade para a qual o certificado foi emitido atue como uma autoridade de atributo. Assim, o proprietário de privilégios que detém alguns atributos pode delegar o todo ou parte desses atributos a outras entidades, emitindo para elas um certificado de atributo. Esse proprietário de privilégios, uma autoridade de atributo, também pode autorizar essas outras entidades a delegar os privilégios recebidos.

A Figura 5-8 a seguir ilustra o modelo com delegação.

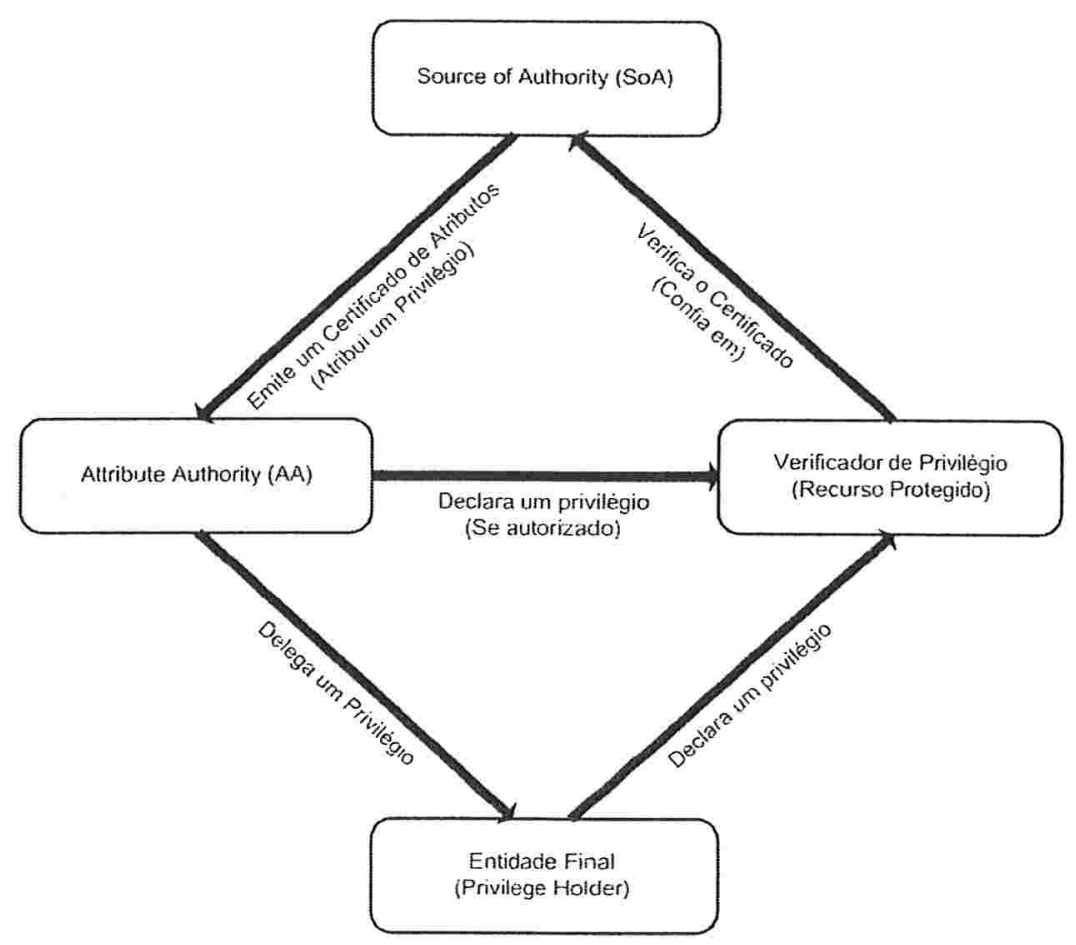

Figura 5-8 - Arquitetura PMI com delegação

A SOA pode impor restrições à cadeia de $A A$, por exemplo, limitando o comprimento dessa cadeia ou o conjunto de privilégios que podem ser delegados. Uma restrição universal é que nenhuma AA pode delegar mais privilégios do que ela possui.

Quando a delegação é usada, o verificador de privilégios confia na SOA para delegar algum ou todos os privilégios para as entidades. Se o certificado apresentado por um declarador de privilégio não foi emitido pela SOA, o verificador de privilégio deve verificar todo o caminho de delegação, ou seja, verificar todos os certificados emitidos 
pelas AA intermediárias até alcançar a SOA. Essa validação deve verificar inclusive se cada AA tem os privilégios suficientes para a emissão dos certificados, além de garantir que a AA tem a permissão de delegar privilégios.

Quando se utilizam certificados de atributos para atribuir privilégios, todo o caminho de delegação deve ser feito pela emissão de certificados de atributos. Por outro lado, quando se utilizam certificados de chave pública para atribuir privilégios por meio da extensão subjectDirectoryAttributes, todo o caminho de delegação deve ser feito com certificados de chaves públicas.

Mais uma vez, vamos aplicar esses conceitos na nossa empresa FHG Consultoria, considerando ainda as políticas descritas na seção anterior.

Quando adotamos o modelo com delegação, os quatro componentes básicos do modelo aplicados na FHG Consultoria seriam:

- Verificador de privilégio: qualquer servidor que tivesse uma solicitação de acesso;

- SOA: seria ainda o diretor de tecnologia, com sua equipe e apoio de outras áreas, quando necessário;

- Autoridades de Atributo: seriam todas as diretorias e supervisões da empresa, que emitiriam certificados de atributo para as entidades subordinadas;

- Declarador de privilégio: seria qualquer usuário que solicitasse acesso a um servidor qualquer da empresa.

Assim, a SOA emitiria certificados de atributo para as diretorias, concedendo a essas o direito de delegar privilégios. As diretorias, por sua vez, emitiriam certificados de atributos para suas supervisões subordinadas, concedendo a essas também o direito de delegação. Por fim, as supervisões emitiriam os certificados de atributos para seus funcionários, sem o direito de delegação. A Figura 5-9 mostra a emissão de certificados de atributo. 


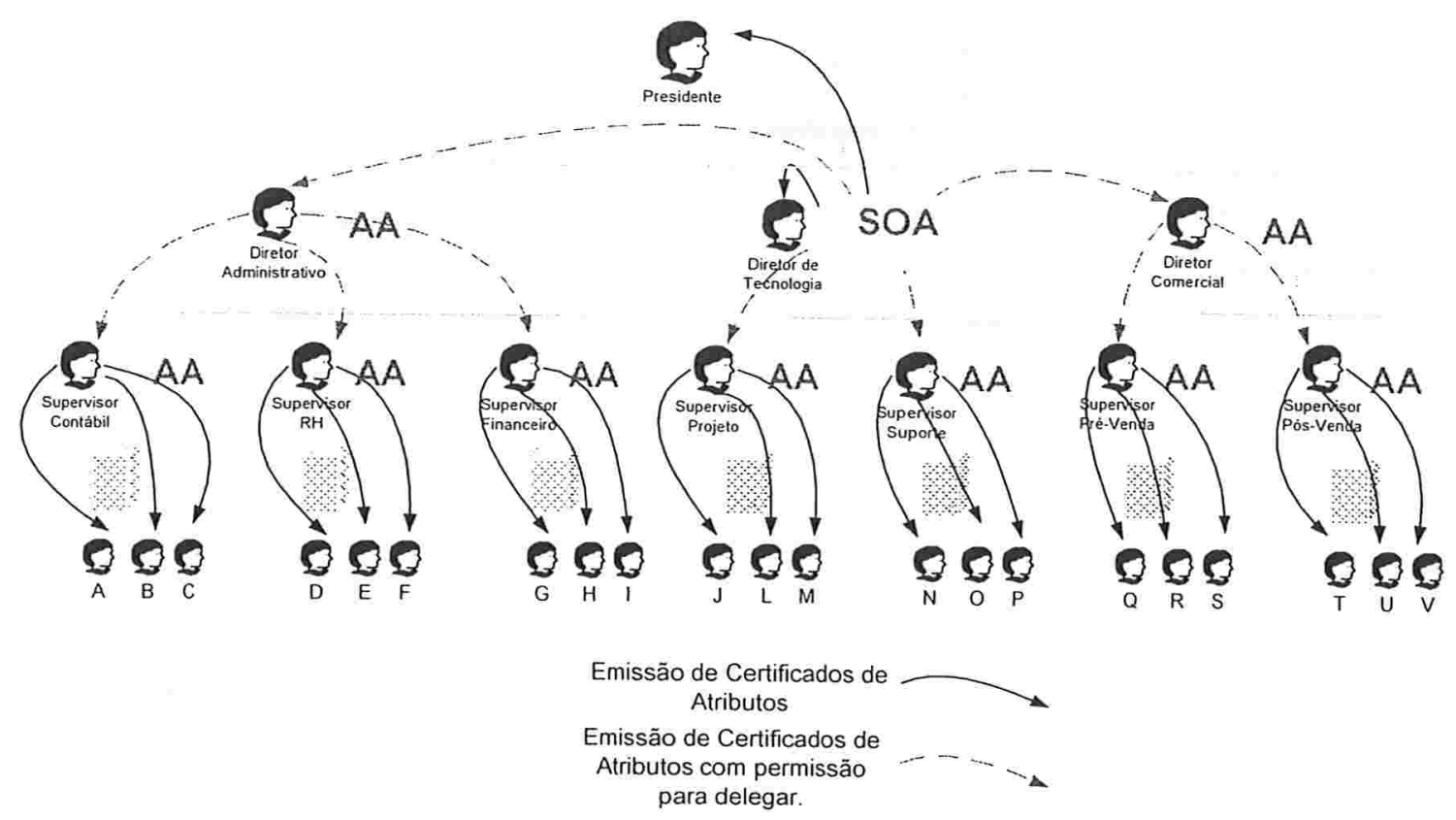

Figura 5-9 - Emissão de Certificados de Atributo no modelo com delegação

Podemos notar que, comparando com o modelo geral exibido na Figura 5-3 no qual existe somente uma autoridade de atributo (AA) que é a própria SOA, o modelo com delegação simplifica sobremaneira a emissão de certificados de atributo, além do fato de que os certificados para os usuários finais são emitidos localmente, dentro de uma determinada supervisão, aproximando o emissor do proprietário de um determinado certificado. Essa situação traz muitas vantagens à infra-estrutura, uma vez que quanto mais próximo o emissor estiver do proprietário, mais fiel à realidade será o certificado de atributo emitido.

Emitidos e distribuídos os certificados de atributos, se o usuário D (declarador de privilégio) do departamento de recursos humanos tentasse acessar o servidor de seu departamento (objeto protegido), ele simplesmente apresentaria seu certificado de atributos (método push) junto com sua solicitação de acesso. O servidor de $\mathrm{RH}$ (verificador de privilégio), então, deveria verificar a autenticidade e validade do certificado de atributos. Além disso, como o emissor do certificado apresentado não é a SOA, o servidor de RH deve validar todo o caminho de delegação, verificando se as $A A$ intermediárias têm o direito de delegar privilégios. Nesse caso, a validação iniciar-se-ia do diretor de tecnologia (SOA), passando em seguida pelo diretor administrativo (AA) e pelo supervisor de RH (AA), autoridade emissora do certificado de atributo do usuário D. Validados o certificado e o caminho de delegação, o servidor de RH tem informações 
suficientes para conceder ou não o acesso requisitado pelo usuário D. Nesse nosso exemplo, o usuário D conseguirá o acesso desejado, conforme ilustrado na Figura 5-10 a seguir.

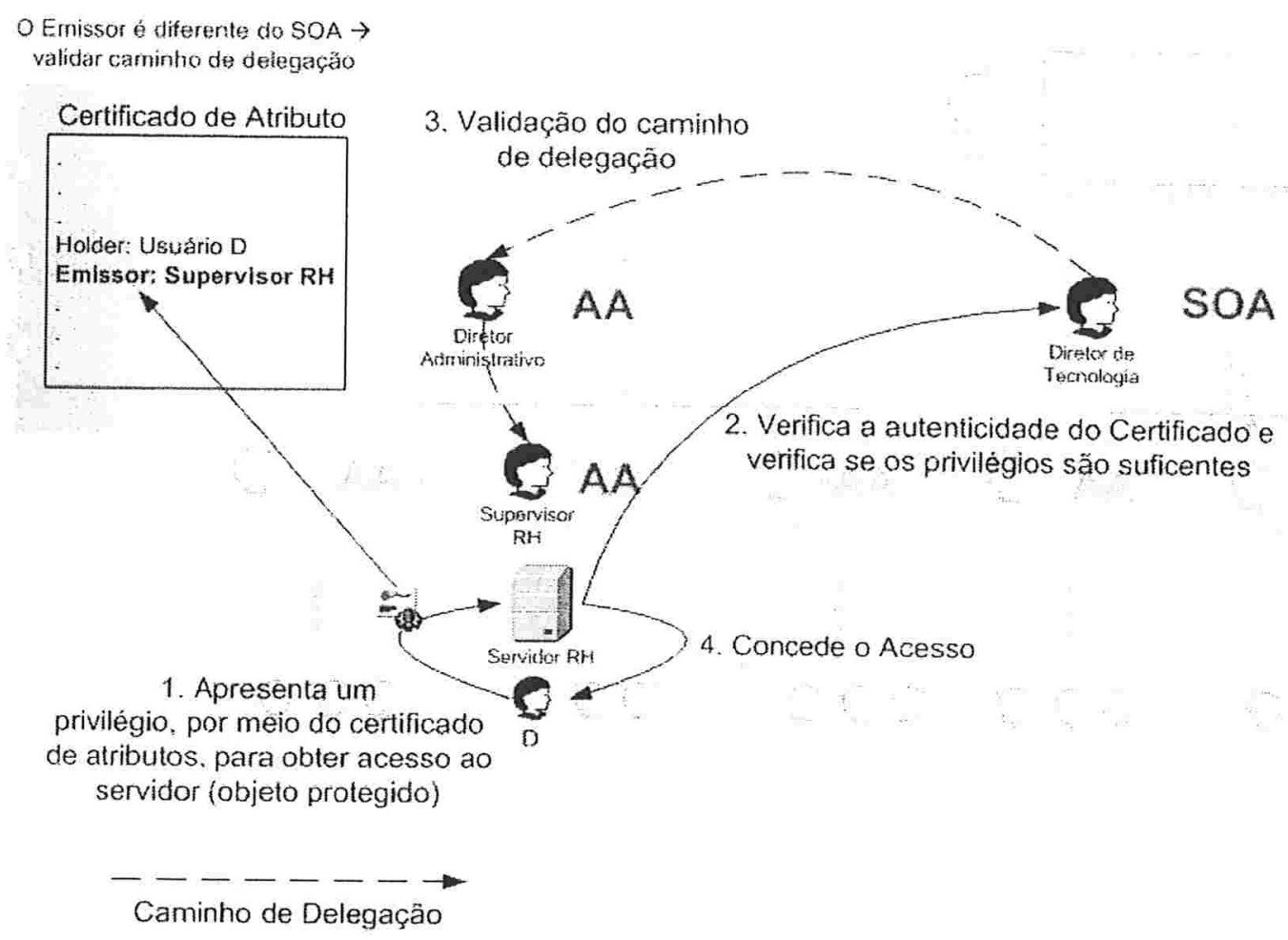

Figura 5-10 - Modelo com Delegação - Concedendo Acesso a um objeto protegido

Se esse mesmo usuário $D$ (declarador de privilégio) do departamento de recursos humanos tentasse acessar o servidor financeiro (objeto protegido), esse servidor, trabalhando como verificador de privilégios e após todas as verificações descritas anteriormente, não concederia o acesso, pois embora o certificado e o caminho de delegação sejam válidos, os privilégios apresentados não são suficientes para o acesso desejado. A figura a seguir mostra justamente essa situação de negação de acesso no modelo de PMI com delegação. 


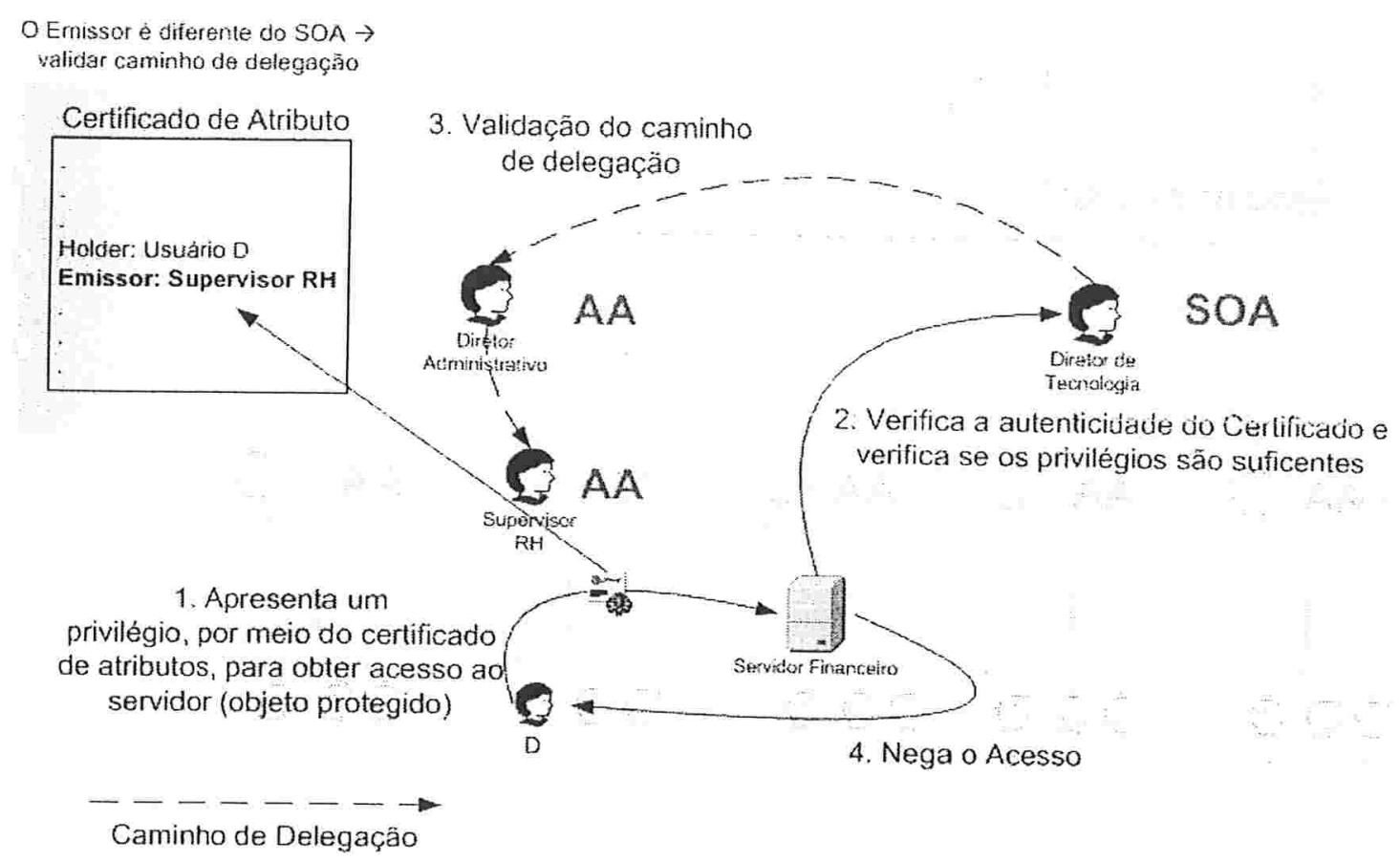

Figura 5-11 - Modelo com Delegação - Negando Acesso a um objeto protegido

\subsubsection{Modelo de papéis}

Papéis fornecem um meio de se atribuir indiretamente privilégios a indivíduos. Para os indivíduos são emitidos certificados de atribuição de papel que definem um ou mais papéis (roles) a ele. Os privilégios são atribuídos aos papéis através de certificados de especificação de papel, ao invés da atribuição direta a entidades finais por meio de certificados de atributos. Esse mecanismo permite que se altere o privilégio de um papel, sem qualquer necessidade de alteração ou operação, como revogação, do certificado de atribuição de papel emitido para as entidades.

A Figura 5-12 exibe o modelo de uma PMI com papéis. 


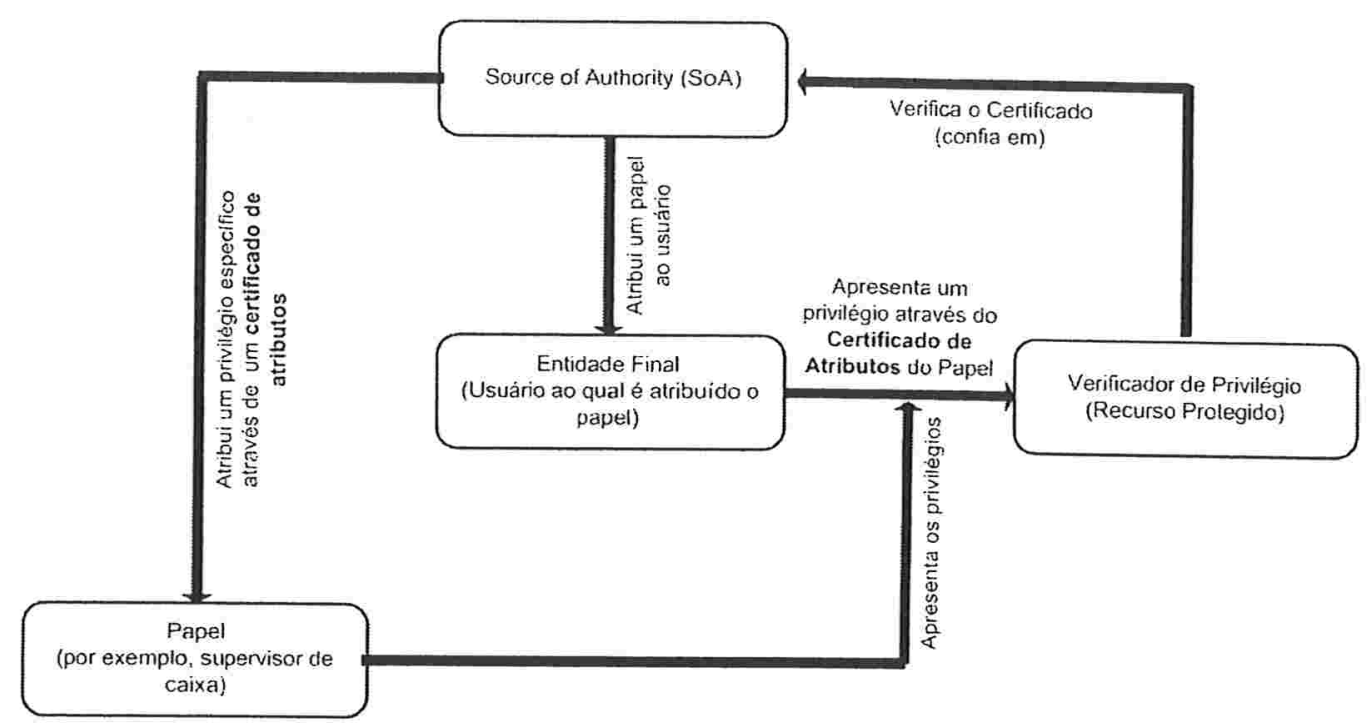

Figura 5-12 - Modelo PMI com suporte a papéis

Os certificados de atribuição de papel podem ser certificados de atributos ou certificados de chave pública. Certificados de especificação de papel só podem ser certificados de atributo [ITU 00].

Vamos agora aplicar os conceitos do modelo com suporte a papéis na FHG Consultoria. A recomendação X.509 permite que tenhamos duas entidades diferentes para emissão de certificados: uma para emitir os certificados de especificação de papéis para os vários papéis ou funções existentes na empresa e outra para emitir os certificados de atribuição de papel, que são emitidos para as entidades finais. Para simplificar nosso exemplo, vamos utilizar apenas uma entidade para emitir ambos os certificados.

Para compor nosso cenário, vamos definir os seguintes papéis:

- Contabilista, para funcionários da contabilidade;

- Analista_RH, para funcionários dos recursos humanos;

- Analista_Financeiro, para funcionários do financeiro;

- Projetista, para funcionários do projeto;

- Analista_suporte, para funcionários do suporte;

- Analista_pré-venda, para funcionários da pré-venda;

- Analista_pós-venda, para funcionários da pós-venda;

- Diretor, para os diretores administrativo, de tecnologia e comercial; e

- Presidente, para o presidente da empresa. 
Em uma situação real, a definição dos papéis e atributos de cada papel deve ser feita por uma equipe capaz de definir o escopo de trabalho e as permissões necessárias para o desenvolvimento desse trabalho para cada papel ou função existente na empresa.

No nosso exemplo, os funcionários de cada departamento só têm acesso ao seu servidor local. Os supervisores e o presidente têm acesso a qualquer servidor na empresa. Assim, seguindo o modelo PMI com suporte a papéis, devemos emitir um certificado de especificação de papel para cada um dos papéis anteriormente definidos, com os respectivos atributos citados. Considerando que o Diretor de Tecnologia é a entidade que emitirá os certificados, atuando coma SOA, podemos verificar na figura a seguir como se dá o processo de emissão dos certificados de especificação de papel:

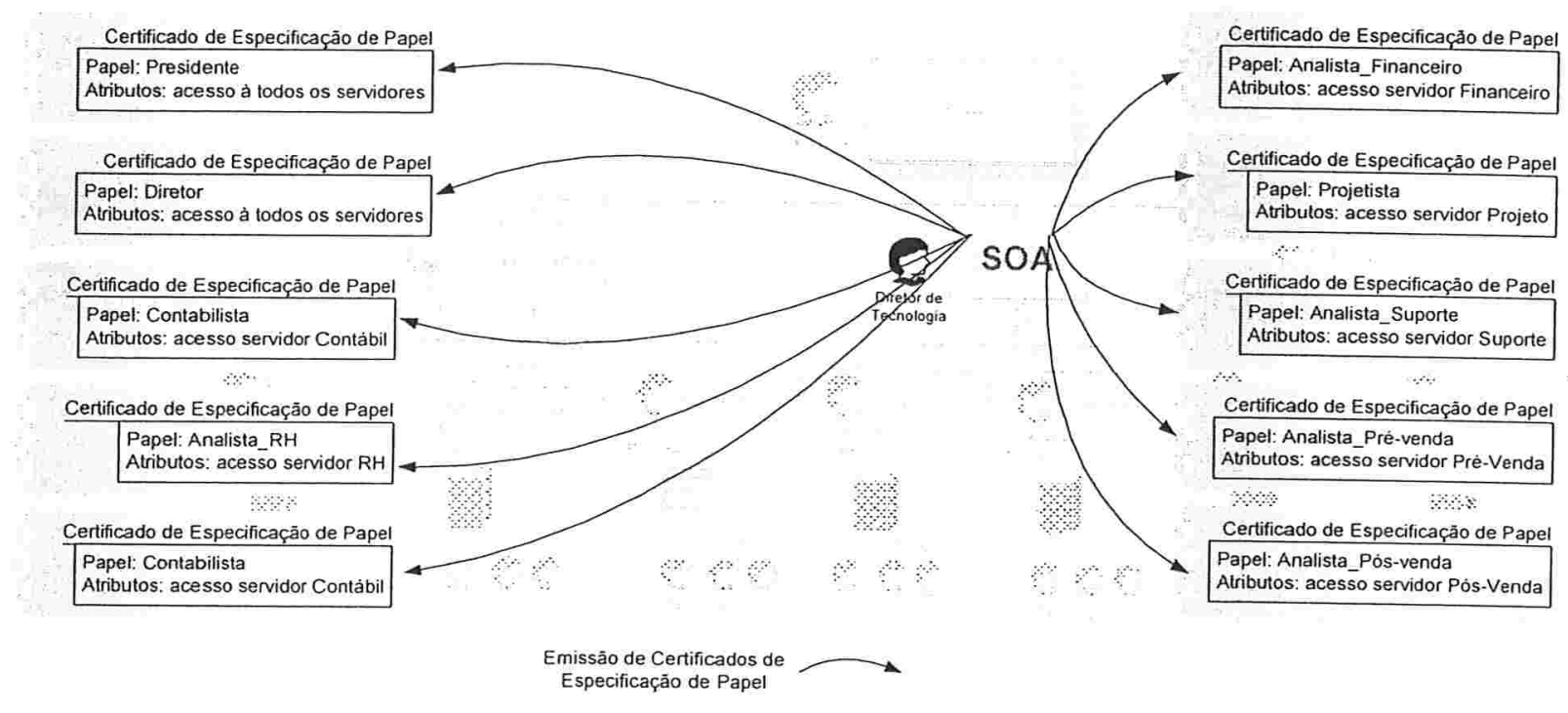

Figura 5 - 13 - Emissão de Certificado de Especificação de Papel no modelo com suporte a papéis

A próxima etapa seria a emissão dos certificados de atribuição de papel para os usuários. Nesse caso, a SOA - Diretor de Tecnologia - também seria responsável por essa emissão. A Figura 5-14 a seguir exibe essa etapa. 


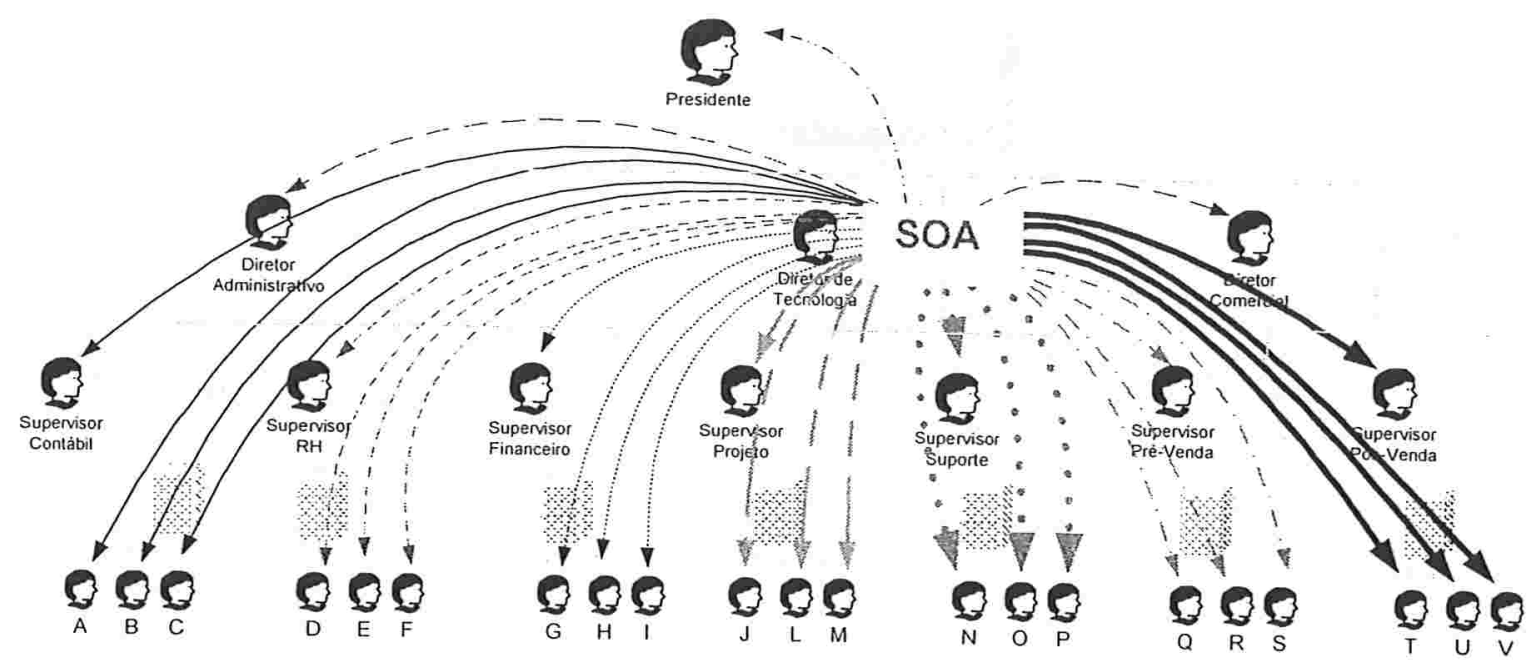

Emissão de Certificados de Atribuição de Papel

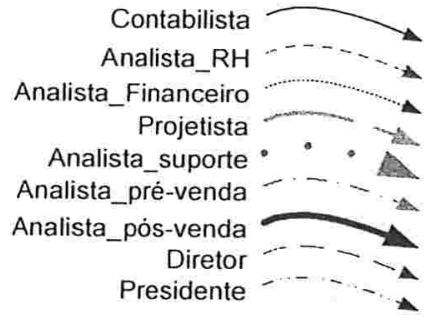

Figura 5 - 14 - Emissão de Certificados de Atribuição de Papel no modelo com suporte a papéis

Nesse momento, se o usuário D do departamento de recursos humanos tentasse acessar o servidor de seu departamento, ele apresentaria seu certificado de atribuição de papel e o Servidor de $\mathrm{RH}$, na função de verificador de privilégio, teria de obter o certificado de especificação do papel de Analista_RH apresentado. O servidor poderia obter esse certificado em um serviço diretório ou poderia ter esse certificado localmente. Após a recuperação do certificado de especificação de papel, o servidor faria, então, a verificação se os atributos correspondentes são suficientes para o acesso desejado. A Figura 5-15 a seguir ilustra essa situação. 


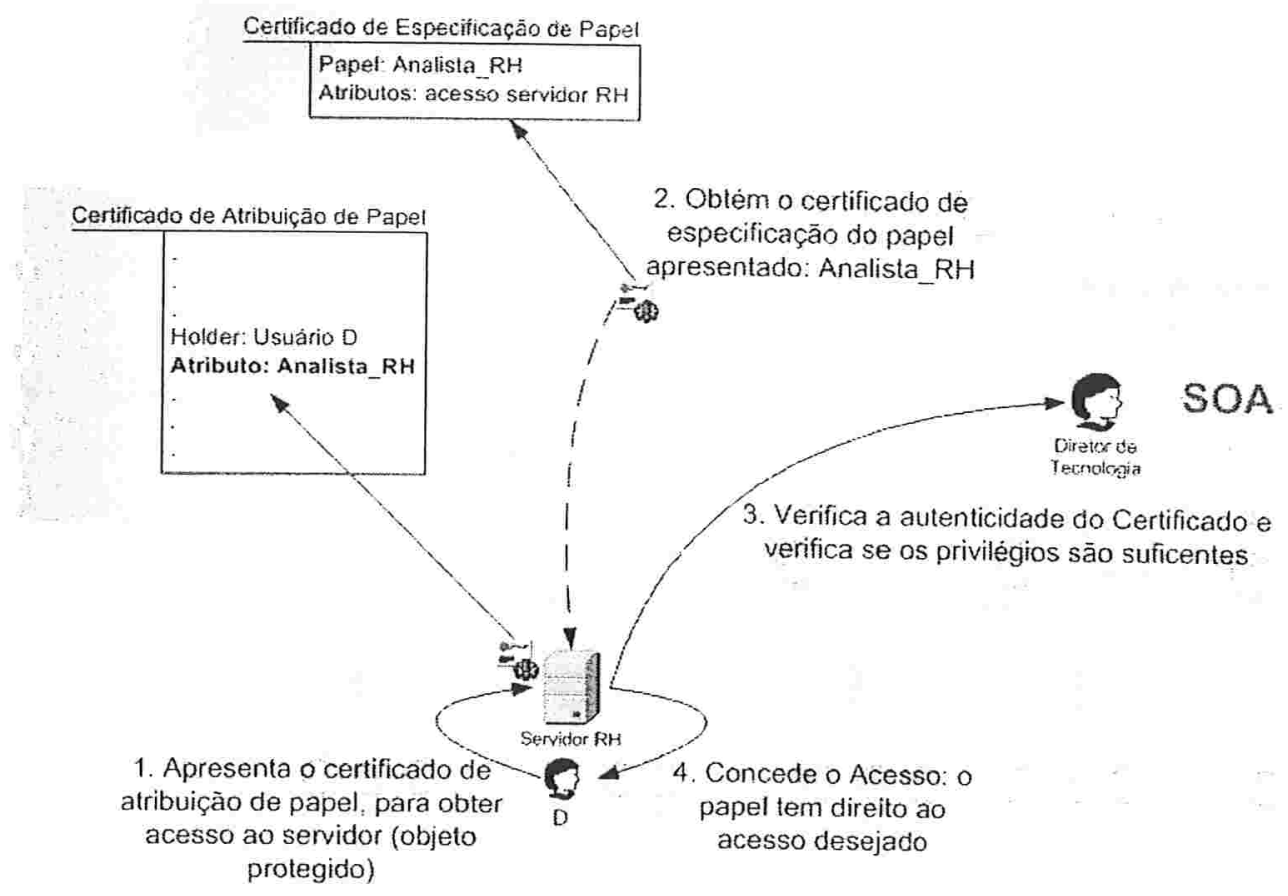

Figura 5 - 15 - Modelo com papéis - concedendo acesso a um objeto protegido

Se esse mesmo usuário $D$ do departamento de recursos humanos tentasse acessar o servidor financeiro, esse servidor, trabalhando como verificador de privilégios, não concederia o acesso, pois embora o certificado de atribuição de papel seja válido, e o certificado de especificação de papel exista e seja também válido, o privilégio constante deste último certificado não é suficiente para o acesso desejado, de acordo com a política de segurança adotada pela empresa. A figura a seguir mostra justamente essa situação de negação de acesso. 


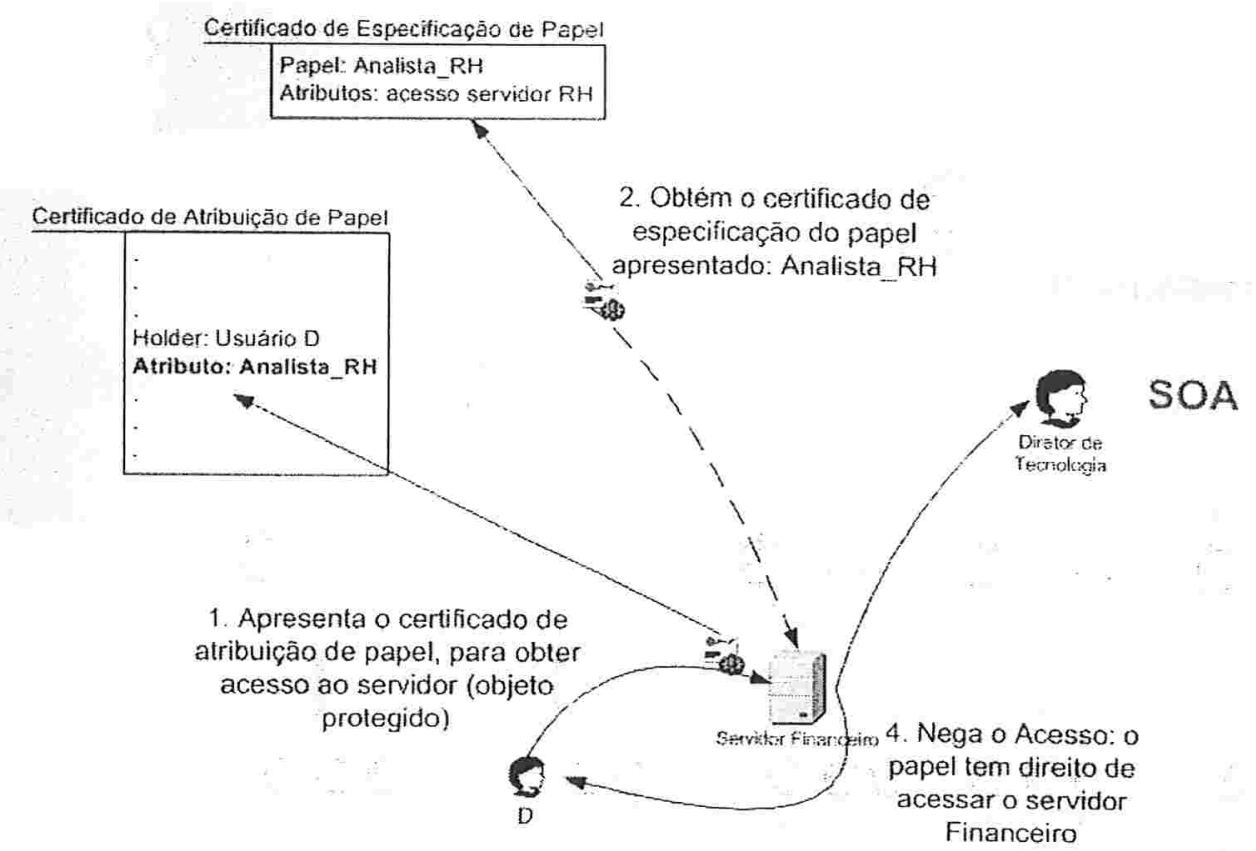

Figura 5 - 16 - Modelo com papéis - negando acesso a um objeto protegido

\subsection{Quadro resumo das entidades de uma PMI}

A Tabela 5-3 consolida as informações das seções anteriores, exibindo as principais entidades de uma PMI, bem como suas funções, independentemente do modelo arquitetural adotado.

Tabela 5 - 3 - Componentes de uma PMI

\section{Entidade}

\section{Principal Função}

\begin{tabular}{c|l}
$\begin{array}{c}\text { Start of Authority } \\
\text { (SOA) }\end{array}$ & $\begin{array}{l}\text { Entidade que emite e assina certificados de atributos, sendo } \\
\text { equivalente ao CA raiz de uma PKI. }\end{array}$ \\
\hline $\begin{array}{c}\text { Autoridade de Atributo } \\
\text { (AA) }\end{array}$ & $\begin{array}{l}\text { Entidade que emite e assina o certificado de atributo, em alguns } \\
\text { casos chamada de emissora do certificado de atributo. }\end{array}$ \\
\hline $\begin{array}{c}\text { Usuário do certificado } \\
\text { de atributo ou } \\
\text { declarador de } \\
\text { privilégio }\end{array}$ & $\begin{array}{l}\text { Qualquer entidade que faz uso ou processa um certificado de } \\
\text { atributo }\end{array}$ \\
\hline $\begin{array}{c}\text { Verificador de } \\
\text { privilégio }\end{array}$ & $\begin{array}{l}\text { Qualquer entidade que verifica a validade de um certificado de } \\
\text { atributo e então faz uso do resultado. Geralmente é a entidade } \\
\text { protegida pelo esquema de autorização implementado. }\end{array}$ \\
\hline
\end{tabular}


Entidade

Depósito ou

repositório

\section{Principal Função}

Um depósito é um termo genérico usado para denotar qualquer método de armazenamento de certificados e Listas de Certificados Revogados de modo que eles possam ser obtidos pelas Entidades componentes do sistema.

\subsection{Premissas do modelo}

O modelo proposto na referência [FAR 02] apresenta algumas premissas que devem ser observadas pelos implementadores. Essas premissas são classificadas em premissas de validade, tipos de atributos, objetivo do certificado e método de apresentação do certificado.

Quanto à validade do certificado de atributo, o modelo permite o uso de um tempo de vida curto tanto quanto um tempo de vida longo. Um período de validade curto, geralmente é definido em horas, enquanto um período longo é definido em meses. Devese, no entanto, observar que o uso de curtos períodos de validade permite que um certificado seja confiável sem o uso de mecanismos de revogação. Essa característica simplifica o modelo, além de acrescentar uma maior confiabilidade. Por outro lado, períodos de validade longos evitam a necessidade constante da emissão de novos certificados para seus usuários.

Quanto ao tipo de atributo, a autoridade de atributo (AA) deveria ser capaz de definir os tipos de atributos específicos para uso dentro de seus domínios. A AA deve também ser capaz de definir e trabalhar com tipos de atributos-padrão, além de poder diferenciar o uso de um mesmo atributo em domínios diferentes. Um exemplo é o grupo de administradores definido no domínio IME e o grupo de administradores definido no domínio POLI. Embora o atributo seja o mesmo - grupo de administradores - o contexto em que eles são válidos são diferentes. Essa diferença deve ser facilmente identificada pela AA.

Quanto ao objetivo de um certificado de atributo, deve-se definir um servidor ou um pequeno grupo deles que serão o alvo para o uso do certificado. Em outras palavras, um servidor que não esteja definido como "alvo", embora confiável, rejeitará as decisões de autorização contidas no certificado. 
Finalmente, quanto ao método de apresentação do certificado, o modelo define dois métodos - push e pull - já apresentados anteriormente. O certificado de atributo deveria ser definido de modo que ambos os métodos sejam suportados. Essa premissa é importante porque torna o modelo flexível o suficiente para atender às necessidades e às políticas de qualquer empresa.

\subsection{Certificados de atributo $X .509$}

A recomendação X.509 da ITU-T contém a definição de um certificado de atributo apresentada a seguir no padrão Abstract Syntax Notation One - ASN.1 [ASN 03].

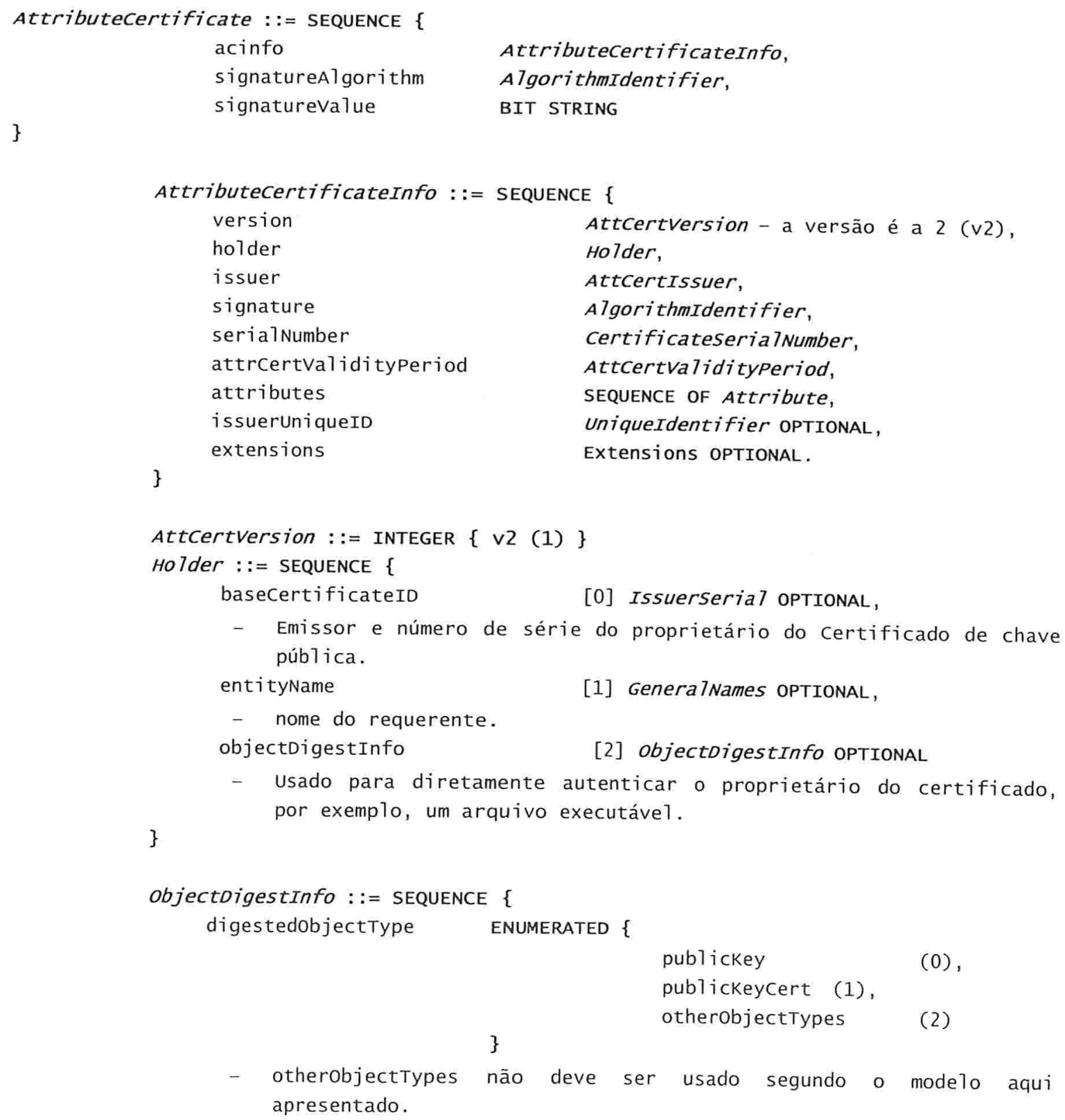




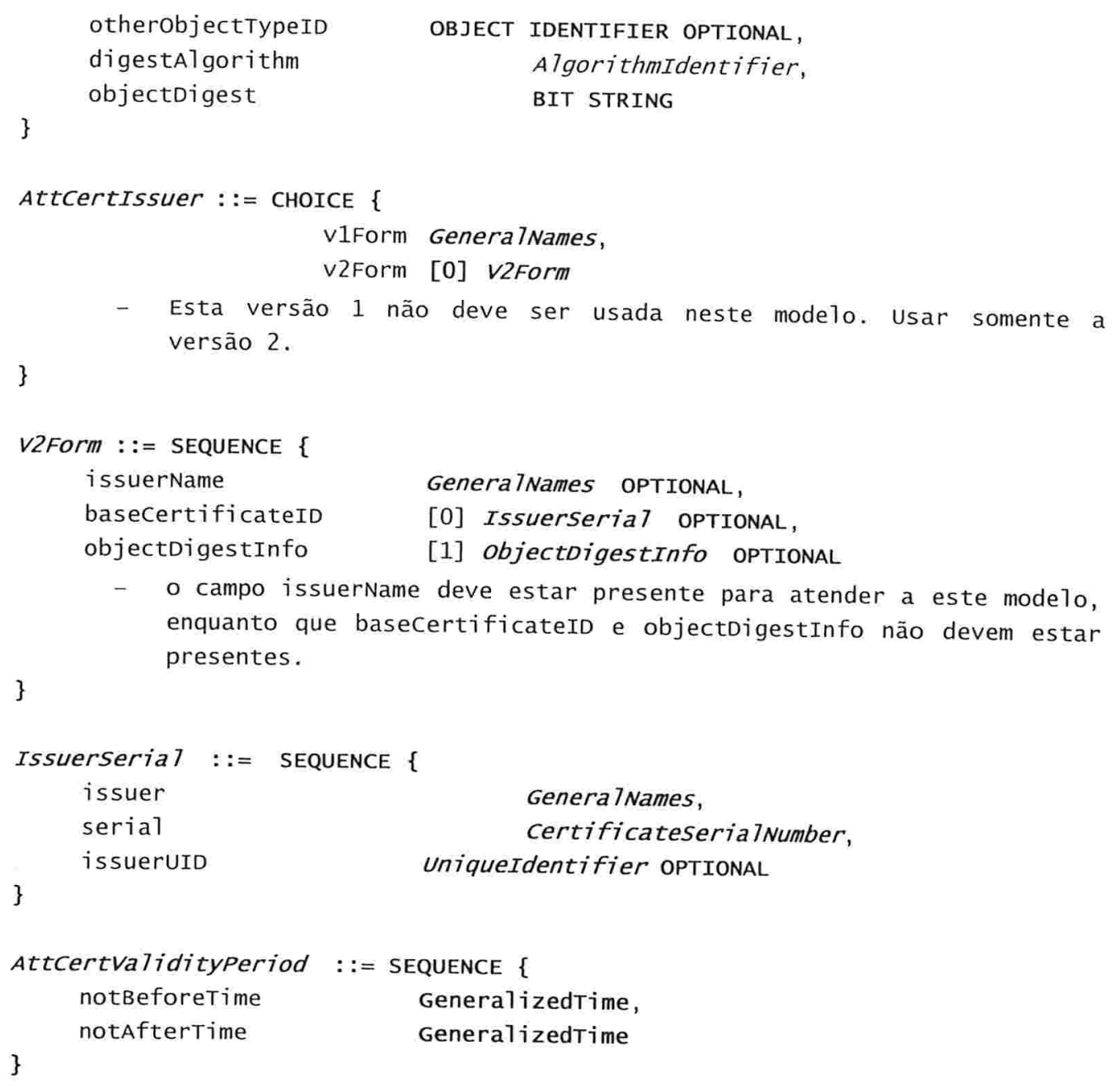

Embora a sintaxe de atributo esteja definida em [HOU 02], essa é repetida a seguir por conveniência:

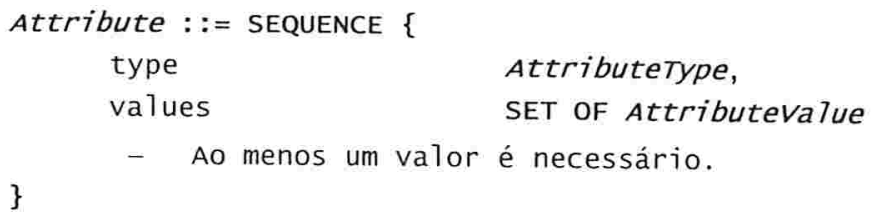

\section{AttributeType ::= OBJECT IDENTIFIER}

\section{AttributeValue ::= ANY DEFINED BY AttributeType}

A opção GeneralName, que identifica os participantes no processo, oferece grande flexibilidade. Quando falamos de interoperabilidade, a flexibilidade tem de ser 
limitada. Assim, o uso da opção GeneralName é restringida pelo modelo proposto pela referência [FAR 02]. Essas restrições baseiam-se na definição de que opções podem ser utilizadas em GeneralName. Para que uma implementação esteja de acordo com o modelo proposto, as opções aNSName, directoryName, uniformResourceldentifier e iPAddress devem ser suportadas [HOU 02].

Além disso, as implementações não devem permitir o uso das opções x400Address, ediPartyName ou registeredID em GeneralName.

A figura a seguir mostra o certificado de atributo anteriormente definido.

\begin{tabular}{|c|}
\hline Versão \\
\hline Proprietário (Holder) \\
\hline Emissor \\
\hline Algoritmo \\
\hline Parâmetros \\
\hline Número de Série \\
\hline Não antes de \\
\hline Não depois de \\
\hline Atributos \\
\hline Identificador Único do Emissor \\
\hline Extensões \\
\hline Algoritmos \\
\hline Parâmetros \\
\hline Resumo Cifrado \\
\hline
\end{tabular}

Figura 5-17 - Certificado de Atributo

As seções seguintes apresentam uma descrição da sintaxe dos campos-padrão de um certificado de atributo.

\subsubsection{Versão}

Esse campo deve ser definido como versão 2.

A versão 2 não é compatível com a versão 1 anterior, definida na recomendação X.509 de 1997. 


\subsubsection{Proprietário (Holder)}

Esse campo é um seqüencial que permite três sintaxes diferentes: baseCertificateID, entityName e objectDigestlnfo. Essas opções podem ser utilizadas em conjunto ou individualmente. Para evitar confusão sobre qual opção é normativa e qual seria uma dica, é recomendável utilizar somente uma das opções acima no campo proprietário do certificado de atributos.

Nos ambientes em que o certificado de autorização é passado em uma mensagem ou sessão autenticada e em que essa autenticação é baseada no certificado de chave pública, o campo proprietário deveria conter a opção baseCertificatelD. Quando utilizamos essa opção, o campo proprietário do certificado de atributo é idêntico ao campo número serial do certificado de chave pública. Isso é desejável, uma vez que se forma aí o vínculo necessário entre a identidade de um objeto e a autorização fornecida por infraestruturas diferentes. A figura a seguir mostra o vínculo criado através da opção baseCertificatelD.

Certificado de Atributos

Certificado de Identidade

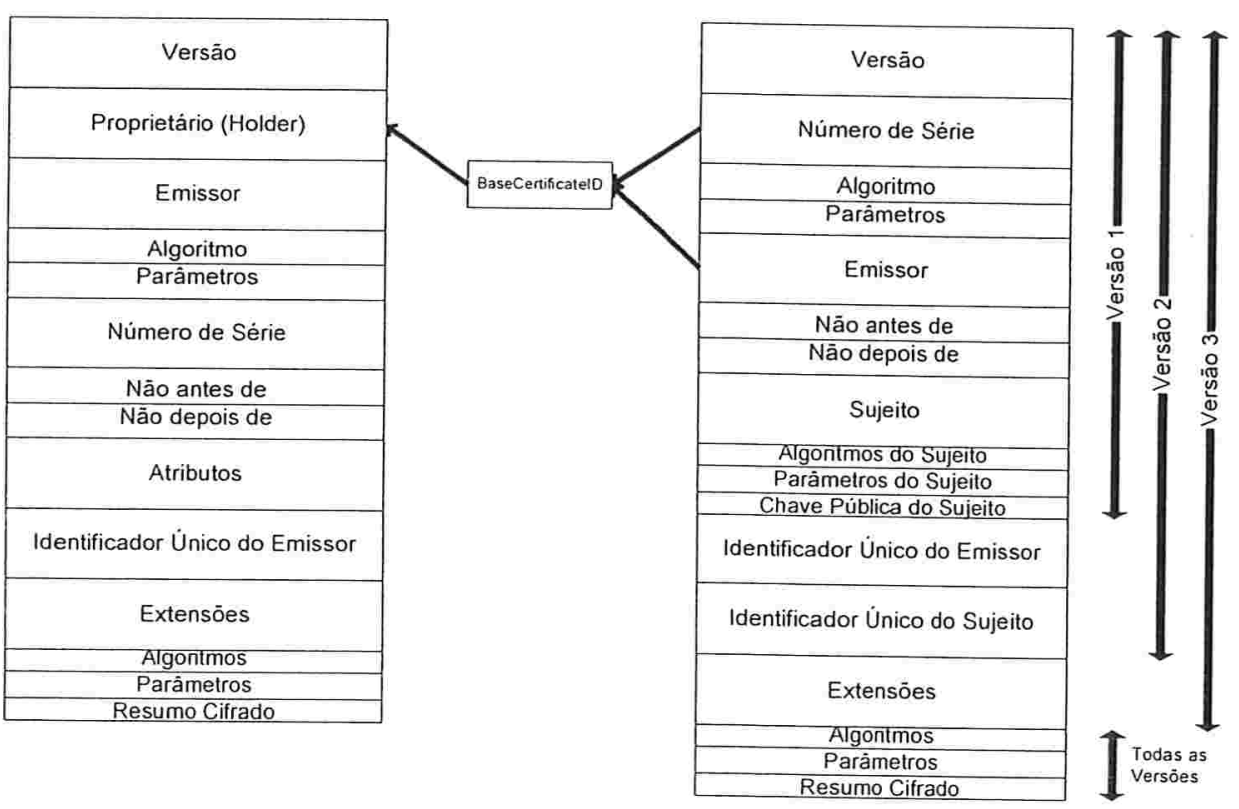

Figura 5-18 - Vínculo através da opção BaseCertificateID

Existe a possibilidade de se utilizar a opção entityName no campo proprietário. Nesse caso, a entityName deve ter o mesmo valor colocado no campo sujeito do certificado de chave pública, caso uma infra-estrutura de chave pública seja a autoridade de autenticação. Assim, o vínculo entre a identidade e a autorização está mais uma vez garantido. A figura a seguir mostra o vínculo criado com a opção entityName. 
Certificado de Atributos

Certificado de Identidade

\begin{tabular}{|c|c|}
\hline Versão & Versão \\
\hline Proprietário (Holder) & Número de Série \\
\hline \multirow[t]{2}{*}{ Emissor } & Algoritmo \\
\hline \multirow{2}{*}{\multicolumn{2}{|c|}{ Parâmetros }} \\
\hline & \\
\hline \multicolumn{2}{|l|}{ Parâmetros } \\
\hline Número de Série & Não antes de \\
\hline Não antes de & Não depois de \\
\hline \multicolumn{2}{|l|}{ Não depois de } \\
\hline \multirow[b]{2}{*}{ Atributos } & Algoritmos do Sujeito \\
\hline & $\begin{array}{l}\text { Parâmetros do Sujeito } \\
\text { Chave Pública do Suieito }\end{array}$ \\
\hline Identificador Único do Emissor & Identificador Único do Emissor \\
\hline Extensões & Identificador Único do Sujeito \\
\hline \multirow{2}{*}{$\begin{array}{c}\text { Algoritmos } \\
\text { Parâmetros }\end{array}$} & \\
\hline & Extensões \\
\hline \multirow[t]{3}{*}{ Resumo Cifrado } & Algoritmos \\
\hline & Parâmetros \\
\hline & Resumo Cifrado \\
\hline
\end{tabular}

Figura 5-19 - Vínculo através da opção EntityName

A última possibilidade para o campo proprietário é a utilização da opção objectDigest. Essa opção é utilizada quando não se deseja vincular um certificado de atributo diretamente a uma entidade, através da opção entityName, ou a um certificado de chave pública, através da opção baseCertificatelD.

Uma vez que a opção objectDigest/nfo é utilizada no campo proprietário, o certificado de atributo deve ser da versão 2, indicada no campo versão desse certificado.

O objetivo da opção objectDigest/nfo é permitir vincular o certificado de atributo à um objeto, como um programa Java ou até mesmo diretamente a uma chave pública, através de uma função hash desse objeto. O resultado dessa função hash seria então colocado no campo proprietário do certificado de atributo. O padrão proposto na referência [FAR 02] só reconhece o uso da opção objectDigestlnfo para uso em chaves públicas, desconsiderando qualquer outro objeto, embora seja tecnicamente viável. 
Certificado de Atributos

\begin{tabular}{|c|c|}
\hline Versão & \multirow[b]{2}{*}{ Hash (Chave Pública) } \\
\hline Proprietário (Holder) & \\
\hline Emissor & \multirow{12}{*}{ ObjectDigestinfo } \\
\hline Algoritmo & \\
\hline Parâmetros & \\
\hline Número de Série & \\
\hline Não antes de & \\
\hline Não depois de & \\
\hline Atributos & \\
\hline Identificador Único do Emissor & \\
\hline Extensões & \\
\hline Algoritmos & \\
\hline Parâmetros & \\
\hline Resumo Cifrado & \\
\hline
\end{tabular}

Figura 5-20 - Vínculo através da opção ObjetctDigestInfo

\subsubsection{Emissor}

O campo emissor do certificado de atributo deve utilizar a opção v2Form, para estar em conformidade com o padrão da referência [FAR 02]. Essa opção deve conter um e somente um GeneralName no subcampo issuerName, que deve conter um nome distinto não vazio. Isto significa que toda entidade emissora de certificados de atributo deve ter um nome distinto não vazio registrado em algum diretório. Além desses requisitos, os certificados de atributo que buscam a conformidade com o padrão da referência [FAR 02] não devem utilizar as opções baseCertificatelD e objetctDigestInfo do formulário v2Form do campo emissor. Esses campos devem ser omitidos segundo o padrão proposto. Isso evita que o emissor do certificado de atributo tenha de saber que certificado de chave pública o verificador do certificado de atributo usará para identificá-lo.

\subsubsection{Assinatura}

Esse campo contém o algoritmo criptográfico utilizado para a criação da assinatura do certificado de atributo. O algoritmo escolhido deve ser um dos algoritmos de assinatura definidos na referência [BAS 02]. 


\subsubsection{Número Serial}

É de fundamental importância que a combinação de Entidade Emissora (emissor) e o número serial identifiquem unicamente qualquer certificado de atributo. Para isso, as entidades emissoras utilizam números inteiros positivos geralmente grandes no campo número serial. O tamanho desse campo, entretanto, não pode ser maior que vinte octetos.

Não há nenhuma regra definida para a geração dos números seriais. A entidade emissora deve garantir somente que os números gerados crescerão com o tempo e que todo número serial gerado é único.

\subsubsection{Período de validade}

O campo AttCertValidityPeriod do certificado de atributos define o período no qual o vínculo entre o proprietário do certificado e os atributos definidos são válidos. Em qualquer outro período, antes ou depois, os atributos especificados no certificado não são válidos para aquele proprietário.

Existem diferentes notações que podem ser usadas para designar informações de datas e horários. Visando a dirimir dúvidas, nos campos notBeforeTime e notAfterTime é colocada uma representação padrão Abstract Syntax Notation One (ASN.1) [LAR 99]. O tipo de padrão ASN.1 utilizado é chamado GeneralizedTime.

A sintaxe do GeneralizedTime utiliza 4(quatro) dígitos para o ano, 2(dois) dígitos para o mês, dia, hora minuto e segundo, além de um campo fração de segundo. Se há qualquer informação adicional, a data e hora são entendidas como locais. Para indiciar uma hora em Coordinated Universal Time (UTC), adiciona-se uma letra Z maiúscula à representação.

Para que o certificado esteja aderente ao padrão definido na referência [FAR 02], os valores em GeneralizedTime devem estar expressos em Coodinated Universal Time (UTC), também conhecido como hora de Greenwich. Além disso, os segundos também devem ser expressos, mesmo que sejam iguais a zero, sem, contudo, utilizar valores fracionários.

Como exemplo, para representar a data 15 de fevereiro de 2002 no horário 17:00:10 o valor válido seria 20020515170010Z, em que o Z maiúsculo representa o horário de Greenwich. 
Os usuários do certificado de atributo devem estar habilitados a lidar e processar corretamente certificados cujo período de validade ainda não se iniciou e também com outros cuja validade já expirou.

\subsubsection{Atributos}

O campo atributos fornece informações sobre o proprietário do certificado. Se o certificado é utilizado para autorização, o campo atributos contém privilégios concedidos ao proprietário sobre os objetos protegidos.

Esse campo contém uma seqüência de atributos, em que cada atributo pode conter um conjunto de valores. Para um dado certificado de atributo, cada identificador de objeto (AttributeType) deve ser único. Em outras palavras, um atributo deve aparecer somente uma vez no certificado, mas esse atributo pode ser atribuído a vários objetos protegidos.

Para que um certificado de atributo seja válido, o campo atributos deve ter pelo menos um atributo. A esse campo não é permitida a atribuição de uma seqüência vazia.

\subsubsection{Identificador único do emissor}

A utilização desse campo tem duas situações distintas:

1) Esse campo não deve ser usado, se ele não estiver sendo utilizado no certificado de chave pública do emissor do certificado de atributo;

2) Esse campo deve ser usado, se ele também for utilizado no certificado de chave pública do emissor do certificado de atributo.

As entidades, porém, devem estar habilitadas a tratar esse campo, caso ele seja utilizado ou não.

\subsubsection{Extensões}

Diferentemente dos campos anteriores, que fornecem informações sobre o proprietário do certificado, as extensões fornecem informações adicionais sobre o próprio certificado de atributo.

O uso de extensões é adicional. Certificados de atributo sem extensões estão de acordo com o padrão especificado na referência [FAR 02].

\subsection{Revogação de Certificados de Atributos}


Como já abordamos anteriormente, em muitos casos utiliza-se um tempo de validade curto para os certificados de atributos, o que muitas vezes não gera a necessidade de revogação. No entanto, em algumas situações, especialmente quando o tempo de validade do certificado de atributo é grande, as Autoridades Certificadoras podem oferecer a possibilidade de revogação de certificados de atributos.

De acordo com a RFC 3281 [FAR02] há dois modelos de revogação aceitos: o modelo "nunca revogar" e o modelo "Apontado no Certificado".

O modelo "nunca revogar" define que os certificados de atributos emitidos não serão revogados. Para isso, a entidade final deve ficar ciente dessa informação e a AC faz uso da extensão noRevAvail, que indica a utilização desse modelo.

Já quando a AC opta por utilizar o modelo "Apontado no Certificado", uma extensão do certificado de atributos é utilizada para indicar locais onde podem ser encontradas informações sobre revogação. As extensões utilizadas nesses casos podem ser a authorityInfoAccess ou criDistributionPonts. O que é importante ressaltar é que quando não existe a extensão noRevAvail, implicitamente podemos entender que há um esquema de revogação em uso.

Quando revogamos um certificado de atributos, todos os privilégios dados ao proprietário estão automaticamente revogados. Isso pode ser necessário em situações em que um funcionário tem seus privilégios mudados por algum evento na empresa. Eventos como demissão, transferência, fim de um projeto, ou mesmo promoção podem mudar radicalmente os privilégios que o funcionário tem dentro da empresa. Se essa mesma empresa utilizar um período de validade grande, um esquema de revogação se faz necessário para evitar possíveis perdas.

Vale ressaltar que os mesmos problemas encontrados no processo de revogação dos certificados de chave pública ainda valem nesse caso. Quando a entidade final ou o responsável pela emissão e controle de certificados de atributos solicita a revogação de um certificado, o processo muitas vezes não é instantâneo. O período de tempo entre a solicitação e a emissão de uma nova lista de certificados de atributos revogados é crítico sob o ponto de vista de segurança. Nesse período, o funcionário ainda possui os privilégios revogados e pode utilizá-los de maneira inadequada, comprometendo a segurança da empresa. Essa situação não ocorrerá no modelo proposto neste trabalho, como mostraremos no capitulo seguinte. 


\section{CAPÍTULO 6: UM CERTIFICADO DE ATRIBUTOS DINÂMICO}

Como vimos, os modelos de autorização tradicionais não têm a flexibilidade necessária para os atuais ambientes computacionais.

As infra-estruturas de gerenciamento de privilégios surgiram como uma solução para os novos sistemas, que precisam atender a uma diversidade de ambientes, muitas vezes necessitando de privilégios diferentes para um mesmo usuário.

Porém, quando há a necessidade de revogação de certificados de atributos, o mesmo problema de segurança no período de tempo entre o pedido de revogação e a publicação de uma nova lista de certificados revogados aparece.

Em nosso trabalho, propomos uma pequena alteração no certificado de atributos que tornará esse certificado dinâmico, ou seja, poderemos mudar os privilégios descritos no certificado sem a necessidade de revogação e emissão de um novo certificado.

A alteração é feita no campo atributos do certificado, descrito na seção 5.5.7. Segundo a RFC 3281 [FAR02], o campo atributos deve conter os privilégios concedidos ao proprietário do certificado de atributos. Esses privilégios podem ser de um dos seguintes tipos:

- Informação para um serviço de autenticação;

- Identidade de Acesso;

- Identidade de "carregamento";

- Grupo;

- Papel (role);

- Classificação.

O primeiro tipo, informação para um serviço de autenticação (Service Authentication Information), identifica o proprietário do certificado de atributos para um servidor ou serviço por um nome. Geralmente, esse tipo de atributo contém um nome de usuário e uma senha. Opcionalmente podem ser fornecidas informações sobre o método de autenticação a ser utilizado. O Certificado de Atributo que contém esse tipo de atributo 
é utilizado pelo verificador de privilégios para autenticar o proprietário em outra aplicação ou sistema.

O tipo de atributo Identidade de Acesso (Access Identity) também identifica o proprietário do Certificado de Atributos perante um servidor ou serviço. Porém, não existe um campo sobre informações sobre o método de autenticação. O Certificado de Atributos que contém esse tipo de atributo é usado pelo verificador de privilégios para autorizar as ações do proprietário dentro do sistema do verificador de privilégios, diferentemente do atributo anterior.

O tipo de atributo Identidade para "carregamento" é um atributo que identifica o proprietário do certificado com o objetivo de carregar um serviço e, geralmente, a identidade de carregamento é diferente das outras identificações do proprietário.

O tipo de atributo grupo serve para identificar um ou mais grupos aos quais pertence o proprietário do Certificado de Atributos.

O tipo de atributo papel, especificado na $4^{\text {a }}$ edição da recomendação X.509, identifica papéis (rules) ou funções que são exercidas pelo proprietário do Certificado de Atributos dentro do ambiente em que esse certificado é válido.

Finalmente, o último tipo de atributo especificado em [FAR02], classificação (clearance), identifica uma classificação de segurança à qual o proprietário do Certificado de Atributo pertence. Essa classificação é associada às etiquetas de segurança que classificam os recursos.

Em nosso trabalho, propomos a criação de um novo tipo de atributo que chamamos de arquivo de atributos. Ao invés de definir os atributos que o proprietário possui no próprio Certificado de Atributos, identifica um arquivo no qual serão listados os atributos propriamente ditos. Com isso, o Certificado de Atributos, que antes era estático, agora é dinâmico. Com a utilização de qualquer um dos tipos de atributos previstos em [FAR 02], qualquer mudança de privilégio do proprietário do certificado gerava a revogação do certificado atual e a emissão de um novo certificado com os novos atributos. Com a nossa proposta não: quando os privilégios mudam, basta alterar o arquivo no qual estão gravados os atributos daquele certificado. Dessa forma, eliminamos a necessidade de revogação, pois, mesmo quando o certificado tiver de ser revogado, basta retirarmos todos os atributos existentes no arquivo de atributos que o mesmo não terá nenhuma utilidade. 


\subsection{Validação do Certificado de Atributos}

Com a nossa proposta, o processo de validação do Certificado de Atributos mudará um pouco. O processo de validação inicia-se com o processo de autenticação utilizado pelo proprietário do Certificado de Atributos. Se o proprietário utiliza um certificado de chave pública no processo de autenticação, todo o caminho de certificação deverá ser validado, de acordo com [HOU 02]. Se não há um esquema de autenticação forte, como a utilização de PKC, o verificador de privilégios deve se certificar de que o Certificado de Atributo a ser validado pertence realmente à identidade autenticada nessa fase.

Após a autenticação, o verificador deve começar a validação propriamente dita do Certificado de Atributos. Para isso, deve-se localizar de alguma forma o Certificado de Atributos, utilizando-se para isso um dos dois métodos disponiveis: push ou pull.

Sobre o Certificado de Atributos, a primeira validação a ser feita é da assinatura digital do Certificado. A assinatura deve estar criptograficamente correta e todo o caminho de certificação da entidade emissora do Certificado de Atributos deve ser validado, seguindo as recomendações em [HOU 02]. Além disso, a entidade emissora do Certificado de Atributos deve ser reconhecida como tal.

A seguir, deve-se avaliar o período de validade do Certificado de Atributos. Para isso, a hora da avaliação deve ser comparada aos campos notBeforeTime e notBeforeTime, devendo estar entre os dois valores constantes nesses campos.

Se a validade do Certificado de Atributos está de acordo, deve-se então verificar uma extensão do Certificado de Atributos: a extensão AC Targeting. Com essa extensão, é possivel definir para que sistemas, serviços ou servidores destina--se o Certificado de Atributos. Dessa forma, se há essa extensão no Certificado, ela deve ser verificada para validarmos se o Certificado de Atributos destina-se a uma aplicação ou serviço que o verificador de privilégios fornece.

Após todos esses passos, finalmente o verificador de privilégios deverá checar se os atributos constantes do Certificado de Atributos são suficientes para o acesso desejado. Para isso, o verificador de privilégios irá validar o campo Atributos do Certificado de Privilégios. A figura 6-1 a seguir mostra esse processo de validação do Certificado de Atributos. 


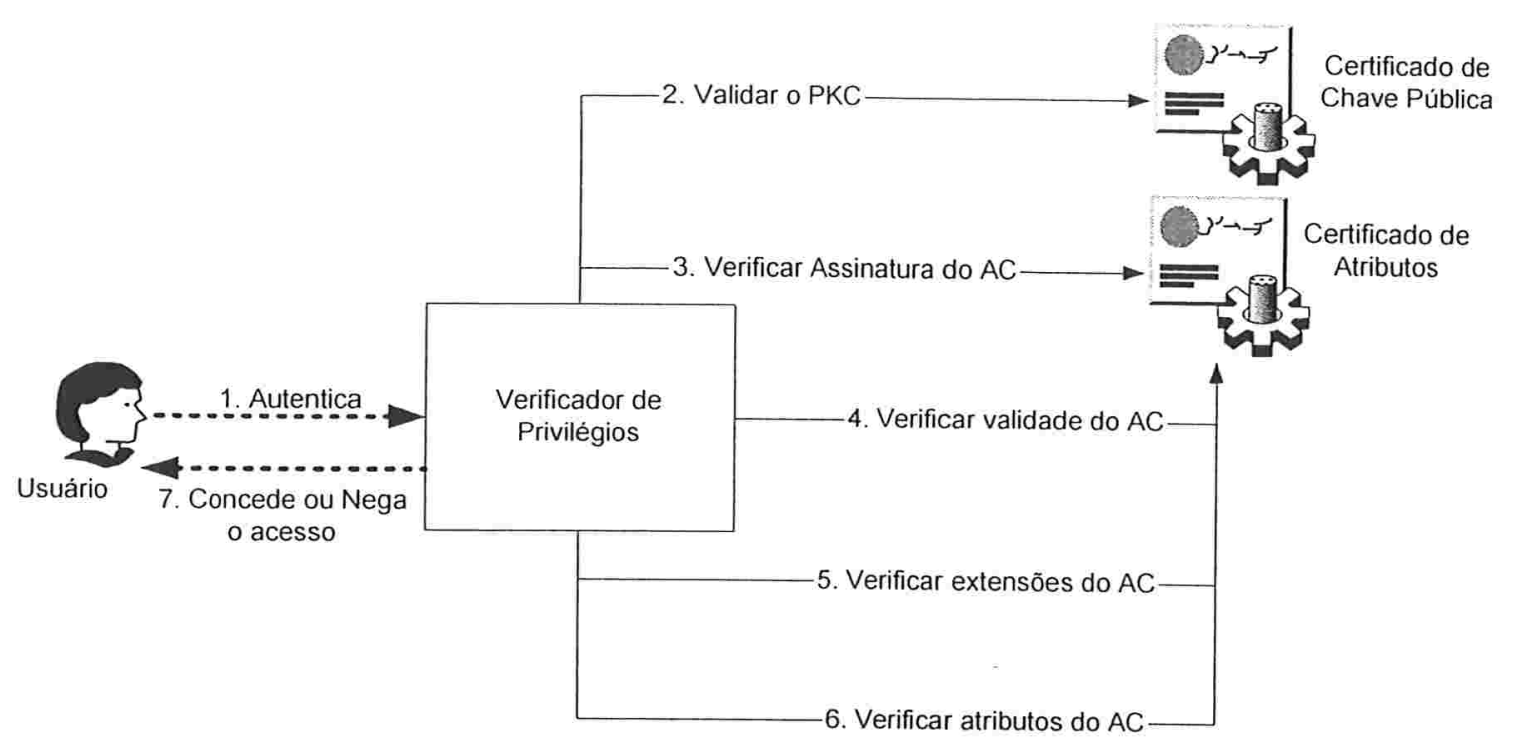

Figura 6-1 - Validação do Certificado de Atributos

Como podemos notar no processo de validação acima, o único passo que é afetado com a nossa proposta é a verificação dos privilégios: ele deveria buscar no campo Atributos o nome do arquivo que realmente contém os atributos do proprietário desse Certificado de Atributos. Com isso, o verificador de privilégios deverá, então, localizar e abrir o arquivo com os Atributos, verificando, assim, se são suficientes ou não para o acesso solicitado. A figura 6-2 mostra o processo de validação no modelo proposto.

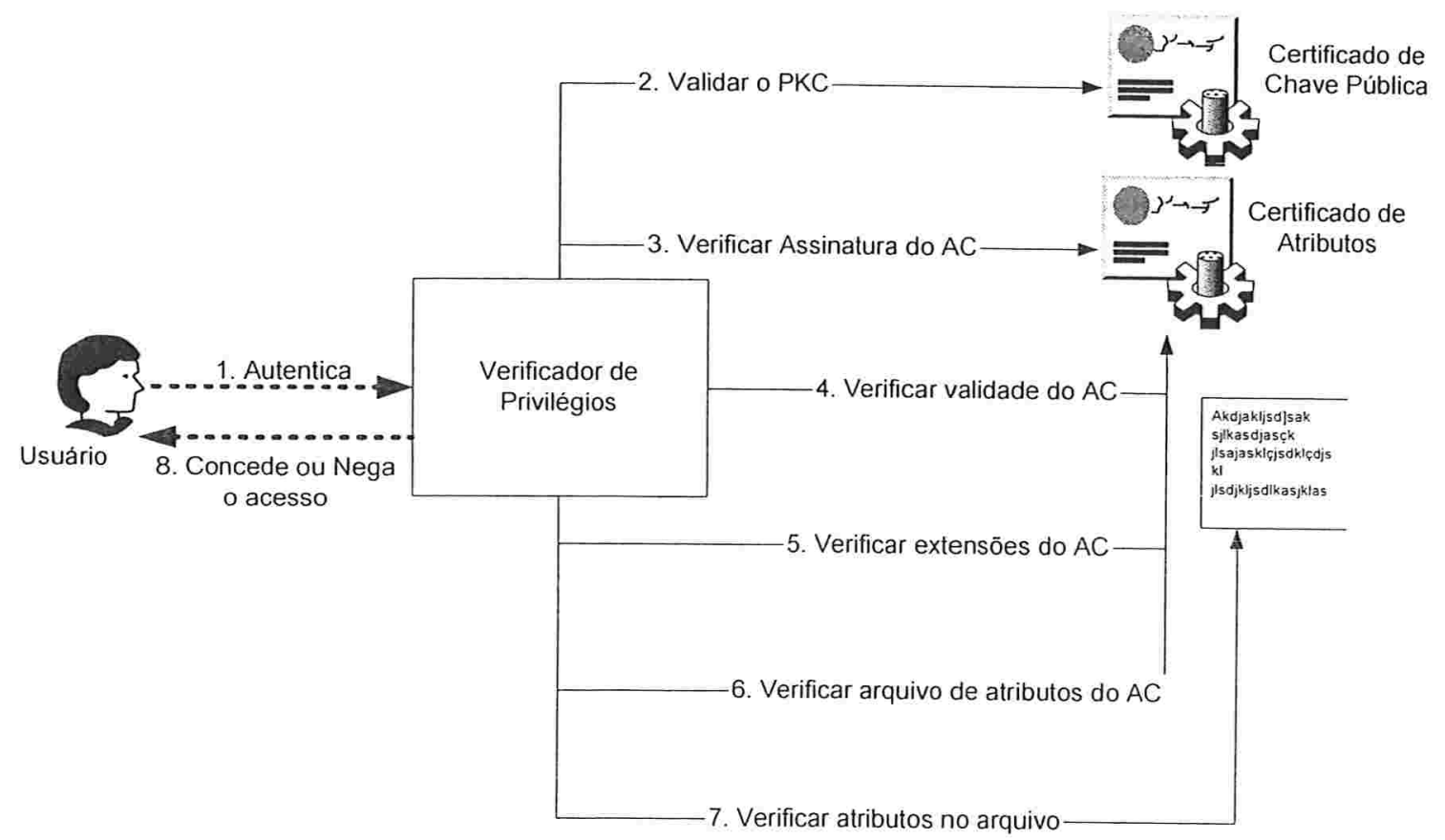

Figura 6-2 - Validação do Certificado de Atributos no modelo proposto 


\subsection{Vantagens e desvantagens do modelo proposto}

O modelo proposto apresenta algumas vantagens em relação ao modelo padronizado de uma Infra-estrutura de gerenciamento de privilégios. A principal vantagem é a eliminação do processo de revogação de certificados, um processo notadamente inseguro e muitas vezes ineficiente, tendo em vista todos os aspectos listados na seção 5.6 .

No nosso modelo, caso seja necessária a revogação dos privilégios do proprietário do Certificado de Atributos, basta retirar os atributos do arquivo de atributos associado ao Certificado de Atributos em questão. Dessa forma, mesmo que o certificado ainda esteja dentro do período de validade, o proprietário não terá mais nenhum privilégio, pois os atributos não estão no Certificado e sim no arquivo de atributos. Essa metodologia elimina a necessidade de revogação do Certificado de Atributos, a emissão de uma nova Lista de Certificados de Atributos Revogados e, caso seja necessário, a emissão de um novo Certificado de Atributos com os novos privilégios do proprietário.

Para exemplificarmos essa situação, vamos contextualizar a situação de mudança de privilégios na FHG Consultoria. Suponhamos que um funcionário dos recursos humanos foi demitido e, conseqüentemente, seu Certificado de Atributos deva ser revogado. Suponhamos também que o modelo de PMI implementado na FHG seja o modelo com delegação e que o Supervisor de RH seja a Autoridade de Atributo que emitiu o Certificado de Atributo para os seus funcionários. Nesse caso, quando o funcionário é demitido (fato gerador de mudança de privilégios), o seu supervisor, que é o AA, poderá revogar o Certificado de Atributos e emitir uma nova Lista de Certificados de Atributos Revogados (LCAR). O intervalo de tempo entre o fato gerador de mudança de privilégios e a emissão de uma nova LCAR, embora seja minimizado pela adoção do modelo com delegação, é crítico sob o ponto de vista da segurança. A figura 6-3 a seguir ilustra essa situação. 


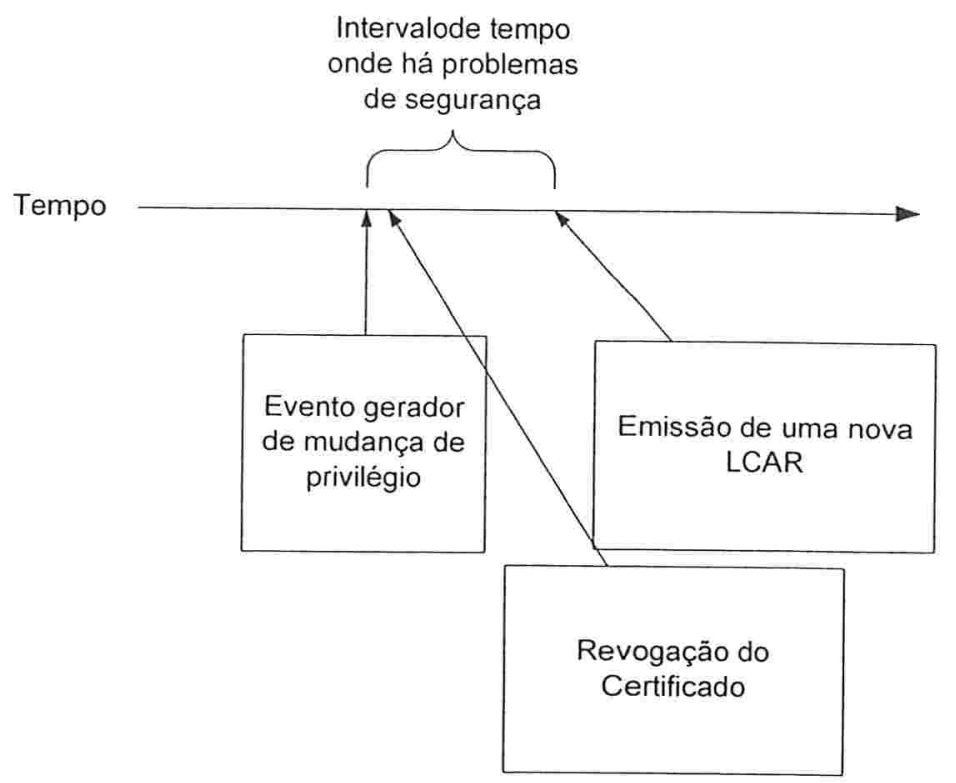

Figura 6-3 - Revogação de um Certificado de Atributo no modelo tradicional

No nosso modelo, o intervalo de tempo crítico seria praticamente eliminado, uma vez que, ao invés de revogar o Certificado de Atributos e emitir uma nova Lista de Certificados de Atributos Revogados, bastaria que a Autoridade de Atributos alterasse o arquivo de atributos, retirando todos os privilégios do funcionário demitido. A figura 6-4 a seguir ilustra essa situação.

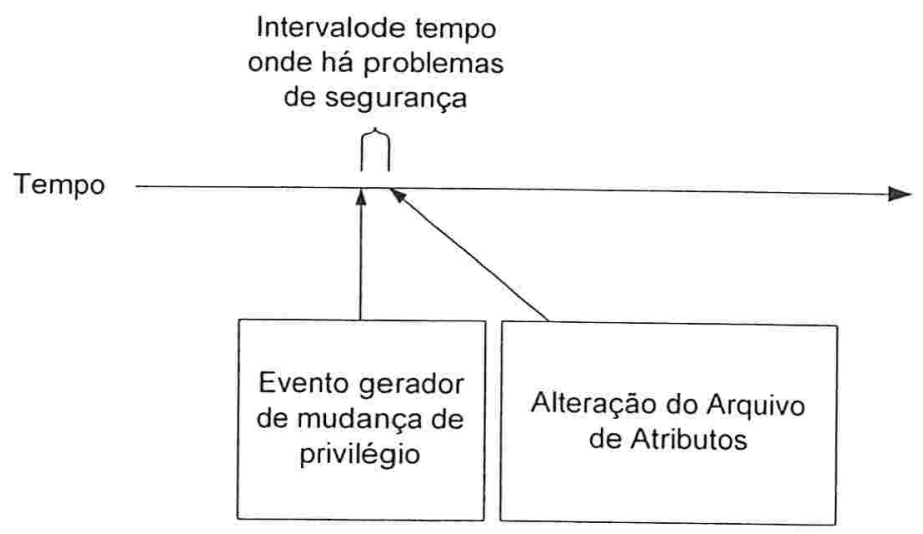

Figura 6-4 - Revogação de um Certificado de Atributo no modelo proposto

Podemos notar claramente, nas duas figuras anteriores, que o processo de revogação é simplificado e agilizado, diminuindo-se, inclusive, a quantidade de ações a serem realizadas. Além disso, as tarefas administrativas de gerar, manter e distribuir Listas de Certificados de Atributos Revogados são eliminadas no modelo aqui proposto. Em nosso modelo, adicionamos mais uma tarefa administrativa, a de manter o arquivo de atributos, porém as vantagens em sua utilização sobrepujam as desvantagens. 
Para mantermos a integridade do arquivo de atributos, a Autoridade de Atributos que gerou o certificado de atributos deverá assinar esse arquivo de atributos. Assim, quando o verificador de privilégios for buscar os atributos, ele deverá antes se certificar de que o arquivo é autêntico por meio da verificação da assinatura da Autoridade de Atributos que emitiu o certificado de atributos. Se houver necessidade de alteração ou revogação de atributos, a Autoridade de Atributos deverá editar o arquivo de atributos e assinar a nova versão. Esse procedimento garante que somente a Autoridade de Atributos poderá alterar o arquivo de atributos.

Todas as outras tarefas administrativas permanecem inalteradas nos dois modelos de infra-estrutura de gerenciamento de privilégios.

\subsection{Aplicabilidade do modelo proposto}

A infra-estrutura de gerenciamento de privilégios, tanto a tradicional definida em [FAR 02], quanto o modelo proposto, atende a todo tipo de empresa, seja qual for o modelo gerencial e organizacional por ela adotado. Nesta seção, abordaremos algumas situações de uso da infra-estrutura de gerenciamento de privilégios.

\subsubsection{Empresas hierarquicamente organizadas}

As empresas hierarquicamente organizadas, como a FHG Consultoria utilizada como modelo neste trabalho, podem perfeitamente implementar uma infra-estrutura de gerenciamento de privilégios, seguindo o modelo geral, com delegação ou com papéis. Para essas empresas, contextualizamos a aplicação dos conceitos e modelos de Infraestrutura de gerenciamento de privilégios nas seções 5.2.1, 5.2.3 e 5.2.4 anteriores.

\subsubsection{Novas formas organizacionais}

Com o aperfeiçoamento da tecnologia e com a globalização dos mercados, as empresas sentiram-se forçadas a rever suas formas organizacionais. Surgiu, então, o conceito de redes estratégicas, que são uma forma alternativa de se organizar a produção de bens e serviços, permitindo uma maior competitividade para as empresas. Nesse modelo, várias empresas unem-se e formam uma rede estratégica, na qual cada empresa tem domínio e realiza uma ou poucas etapas da cadeia de valor (suprimentos, logística, P\&D, produção e marketing). Essa passa a ser uma solução interessante para pequenas 
e médias empresas em um mercado globalizado, pois, através das redes estratégicas formadas, passam a competir em condição de igualdade com as grandes empresas.

\subsubsection{Empresas virtuais}

Uma maneira de colocar em prática as redes estratégicas é por meio de empresas virtuais. Empresas virtuais são formas de cooperação entre empresas que utilizam novas tecnologias de comunicação, como a Internet, para aumentar a competitividade dos participantes e também para abrir novos nichos de mercado. O grande diferencial desse tipo de organização é a grande agilidade e velocidade que os negócios e transações inter-empresariais conseguem, graças às novas e revolucionárias tecnologias de comunicação de dados.

Segundo Prahalad e Hamel [PRA 95], as empresas virtuais podem ser vistas de duas formas: uma funcional e outra institucional. Do ponto de vista institucional, a empresa virtual consegue reunir as melhores competências de várias empresas legalmente independentes, mas que cooperam entre si, conectadas por de tecnologias de transmissão de dados, e que, dessa forma, rompem limites físicos.

Do ponto de vista funcional, as empresas virtuais podem ser vistas como uma concentração de competências essenciais que são coordenadas dinamicamente e orientadas para a solução de problemas, utilizando como ferramenta a Tecnologia da Informação.

Em empresas virtuais, a Infra-estrutura de gerenciamento de privilégios também é perfeitamente implementável. Mais do que isso, nesse tipo de organização, muitas vezes os privilégios de um usuário mudam de um parceiro para outro na empresa virtual. Nesses casos, a identidade é sempre a mesma e a utilização de certificados de atributos específicos para cada caso torna-se essencial.

Nesse tipo de organização, existe a figura da empresa-centro ou empresa-mãe, em torno da qual se constrói toda a rede. A figura 6-5 a seguir ilustra essa situação. 


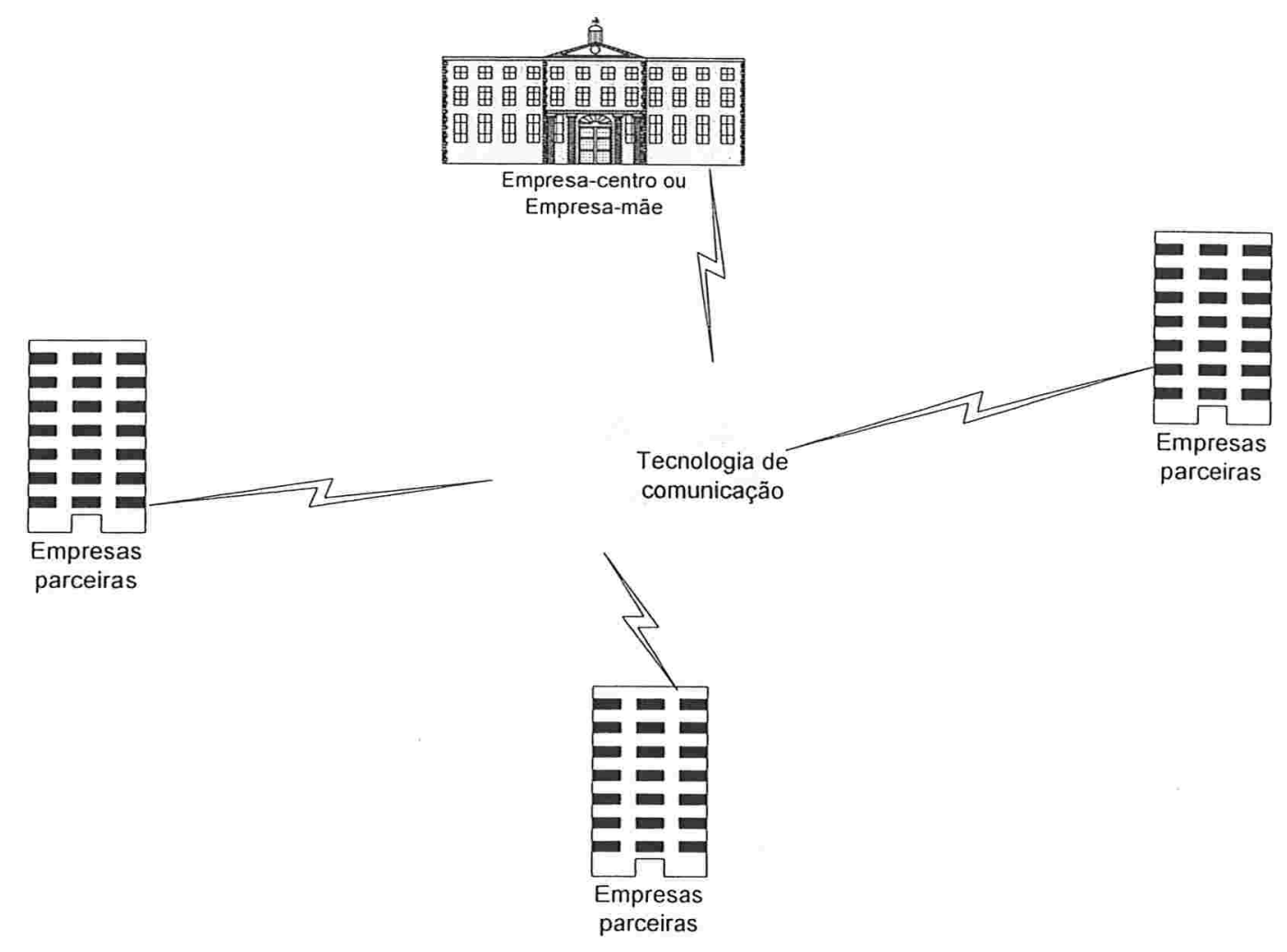

Figura 6-5-Empresa virtual

Assim, a empresa-centro pode trabalhar como a SOA, atribuindo os privilégios necessários para cada uma das empresas parceiras que forma a empresa virtual. Além disso, a SOA também pode autorizar que as empresas parceiras passem a emitir certificados de atributos internamente, como prevê o modelo de PMI com delegação (seção 5.2.3). Com isso, a responsabilidade de definir que privilégios são necessários para cada um dos colaboradores (as entidades finais) das empresas parceiras fica a cargo da própria empresa parceira, que pode, inclusive, criar novas Autoridades de Atributos internamente. Como podemos notar, tanto o modelo tradicional de PMI [FAR 02] quanto o modelo proposto neste trabalho podem ser implementados em empresas virtuais. A figura 6-6 a seguir associa o modelo de empresas virtuais mostrado na figura 65 com o modelo de PMI com delegação, visto na seção 5.2.3. 


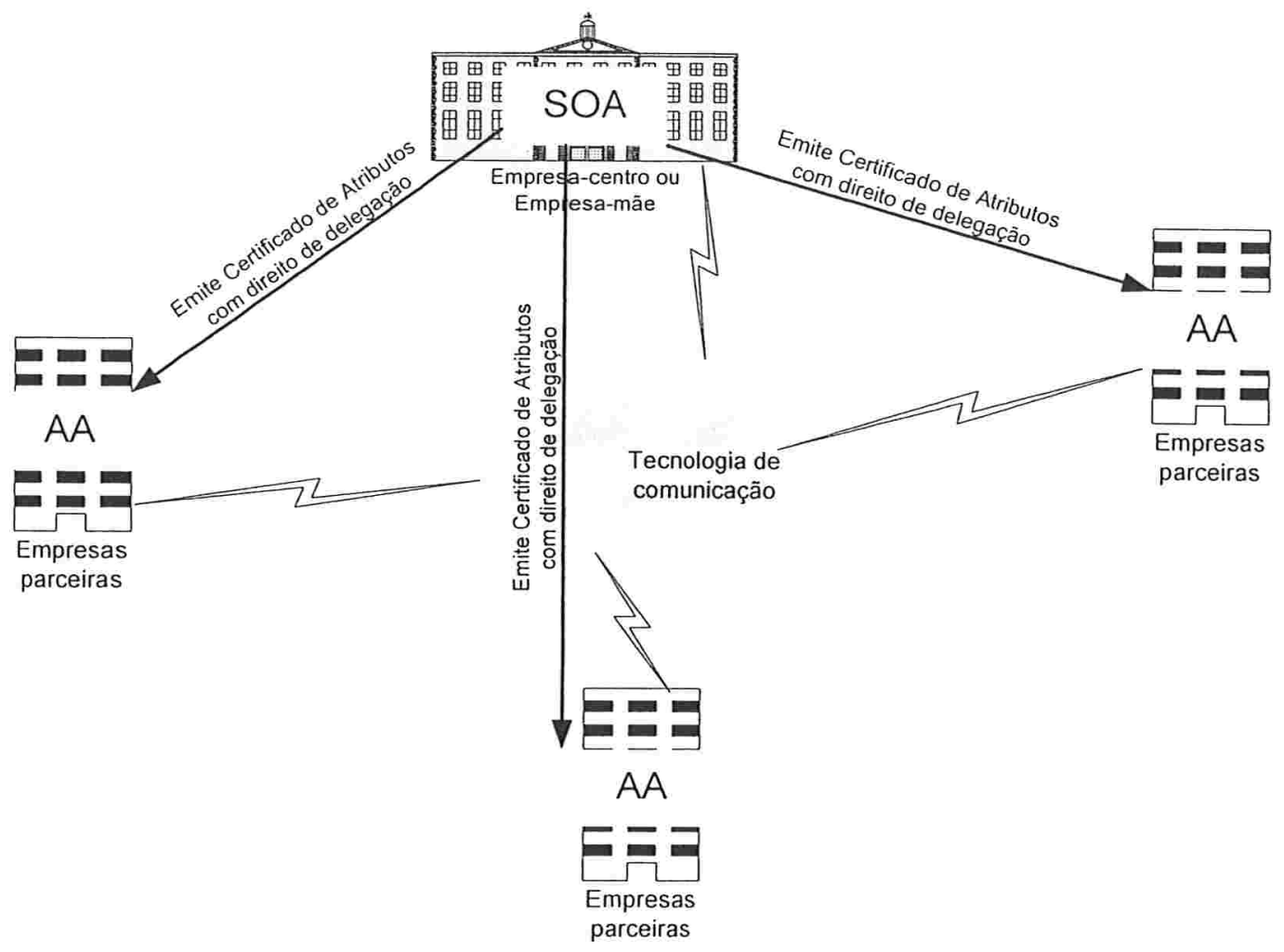

Figura 6-6 - A adequação da PMI às empresas virtuais

Nesse modelo, caso seja necessária a alteração ou revogação de privilégios de entidades finais, cabe à Autoridade de Atributos que emitiu o Certificado adotar os procedimentos necessários, de acordo com a explicação da seção 5.6. Caso o modelo implementado seja o modelo de certificados de atributos dinâmicos proposto neste trabalho, a mesma Autoridade de Atributos tem a responsabilidade de alterar o arquivo de atributos, de acordo com o descrito na seção 6.2.

\subsubsection{Gestão de projetos distribuídos}

Uma outra situação na qual o uso de uma infra-estrutura de gerenciamento de privilégios pode ser de grande valia é a gestão de projetos distribuídos, ou seja, projetos que envolvem recursos distribuidos geograficamente, muito comuns em empresas multinacionais. Segundo o especialista no assunto, o professor Roberto Evaristo, da Universidade de Illinois [ITW 03], são necessários sistemas flexiveis e poderosos para facilitar o acesso às informações na gestão de projetos distribuídos. A figura 6-7 a seguir ilustra a situação impar de um projeto distribuído: 


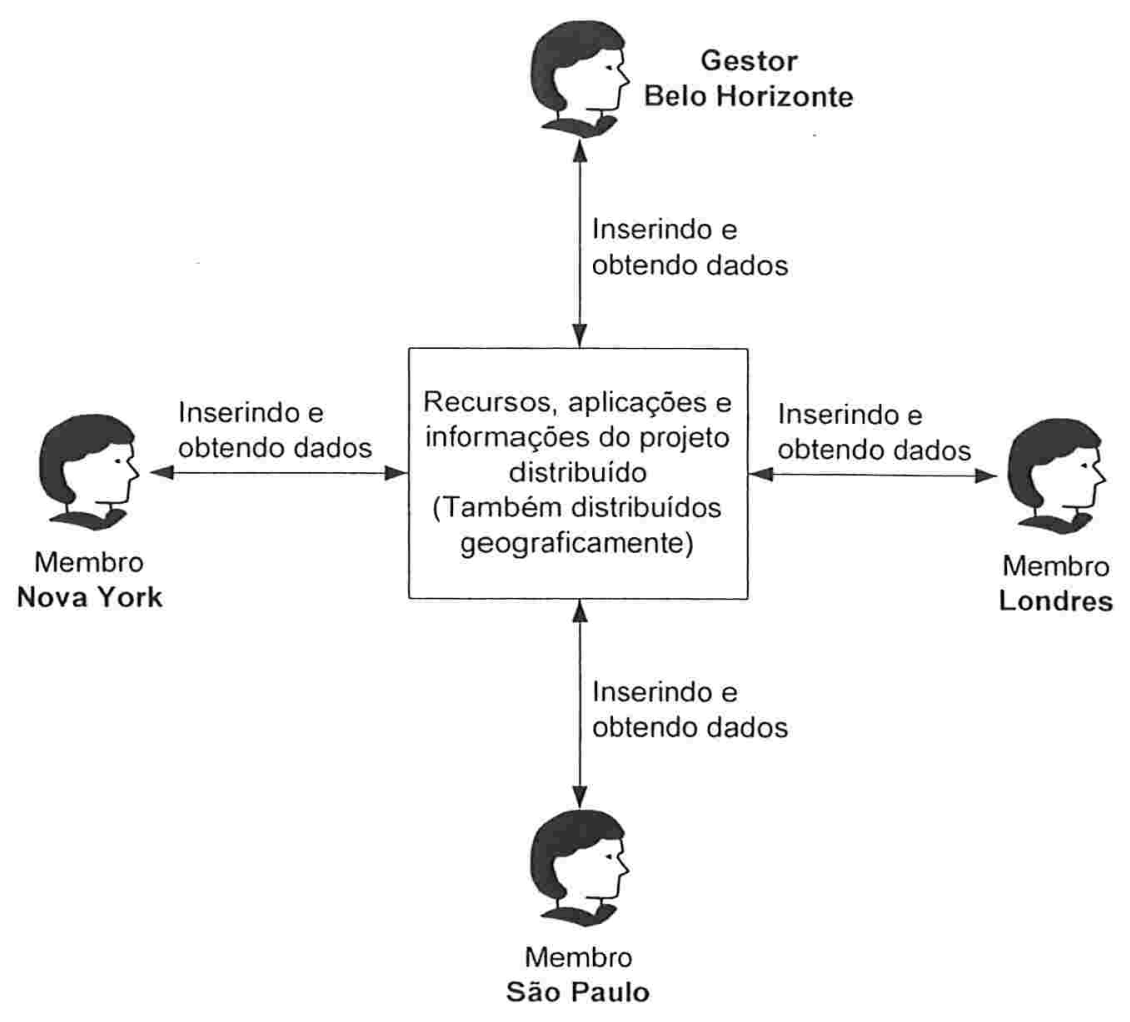

Figura 6-7 - A gestão de projetos distribuídos

A gestão de projetos distribuídos envolve a criação de equipes virtuais, muitas vezes distantes geograficamente, cuja administração é uma tarefa complexa. Nesse contexto, a gestão do conhecimento é fundamental para o sucesso dos projetos distribuidos [ITW 03]. Os integrantes das equipes virtuais têm de ter o devido acesso à informação que está sendo trabalhada pelo grupo, independentemente da distância geográfica ou localização dessas informações. Assim, um sistema de autorização eficiente facilita as atividades do gestor do projeto distribuído. Com a utilização da infraestrutura de gerenciamento de privilégios aqui proposta, o gestor do projeto distribuído pode executar a função de Autoridade de Atributos. Dessa forma, o próprio gestor pode emitir os certificados de atributos para sua equipe virtual, concedendo todos os privilégios necessários para que cada membro da equipe execute suas funções. Além disso, quando houver necessidade de alteração ou revogação dos privilégios, o próprio gestor do projeto poderá simplesmente alterar o arquivo de atributos, sem a necessidade de revogação e emissão de um novo certificado de atributos.

Assim, no modelo de infra-estrutura de gerenciamento de privilégios proposto neste trabalho, o gestor de um projeto distribuído teria as seguintes funções básicas: 
- Atuar com uma Autoridade de Atributos, emitindo os certificados de atributos para os membros de sua equipe, ajustando a validade do mesmo de acordo com o cronograma de execução do projeto;

- Administrar o arquivo de atributos, fazendo as alterações necessárias quando houver alguma alteração ou revogação de privilégios ou mesmo quando o projeto for finalizado antes do prazo de validade do certificado de atributos.

A outra preocupação que a empresa que atua com projetos distribuídos deve ter é a de integrar os aplicativos e recursos à infra-estrutura de gerenciamento de privilégios. Essa integração seria a criação de um módulo de verificação de privilégios integrado a suas aplicações e recursos, trabalhando como um verificador de privilégios. Fazendo uma analogia com o modelo geral de uma PMI (seção 5.2.1), o gestor do projeto seria a SOA (única Autoridade de Atributos), os membros do projeto seriam as entidades finais trabalhando com declaradores de privilégios junto aos recursos (aplicações e informações) compartilhados por toda a equipe, que seriam protegidos por um verificador de privilégios. A figura 6-8 a seguir mostra essa analogia:

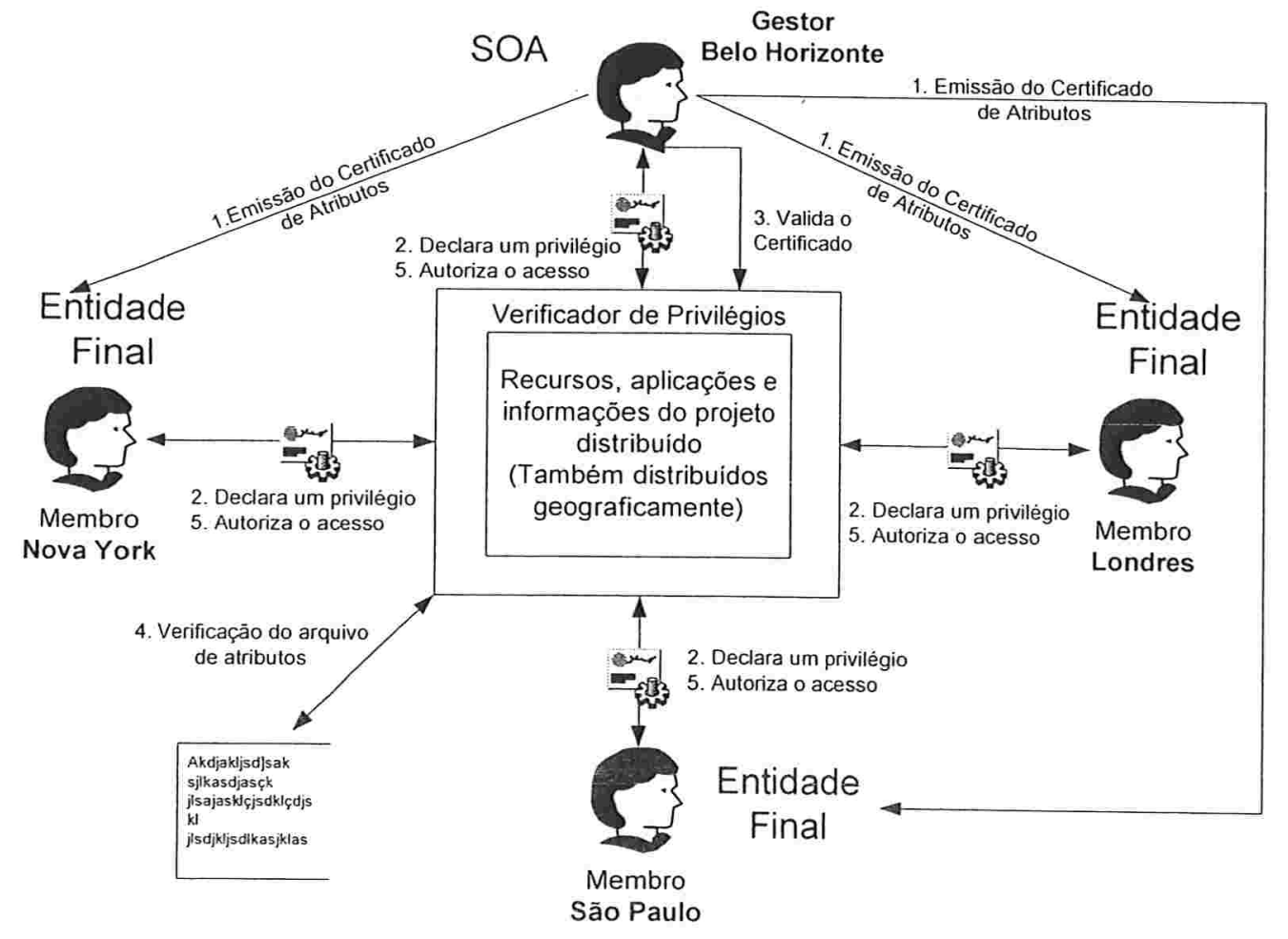

Figura 6-8 - A gestão de projetos distribuídos e a infra-estrutura de gerenciamento de privilégios

A figura 6-8 acima descreve o fluxo de funcionamento do modelo de infraestrutura de gerenciamento de privilégios da seguinte forma: 
1) O gestor do projeto, atuando com Source of Authority (SOA), emitiria os certificados de atributos para todos os membros de sua equipe, as entidades finais, adequando a validade do certificado de acordo com o cronograma do projeto;

2) Os membros da equipe, de posse de seus certificados de atributos, poderiam apresentá-lo ao verificador de privilégios que estaria integrado aos recursos (objetos) protegidos;

3) O verificador de privilégios faria a validação do certificado de atributos de acordo com o descrito na seção 6.1;

4) Se o certificado é válido, o verificador de privilégios então verificaria o arquivo de atributos e decidiria se os atributos são suficientes para a solicitação feita pela entidade final;

5) Finalmente, o verificador de privilégios concederia o acesso solicitado aos recursos protegidos, permitindo assim que a equipe insira e obtenha as informações necessárias para o desenvolvimento do projeto.

Desta forma estaríamos garantindo o acesso às informações de uma maneira flexivel e segura, atendendo às recomendações do professor Roberto Evaristo [ITW 03]. 


\section{CAPÍTULO 7: O PROTÓTIPO}

Como produto do trabalho aqui apresentado, construímos um protótipo do modelo de infra-estrutura de gerenciamento de privilégios aqui proposto. O protótipo foi implementado na linguagem Java e utilizamos algumas bibliotecas existentes que serão descritas na seção 7-1 seguinte.

Em nosso protótipo, implementamos dois módulos distintos: o de atribuição de privilégios e o de verificação de privilégios. A figura 7-1 a seguir mostra a interação entre esses dois módulos.

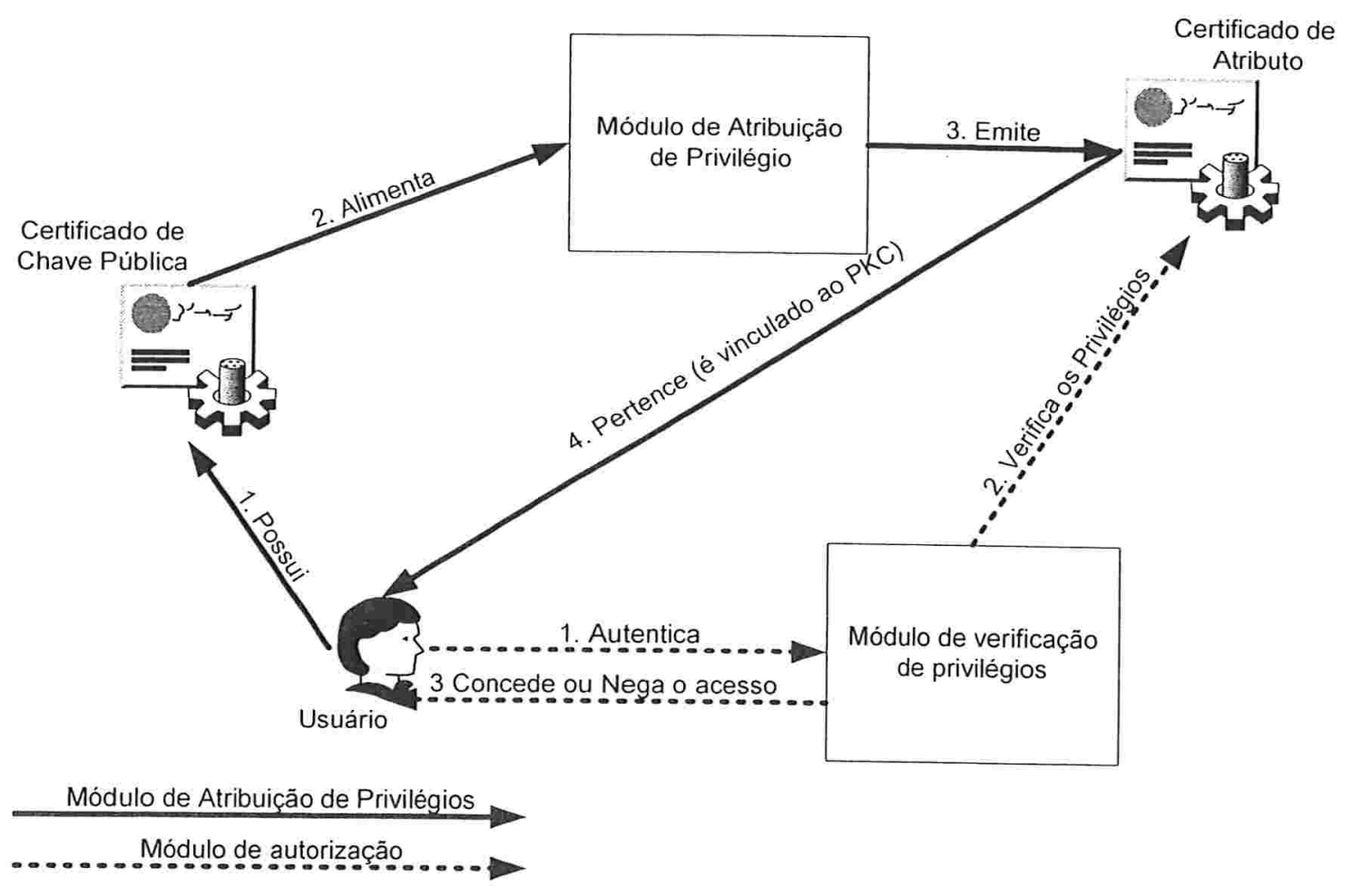

Figura 7-1 - Os módulos do protótipo implementado

Como podemos notar na figura 7-1, o módulo de atribuição de privilégios é o módulo que gerará o Certificado de Atributos dos usuários. A Autoridade de Atributos é quem utilizará o módulo de atribuição de privilégios. No nosso protótipo, o certificado de atributos e o arquivo de atributos são armazenados em uma pasta específica do sistema 
de arquivos da máquina. Para simplificar o modelo, não utilizamos nenhum recurso de diretório, como LDAP.

O módulo de verificação de privilégios é o módulo que será utilizado pelo verificador de privilégios, quando um usuário desejar acessar um recurso protegido. No nosso protótipo, esse módulo é integrado ao sistema protegido: o sistema de contabilidade. Nesse protótipo, o módulo de verificação de privilégios não é universal, ou seja, ele não se integra a qualquer sistema. Consideramos que a criação de uma interface universal para os sistemas protegidos que suporte a verificação de privilégios através de certificados de atributos é um trabalho futuro.

O protótipo implementa o modelo geral de uma infra-estrutura de gerenciamento de privilégios, abordado na seção 5.2.1. Nesse modelo, existem apenas o objeto ou recurso protegido, a SOA, o declarador de privilégio e o verificador de privilégio, como mostra a figura 7-2 a seguir.

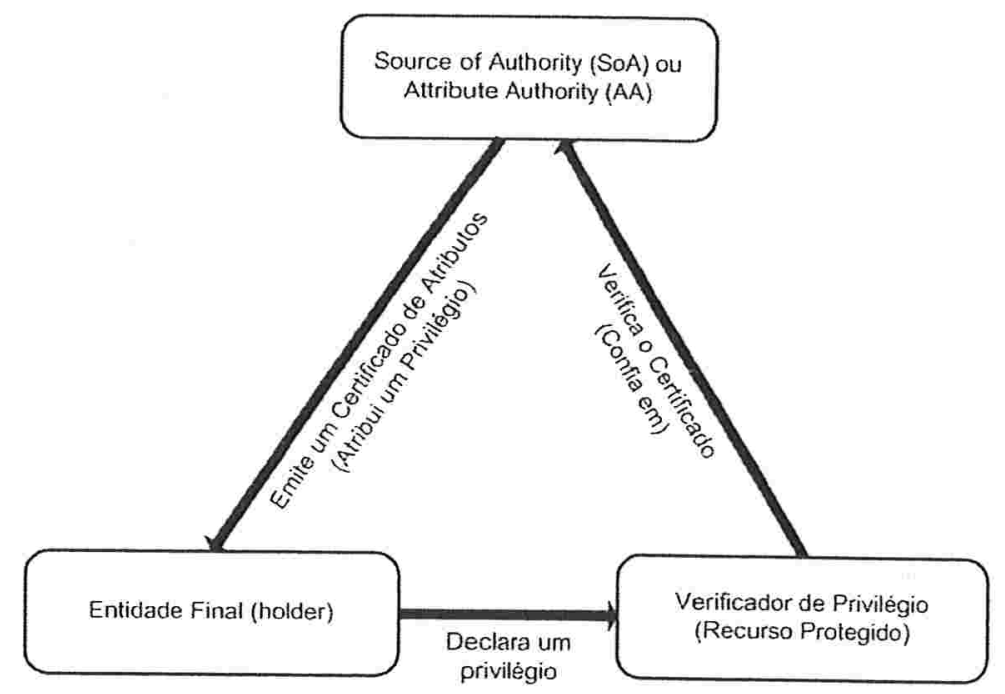

Figura 7-2 - Modelo geral de uma PMI

Nesse modelo, a SOA emite todos os certificados de atributos para todas as entidades finais. Assim, a Autoridade de Atributos é somente a SOA. O usuário seria o declarador de privilégios e o módulo de verificação de privilégios está integrado ao objeto. A figura 7-3 a seguir mostra essa situação: 


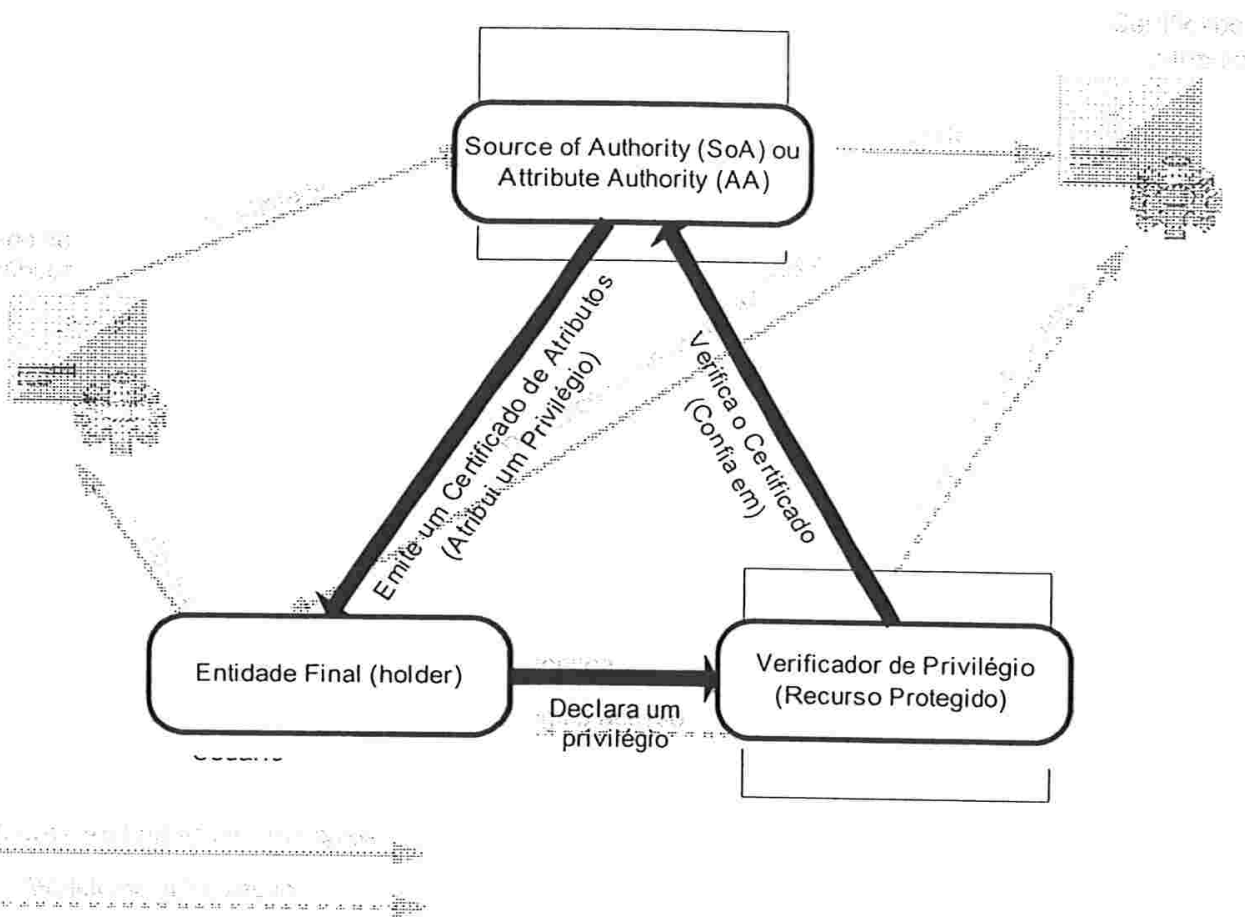

Figura 7-3 - O protótipo e o modelo geral de uma PMI

\subsection{Caracterização do cenário}

O protótipo aqui desenvolvido é adequado a empresas hierarquicamente organizadas que implementam o modelo geral de PMI. Todo o protótipo foi desenvolvido para atender a empresa FHG Consult, utilizadas como exemplo em várias situações neste trabalho. Portanto, o cenário para o qual o protótipo é adequado deve apresentar as seguintes características:

- Implementação em empresas hierarquicamente organizadas;

- Adoção do Modelo Geral de PMI (seção 5.2.1);

- Autorização o acesso ao sistema de contabilidade (recurso protegido);

- Integração do módulo de verificação de privilégios ao sistema de contabilidade;

- Utilização de certificados de atributos e arquivo de atributos, de acordo com o modelo proposto no capítulo 6 deste trabalho;

- Definição na política de segurança de que somente os funcionários do departamento de contabilidade, diretor administrativo e presidente têm acesso ao sistema de contabilidade. 
Além disso, como o objetivo é meramente de aplicação do modelo proposto, o módulo de atribuição de privilégio, o módulo de verificação de privilégio, o sistema protegido, os certificados de chave pública, os certificados de atributos e os arquivos de atributos devem estar na mesma máquina. Outra característica do protótipo é que o método de apresentação do certificado de atributos é o método pull, explicado na seção 5.1.

\subsection{Classes e componentes utilizados no protótipo}

O protótipo foi desenvolvido em Java e uma das principais características dessa linguagem é a possibilidade de utilização de classes já existentes. Assim, empregamos algumas classes já desenvolvidas que nos forneceram algumas funções necessárias para a implementação do protótipo.

A principal classe utilizada no desenvolvimento do protótipo foi a classe IAIK JCE (Java Cryptography Extension) desenvolvida pelo Institute for Applied Information Processing and Communication (IAIK, http://jce.iaik.tugraz.at/) da Technical University Graz (http://www.tugraz.at/).

A classe IAIK JCE é um conjunto de API (Application Program Interface) e implementações de funções de criptografia, incluindo funções hash, resumo criptográfico ou MAC (message authentication code) [TER 00], criptografia simétrica e assimétrica, criptografia de bloco (CBC - Cipher Block Chaining Mode; ECB - Electronic Code Book Mode; CFB - s-bit Cipher Feedback Mode e OFB - s-bit Output Feedback Mode) [TER 00]. Além dessas diversas funções criptográficas, a classe IAIK JCE também disponibiliza funções para gerenciamento de chaves criptográficas e certificados X.509.

A classe IAIK JCE complementa algumas funcionalidades fornecidas pelo pacote padrão JDK (Java Development Kit). As suas principais características são:

- Re-implementação do pacote JCE (Java Cryptography Extension) da Sun;

- Suporte nativo à notação de sintaxe abstrata um (ASN.1);

- Suporte a diversos padrões de certificados de chave pública;

- Soluções para gerenciamento de certificados X.509 e Listas de Certificados Revogados (LCR);

A classe IAIK JCE é distribuída gratuitamente para projetos de pesquisa, de acordo com a licença disponivel em http://jcewww.iaik.at/sales/licences. Porém, a licença 
educacional não permite a distribuição do pacote IAIK JCE, sem a compra da licença comercial. Para projetos de software livre, o pacote IAIK JCE oferece uma licença especial que garante a redistribuição do pacote IAIK JCE na forma binária, em combinação com a aplicação. Exatamente por isso, o protótipo desenvolvido tem apenas o objetivo de implementar o modelo proposto neste trabalho e, em nenhum momento, tem caráter comercial ou mesmo de livre distribuição.

Utilizamos também alguns subpacotes da classe Java.security, um pacote de segurança padrão da linguagem Java. Dentre os subpacotes utilizados, temos a classe Java.security.key, uma classe que trabalha com a geração e operação de chaves criptográficas. A classe Java.security.cert representa qualquer tipo de certificado de criptografia, como os certificados X.509 muito utilizados neste trabalho. E, finalmente, a classe Java.security.spec fornece algumas especificações necessárias para a geração de chaves.

Por último, como o modelo prevê a integração com certificados de chave pública, era necessário que o módulo de atribuição de privilégios interagisse com um repositório ou diretório de certificados. O keytool é uma ferramenta para gerenciamento de chaves fornecida em conjunto com o Java 1.2. Segundo Oaks [OAK 99], a ferramenta keytool permite o gerenciamento de chaves, certificados e identidades, de uma maneira prática e segura. Dessa forma, utilizamos a ferramenta keytool para gerar os certificados de chave pública de alguns usuários. Além disso, o módulo de atribuição de privilégios busca os dados dos certificados de chave pública armazenados no banco de dados keytool.

\subsection{Módulo de atribuição de privilégios}

O módulo de atribuição de privilégios é o módulo que a Autoridade de Atributos utilizará para gerar os certificados de atributos para os usuários, suas entidades finais. A figura 7-4 a seguir mostra a tela do módulo de atribuição de privilégios: 


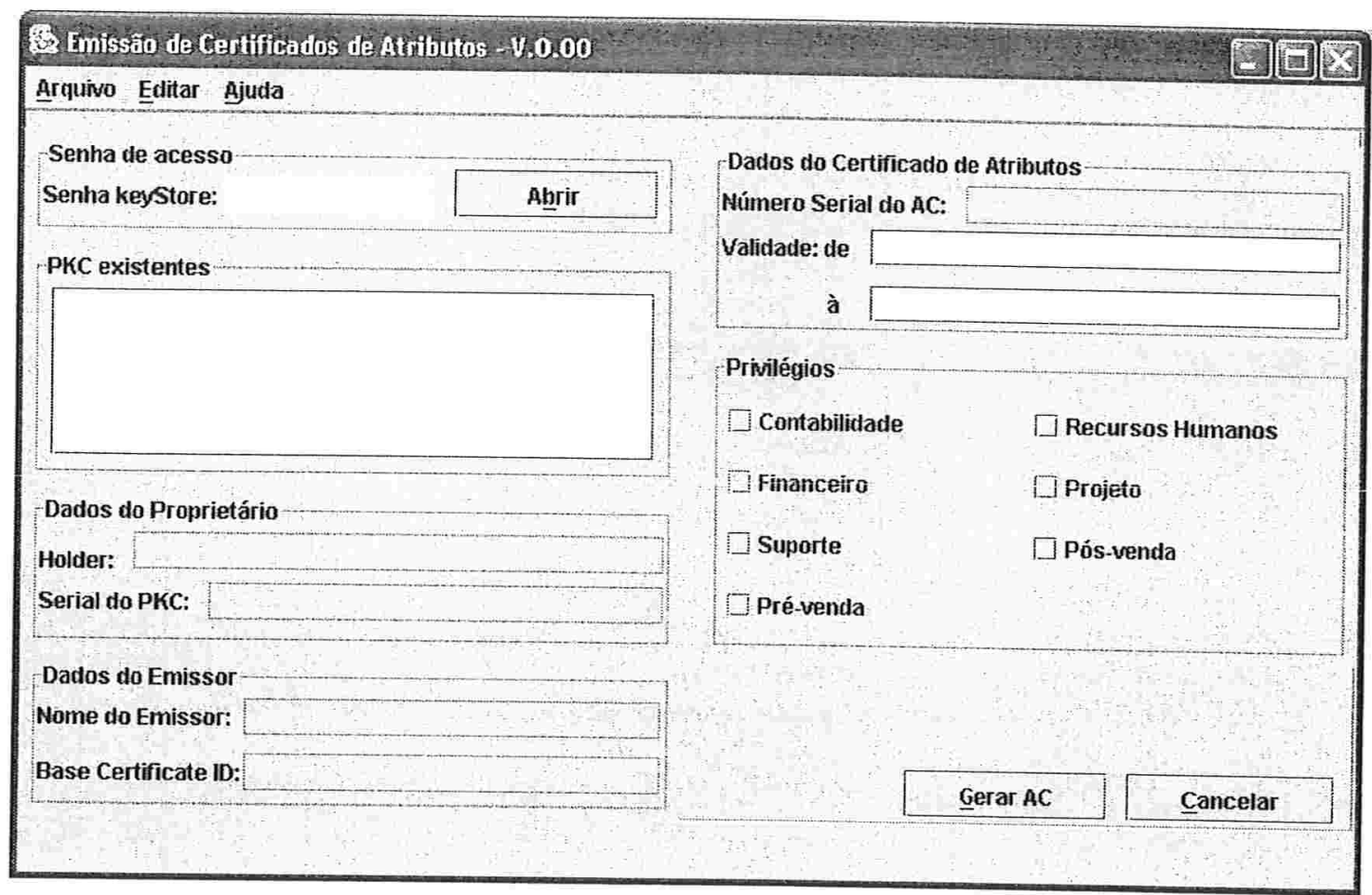

Figura 7-4 - O módulos de atribuição de privilégio

O módulo de atribuição de privilégios funciona de forma integrada com a ferramenta keytool. A ferramenta keytool, como já abordado na seção anterior, é um conjunto de funções para administração de chaves, identidades e certificados de chave pública, e é distribuída em conjunto com o Java 1.2. Todas as chaves e certificados de chave pública necessários devem existir antes de a Autoridade de Atributos utilizar o módulo de atribuição de privilégios.

O módulo de atribuição de privilégio tem uma interface bem intuitiva e é de fácil operação. A primeira tarefa para a geração de Certificados de Atributos, função do módulo de atribuição de privilégios, é fornecer a senha de acesso ao banco de dados keytool. Após fornecermos a senha, o aplicativo busca todas as informações de todos os certificados de chave pública existentes nesse banco de dados. A figura 7-5 a seguir mostra essa situação. 
Neste momento, devemos ajustar o período de validade do certificado de atributos de acordo com as necessidades e políticas da Autoridade de Atributos e selecionar quais privilégios (atributos) esse usuário terá, de acordo com a figura 7-7.

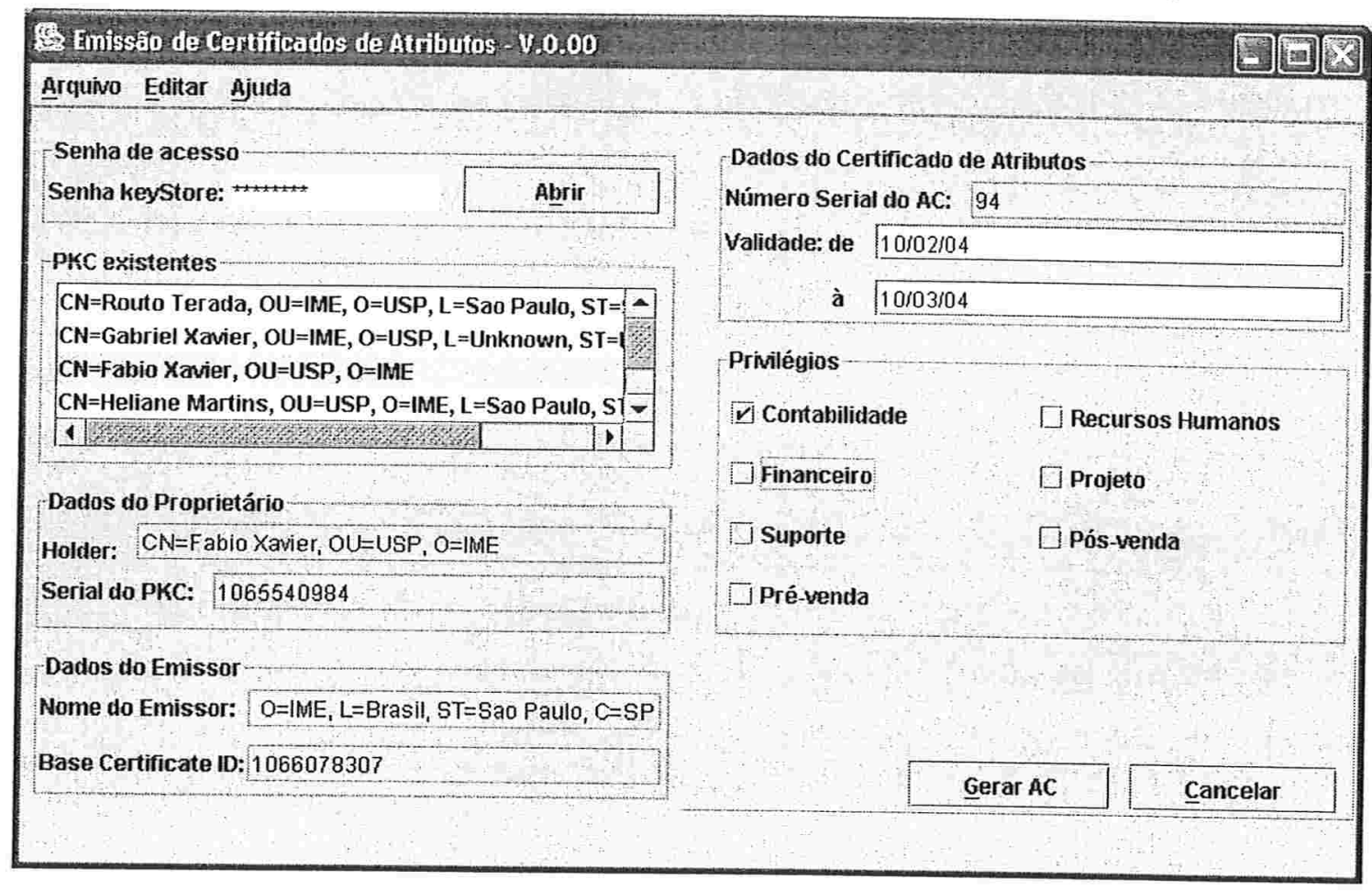

Figura 7-7 - Definindo a validade e os privilégios

Finalmente, basta agora clicar no botão "Gerar AC" para que o certificado de atributos seja criado e salvo no disco no padrão de codificação DER. No nosso protótipo, para fins de demonstração da validade da proposta apresentada neste trabalho, o arquivo com o certificado de atributos é salvo no diretório c:Itemp da máquina em que o módulo de atribuição de privilégios está instalado. A figura 7-8 a seguir mostra a geração com sucesso de um certificado de atributos. 


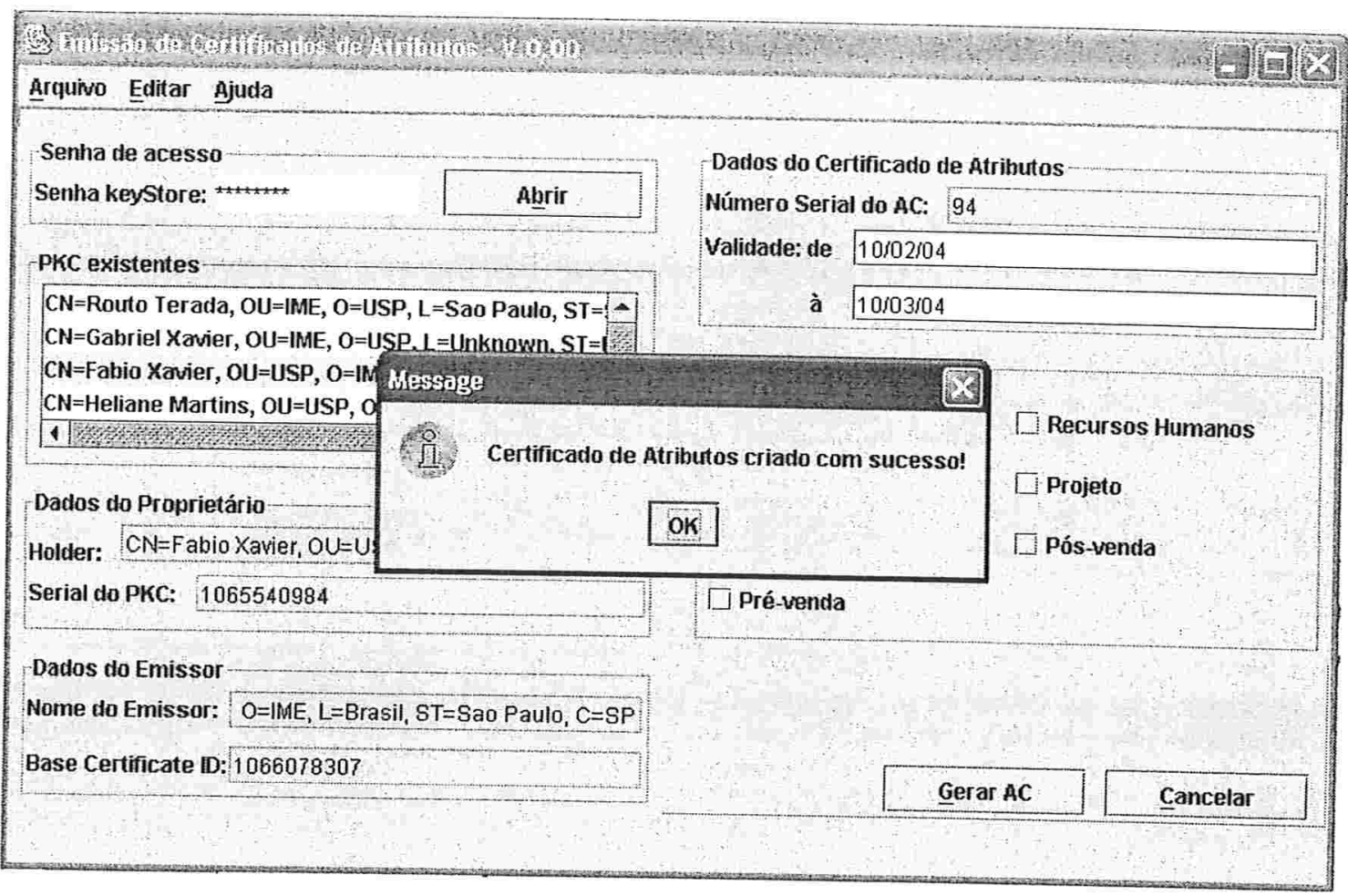

Figura 7-8 - Geração do certificado de atributos

O aplicativo acima gera todas as informações necessárias para a criação de um certificado de atributos, como mostrado pela figura 7-9 a seguir.

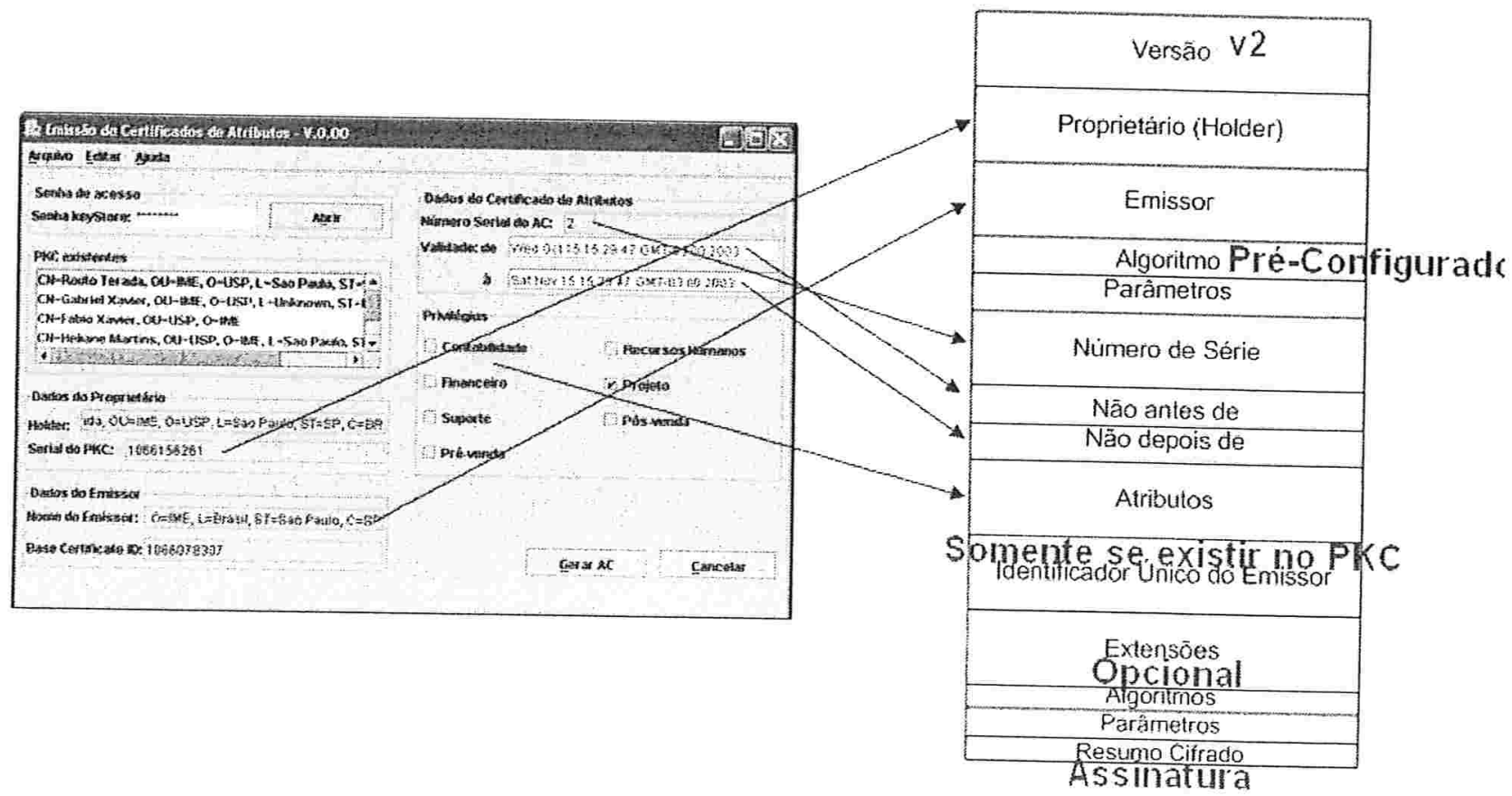

Figura 7-9 - Comparação entre o módulo de atribuição de privilégios e o certificado de atributos 


\subsection{Módulo de verificação de privilégios}

O módulo de verificação de privilégios é o módulo que o verificador de privilégio usa para decidir se os privilégios especificados no arquivo de atributos associado ao Certificado de Atributos são suficientes para o acesso desejado. Em nosso protótipo, embutimos esse módulo na aplicação a ser protegida pela Infra-estrutura de Gerenciamento de Privilégios, no caso, a aplicação do Departamento de Contabilidade da FHG Consult Ltda.

Como já discutimos neste trabalho, a primeira ação que um sistema protegido deve adotar é autenticar o usuário, por meio de qualquer técnica. Em nosso protótipo, como o foco não é a autenticação, fizemos a autenticação por usuário e senha. O usuário a ser utilizado é o nome do arquivo que contém o Certificado de Atributos criado pelo módulo de atribuição de atributos, um arquivo com a extensão DER. Com isso, a primeira tela do módulo de verificação de privilégios é a tela de login mostrada na figura 7.10 a seguir.

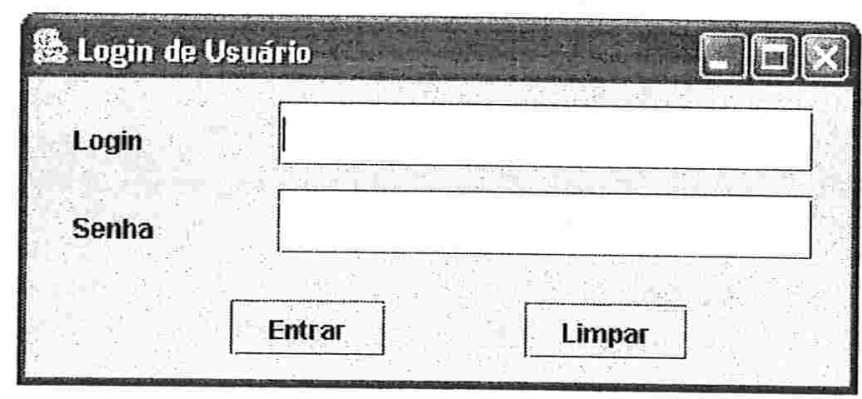

Figura 7-10 - Tela de login do módulo de verificação de privilégios

Após o usuário ser autenticado, o sistema de contabilidade chamará o módulo de verificação de privilégios, que, na verdade, é um método dentro do sistema. Esse método é chamado de autoriza() e o código-fonte é mostrado no Anexo A-2.

O módulo de verificação de privilégios (método autoriza()) de nosso protótipo executa as seguintes ações:

- Localizar e carregar para a memória o Certificado de Atributos do usuário que já foi autenticado;

- Verificar a validade do Certificado de Atributos, negando o acesso caso esse esteja expirado ou o período de validade ainda não tenha se iniciado;

- Localizar e carregar para a memória o arquivo de atributos indicado no campo Atributos do Certificado de Atributos; 
- Verificar se os atributos listados no arquivo de atributos são suficientes para o acesso ao sistema de contabilidade da FHG Consultoria Ltda.

Considerando que todos os passos anteriores foram validados com sucesso, o usuário terá acesso ao sistema de contabilidade, cuja tela é mostrada na figura 7.11 a seguir.

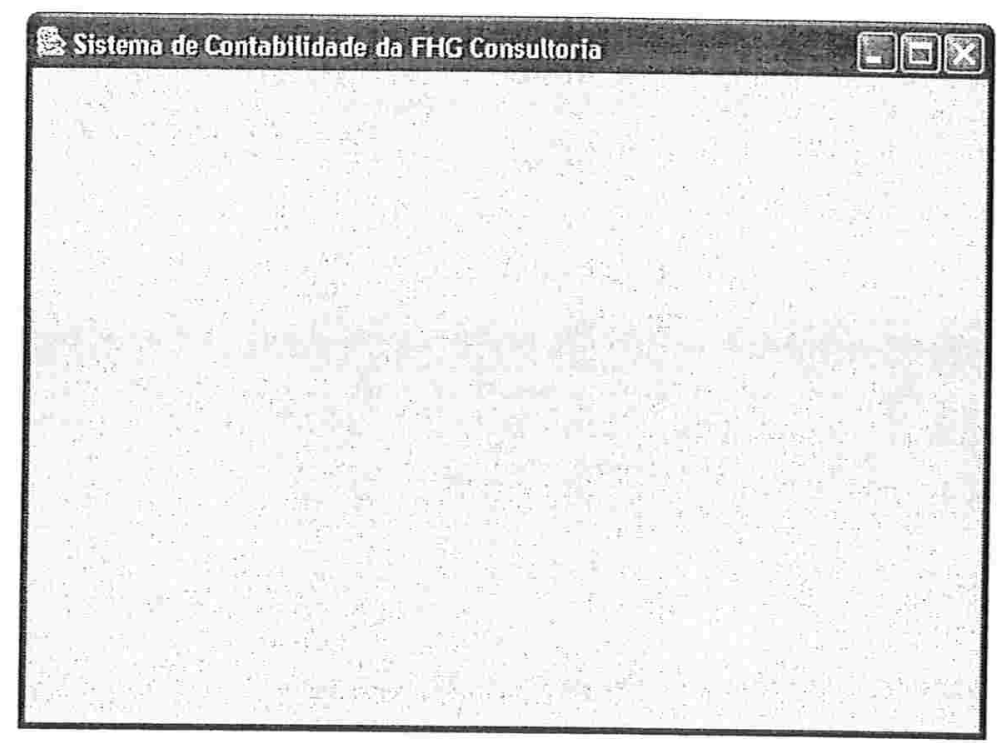

Figura 7-10 - Tela de login do módulo de verificação de privilégios

Em nosso protótipo, o sistema de contabilidade não executa nenhuma ação. O propósito é mostrar a funcionalidade do modelo de PMI proposto no trabalho.

\subsection{Testes de validação do protótipo}

A fase de teste de um software requer mudança de ponto de vista por parte dos desenvolvedores. Enquanto na fase de desenvolvimento o objetivo é construir, na fase de teste a intenção é "demolir" o sistema que foi construído [PRE 94]. Essa demolição tem o objetivo de descobrir todos os possíveis erros de implementação, garantindo, assim, que o software atende as premissas propostas.

O nosso protótipo é dividido em dois módulos, cada um com seus objetivos especificos:

- Modulo de Atribuição de Privilégios: tem o objetivo de gerar o Certificado de Atributos das entidades finais, coletando dados dos Certificados de Chave Pública e dados fornecidos em sua interface pela Autoridade de Atributos;

- Módulo de Verificação de Privilégios: tem o objetivo de validar o Certificado de Atributos da entidade final que deseja obter acesso à aplicação protegida. 
Para isso, o módulo de Verificação de Privilégios deve executar as tarefas descritas na seção 7.4 .

No seu livro sobre teste de software [MYE 79], Glen Myers listou algumas regras para a fase de testes:

- O teste é um processo de execução de programa com a intenção de encontrar um erro;

- Um bom caso de teste é aquele em que há alta probabilidade de encontrarmos um erro ainda não descoberto;

- Um teste bem sucedido é aquele que descobre erros não encontrados.

Segundo Roger S. Pressman, um produto de engenharia, como um software, pode ser testado ou pelo teste de Caixa Branca ou pelo teste de Caixa Preta [PRE 94]. No teste de Caixa Branca, conhecendo-se o funcionamento interno de um produto, os testes são conduzidos de forma a se verificar se a operação interna está de acordo com as especificações e se todos os componentes internos foram adequadamente testados.

No teste de Caixa Preta, conhecendo-se as funções específicas que um software deve ter, os testes são conduzidos de forma a demonstrar que cada função está perfeitamente funcional, ou seja, que a entrada é corretamente aceita e a saída é aquela esperada.

Para validar o protótipo desenvolvido neste trabalho, aplicaremos o teste de Caixa Preta. Como vimos, o teste de Caixa Preta está focado em verificar se o software atende os requisitos funcionais propostos.

Para o Módulo de Atribuição de Privilégios, os requisitos funcionais do nosso protótipo são os seguintes:

- Interagir com a ferramenta keytool, lendo e buscando Certificados de Chave Pública armazenados em seu serviço de diretórios;

- Gerar e gravar em disco o Certificado de Atributos para o proprietário do Certificado de Chave Pública selecionado;

- Gerar e gravar em disco o arquivo de atributos correspondente ao Certificado de Atributos gerado.

Para o Módulo de Verificação de Privilégios, os requisitos são:

- Buscar o Certificado de Atributos do usuário que deseja autorização;

- Ler o Certificado de Atributos; 
- Verificar o período de validade do Certificado de Atributos;

- Verificar a localização do arquivo de atributos;

- Ler o arquivo de atributos;

- Verificar se os atributos são suficientes para o acesso desejado, de acordo com a política descrita na seção 7.1 ;

Assim, tendo em vista os requisitos funcionais anteriormente listados, foram elaboradas as seguintes tabelas de testes:

Tabela 7-2 - Testes de Validação do Módulo de Atribuição de Privilégios

\begin{tabular}{|c|c|c|c|}
\hline \multicolumn{4}{|c|}{ Módulo de Atribuição de Privilégios } \\
\hline $\begin{array}{l}\text { Requisito } \\
\text { Funcional }\end{array}$ & Ação & Resultado Esperado & $\begin{array}{c}\text { Resultado } \\
\text { Obtido }\end{array}$ \\
\hline \multirow{4}{*}{$\begin{array}{l}1 \text { - Interagir com a } \\
\text { ferramenta keytool, } \\
\text { lendo e buscando } \\
\text { Certificados } \text { de } \\
\text { Chave Pública } \\
\text { armazenados em } \\
\text { seu serviço de } \\
\text { diretórios; }\end{array}$} & $\begin{array}{l}1.1 \text { - Digitar a senha } \\
\text { do banco de dados } \\
\text { do keytool e clicar } \\
\text { no botão "abrir". }\end{array}$ & $\begin{array}{l}\text { Preenchimento do campo PKC } \\
\text { existentes com alguns dados } \\
\text { de todos os Certificados de } \\
\text { Chave Pública armazenados } \\
\text { no banco de dados da Keytool. }\end{array}$ & Ok \\
\hline & $\begin{array}{l}1.2 \text { - Criar um novo } \\
\text { PKC com a } \\
\text { ferramenta Keytool }\end{array}$ & $\begin{array}{l}\text { Ao executar a ação 1.1, o novo } \\
\text { certificado criado aparecerá no } \\
\text { campo PKC existentes. }\end{array}$ & Ok \\
\hline & $\begin{array}{l}1.3-\text { Apagar um } \\
\text { PKC com a } \\
\text { ferramenta Keytool }\end{array}$ & $\begin{array}{l}\text { Ao executar a ação } 1.1 \text {, o PKC } \\
\text { apagado não irá mais aparecer } \\
\text { no campo PKC existentes. }\end{array}$ & Ok \\
\hline & $\begin{array}{l}\text { 1.4 - Digitar a senha } \\
\text { errada no campo } \\
\text { Senha KeyStore e } \\
\text { clicar no botão Abrir. }\end{array}$ & $\begin{array}{l}\text { Exibição de mensagem de erro } \\
\text { explicando que a senha está } \\
\text { incorreta. }\end{array}$ & Ok \\
\hline \multirow{3}{*}{ 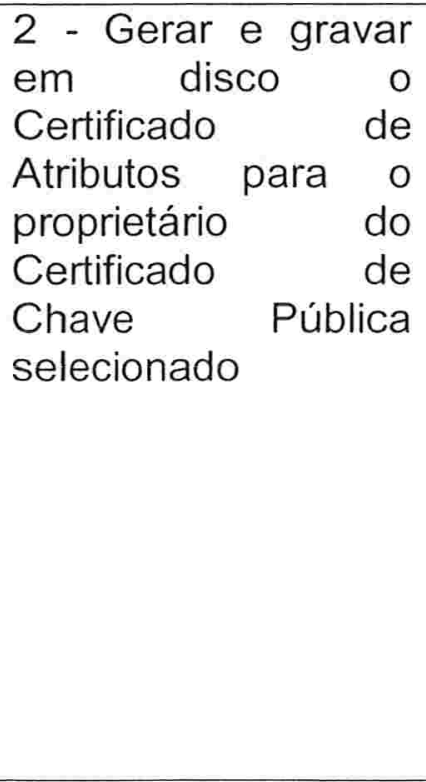 } & $\begin{array}{l}2.1 \text { - Selecionar um } \\
\text { PKC no campo PKC } \\
\text { existentes }\end{array}$ & $\begin{array}{l}\text { Preenchimento automático dos } \\
\text { campos Holder, Serial do PKC, } \\
\text { Nome do Emissor, Base } \\
\text { Certificate ID, Número Serial } \\
\text { do AC e Validade. }\end{array}$ & Ok \\
\hline & $\begin{array}{l}2.2 \text { - Ação } 2.1 \text { e } \\
\text { selecionar } \quad \text { os } \\
\text { atributos no campo } \\
\text { Privilégios e clicar } \\
\text { no botão Gerar AC }\end{array}$ & $\begin{array}{l}\text { Exibição da mensagem } \\
\text { "Certificado de Atributos criado } \\
\text { com sucesso!" e criação de um } \\
\text { arquivo com extensão DER e o } \\
\text { arquivo de atributos com a } \\
\text { extensão AC no diretório } \\
\text { c:Itemp da máquina. }\end{array}$ & Ok \\
\hline & $\begin{array}{l}2.3 \text { - Não alterar o } \\
\text { campo Validade } \\
\text { aumentando para } \\
\text { pelo menos um dia a }\end{array}$ & $\begin{array}{l}\text { Exibição de uma mensagem } \\
\text { de erro, informando que as } \\
\text { datas de validade do } \\
\text { Certificado são inválidas. }\end{array}$ & Ok. \\
\hline
\end{tabular}




\begin{tabular}{|c|c|c|c|}
\hline $\begin{array}{l}\text { Requisito } \\
\text { Funcional }\end{array}$ & Ação & Resultado Esperado & $\begin{array}{c}\text { Resultado } \\
\text { Obtido }\end{array}$ \\
\hline & $\begin{array}{ll}\text { validade } & \text { do } \\
\text { Certificado } & \text { de } \\
\text { Atributos } & \end{array}$ & & \\
\hline & $\begin{array}{l}2.4 \text { - Clicar no botão } \\
\text { cancelar a qualquer } \\
\text { momento }\end{array}$ & $\begin{array}{l}\text { Sai do Módulo de Atribuição } \\
\text { de Privilégios. }\end{array}$ & Ok. \\
\hline $\begin{array}{l}3 \text { - Gerar e gravar } \\
\text { em disco o arquivo } \\
\text { de atributos } \\
\text { correspondente ao } \\
\text { Certificado } \quad \text { de } \\
\text { Atributos gerado }\end{array}$ & 3.1 - Ação 2.2 & $\begin{array}{l}\text { Exibição da mensagem } \\
\text { "Certificado de Atributos criado } \\
\text { com sucesso!" e criação de um } \\
\text { arquivo com extensão DER e o } \\
\text { arquivo de atributos com a } \\
\text { extensão AC no diretório } \\
\text { c:ltemp da máquina. }\end{array}$ & Ok. \\
\hline
\end{tabular}

Tabela 7-2 - Testes de Validação do Módulo de Verificação de Privilégios

\begin{tabular}{|c|c|c|c|}
\hline \multicolumn{4}{|c|}{ Módulo de Verificação de Privilégios } \\
\hline $\begin{array}{l}\text { Requisito } \\
\text { Funcional }\end{array}$ & Ação & Resultado Esperado & $\begin{array}{c}\text { Resultado } \\
\text { Obtido }\end{array}$ \\
\hline \multirow{2}{*}{$\begin{array}{l}1 \text { Buscar o } \\
\text { Certificado r de } \\
\text { Atributos do usuário } \\
\text { que } \\
\text { autorização }\end{array}$} & $\begin{array}{lrr}1.1 \quad- & \text { Digitar } & \text { um } \\
\text { usuário } & \mathrm{e} & \text { uma } \\
\text { senha válidas } & \text { no } \\
\text { sistema } & & \end{array}$ & $\begin{array}{l}\text { Exibição de uma mensagem } \\
\text { indicando que a autenticação } \\
\text { foi feita com sucesso. }\end{array}$ & Ok \\
\hline & $\begin{array}{l}1.2-\text { Digitar um } \\
\text { usuário e/ou senha } \\
\text { inválidos no sistema }\end{array}$ & $\begin{array}{l}\text { Exibição de uma mensagem } \\
\text { indicando que foi digitado um } \\
\text { usuário elou senha inválidos. }\end{array}$ & Ok \\
\hline \multirow[t]{2}{*}{$\begin{array}{l}2 \text { - Ler o Certificado } \\
\text { de Atributos }\end{array}$} & $\begin{array}{ll}2.1-\text { Ação } & 1.1 \text { e } \\
\text { Certificado } & \text { de } \\
\text { Atributos existente }\end{array}$ & $\begin{array}{llr}\text { Exibição } & \text { da mensagem } \\
\text { "Usuário autenticado" e } & \text { em } \\
\text { seguida } & \text { "Certificado } & \text { de } \\
\text { Atributos } & \text { encontrado } & \text { e } \\
\text { carregado.". } & & \\
\end{array}$ & Ok \\
\hline & $\begin{array}{lr}2.2 \text { - Ação } & 1.1 \text { e } \\
\text { Certificado } & \text { de } \\
\text { Atributos inexistente }\end{array}$ & $\begin{array}{l}\text { Exibição da mensagem } \\
\text { "Usuário autenticado", outra } \\
\text { mensagem indicando que o } \\
\text { Certificado de Atributos não } \\
\text { existe e sai do sistema. }\end{array}$ & Ok \\
\hline $\begin{array}{l}3 \quad-\quad \text { Verificar o } \\
\text { período de validade } \\
\text { do Certificado de } \\
\text { Atributos }\end{array}$ & $\begin{array}{l}3.1-\text { Ação 1.1, } \\
\text { Certificador de } \\
\text { Atributos existente e } \\
\text { dentro do prazo de } \\
\text { validade }\end{array}$ & $\begin{array}{l}\text { Exibição das mensagens: } \\
\text { "Usuário autenticado", } \\
\text { "Certificado de Atributos } \\
\text { encontrado e carregado." e } \\
\text { outra indicando que o período }\end{array}$ & Ok \\
\hline
\end{tabular}




\section{Módulo de Verificação de Privilégios}

\begin{tabular}{|c|c|c|c|}
\hline $\begin{array}{l}\text { Requisito } \\
\text { Funcional }\end{array}$ & Ação & Resultado Esperado & $\begin{array}{c}\text { Resultado } \\
\text { Obtido }\end{array}$ \\
\hline & & de validade está ok. & \\
\hline & \begin{tabular}{|lr}
$3.2-$ Ação & 1.1 \\
Certificado & de \\
Atributos existente e \\
com prazo de de \\
validade expirado
\end{tabular} & $\begin{array}{l}\text { Exibição das mensagens } \\
\text { "Usuário autenticado", } \\
\text { "Certificado de Atributos } \\
\text { encontrado e carregado." e } \\
\text { outra indicando que o período } \\
\text { de validade expirou. Em } \\
\text { seguida, sai do sistema. }\end{array}$ & Ok \\
\hline & \begin{tabular}{lrr|}
3.3 - Ação & 1.1 \\
Certificado & de \\
Atributos existente e \\
com prazo r de \\
validade ainda \\
iniciado
\end{tabular} & $\begin{array}{l}\text { Exibição das mensagens } \\
\text { "Usuário autenticado", } \\
\text { "Certificado de Atributos } \\
\text { encontrado e carregado." e } \\
\text { outra indicando que o período } \\
\text { de validade ainda não se } \\
\text { iniciou. Em seguida, sai do } \\
\text { sistema. }\end{array}$ & Ok \\
\hline $\begin{array}{l}4 \quad-\quad \text { Verificar a } \\
\text { localização do do } \\
\text { arquivo de atributos } \\
\text { e carregá-lo para a } \\
\text { memória }\end{array}$ & $\begin{array}{l}4.1 \text { - Ação } 3.1, \text { e } \\
\text { arquivo de atributos } \\
\text { existente }\end{array}$ & $\begin{array}{l}\text { Exibição das mensagens } \\
\text { "Usuário autenticado", } \\
\text { "Certificado de Atributos } \\
\text { encontrado e carregado.", uma } \\
\text { indicando que o período de } \\
\text { validade está ok e outra } \\
\text { indicando que o arquivo de } \\
\text { atributos foi encontrado e } \\
\text { carregado. }\end{array}$ & Ok \\
\hline & $\begin{array}{l}4.2 \text { - Ação } 3.1 \text { e } \\
\text { arquivo de atributos } \\
\text { inexistente }\end{array}$ & $\begin{array}{l}\text { Exibição das mensagens } \\
\text { "Usuário autenticado", } \\
\text { "Certificado de Atributos } \\
\text { encontrado e carregado.", uma } \\
\text { indicando que o periodo de } \\
\text { validade está ok e outra } \\
\text { indicando que o arquivo de } \\
\text { atributos não foi encontrado. } \\
\text { Em seguida, sai do sistema. }\end{array}$ & \\
\hline $\begin{array}{l}5 \text { - Verificar se os } \\
\text { atributos rão } \\
\text { suficientes para o } \\
\text { acesso desejado, de } \\
\text { acordo com r a } \\
\text { política descrita na } \\
\text { seção } 7.1\end{array}$ & $\begin{array}{l}5.1 \text { - Ação } 4.1 \text { e } \\
\text { atributos no arquivo } \\
\text { de } \quad \text { atributos } \\
\text { suficientes para o } \\
\text { acesso desejado }\end{array}$ & 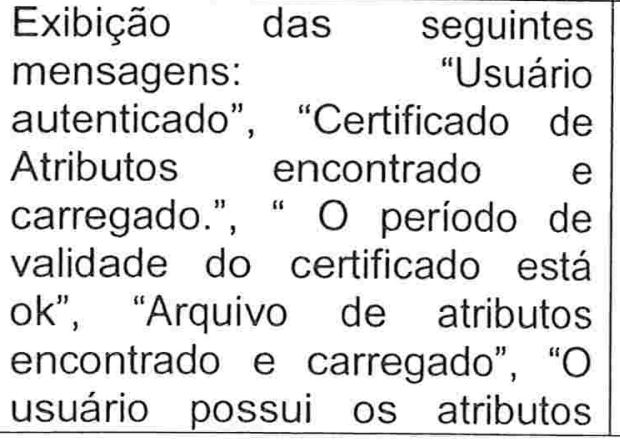 & Ok \\
\hline
\end{tabular}




\section{Módulo de Verificação de Privilégios}

\section{Requisito Funcional}

\begin{tabular}{|l|l|l|}
\hline \multicolumn{1}{|c|}{ Ação } & \multicolumn{1}{|c|}{ Resultado Esperado } & Resultado \\
Obtido
\end{tabular}


Todas as ações listadas nas tabelas de testes anteriormente apresentadas foram executadas e os resultados esperados foram obtidos com sucesso. 


\section{CAPÍTULO 8: CONCLUSÃO}

Neste trabalho, estudamos a infra-estrutura de gerenciamento de privilégios (PMI - Privilege Management Infrastructure), baseada na $4^{\text {a }}$ edição da recomendação X.509 de 2000 [ITU 00] e padronizada pela RFC 3281 [FAR 02] que fornece serviços de autorização para sistemas, servidores e serviços. Apresentamos suas características, funções, similaridades com a infra-estrutura de chaves públicas (ICP), além de vantagens e desvantagens.

Como principal vantagem, identificamos a utilização de uma infra-estrutura de gerenciamento de privilégios para fornecer serviços de autorização, que torna esse serviço independente do serviço de autenticação utilizado. Além disso, o modelo fornece diversos tipos de implementação que dão flexibilidade suficiente para que qualquer organização possa implementá-la, mesmo que possua um serviço de autenticação terceirizado, e também aproxima a entidade final da autoridade (Autoridade de Atributos) que decidirá quais privilégios serão alocados a essa entidade final. Essa situação é especialmente importante uma vez que apresentamos que a identidade e os privilégios têm muitas características divergentes, sendo o período de validade a principal (Capítulo 5).

Na direção contrária, indicamos com principal desvantagem da Infra-estrutura de Gerenciamento de Privilégios, herdada de sua similaridade com a Infra-estrutura de Chaves Públicas, a questão da revogação do Certificado de Atributos. Vimos nas seções 5.6 e 6.2 que, quando temos a necessidade de revogar algum Certificado de Atributos antes que seu período de validade expire, a tarefa administrativa gera problemas graves de segurança (figura 6-3). Tendo em vista esse problema, neste trabalho propusemos uma mudança no modelo de Infra-estrutura de Gerenciamento de Privilégios da referência [FAR 02]. Na nossa proposta, alteramos o campo atributos (seção 5.5.7) do Certificado de Atributos para que ele refletisse não os atributos diretamente e sim apontasse para um arquivo de atributos. Essa alteração torna o Certificado de Atributos "dinâmico", eliminando a necessidade de revogação e sua falha de segurança, abordadas na seção 
6.2. Propusemos, ainda, que o arquivo de atributos fosse assinado pela Autoridade de Atributos, como forma de garantir a sua autenticidade (seção 6.3).

Após apresentarmos o modelo proposto, mostramos na seção 6.3 sua adequação a empresas que utilizam diversas formas organizacionais, dentre elas a organização hierárquica e as empresas virtuais, além da utilização da Infra-estrutura de Gerenciamento de Privilégios na gestão de projetos distribuidos.

Finalmente, como produto desta dissertação, desenvolvemos um protótipo em Java do modelo de Infra-estruturada de Gerenciamento de Privilégios proposto. Para isso, criamos um módulo de atribuição de privilégios, utilizado pela Autoridade de Atributo, e um módulo de verificação de privilégios, utilizado pelo verificador de privilégios, integrado à aplicação (objeto ou recurso) protegida. Apresentamos todos os detalhes da implementação no capítulo 7 desta dissertação e os códigos-fontes estão no Anexo A.

\subsection{Trabalhos futuros}

Baseado nos resultados obtidos nesta dissertação, apresentamos como sugestão de trabalhos futuros os seguintes assuntos:

- Otimização do código da implementação da Infra-estrutura de gerenciamento de privilégios apresentada, melhorando seu desempenho e segurança;

- Implementação da assinatura da Autoridade de Atributos no arquivo de atributos, visando a garantir sua autenticidade;

- Implementação de um serviço de diretório no qual possamos armazenar os certificados de atributos e também os arquivos de atributos, de forma a permitir a utilização do modelo proposto em grande escala;

- Desenvolvimento e implementação de um módulo de verificação de privilégios genérico, que funcione como uma interface entre as aplicações e recursos protegidos e a Infra-estrutura de Gerenciamento de Privilégios, tornando o modelo universal.

As indicações anteriores não esgotam o assunto, tendo em vista a originalidade da proposta. 


\section{ANEXO A: CÓDIGO FONTE DO PROTÓTIPO}

\section{A.1 - MÓDULO DE ATRIBUIÇÃO DE PRIVILÉGIOS}

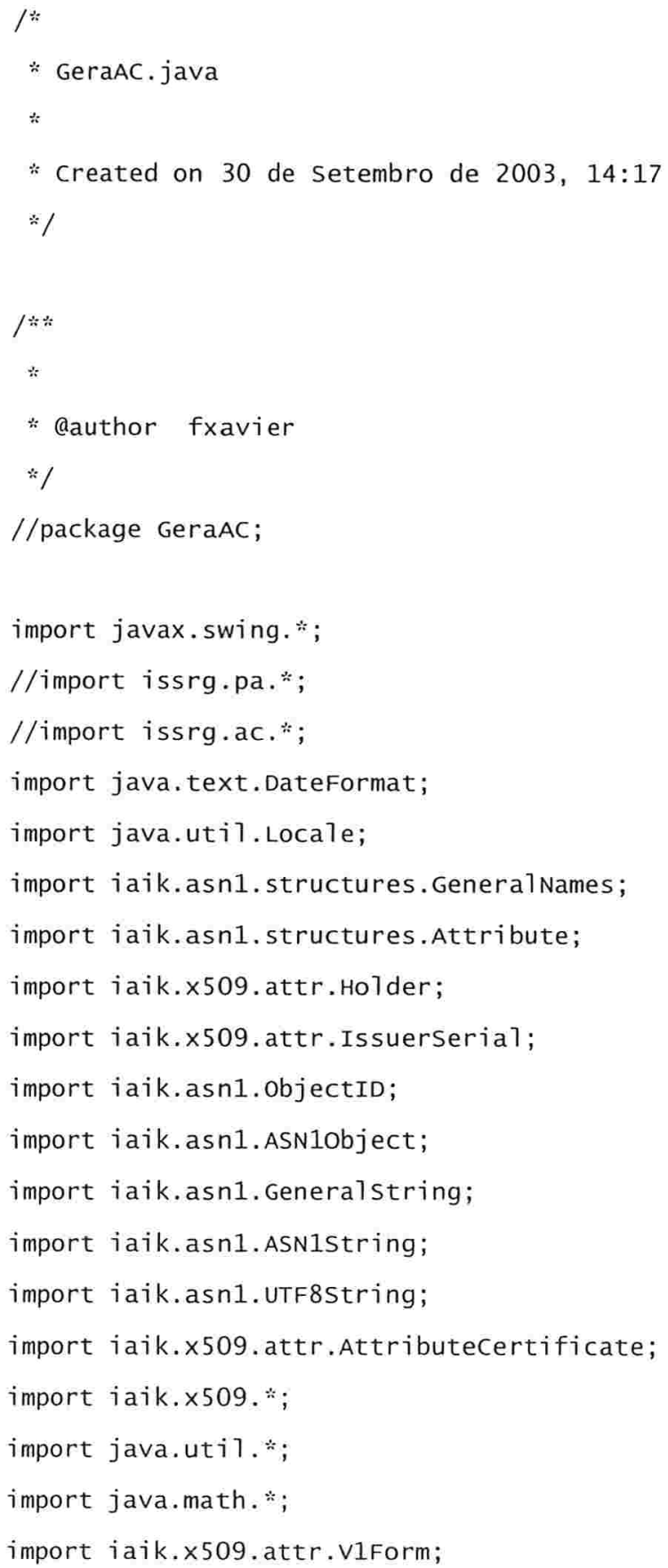


import iaik.asn1.structures.A1gorithmID;

import java.io." ;

import java.security. ";

import java.security.cert. *;

import java.security.spec. *;

public class GeraAC extends javax.swing.JFrame \{

static Enumeration alias_enum;

static string vetor_alias[];

static Keystore ks;

static String senha;

static java.security.cert.X509certificate PKC;

//static iaik.×509.X509Certificate PKC;

static iaik.x509.X509certificate PKC_iaik;

static java.security.cert.X509Certificate PKC_Emissor;

static char senha_char[];

calendar rightNow;

public static void Consertadata() \{

text_a.hasfocus();

\}

public static void Limpacampos() \{

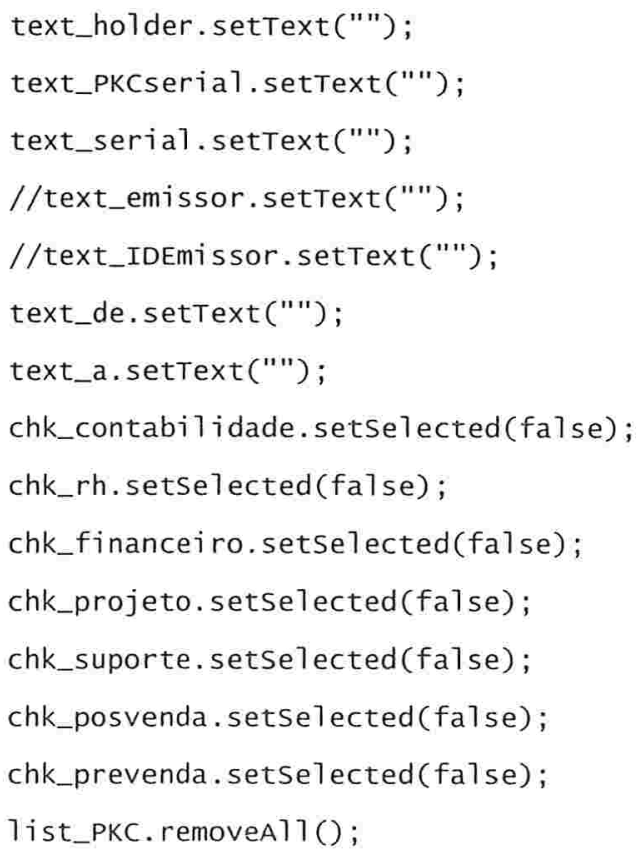




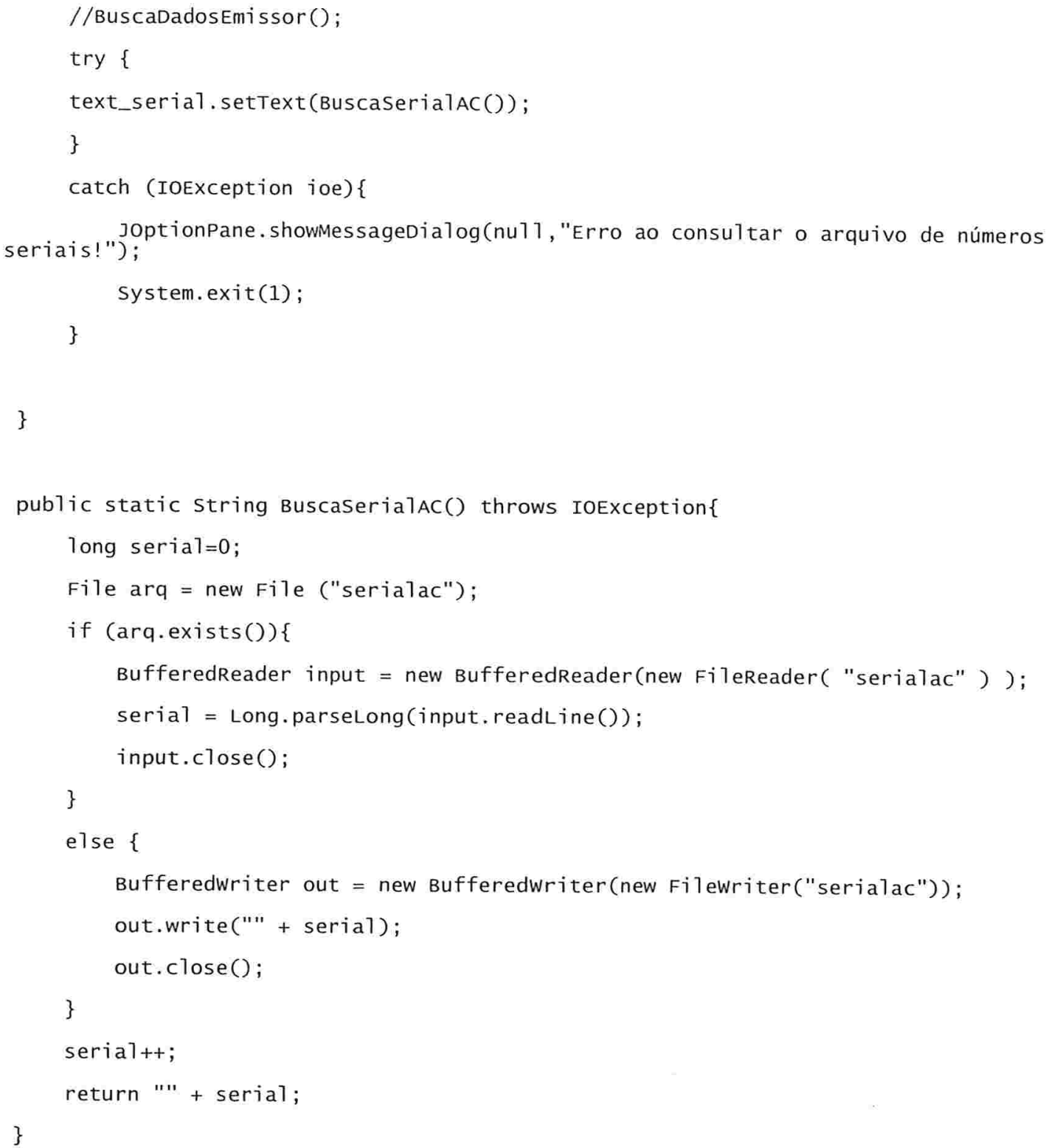


selecao=1ist_PKC.getSelectedvalue(), tostring();

text_holder.setText(selecao);

CarregaPKC(1ist_PKC.getSelectedIndex());

serial = PKC.getSerialnumber ();

text_PKCserial.setText("' + serial);

DateFormat mydate $=$ DateFormat.getDateInstance $($ DateFormat. SHORT, 1ocal);

text_de.setText (mydate.format(data));

text_a.setText (mydate.format(data));

\}

public static void Abrestore()\{

try \{

$\mathrm{ks}=$ Keystore.getInstance(Keystore.getDefauttType ( ));

String fname = System.getProperty ("user.home") + File.separator + ".keystore";

FileInputstream fis = new FileInputstream(fname);

senha $=$ text_senha.getText () ;

senha_char $=$ new $\operatorname{char}[\operatorname{senha}$. length ()$]$;

senha_char=senha $\cdot$ tochararray () ;

ks. 1oad(fis, senha_char);

\} catch (java.security.keystoreException kse) \{

JoptionPane.showMessagedialog(nu17, "Senha
correta!","Erro", JoptionPane.ERROR_MESSAGE);

\}

catch (Exception e) \{

JoptionPane.showMessagedialog(nu71, "Erro: " +

e.tostring (), "Erro", JoptionPane. ERROR_MESSAGE);

\}

\}

public static void BuscadadosEmissor()\{

text_emissor.setText("" + PKC_Emissor.getSubjectDN( ));

text_IDEmissor.setText("" + PKC_Emissor.getSerialnumber());

\}

public void CarregaPKC(int i) \{

try \{

String alias = vetor_alias $[i]$;

java.security.cert.Certificate certs []$=$ ks.getCertificatechain(alias);

PKC $=$ (java.security. cert.x509certificate) certs $[0]$; 


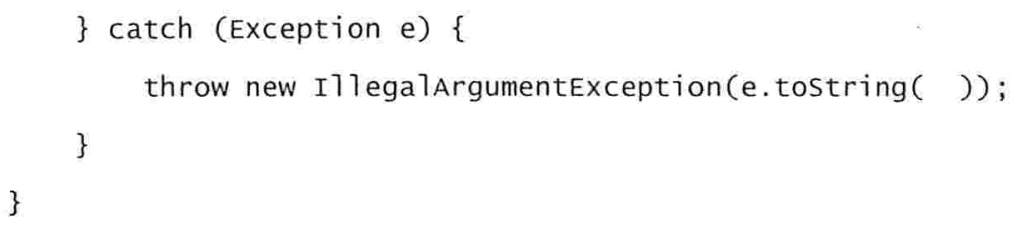




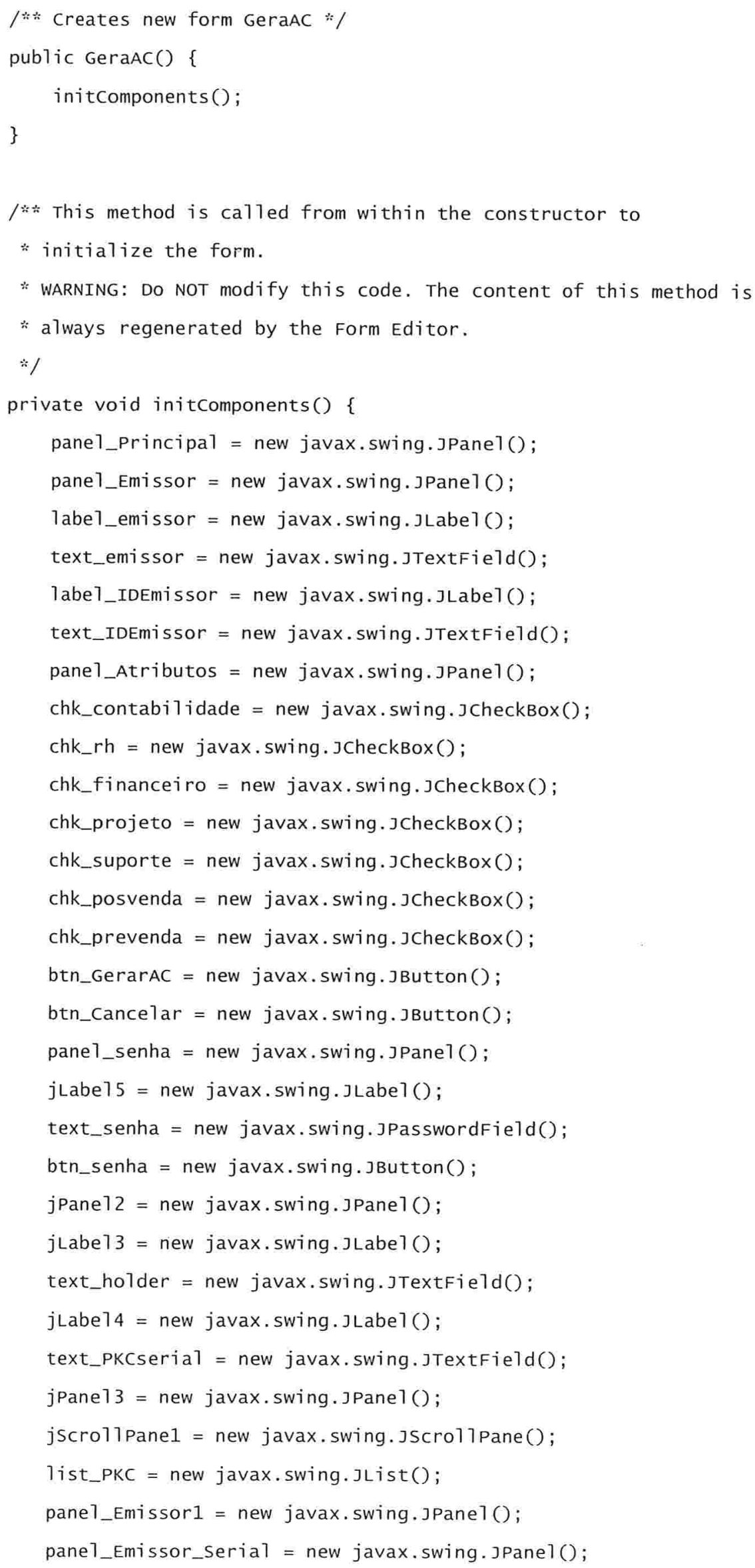


1abe1_serial = new javax. swing.JLabe1();

text_serial = new javax.swing. JTextField();

panel_Emissor_validade $=$ new javax.swing. JPanel();

jLabel1 = new javax. swing. JLabe 1() ;

text_de = new javax.swing.JTextField();

jLabe12 = new javax. swing.JLabe1();

text_a = new javax.swing. JTextField();

menuBar $=$ new javax. swing. JMenuBar () ;

filemenu $=$ new javax.swing. JMenu();

openMenuItem $=$ new javax. swing. JMenuItem();

savemenuItem $=$ new javax. swing. JMenuItem();

saveAsMenuItem = new javax.swing. JMenuItem();

exitmenuItem $=$ new javax. swing. JMenuItem();

editmenu $=$ new javax. swing. JMenu( $)$;

cutmenuItem $=$ new javax.swing. JMenuItem ()$;$

copymenuItem $=$ new javax. swing. JMenuItem () ;

pastemenuItem $=$ new javax. swing. JMenuItem();

deletemenuItem $=$ new javax. swing. $\operatorname{jmenuItem}()$;

helpmenu $=$ new javax. swing. JMenu();

contentsmenuItem = new javax. swing. JMenuItem();

aboutMenuItem $=$ new javax. swing. JMenuItem();

getContentPane(). setLayout (new java.awt.BorderLayout(30, 30));

setTitle("Emiss \u00e3o de Certificados de Atributos - v.0.00");

addwindowListener (new java.awt.event. WindowAdapter () \{

public void windowclosing(java.awt.event.windowEvent evt) \{

exitForm(evt);

\});

panel_Principal.setLayout(new org.netbeans.1ib.awtextra.AbsoluteLayout());

pane1_Principal.setBorder(new javax.swing.border.EtchedBorder());

pane1_Emissor.setLayout (new org.netbeans.1ib.awtextra.AbsoluteLayout());

pane1_Emissor.setBorder(new javax.swing.border.CompoundBorder (new javax.swing.border. EmptyBorder (new java.awt. Insets (5, 5, 5, 5)), new javax.swing.border. TitledBorder("Dados do Emissor")));

1abe1_emissor.setHorizonta1A1ignment (javax.swing.Swingconstants.LEFT) ;

1abe1_emissor.setText("Nome do Emissor:"); 


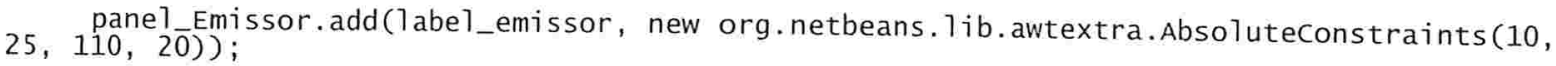

text_emissor.setEditable(false);

text_emissor.setHorizontalAlignment(javax.swing. JTextField.LEFT);

25, 220,20$)$ ).

Tabe1_IDEmissor.setText("Base Certificate ID:");

pane1_Emissor.add(1abe1_IDEmissor, new

org.netbeans. 1ib.awtextra.Absoluteconstraints $(10,55,110,20))$;

text_IDEmissor.setEditable(false);

text_IDEmissor.setHorizontalA1 ignment (javax.swing. JTextField.LEFT);

pane1_Emissor.add(text IDEmissor, new

org.netbeans.7ib. awtextra.Absoluteconstraints (119, 55, 220, 20));

pane1_Principa1.add(pane1 Emissor, new

org.netbeans. 1ib.awtextra.Absoluteconstraints $(0,290,350,90))$;

pane1_Atributos.setLayout (new java.awt.GridLayout $(4,2)$ );

pane1_Atributos.setBorder (new javax.swing.border.CompoundBorder (new javax. swing.border. EmptyBorder (new java.awt. Insets (5, 5, 5, 5)), new javax.swing.border. Tit ledBorder("Privi† \u00e9gios")));

chk_contabilidade.setText("Contabilidade");

pane1_Atributos.add(chk_contabilidade);

chk_rh.setText("Recursos Humanos");

pane1_Atributos.add(chk_rh);

chk_financeiro.setText("Financeiro");

pane1_Atributos.add(chk_financeiro);

chk_projeto.setText("Projeto");

pane1_Atributos.add(chk_projeto);

chk_suporte.setText("Suporte");

pane1_Atributos.add(chk_suporte);

chk_posvenda.setText("P\u00f3s-venda") ;

pane1_Atributos.add(chk_posvenda);

chk_prevenda.setText ("Pr\u00e9-venda"); 
pane1_Atributos.add(chk_prevenda);

pane1_Principal.add(pane1_Atributos, new org.netbeans. 1ib.awtextra.Absoluteconstraints $(360,120,350,170))$;

btn_GerarAC.setmnemonic('g');

btn_GerarAC.setText("Gerar AC");

btn_GerarAC.addActionListener(new java.awt.event.ActionListener ()\{ public void actionPerformed(java.awt.event. ActionEvent evt) \{ btn_GerarACActionPerformed(evt); \}

\});

pane1_Principal.add(btn_Gerarac, new org.netbeans. 1ib.awtextra.Absoluteconstraints $(470,350,110,-1)$ );

btn_Cancelar.setmnemonic( 'c');

btn_Cancelar.setText("Cancelar");

btn_Cancelar.addActionListener(new java.awt.event.ActionListener $($ ) \{ pub7ic void actionPerformed(java.awt.event. ActionEvent evt) \{ btn_CancelarActionPerformed(evt); \}

\});

pane1_Principal.add(btn_Cancelar, new org.netbeans.1 ib.awtextra.Absoluteconstraints $(590,350,110,-1))$;

pane1_senha.setLayout(new org.netbeans. 1ib.awtextra.AbsoluteLayout());

panel_senha.setBorder (new javax.swing. border. CompoundBorder (new javax. swing.border. EmptyBorder (new java.awt. Insets (5, 5, 5, 5)), new javax.swing.border.TitledBorder("Senha de acesso"))):

jLabe15.setText("Senha keystore:"); $106,20))$

text_senha.setcolumns ( 8 );

text_senha.setToolTipText("Digite a senha para acessar o keystore");

text_senha.setBorder(nu11); $110,20))$

pane1_senha.add(text_senha, new org.netbeans.7ib.awtextra.Absoluteconstraints (107, 25,

btn_senha.setmnemonic('b');

btn_senha.setText("Abrir"); 
btn_senha.addActionListener(new java.awt.event.ActionListener ()\{ public void actionPerformed(java.awt.event.ActionEvent evt) \{ btn_senhaActionperformed(evt); \}

\}) ;

btn_senha.addkeyListener(new java.awt.event.KeyAdapter ()\{ pub7ic void keypressed(java.awt.event.KeyEvent evt) \{ btn_senhakeypressed(evt); \}

\});

106, -1)); pane1_Principal.add(pane1_senha, new org.netbeans. 1 ib.awtextra.Absoluteconstraints $(0$,
10, 350,60));

jPane12.setLayout (new org.netbeans. 1ib.awtextra.AbsoluteLayout ());

jPane12. setBorder (new javax. swing. border. CompoundBorder (new javax.swing.border. EmptyBorder (new java.awt. Insets $(5,5,5,5)$ ), new javax.swing.border.TitledBorder("Dados do Propriet\u00eirio")));

jLabe13.setText("Holder:"); 20));

jpane12.add(jLabe13, new org.netbeans.1ib.awtextra.Absoluteconstraints (10, 30, 50,

text_holder.setcolumns(10);

text_holder.setEditable(false); 280, 20));

jLabe14.setHorizonta1A7ignment(javax.swing. SwingConstants. LEFT);

jLabe14.setText("Serial do PKC:");

20)); jPane12.add(jLabe14, new org.netbeans.7ib.awtextra.Absoluteconstraints(10, 52, 90 ,

text_PKCserial.setEditable(false);

text_PKCSerial.setHorizontalAlignment (javax.swing.JTextField.LEFT); 240, 20));

jPane12.add(text_PKCserial, new org.netbeans.1ib.awtextra.AbsoluteConstraints(100, 52 ,

pane1_Principal.add(jPane12, new org.netbeans.1ib.awtextra.Absoluteconstraints $(0,200$, $350,90))$; 
jPane13. setLayout (new org.netbeans.1ib.awtextra.Absolutelayout());

jPane13. setBorder (new javax. swing.border. CompoundBorder (new javax.swing.border. EmptyBorder (new java.awt. Insets (5, 5, 5, 5)), new javax.swing.border.TitledBorder("PKC existentes")));

1ist_PKC.setToolTipText("PKCs encontrados em keystore");

list_PKC.setAlignmentX(30.0F);

list_PKC.setATignmentY(30.0F);

1ist_PKC.setSelectionMode(javax.swing.ListSelectionMode1.SINGLE_SELECTION);

1ist_PKC.setVisibleRowCount (5);

1ist_PKC.addListSelectionListener(new javax.swing.event.ListSelectionListener() \{ public void valuechanged(javax.swing.event.ListSelectionEvent evt) \{

Tist_PKCValuechanged(evt);

\}

\});

jscrol1Pane1.setViewportView(1ist_PKC);

jPane13.add(jscrollpane1, new org.netbeans.1ib.awtextra.Absoluteconstraints (15, 25, $320,90)$ ); 350, 130))

pane1_Principal.add(jPane13, new org.netbeans.1ib.awtextra.Absoluteconstraints $(0,70$,

pane1_Emissor1.setLayout(new org.netbeans.1ib.awtextra.AbsoluteLayout());

pane1_Emissor1.setBorder(new javax.swing.border. CompoundBorder (new javax.swing. border. EmptyBorder (new java.awt. Insets (5, 5, 5, 5)), new javax.swing.border.TitledBorder("Dados do Certificado de Atributos")));

pane1_Emissor_Serial.setLayout(new org.netbeans.1ib.awtextra.AbsoluteLayout());

labe1_serial.setHorizonta1A1ignment (javax.swing.Swingconstants.LEFT);

labe1_serial.setText("N\u00famero Serial do AC:");

pane1_Emissor_Serial.add(1abel_serial, new

org.netbeans. lib.awtextra.Absoluteconstraints (0, 0, 165, 20));

text_serial.setcolumns(20);

text_serial.setEditable(false);

text_serial.setHorizonta1A1ignment(javax.swing.JTextField.LEFT);

pane1_Emissor_serial.add(text_serial, new

org.netbeans.1 ib.awtextra.AbsoluteConstraints (130, 0, 200, 20));

pane1_Emissor1.add(pane1_Emissor_Serial, new

org.netbeans. 1 ib.awtextra.Absoluteconstraints $(10,25,-1,20))$; 
pane1_Emissor_Validade.setLayout(new org.netbeans.1ib.awtextra.AbsoluteLayout());

jLabe11.setText("Validade: de");

pane1_Emissor_Validade.add(jLabe11, new

org.netbeans.lib.awtextra.Absoluteconstraints $(0,0,82,20))$;

panel_Emissor_Validade.add(text_de, new

org.netbeans. lib.awtextra.Absoluteconstraints $(80,0,250,20))$;

jLabe12.setHorizonta1A1 ignment (javax.swing. SwingConstants. CENTER);

jLabe12. setText("\u00e0");

pane1_Emissor_Validade.add(jLabe12, new

org.netbeans.7ib.awtextra.Absoluteconstraints $(40,30,40,20))$;

text_a.setHorizontalAlignment (javax.swing.JTextField.LEFT);

pane1_Emissor_validade.add(text_a, new

org.netbeans. 1ib.awtextra.Absoluteconstraints $(80,30,250,20))$;

panel_Emissor1.add(panel_Emissor_VaTidade, new

org.netbeans.7ib.awtextra.Absoluteconstraints $(10,49,330,50)$ );

pane1_Principal.add(pane1_Emissor1, new

org.netbeans.7ib.awtextra.Absoluteconstraints $(360,10,350,110))$;

getContentPane().add(pane1_Principa1, java.awt.BorderLayout.NORTH);

filemenu.setMnemonic('a');

filemenu.setText ("Arquivo");

openMenuItem.setText("Abrir");

filemenu.add (openmenuItem);

saveMenuItem.setText("Salvar");

filemenu. add (savemenuItem);

saveAsMenuItem.setText ("SaTvar como...");

filemenu.add (saveasmenuItem);

exitMenuItem.setText("Sair");

exitmenuItem.addActionListener (new java.awt.event.Actionlistener ()\{

public void actionPerformed(java.awt.event.ActionEvent evt) \{ exitMenuItemactionPerformed (evt);

\}

\});

filemenu. add (exitmenuItem);

menuBar.add(fi lemenu);

editmenu. setmnemonic('e'); 


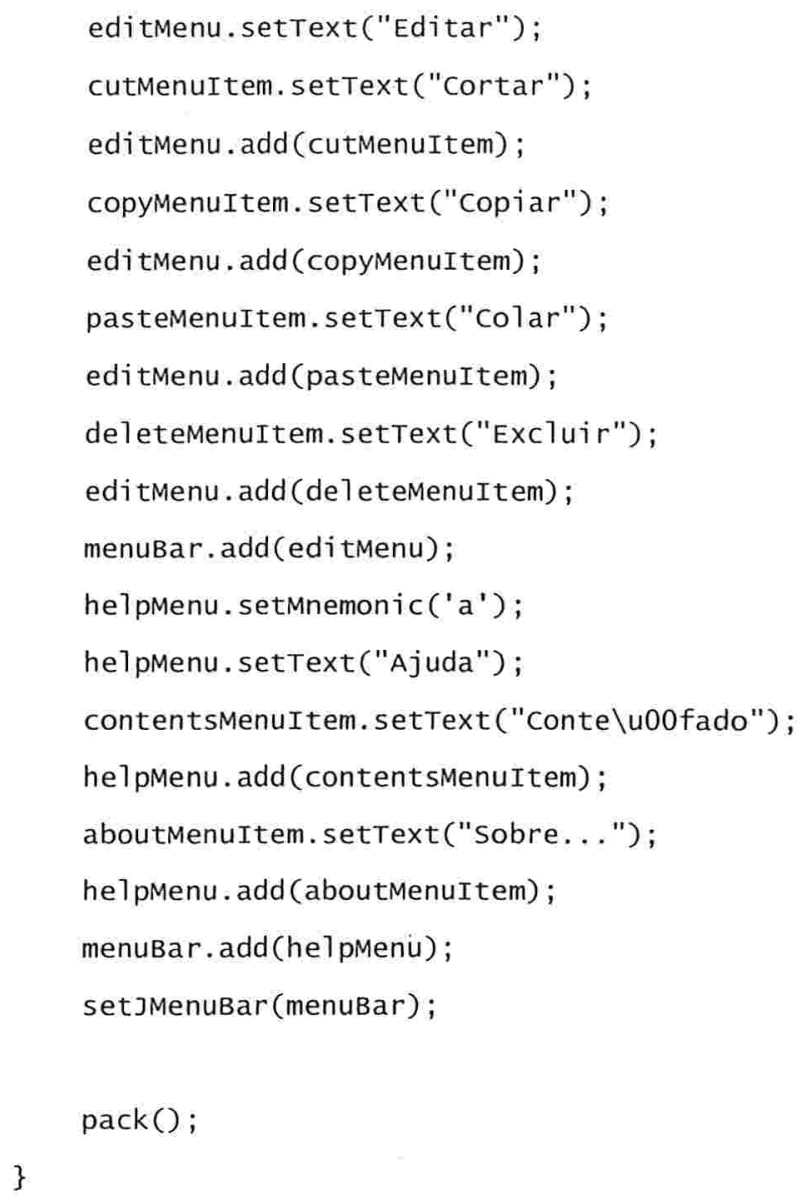


private void btn_GerarACACtionPerformed(java.awt.event.ActionEvent evt) \{

// Add your handling code here:

// Add your handling code here:

issrg.ac.util ferramentas = new issrg.ac.util();

string teste;

BigInteger serial;

string certiaik="";

//Certificado de Atributo

Attributecertificate certificado = new Attributecertificate ();

//Verificação das datas de validade

try \{

DateFormat $\mathrm{df}=$ DateFormat .getDateInstance ();

Date teste_de = new Date();

teste_de $=d f$.parse $($ text_de.gettext ()$)$;

Date teste_a = new Date();

teste_a $=d f$.parse(text_a.getText());

if $($ teste_de.compareTo(teste_a) $==0)\{$

Joptionpane.showmessagedialog(nul1, "As datas de validade do AC são inválidas!");

Consertadata();

\}

certificado.setNotBeforeTime(teste_de);

certificado.setnotafterTime(teste_a);

JoptionPane.showmessagedialog(nu11, "De " + teste_de + "a " + teste_a);

\}

catch (Exception e) \{

e.printstackTrace();

\}

//Certificado de chave Pública

try \{

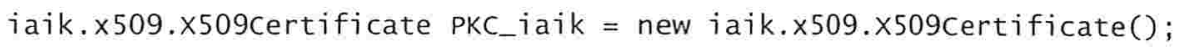

ByteArrayInputstream dados = new ByteArrayInputStream(PKC.getEncoded ());

PKC_iaik.decode(dados);

certiaik=PKC_iaik.tostring();

\} 


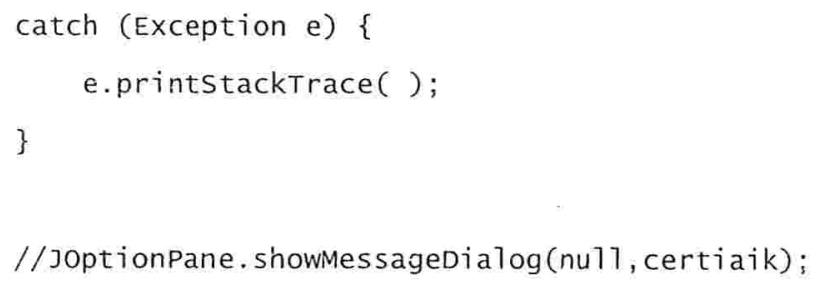


\}

// fim atributos

// assinatura

$\operatorname{try}\{$

KeyFactory keyFactory = KeyFactory.getInstance ("DSA");

Class spec = Class.forName("java.security.spec.DSAPrivatekeyspec");

DSAPrivateKeySpec dsaspec $=$ (DSAPrivatekeySpec)
keyfactory.getKeySpec((Key)ks.getKey(Vetor_alias[1ist_PKC.getSelectedIndex()], senha_char), s pec);

certificado.sign(iaik.asn1.structures.AlgorithmID.dsa, keyfactory.generateprivate(dsaspec));

\}

catch (Exception e) \{

e.printstackTrace();

\}

// fim assinatura

//string certac=certificado. tostring();

//JoptionPane. showMessagedialog(nu11, certac);

//Joptionpane.showmessagedialog(nu11, "o serial do certificado é " + certificado.getserialnumber());

//JoptionPane.showmessageDialog(nul1, "O atributo é " + certificado.getattribute(oid));

//Salvar arquivo de atributos no disco

try \{

Bufferedwriter Atributos = new Bufferedwriter(new Filewriter ("c: $\backslash \backslash$ temp \\AttrAC" + certificado.getSerialNumber ()$\left.+" \cdot a c^{\prime \prime)}\right)$;

Atributos.write("[Atributos] \n");

Atributos. write("//Legenda: Contabilidade=1; Financeiro=2; Suporte=3; Pré-venda=4; $\mathrm{RH}=5$; Projeto $=6$; Pós-Venda $=7 \backslash \mathrm{n}^{\prime \prime}$ );

if (chk_contabilidade.isselected()) \{

Atributos.write("1");

Atributos.newLine();

\}

if (chk_financeiro.isselected()) \{

Atributos.write("2");

Atributos, newline();

\}

if (chk_suporte.isselected()) \{

Atributos.write(" 3 "); 


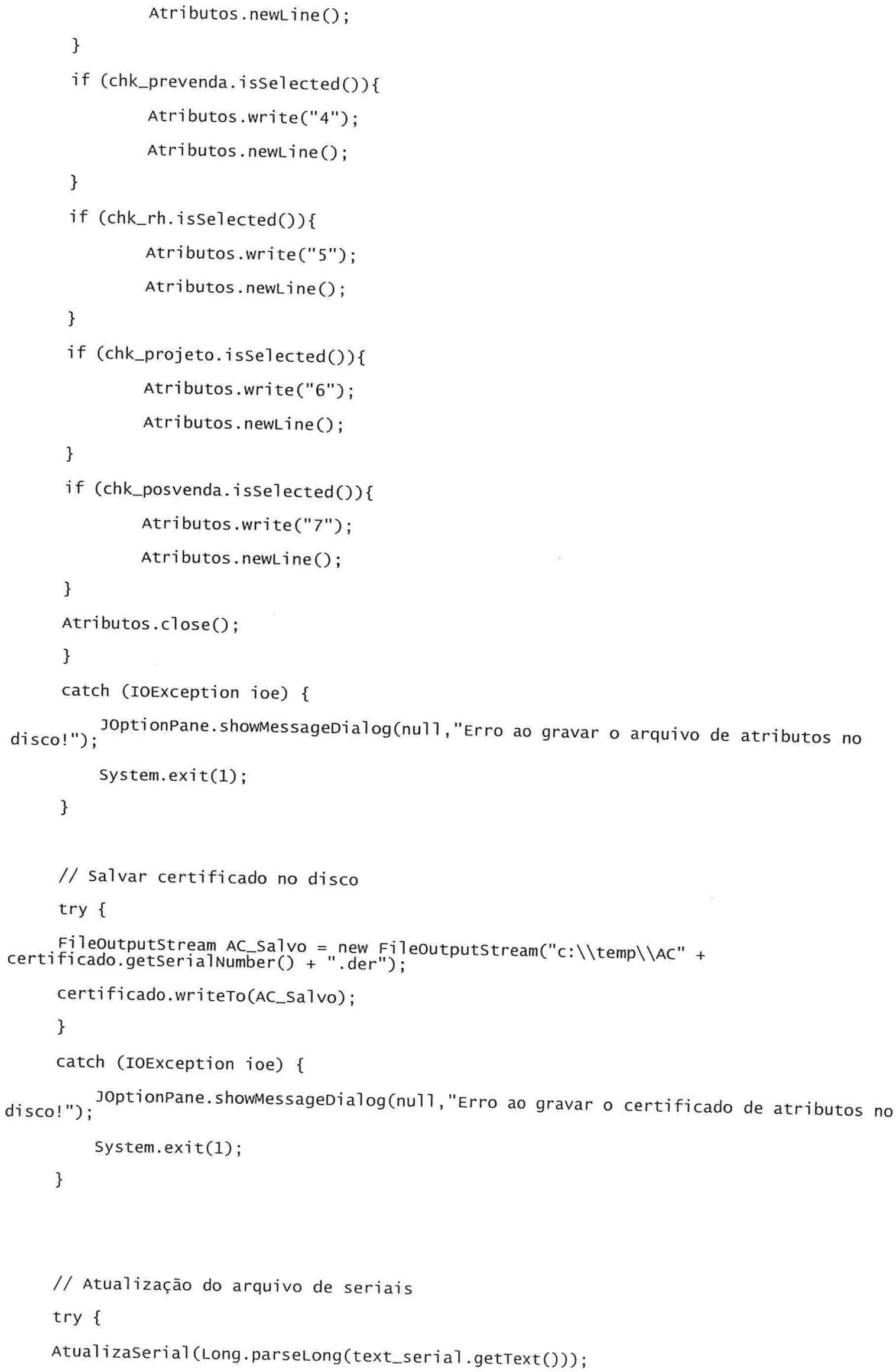


Joptionpane. showmessagedialog(nu11,"Certificado de Atributos criado com sucesso!"); \}

catch (IOException ioe) \{

seriais!"); system.exit(1);

\}

// fim atualização seriais

// Limpar os campos do formulário

LimpaCampos();

\}

private void exitmenuItemactionperformed(java.awt. event. ActionEvent evt) \{ system.exit $(0)$;

\}

$1 * *$ Exit the Application */

private void exitform(java.awt.event. WindowEvent evt) \{

system.exit (0);

\}

$1 * *$

* aparam args the command 1ine arguments

$* /$

public static void main(string args[]) \{

new $\operatorname{GeraAc}() \cdot \operatorname{show}()$;

\}

// variables declaration - do not modify

private javax.swing.JPanel pane1_Emissor1;

public static javax.swing. JTextfield text_a;

private static javax.swing.JTextField text_PKCserial;

private javax.swing. JMenu filemenu;

private javax.swing.JButton btn_cancelar;

private static javax.swing. JTextfield text_emissor;

private javax.swing.JButton btn_GerarAC;

private javax.swing.JPanel panel_Emissor_validade; 
private javax.swing. JMenuItem exitmenuItem;

private static javax.swing.JCheckBox chk_suporte;

private javax.swing. JMenuItem savemenuItem;

private javax.swing.JPane1 pane1_Atributos;

private javax.swing.Jpanel panel_senha;

private static javax.swing.JTextField text_holder;

private javax.swing. JMenuItem copyMenuItem;

private javax.swing. JMenuItem cutmenuItem;

private javax.swing. JMenuBar menuBar;

private static javax.swing.JTextField text_IDEmissor;

private static javax.swing. JCheckBox chk_posvenda;

private javax.swing. JMenu editmenu;

private static javax.swing.JTextField text_serial;

private javax.swing. JMenuItem contentsmenuItem;

private javax.swing.JLabel jLabe15;

private javax.swing.JPanel pane1_Principal;

private javax.swing.JLabel jLabe14;

public static javax.swing.JTextField text_de;

private static javax.swing.JCheckBox chk_prevenda;

private javax.swing.JScrollpane jscrollpane1;

private javax.swing.JLabe1 jLabe11;

private javax.swing. JLabel jLabe13;

private static javax.swing.JPane1 jPane13;

private javax.swing.JLabel jLabe12;

private javax.swing. JMenuItem saveasmenuItem;

private javax.swing.JLabel 1abel_serial;

private javax.swing.JPanel jPane12;

private javax.swing.JPanel pane1_Emissor;

private javax.swing.JLabel 1abe1_IDEmissor;

private javax.swing. JMenuItem pastemenuItem;

private static javax.swing. JcheckBox chk_contabilidade;

private javax.swing. JMenuItem openmenuItem;

private javax.swing.JPanel panel_Emissor_Serial;

private javax.swing.JButton btn_senha;

private javax.swing.JLabel 1abel_emissor;

private static javax.swing.JPasswordfield text_senha;

private javax.swing. JMenuItem aboutmenuItem;

private javax.swing. JMenu helpmenu;

private static javax.swing.JCheckBox chk_rh;

private static javax.swing. JList 1ist_PKC;

private static javax.swing. JcheckBox chk_financeiro; 
private static javax.swing.JCheckBox chk_projeto;

private javax.swing.JMenuItem deletemenuItem;

// End of variables declaration

\}

\section{A.2 - MÓDULO DE VERIFICAÇÃO DE PRIVILÉGIOS}

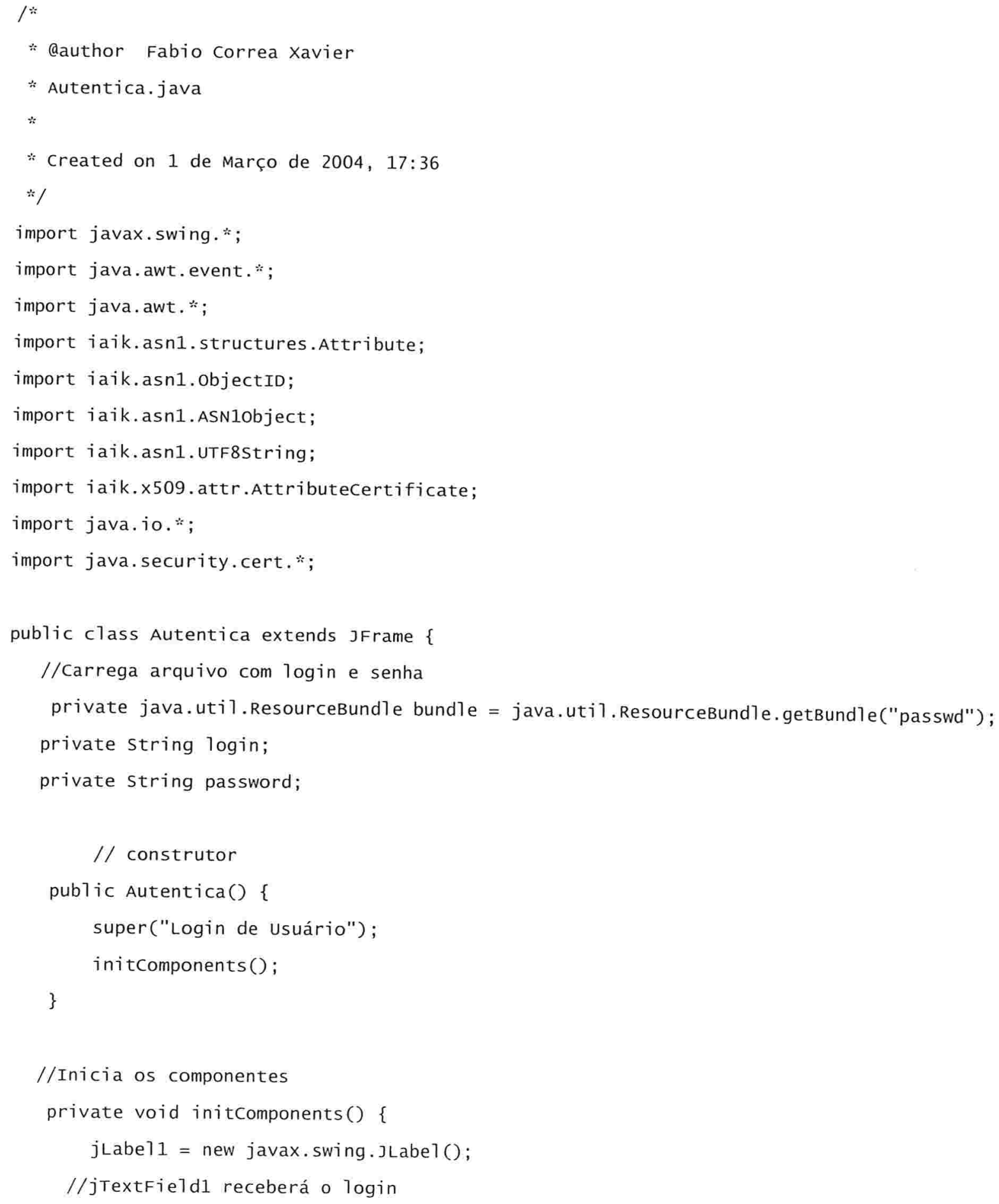




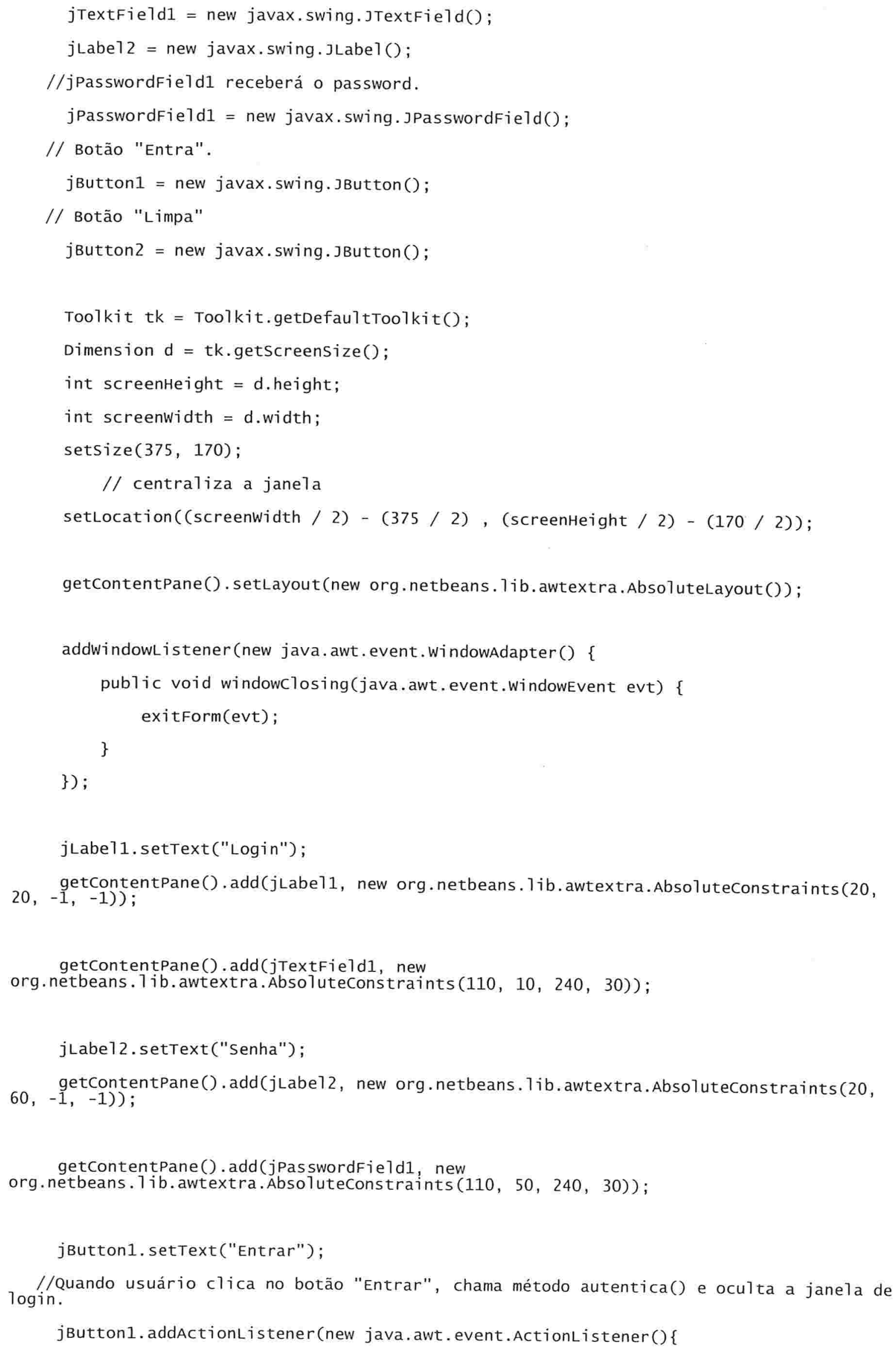




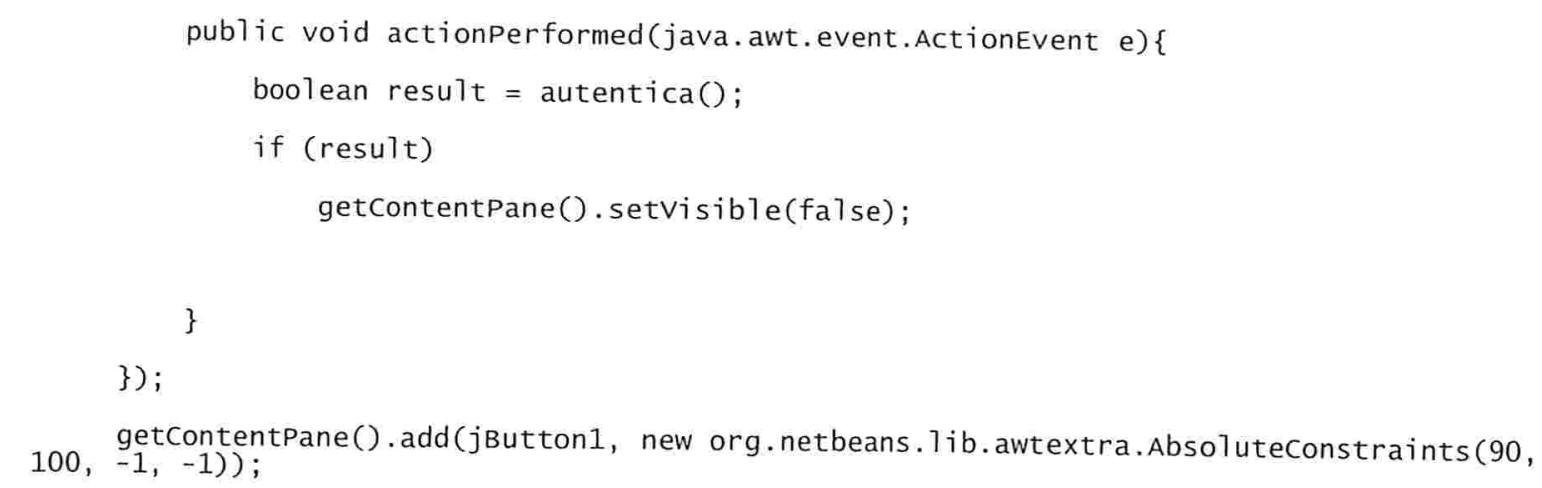

jButton2.setText("Limpar");

//Quando usuário clica no botão "Limpar", chama método limpa()

jButton2.addActionListener (new java.awt.event. ActionListener() \{ public void actionperformed (java.awt. event. Actionevent e) \{ 1 impa(); \}

\}) ;

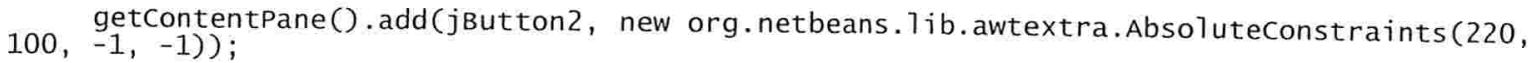
//Carrega login no arquivo passwd,properties.

login = bundle.getstring ("login");

//Carrega o password.

password = bundle.getstring ("password");

\}

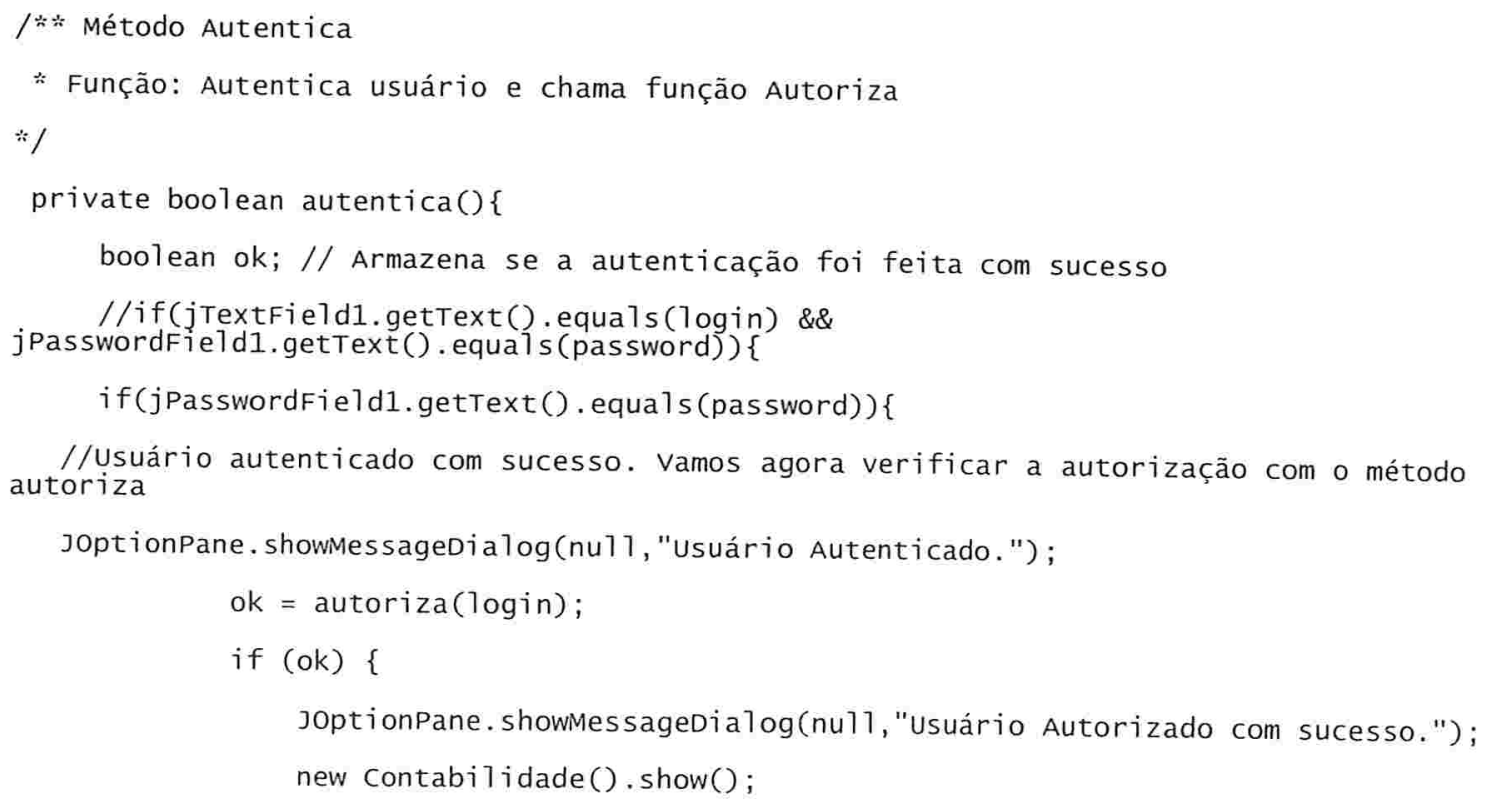




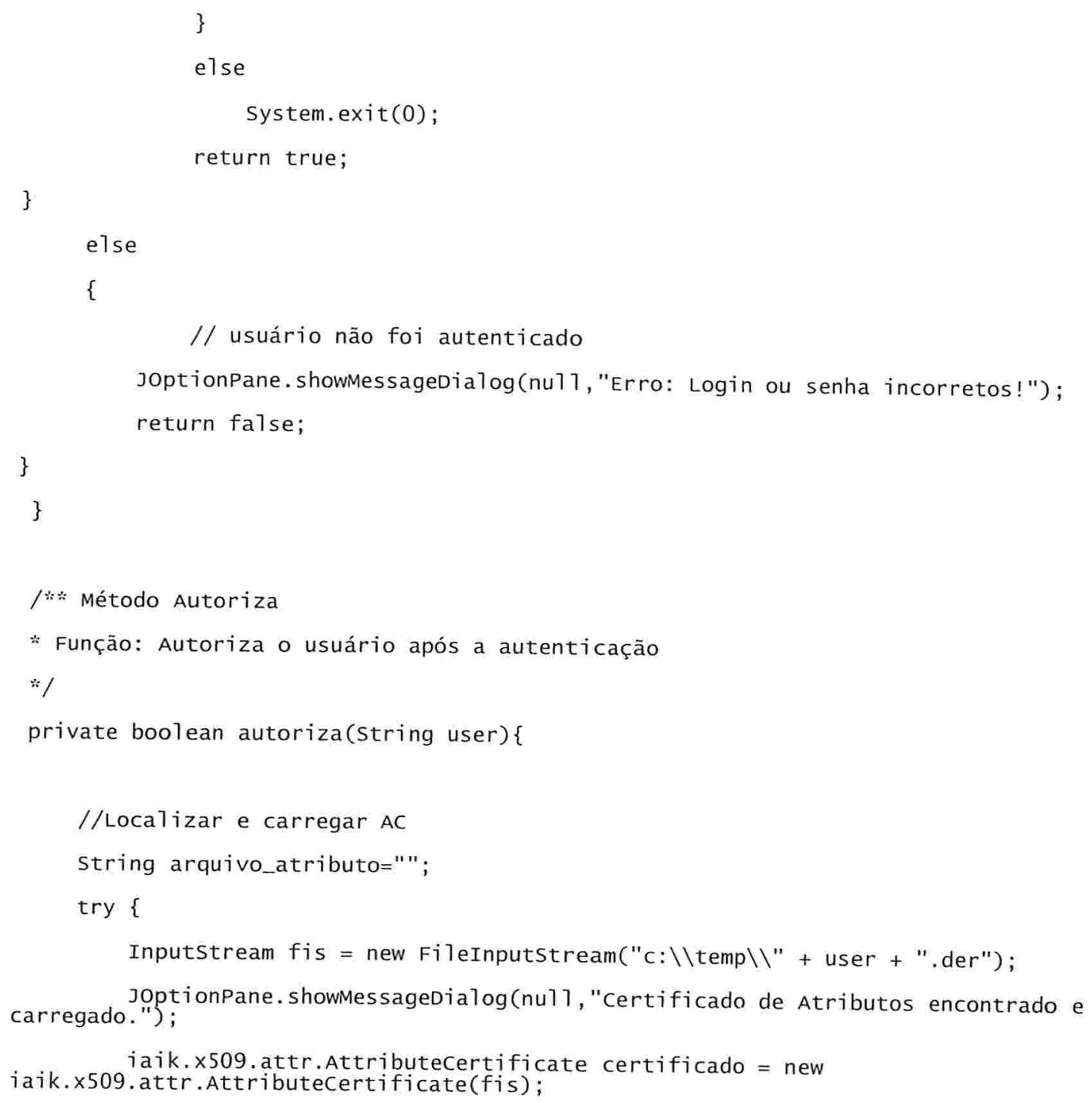


// Certificado ainda não válido

Joptionpane. showMessagedialog(nu17, "o Período de validade do Certificado se inicia somente em " + certificado.getNotBeforeTime());

return false;

\}

catch (Exception e) \{

JoptionPane. showMessagedialog(nu11, "O Período de validade do Certificado ainda não se iniciou ou já expirou!");

return false;

\}

//Localizar e carregar Arquivo de Atributos

String oidstr = "1.3.6.1.4.1.2706.123.1.2.1";

string name = "arquivo";

String shortwame = "arq";

objectID oid = new objectID(oidstr, name, shortName);

$\operatorname{try}\{$

Attribute atributo = new Attribute();

atributo = certificado.getattribute (oid);

ASN1object [] asn1obj = atributo.getvalue();

String str_arquivo $=\operatorname{asn} 10 b j[0] \cdot \operatorname{tostring}()$;

int $i$, inicio $=14$;

$i=s t r \_$arquivo. 1 ength () -1 ;

str_arquivo=str_arquivo.substring $(0, i)$;

int $\mathrm{p}=\mathrm{str}$ _arquivo.indexof ("\\") + 1 ;

while $(i>0)\{$

p=str_arquivo.indexof("\\") + 1;

if $(p>0)\{$

"\\"; arquivo_atributo=arquivo_atributo + str_arquivo.substring(inicio,p) + inicio=0;

str_arquivo=str_arquivo.substring $(p, i)$;

$i=i-(p)$;

\}

else

\{

arquivo_atributo=arquivo_atributo + str_arquivo;

$i=0$;

\} 
\}

catch (Exception e) \{

e.printstackTrace();

\}

//Verificar se atributos são suficientes para o acesso desejado string valor_atributo;

try \{

BufferedReader in = new BufferedReader(new FileReader(arquivo_atributo));

valor_atributo=in. readtine();

valor_atributo=in.readLine();

valor_atributo=in.readtine(); carregado!" )

JOptionPane.showmessagedialog(nu11, "Arquivo de atributos encontrado e

while (valor_atributo $!=$ nu11) \{

if $($ Integer , parseInt (valor_atributo $)==1)\{/ /$ Contabi 1 idade $=1$

fis.close();

in.close ();

Joptionpane. showmessagedialog(nu11, "O usuário possui os atributos

necessários no arquivo de atributos!");

return true;

\}

valor_atributo=in. readtine();

\}

no arquivo de atributos!");

// fechar o arquivo de atributos

in.close ();

//fechar o arquivo do $A C$

fis.close();

return false;

\}

catch (IOException e) \{

Joptionpane.showmessagedialog(nul1, "o arquivo de atributos " + arquivo_atributo + " não foi encontrado!");

return false;

\}

\}

catch (Exception e) \{

\}

// Usuário sem os atributos necessários 


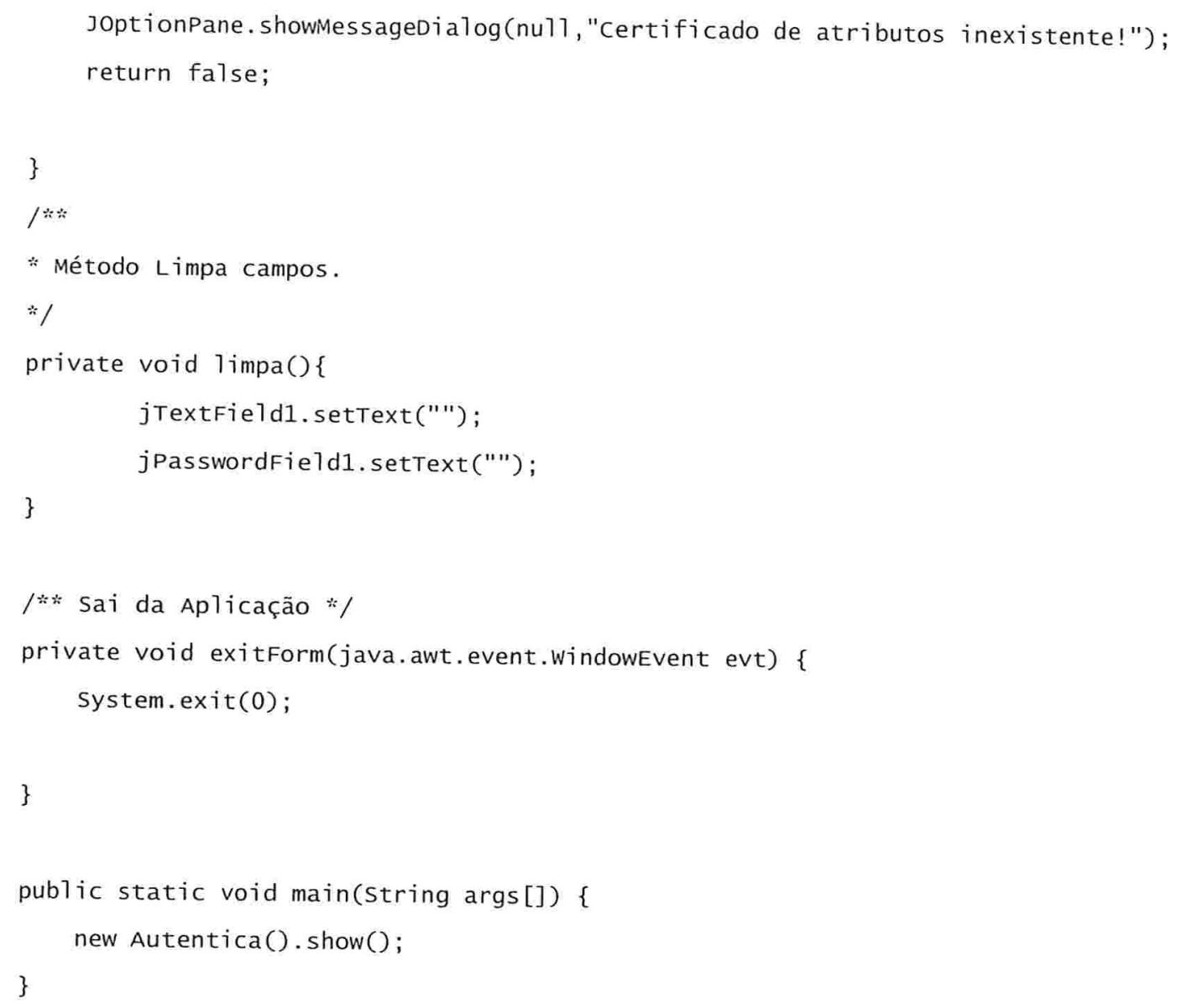




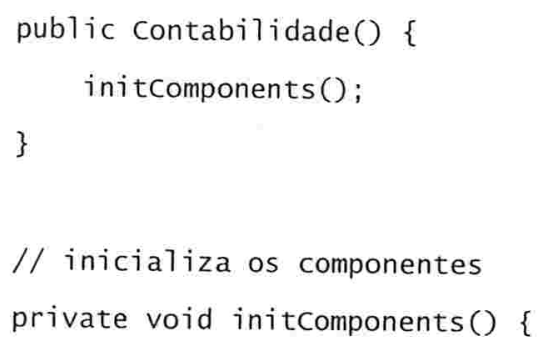




\section{REFERÊNCIAS BIBLIOGRÁFICAS}

[ABN 01] ABNT - Associação Brasileira de Normas Técnicas. Tecnologia da informação - Código de prática para a gestão da segurança da informação. NBR ISO/IEC 17799. 2001.

[ADA 99a] Adams C.; Lloyd S. Understanding Public-key Infrastructure: Concepts, Standards and Deployment Considerations. New Riders, 1999.

[ADA 99b] Adams, C.; Farrell, S. Internet X.509 Public Key Infrastructure Certificate Management Protocols. RFC 2510, 1999.

[ANS 99] ANSI X9.42-2000. Public Key Cryptography for The Financial Services Industry: Agreement of Symmetric Keys Using Discrete Logarithm Cryptography. 1999.

[ASN 03] ASN.1 Consortium. Definições e usos da notação ASN.1.

Disponivel em <http://www.asn1.org>. Acesso em: 25 mar. 2003.

[BAS 02] Bassham, L.; Polk, W.; Housley, R. Algorithms and Identifiers for the Internet X.509 Public Key Infrastructure Certificate and Certificate Revocation List (CRL) Profile. RFC 3279. 2002

[BRI 02] Brink, D. PKI and Financial Return on Investment. Disponivel em <http://www.pkiforum.org/resources.html>. Acesso em 28 dez. 2002.

[CHA 02] Chadwick, D. An X.509 Role-based Privilege Management Infrastructure. Bussiness Briefing: Global Infosecurity, 2002.

[DAW 02] Dawson, E.; Lopez, J.; Montenegro J. A. A New Design of Privilege Management Infrastructure for Organizations Using Outsourced PKI. 2002.

[EAS 01] Eastlake, D.; Jones, P. US Secure Hash Algorithm 1 (SHA1). RFC 3174, 2001.

[FAR 02] Farrell S. An Internet Attribute Certificate Profile for Authorization. RFC3281, 2002. 
[FER 93] Ferraiolo, D., F.,; Gilbert, D., M.; Lynch, N. An examination of federal and commercial access control policy needs. NIST-NCSC National Computer Security Conference, páginas 107-116, Baltimore, MD, Setembro 1993.

[FER 99] Ferreira, A. B. H.. Novo Aurélio - Dicionário da Língua Portuguesa - Século XXI. Nova Fronteira. 1999.

[HOU 02] Housley, R.; Polk, W.; Ford, W.; Solo, D. Internet X.509 Public Key Infrastructure Certificate and Certificate Revocation List (CRL) Profile. RFC 3280, 2002.

[HOU 99] Housley, R.; Polk, W.; Ford, W.; Solo, D. Internet X.509 Public Key Infrastructure Certificate and CRL Profile. RFC 2459, 1999.

[ITU 00] ITU-T Recommendation X.509, Information Technology - Open systems interconnection - The Directory: Public-key and attribute certificate frameworks, 2000

[ITW 03] IT Web. Sucesso por bom comportamento. Disponível em <http://www.itweb.com.br/noticias/artigo.asp?id=44817>. Acesso em: 12 fev. 2004.

[LAR 02] Lareau, P. PKI Basics - A Business Perspective. Disponivel em <http://www.pkiforum.org/resources.html>. Acesso em: 28 dez. 2002.

[LAR 99] Larmouth, J. ASN.1 Complete. Morgan Kaufmann, 1999. 472 p.

[MYE 79] Myers, G., The Art of Software Testing. Wiley. 1979.

[MYE 99] Myers, M.; Ankney, R.; Malpani, A.; Galperin, S.; Adams, C. X.509 Internet Public Key Infrastructure Online Certificate Status Protocol - OCSP. RFC 2560, 1999.

[NAS 01] Nash, A.; Duane, W.; Joseph, C.; Brink, D. PKI: Implementing and Managing E-Security. McGraw-Hill, 2001.

[OAK 99] Oaks, S. Segurança de dados em Java. Rio de Janeiro: Ciência Moderna, 1999.

[PRA 95] Prahalad, C.K., Hamel, G. Competindo pelo futuro - estratégias inovadoras para obter o controle do seu setor e criar os mercados de amanhã. Campus, 1995.

[PRE 94] Pressman, Roger S. Software Engineering: Practitioner's Approach. - European. 3ed. McGraw-Hill International, 1994. 
[SAN 96] Sandhu, R. S.; Coyne, E. J.; Feinstein, H., L. Role-Based Access Control Models. 1996.

[SHI 00] Shirey, R. Internet Security Glossary. RFC 2828, 2000.

[STA 02] Stallings, W. Cryptography and Network Security - Principles and Practice. 3ed. New Jersey: Prentice Hall, 2002.

[TER 00] Terada, R. Segurança de dados - criptografia em redes de computador. 1.ed. São Paulo: E. Blücher, 2000. 242p. 


\section{ÍNDICE REMISSIVO}

\section{A}

\section{AES, 9}

algoritmo criptográfico, 6,67

algoritmo Diffie-Hellman, 10

assinatura digital, $2,32,33,34,73$

atributo, $1,2,43,45,50,51,52,53,56,60,61,62,63,64,65,66,67,68,69,70,71,72$, $99,117,118,125,126,127$

atributos, iii, $18,43,44,45,47,48,51,52,53,57,58,61,68,69,70,71,72,73,74,75$,

$76,77,80,81,82,83,84,86,87,91,93,94,95,96,97,98,99,101,102,118,119,127$, 128

Atributos, viii, $69,72,73,74,75,76,77,79,80,81,82,84,85,88,89,91,93,94,95,96$, $97,98,99,101,102,108,109,110,111,113,117,118,119,120,121,125,126$

autenticação, 1, 2, 3, 9, 15, 21, 26, 37, 38, 65, 71, 72, 73

Autoridade Certificadora, 2, 4, 17, 18, 19, 20, 21, 22, 23, 24, 25, 26, 30, 31, 32

Autoridade de Atributo, viii, 60, 75, 102

AA, viii, 51, 52, 53, 60, 61, 75

Autoridade de Registro, 4, 17, 18, 19, 21, 23, 31

autorização, i, ii, iii, 1, 2, 3, 4, 37, 38, 42, 43, 44, 47, 60, 61, 65, 69, 71, 81, 95, 97, 101, 124

C

certificado de atributos, iii, 4, 43, 44, 45, 48, 53, 65, 68, 70, 71, 77, 81, 82, 83, 84, 87, 90, $91,92,93,94,119$

certificados de atributos, iii, $2,4,44,45,48,51,52,53,55,56,60,70,71,78,79,80,81$, $82,83,85,86,87,88,102$

Certificados de atributos, iii certificados de identidade, 1

\section{Ch}

chave assimétrica, 10

chave de criptografia, 8,9

chave particular, $15,18,22,23,25,28,30,36$

chave pública, 1, 9, 15, 17, 18, 19, 22, 23, 24, 26, 27, 28, 30, 36, 43, 52, 56, 62, 65, 66, $67,69,70,73,87,88,89,90$

chave simétrica, $7,8,9,10$

chaves criptográficas, $6,87,88$ 
C

Cifra de César, 7

classe IAIK JCE, 87

confidencialidade, 10, 12, 14, 37, 40, 47

criptografar, 5, 6, 8, 22

criptografia, 2, 4, 5, 6, 7, 8, 9, 10, 15, 22, 87, 88, 132

D

declarador de privilégio, $46,47,48,51,53,54,60,85$

Declarador de privilégio, 50,52

decriptografia, 5, 7, 22, 25

Depósito, 17, 22, 61

DES, 9

Discretionary Access Control, 38

$\mathrm{E}$

Emissor de Listas de Certificados Revogados, 17

Empresas virtuais, 78

entidade, $2,11,14,17,18,20,22,26,31,32,34,36,44,45,46,47,51,56,57,60,66$, $67,68,70,73,83,94,101$

Entidade Final, 17, 20, 21, 22, 23, 25, 26, 27, 28, 30, 31

Extensões, 30, 69

$\mathbf{F}$

fabricação de informações, 12

FHG Consultoria, 44, 47, 52, 56, 77, 94, 129

ICP, viii, 2, 4, 15, 16, 17, 18, 19, 20, 25, 26, 27, 101

IDEA, 9

Identificador único do emissor, 69

Infra-estrutura de Chaves Públicas, 2, 4, 15, 17, 18, 19, 20, 21, 24, 25, 31, 101

infra-estrutura de gerenciamento de privilégios, iii

Infra-estruturas de Gerenciamento de Privilégios, 2

integridade, 2, 10, 13, 14, 15, 31, 37, 77

interceptação, 6, 12

interrupção, 12

ITU-T, iii, viii, 1, 2, 4, 43, 46, 50, 62, 131

Java.security, 88

L

Listas de Certificados Revogados, 17, 18, 20, 23, 25, 61, 87 
Mandatory Access Control, 39

Modelo de Controle, 50

Modelo de papéis, 55

Modelo Geral, 46, 49, 86

modificação, 4, 12, 13, 37, 45

N

não-repudiação, 2,44

Novas formas organizacionais, 77

$\mathbf{P}$

papel, 1, 2, 3, 42, 43, 55, 56, 57, 58, 59, 72

período de validade, $28,30,35,61,69,70,73,75,91,93,96,97,98,99,101$

PMI, iii, 2, 4, 45, 46, 47, 50, 51, 54, 55, 56, 57, 60, 75, 79, 80, 82, 85, 86, 94, 101

política de privilégio, 47,50

Privilege Management Infrastructure, iii, 2, 4, 46, 101, 130

privilégios, i, ii, iii, 1, 2, 13, 40, 41, 43, 44, 45, 46, 47, 49, 50, 51, 52, 53, 54, 55, 59, 69, 70,

$71,72,73,74,75,76,77,78,79,80,81,82,83,84,85,86,88,89,91,92,93,101,102$ projetos distribuídos, $80,81,82,102$

Proprietário, 65

protótipo, iii, 4, 84, 85, 86, 87, 88, 91, 94

Protótipo

módulo de atribuição de privilégios, $84,88,89$

módulo de verificação de privilégios, $82,84,85,102$

pull, 44, 45, 62, 73, 87

push, $44,45,48,53,62,73$

R

recomendação X.509, iii, 1, 4, 50, 56, 62, 64, 72, 101

Revogação, 23, 25, 35, 69, 76

Role-based Access Control, 40

RSA, 10

$\mathrm{s}$

segurança, iii, 4, 5, 6, 10, 11, 14, 18, 21, 22, 30, 31, 32, 36, 37, 38, 39, 40, 42, 47, 59, 70,

$71,72,75,86,88,101,102,130$

serviço de autorização, 1, 2, 3

serviços de autorização, iii

SOA, viii, $47,48,51,52,53,57,60,79,82,83,85$

Start of Authority, 60

SOA, 60

Testes de validação, 94 


\section{V}

verificador de privilégio, $46,48,50,51,53,58,85$ 